


\title{
Ein Netzwerk von heterodimerisierenden C/S1 AtbZIP-Transkriptionsfaktoren und seine Funktion in Seneszenz, Stressantwort und Samenentwicklung
}

\author{
Dissertation \\ zur Erlangung des Doktorgrades der \\ Mathematisch-Naturwissenschaftlichen Fakultäten \\ der Georg-August-Universität zu Göttingen
}

\author{
vorgelegt von \\ Fridtjof Walter Engelbert Weltmeier \\ aus Dortmund
}

Göttingen, 2005 
D7

Referent:

PD Dr. Wolfgang Dröge-Laser

Korreferent:

Professorin Dr. Christiane Gatz

Tag der mündlichen Prüfung:

19. Januar 2006 


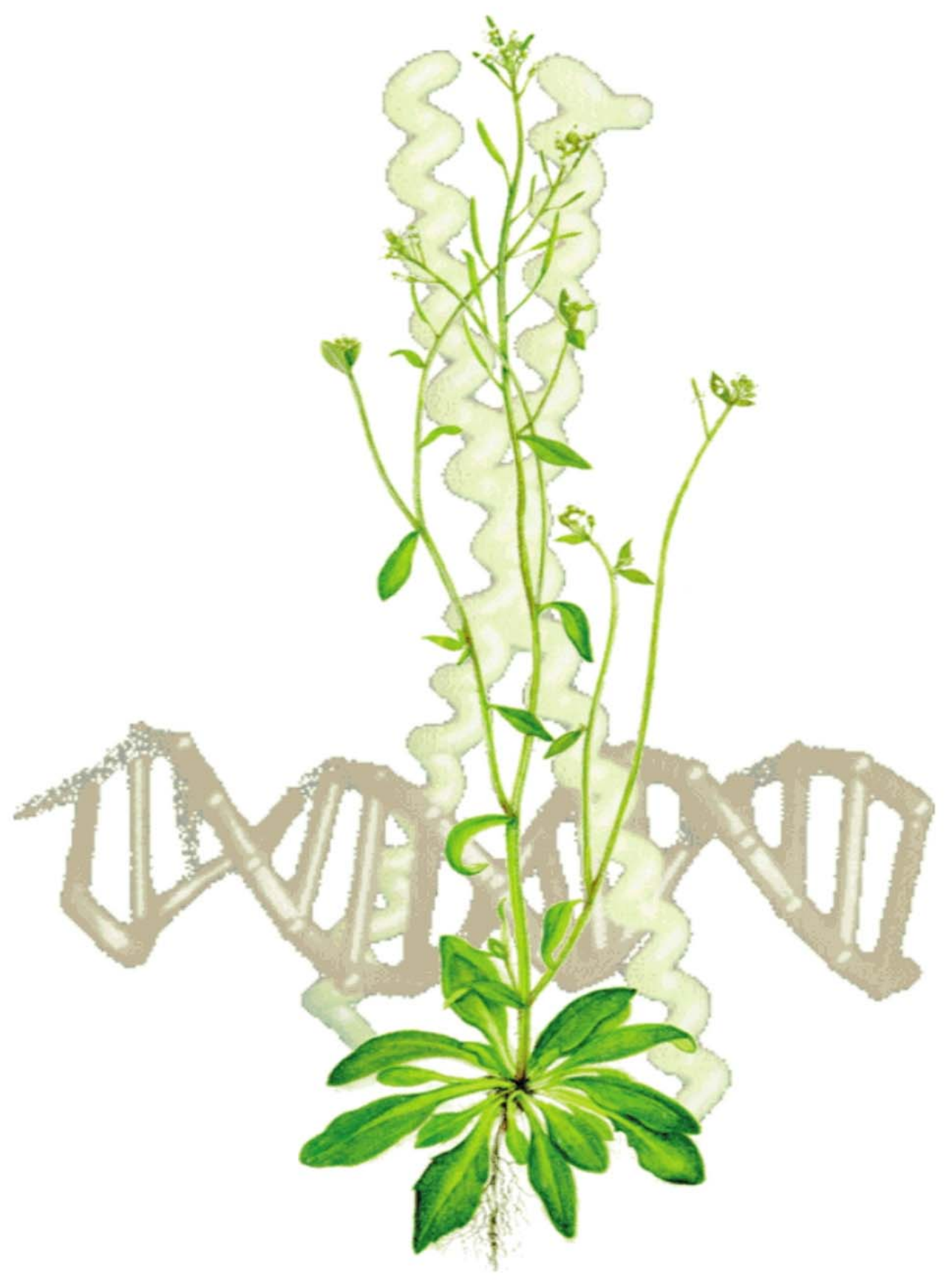




\section{INHALTSVERZEICHNIS}

2 EINLEITUNG 3

2.1 Transkriptionsfaktoren 3

2.2 bZIP-Transkriptionsfaktoren 4

2.3 Die Gruppen C und S der AtbZIP-Transkriptionsfaktoren 6

$\begin{array}{lll}2.4 & \text { Zucker und Zucker-abhängige Signalwege } & 8\end{array}$

2.5 AtbZIP-Transkriptionsfaktoren der Gruppen C und S1 in der 10 Pollen- und Samenentwicklung

2.6 Abiotischer Stress und die Funktion von Prolin im Schutz vor Stress 12

2.7 Seneszenz und bZIP-Transkriptionsfaktoren 14

$\begin{array}{lll}2.8 & \text { Fragestellung und Zielsetzung der Arbeit } & 15\end{array}$

$3 \quad$ MATERIAL 17

$\begin{array}{lll}3.1 & \text { Organismen } & 17\end{array}$

$\begin{array}{ll}3.1 .1 & \text { Hefestämme (Saccharomyces cerevisiae) } \\ 3\end{array}$

$\begin{array}{lll}3.1 .2 & \text { Bakterienstämme } & 17\end{array}$

3.1.3 Pflanzenmaterial: Ackerschmalwand (Arabidopsis thaliana) 17

$\begin{array}{lll}3.2 & \text { Nukleinsäuren } & 18\end{array}$

$\begin{array}{lll}3.2 .1 & \text { Plasmide } & 18\end{array}$

$\begin{array}{lll}3.2 .2 & \text { Primer } & 19\end{array}$

3.2.3 Hybridisierungssonden 21

3.3 Nährmedien und Zusätze 22

3.3.1 Hefemedien 22

3.3.2 Bakterienmedien 23

3.3.3 Pflanzenmedien 23

3.4 Medienzusätze 25

3.4.1 Aminosäuren und Purine 25

3.4.2 Antibiotika 25

$\begin{array}{lll}3.4 .3 & \text { Agar } & 25\end{array}$ 
$\begin{array}{lll}3.6 & \text { Geräte } & 30\end{array}$

$\begin{array}{lll}3.7 & \text { Verbrauchsmittel } & 31\end{array}$

3.8 Chemikalien $\quad 32$

$\begin{array}{llr}3.9 & \text { Enzyme } & 34\end{array}$

3.10 Antikörper 34

3.11 Kits 35

$\begin{array}{lll}3.12 & \text { DNA-Marker } & 35\end{array}$

4 METHODEN 36

4.1 Anzucht und Transformation von Arabidopsis thaliana 36

4.1.1 Anzucht der Pflanzen 36

4.1.2 Floral-dip Transformation 36

4.1.3 Selektion auf Basta ${ }^{\circledR}-$ Resistenz $\quad 37$

4.1.4 Selektion auf Kanamycin- / Hygromycin-Resistenz 37

4.2 Anzucht und Lagerung von Bakterien und Hefen 37

$\begin{array}{lll}\text { 4.2.1 Anzucht von Escherichia coli } & 37\end{array}$

4.2.2 Anzucht von Agrobacterium tumefaciens 38

4.2.3 Anzucht von Saccharomyces cerevisiae 38

$\begin{array}{ll}\text { 4.2.4 Lagerung der Bakterien } & 38\end{array}$

4.2.5 Lagerung der Hefen 38

4.3 Methoden zur Isolierung von genomischer DNA aus Arabidopsis $\quad 38$

4.3.1 DNA-Extraktion aus Arabidopsis thaliana nach (Fulton et al., 1995) 38

4.3.2 Schnelle Präparation von genomischer DNA 39

4.4 RNA-Extraktion aus Arabidopsis thaliana 39

4.4.1 RNA-Extraktion aus Arabidopsis thaliana mit dem "Invisorb Spin Plant 39 RNA Mini Kit"

4.4.2 RNA Extraktion aus Arabidopsis thaliana mit Trizol 39

4.5 Gateway-Rekombination 39

4.5.1 Aufreinigung von $a t t B$-PCR Produkten $\quad 40$

$\begin{array}{lll}4.5 .2 & \text { BP-Reaktion } & 40\end{array}$

$\begin{array}{lll}4.5 .3 & \text { LR-Reaktion } & 40\end{array}$

4.6 Isolation von Plasmiden aus E. coli 41

4.6.1 Alkalische Lyse $\quad 41$

4.6.2 Plasmidpräparation für Sequenzierung 41

4.6.3 Schnellyse von E.coli Zellen für eine anschliessende PCR 41

4.6.4 DNA-Elution aus Agarosegelen 41

$\begin{array}{lll}4.7 & \text { Phenol-Chloroform Extraktion } & 41\end{array}$

4.8 Ethanolfällung von DNA aus wässerigen Lösungen 42 
4.9 Konzentrationsbestimmung von Nukleinsäuren 42

4.10 Restriktionsspaltung von DNA

4.11 Ligation 42

4.12 TA-Klonierung 43

4.13 Blau-Weiß-Selektion 43

4.14 Agarosegelelektrophorese von DNA-Molekülen 43

4.15 DNA Sequenzierung $\quad 44$

4.15.1 Aufreinigung der Sequenzierreaktion 45

4.16 Polymerase-Kettenreaktion 45

4.17 Colony-Screen mittels PCR 46

4.18 Transformation von Mikroorganismen 46

4.18.1 Herstellung kompetenter Escherichia coli 46

4.18.2 Transformation von Escherichia coli 46

4.18.3 Herstellung kompetenter Agrobakterien 46

4.18.4 Transformation von Agrobacterium tumefaciens 47

4.18.5 Herstellung kompetenter Hefezellen 47

4.18.6 Transformation der kompetenten Hefezellen 47

4.19 Transformation von Arabidopsis thaliana-Protoplasten 48

4.19.1 Protoplastengewinnung 48

4.19.2 Protoplasten- PEG- Transformation 48

4.19.3 Messung der ß-Glucuronidase (GUS)- Aktivität 48

4.20 GUS-Färbung

4.21 Northernblot / Kapillarblot $\quad \mathbf{5 0}$

4.21.1 Denaturierende Agarosegelelektrophorese von RNA-Molekülen 50

4.21.2 Kapillarblot 50

4.21.3 Herstellen einer radioaktiv markierten DNA-Sonde 50

4.21.4 Hybridisierung der Northern Blot Membran 51

4.21.5 Rehybridisierung 51

4.22 Transkriptomanalyse mit 'ARIZONA whole genome arrays' 51

4.22.1 Amplifikation der eingesetzten RNA 52

4.22.2 Indirekte Markierung der aRNA $\quad 52$

4.22.3 Hybridisierung der ARIZONA whole genome arrays 53

4.22.4 Auswertung der ARIZONA whole genome arrays 53

4.23 Herstellung von Chloroform / Methanolextrakten zur Bestimmung 53 des Zuckergehaltes

4.24 Nachweis der $\beta$-Galaktosidaseaktivität in Hefen durch oNPG-Tests 54

4.25 Chromatin-Immunopräzipitation $\quad \mathbf{5 4}$

4.25.1 Chromatinpräparation $\quad 54$

4.25.2 Immunopräzipitation $\quad 55$ 
4.27 Western Blot Analyse $\quad 56$

4.27.1 SDS-Polyacrylamidgelelektrophorese 56

4.27.2 Coomassie-Färbung 56

4.27.3 Proteintransfer auf PVDF-Membranen 56

4.27.4 Immunodetektion mit dem ECL+ System 57

$\begin{array}{lll}4.28 & \text { Verwendete Computerprogramme } & 57\end{array}$

4.29 Mathematische Formeln $\quad 58$

$5 \quad$ ERGEBNISSE: $\quad 59$

5.1 AtbZIP-Transkriptionsfaktoren der Gruppe C interagieren mit 59 AtbZIP-Transkriptionsfaktoren der Gruppe S1

5.1.1 AtbZIP-Transkriptionsfaktoren der Gruppen $\mathrm{C}$ und $\mathrm{S1}$ zeigen 60 unterschiedliche Aktivierungseigenschaften

5.1.2 AtbZIP-Transkriptionsfaktoren der Gruppe C heterodimerisieren in Hefe 61 bevorzugt mit AtbZIP-Transkriptionsfaktoren der Gruppe S1

5.2 Promotor-GUS Fusionen zeigen eine Kolokalisation von AtbZIP 66 Transkriptionsfaktoren der Gruppen C und S1

5.2.1 AtbZIP-Transkriptionsfaktoren der Gruppen $\quad$ C und S1 zeigen 66 überlappende gewebespezifische Expressionsmuster

5.3 Erzeugung und Charakterisierung von Mutanten und ektopischen Überexpressionslinien der AtbZIP-Transkriptionsfaktoren 1, 53, 9 und 63

5.3.1 Ektopische Expression von AtbZIP-Transkriptionsfaktoren der Gruppen $\mathrm{C}$ und $\mathrm{S} 1$ unter Kontrolle des 35S-Promotors

5.3.2 Identifizierung und Charakterisierung von T-DNA Insertionsmutanten 73

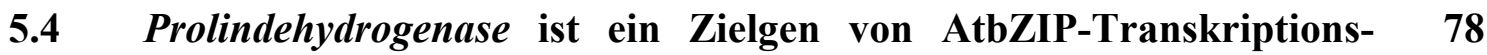
faktoren der Gruppen C und S1

5.4.1 AtbZIP53 und AtbZIP1 regulieren die Expression der ProDH 78

5.4.2 AtbZIP1, 53, 9, 63 und die ProDH werden durch Zuckermangel, 79 AtbZIP53 und die ProDH auch durch Hypoosmolarität induziert

5.4.3 Eine Dunkel-induzierte Expression von ProDH, AtbZIP1, AtbZIP53, 81 AtbZIP9 und AtbZIP63 wird durch Zucker reprimiert.

5.4.4 Die Induktion von AtbZIP53 durch Hypoosmolarität findet vorwiegend 83 in Blättern statt

5.4.5 AtbZIP53 wird durch Prolin induziert 83

5.4.6 Die ProDH ist ein direktes Zielgen von AtbZIP53 85

5.4.7 Heterodimere von AtbZIP53 mit Gruppe C AtbZIP-Transkriptions- 88 faktoren führen zu einer synergistischen Aktivierung der ProDH

5.4.8 Einzelne AtbZIP-Transkriptionsfaktoren der Gruppen C und S1 werden 89 wie die ProDH stark in Pollen exprimiert

5.5 Eine Regulation von AtbZIP-Transkriptionsfaktoren der Gruppen C/S1 durch Zucker lässt sich durch Transkriptomanalyse-Daten und Promotor-GUS Fusionen bestätigen 
5.5.1 Transkriptionelle Regulation von AtbZIP-Transkriptionsfaktoren der 92 Gruppen C und S1 durch Saccharose

5.5.2 Transkriptionelle Regulation von AtbZIP-Transkriptionsfaktoren der 93 Gruppen C und S1 durch Glukose

5.5.3 Saccharose reprimiert die Translation von AtbZIP1 und AtbZIP53 95

5.6 Transkriptomanalyse einer 35S:AtbZIP53 Linie zur Identifizierung 97 von Zielgenen

5.6.1 Gene mit einer erhöhten Expression in der 35S:AtbZIP53 Linie zeigen 102 gewebespezifische Expressionsmuster

5.6.2 Gene mit einer reduzierten Expression in der 35S:AtbZIP53 Linie zeigen 105 keine einheitlichen Expressionsmuster

5.6.3 Die Analyse der Promotoren von in der 35S:AtbZIP53 Linie stärker 108 exprimierten Genen zeigt ein gehäuftes Auftreten eines $A C G T G G C$ Motivs

5.6.4 Verifikation von einzelnen in dem Mikroarrayexperiment durch 111 AtbZIP53 induzierten Genen in Northern Analysen

5.6.5 ASN1 ist ein direktes Zielgen von AtbZIP53

5.7 AtbZIP-Transkriptionsfaktoren der Gruppen C und S1 sind an der Antwort auf abiotischen Stress beteiligt

5.7.1 AtbZIP53 wird in Schließzellen exprimiert 114

5.7.2 Ektopische Expression von AtbZIP53 vermittelt eine erhöhte Resistenz 115 gegen Salzstress

5.7.3 AtbZIP-Transkriptionsfaktoren der Gruppen C und S1 werden durch 117 abiotischen Stress reguliert

5.7.4 Die wurzelspezifische Induktion eines Trehalosephosphat-PhosphataseGens nach Salzstress wird durch AtbZIP1 und/oder AtbZIP53 vermittelt

5.8 AtbZIP-Transkriptionsfaktoren der Gruppen C und S1 sind an der Samenentwicklung beteiligt

5.8.1 AtbZIP-Transkriptionsfaktoren der Gruppe S1 zeigen eine gegenläufige Expressionskinetik während der Samenentwicklung

5.8.2 AtbZIP53 wird während der Samenreifung im Embryo und in der Aleuronschicht exprimiert

5.9 AtbZIP-Transkriptionsfaktoren der Gruppen C und S1 sind Regulatoren natürlicher und induzierter Seneszenz

5.9.1 AtbZIP1, AtbZIP53, AtbZIP9, AtbZIP25 und AtbZIP63 werden durch Seneszenz induziert

5.9.2 35S:AtbZIP1 Linien zeigen ein rascheres Eintreten in die Dunkel- 131 induzierter Seneszenz

5.9.3 Transkriptionelle Regulation von AtbZIP-Transkriptionsfaktoren der 132 Gruppen C und S1 in Mikroarray-Experimenten zur Seneszenz

5.10 Analyse der Transkriptome von 35S:AtbZIP1 und atbzip1/atbzip53 136 Pflanzen

5.10.1 Viele der Gene mit einer erhöhten Expression in der 35S:AtbZIP1 Linie 138 werden durch Seneszenz induziert

5.10.2 Die Promotoren von in der 35S:AtbZIP1 Linie stärker exprimierten 144 zeigen ein gehäuftes Auftreten eines $A C G T T A C$-Motivs 
5.10.3 Gene mit einer im Vergleich zum Wildtyp reduzierten Expression in der 146 atbzip1/atbzip53 Doppelmutante

5.10.4 Analyse der Promotoren von Genen mit einer reduzierten Expression in 148 der atbzip1/atbzip53 Doppelmutante

6 DISKUSSION:

6.1 AtbZIP-Transkriptionsfaktoren der Gruppen C und S1 bilden ein 150 Heterodimerisierungsnetzwerk

6.2 Bisher unbekannte Strukturmerkmale der Zipper-Domäne sind für $\mathbf{1 5 2}$ die Spezifität von C/S1 Heterodimerisierungen verantwortlich

6.3 AtbZIP-Transkriptionsfaktoren der Gruppen C und S1 155 unterscheiden sich in ihren Aktivierungseigenschaften

6.4 AtbZIP-Transkriptionsfaktoren der Gruppen C und S1 sind Teil 157 eines Zucker-abhängigen Signalweges

6.5 C/S1 Heterodimere vermitteln eine durch Zucker, Prolin und 160 osmotische Signale regulierte Expression der ProDH

6.6 AtbZIP53 ist möglicherweise Teil eines ABA-Signalweges 162

6.7 C/S1 Heterodimere regulieren die Expression von 166 Samenspeicherprotein- und LEA-Genen.

6.8 AtbZIP1 und AtbZIP53 regulieren die Umstellung des Metabolismus 167 während Dunkel-induzierter Seneszenz

6.9 Ausblick

7 LITERATUR:

8.1 Abkürzungen

8.2 Aminosäuren

8.3 Einheiten

8.4 Vorsätze zur Bezeichnung von dezimalen Vielfachen und Teilen 


\section{Zusammenfassung}

Transkriptionsfaktoren der bZIP (basic region - leucine zipper) Familie kommen in allen bisher analysierten eukaryotischen Organismen vor. Eine besondere Eigenschaft von Transkriptionsfaktoren dieser Gruppe ist, dass sie als Dimere an DNA binden, wobei einige bZIP-Transkriptionsfaktoren spezifische Heterodimere mit anderen bZIPTranskriptionsfaktoren bilden können. Im Rahmen dieser Dissertation konnte gezeigt werden, dass in dem Modellorganismus Arabidopsis thaliana die bZIPTranskriptionsfaktoren der Gruppe C (AtbZIP9, 10, 25 und 63) mit den bZIP-Faktoren der Gruppe S1 (AtbZIP1, 2, 11, 44 und 53) spezifische Heterodimere formen. Um die Funktion dieses Heterodimerisierungsnetzwerkes $\mathrm{zu}$ verstehen, wurden die Expressionsmuster der AtbZIP-Transkriptionsfaktoren mit Hilfe von Promotor-GUS Fusion, Northern Analysen und Daten aus Mikroarray-Datenbanken analysiert. Dabei zeigte sich, dass die Expression der AtbZIP-Gene vor allem durch die Zucker Glukose und Saccharose und durch Seneszenz, aber auch durch Stresse wie Osmolarität oder Salzstress reguliert wird. Zusätzlich fanden sich Gewebe-spezifische Expressionsmuster, z.B. in den Pollen oder Samen. Für die funktionelle Charakterisierung der bZIP-Transkriptionsfaktoren wurden Überexpressions-Pflanzen und T-DNA Insertionsmutanten erzeugt. Durch Transkriptomanalysen dieser Pflanzen mit Hilfe von Mikroarrays wurden mögliche Zielgene von AtbZIP1 und AtbZIP53 identifiziert. Ektopische Überexpression von AtbZIP1 oder AtbZIP53 (35S:AtbZIP1 und 35S:AtbZIP53) führte zur Aktivierung von Samenspeicherprotein-Genen, Pollenspezifischen Genen sowie Seneszenz-assoziierten Genen. Unter diesen Genen waren vermehrt Gene des Aminosäure-Metabolismus, und für zwei von ihnen, ein ProlinDehydrogenase Gen (ProDH) und ein Asparagin Synthetase Gen (ASN1), wurde mittels Chromatin-Immunopräzipitation (ChIP) gezeigt, dass es sich um direkte Zielgene von AtbZIP53 handelt. Für die ProDH konnte in transienten Protoplasten-Assays gezeigt werden, dass AtbZIP53 alleine in der Lage ist den Promotor zu aktivieren, dass jedoch eine Koexpression mit Gruppe C Faktoren zu einer weiter verstärkten Aktivierung führt, was die Bedeutung der Heterodimerisierung in Pflanzen belegt. In einer phänotypischen Charakterisierung zeigten 35S:AtbZIP53 Pflanzen eine erhöhte Salzresistenz. Zudem konnte gezeigt werden, dass AtbZIP53 die Expression von Genen der Samenreifung 
vermittelt. Während dieser Phase bilden die Samen ihre Austrocknungstoleranz aus, ein Prozess der Parallelen zur Ausbildung von Salzresistenz zeigt. Für 35S:AtbZIP1 Pflanzen konnte ein früheres Eintreten in eine Dunkel-induzierte Seneszenz gezeigt werden, das sich wahrscheinlich auf die in diesen Pflanzen verstärkt exprimierten Seneszenz-assoziierten Gene zurückführen lässt. Die in dieser Arbeit gezeigte deutliche Repression von AtbZIP1 durch Zucker hat wahrscheinlich die Funktion, das Einsetzen der Dunkel-induzierten Seneszenz zu verhindern, solange die Zellen noch über ausreichende Energie-Reserven verfügen.

Da AtbZIP-Transkriptionsfaktoren der Gruppen C und S1 stark durch Zucker, aber auch durch Stresse und entwicklungsbiologische Signale reguliert werden, und die Mehrheit der identifizierten putativen Zielgene Enzyme des Metabolismus kodieren, wird die Hypothese aufgestellt, dass C/S1 Heterodimere eine komplexe, auf der einen Seite von der Verfügbarkeit von Zuckern, auf der anderen Seite von Stressen und entwicklungsbiologischen Signalen abhängige Regulation des Metabolismus vermitteln. 


\section{Einleitung}

\subsection{Transkriptionsfaktoren}

Im Dezember 2000 wurde die vollständige Sequenz des Genoms von Arabidopsis thaliana mit seinen etwa 27.000 Genen veröffentlicht (Arabidopsis_Genome_Initiative, 2000). Viele dieser Gene haben spezielle Aufgaben und werden nur unter bestimmten Umweltbedingungen, in bestimmten Geweben oder Entwicklungsstadien exprimiert. Die dafür notwendige Regulierung der Genexpression kann auf verschiedenen Ebenen stattfinden, so können z.B. die Transkription, die Prozessierung der mRNA oder die Translation reguliert werden. Die Regulation der Transkription ist dabei die erste und wichtigste Kontrollebene, an deren Kontrolle eine große Gruppe von Proteinen beteiligt ist, die Transkriptionsfaktoren genannt werden. In Arabidopsis thaliana umfasst diese Gruppe mindestens 1533 Gene. Damit codieren über 5\% aller Gene für Transkriptionsfaktoren, was ihre Bedeutung für die Pflanze deutlich macht (Riechmann et al., 2000).

Transkriptionsfaktoren verfügen über eine DNA-Bindedomäne, die an regulatorische Sequenzen im Promotorbereich bindet, und über eine Aktivierungsdomäne, die über Wechselwirkungen mit der basalen Transkriptionsmaschinerie die für die Transkription notwendigen Proteine rekrutiert und so die Transkription einleitet (Ptashne und Gann, 1997). Diese beiden Domänen können auch auf verschiedene Proteine aufgeteilt sein (Brivanlou und Darnell, 2002).

In der Regel binden gleich mehrere verschiedene Transkriptionsfaktoren an den Promotor eines Gens, und die Integration der von diesen verschiedenen Transkriptionsfaktoren übermittelten Signale führt dann $\mathrm{zu}$ einer kontrollierten Aktivierung. Transkriptionsfaktoren können aufgrund ihrer unterschiedlichen DNAbindenden Strukturmotive in verschiedene Familien, wie z.B. bZIP-, Homeobox-, Helix-Loop-Helix-, oder Zinkfinger-Proteine eingeteilt werden (Luscombe et al., 2000). Die in dieser Arbeit untersuchten Gene kodieren Transkriptionsfaktoren der bZIPFamilie. 


\section{2 bZIP-Transkriptionsfaktoren}

Das bZIP-Motiv (basic leucine zipper) besteht aus einer basischen Domäne (b) und einem sich daran anschließenden Leucin-Zipper (ZIP), die zusammen eine $\alpha$-Helix bilden (Hurst, 1995). Der Leucin-Zipper besteht aus heptameren Wiederholungen von Leucin bzw. anderen hydrophoben Aminosäuren, wie Phenylalanin, Isoleucin, Valin oder Methionin. Die sieben Aminosäuren einer heptaden Wiederholung bilden zwei $\alpha$ helikale Umdrehungen der Helix (Abbildung 2.1 C), und werden in der Nomenklatur nach McLachlan und Steward (1975) a, b, c, d, e, f und g genannt. Die Position d in dieser Nomenklatur entspricht den heptameren Wiederholungen von Leucin bzw. anderen hydrophoben Aminosäuren. Diese hydrophoben Aminosäuren liegen alle auf einer Seite der $\alpha$-Helix und bilden eine hydrophobe Fläche, die als Kontaktstelle zwischen zwei bZIP-Proteinen dient und eine Homo- bzw. Heterodimerisierung von bZIP-Transkriptionsfaktoren ermöglicht (Landschulz et al., 1988; O'Shea et al., 1989). Die Dimerisierung der $\alpha$-Helices von zwei Leucin-Zippern führt zur Bildung einer coiled-coil Konformation (Baxevanis und Vinson, 1993; Lupas, 1996). Die amphiphatischen Eigenschaften der $\alpha$-Helix erlauben polaren oder geladenen Aminosäuren an Position e und $g$ eines Leucin-Zippers, mit Aminosäuren an den korrespondierenden Positionen eines anderen Leucin-Zippers $\mathrm{zu}$ interagieren. Eine Dimerisierung wird verhindert, wenn sich die Aminosäuren an Position e und g abstoßen oder aus sterischen Gründen keine Interaktion möglich ist, und gefördert, wenn es zu elektrostatischen Anziehungen oder zur Bildung von Wasserstoffbrücken kommt. Auf diese Art und Weise kann eine Spezifität der Dimerisierung erreicht werden (zur Übersicht siehe Siberil et al., 2001; Vinson et al., 2002).

Die basische Domäne des bZIP-Motivs vermittelt die Bindung des Proteins an spezifische DNA cis-Elemente. Bei der Dimerisierung werden sie so ausgerichtet, dass sie in die große Furche der DNA-Doppelhelix reichen (Vinson et al., 1989; Abbildung 2.1 B). Es wird angenommen, dass die Dimerisierung der bZIP-Proteine der Bindung an die DNA vorangeht. Metallo und Schepartz (1997) konnten jedoch zeigen, dass einige bZIP-Proteine auch als Monomer an die DNA binden und erst danach eine Dimerisierung erfolgt. Die basische Domäne vermittelt neben der DNA Bindung auch 
die Kernlokalisation, da sie eine Kernlokalisierungssequenz (NLS) umfasst (van der Krol und Chua, 1991; Varagona und Raikhel, 1994).

Bisher untersuchte bZIP-Transkriptionsfaktoren haben vielfältige Funktionen, z.B. bei der lichtregulierten Genexpression (Oyama et al., 1997), bei der Pathogenabwehr (Zhou et al., 2000), bei der Hormon-vermittelten Genexpression (Fukazawa et al., 2000) und bei der Regulationen der Expression von Speicherproteinen im Samen (Schmidt et al., 1992). Darüber hinaus wird ihnen eine Rolle bei der Genexpression als Antwort auf Abscisinsäure, Anaerobiosis, und bei der Verarbeitung von Entwicklungssignalen zugesprochen (Menkens et al., 1995).

bZIP-Transkriptionsfaktoren binden in der Regel an cis-Elemente, die eine ACGT Konsensus-Sequenz enthalten (Schindler et al., 1992), aber auch vom ACGTKernmotiv abgewandelte Sequenzen werden von einigen bZIP-Faktoren effektiv als DNA-Bindestellen erkannt (de Pater et al., 1994). Für eine effiziente DNA-Bindung sind zusätzlich die Sequenzen von Bedeutung, die das Kernmotiv flankieren (Foster et al., 1994). Im wesentlichen bevorzugen pflanzliche bZIP-Faktoren als Bindemotive palindromische Sequenzen wie die A-Box (TACGTA), die C-Box (GACGTC) oder die G-Box (CACGTG) (Izawa et al., 1993). Es gibt allerdings auch Beispiele für Bindung an nicht palindromische Motive (Choi et al., 2000; Fukazawa et al., 2000). Niu und Guiltinan (1994) konnten zeigen, dass für die Spezifität der DNA-Bindung nicht nur die basische Domäne des Transkriptionsfaktors entscheidend ist, sondern dass unabhängig davon auch der kurze Bereich von circa fünf Aminosäuren zwischen basischer Domäne und Leucin-Zipper eine DNA-Bindespezifität vermittelt.

Anhand der Struktur bekannter bZIP-Proteine wurden von Jakoby et al. (2002) im Arabidopsis Genom 75 putative AtbZIP-Transkriptionsfaktoren identifiziert, die mit AtbZIP1 bis AtbZIP75 benannt wurden. Anhand von Sequenzhomologien der basischen Domäne wurden die Proteine in Gruppen eingeteilt. Dazu wurden die AtbZIPTranskriptionsfaktoren mit Hilfe des MEME Analyse-Programms (http://meme.sdsc.edu/meme/website/meme.html) nach sich wiederholenden Motiven außerhalb der bZIP-Domäne untersucht. Auf diese Weise konnten 10 Gruppen mit homologer basischer Domäne und gemeinsamen konservierten Sequenzmotiven gebildet werden. 


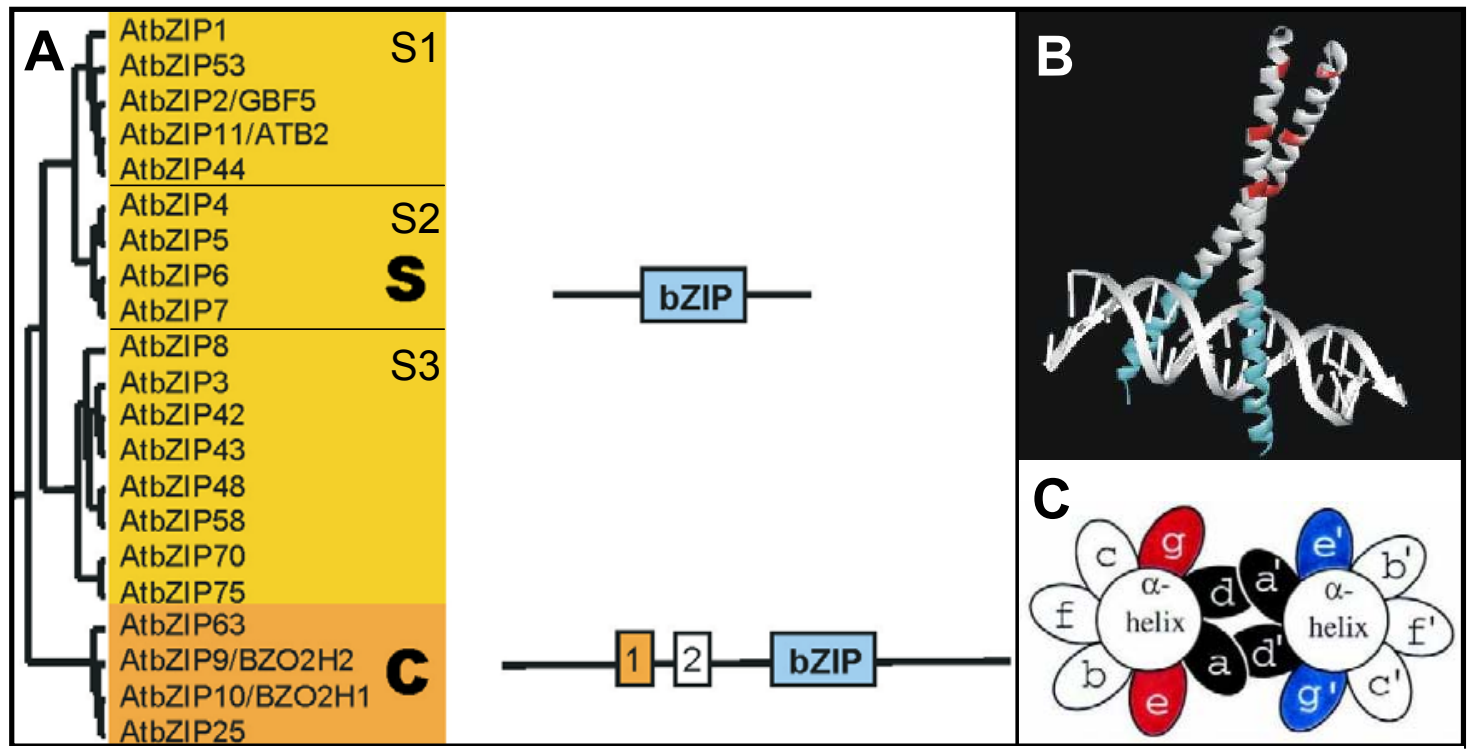

Abbildung 2.1: A) Die Gruppen $S$ und $C$ der AtbZIP-Transkriptionsfaktoren. Links ist ein Stammbaum anhand von Sequenzähnlichkeiten der basischen Domäne wiedergegeben. Rechts ist die für die Gruppe kennzeichnende Domänenstruktur angegeben (Domäne 1: S[QA][SP]E[WL][AT] $[\mathrm{FL}]$; Domäne 2: Y[RTH]x2L[KR]x[KS]L). S1-S3: Untergruppen der Gruppe S. B) Dreidimensionale Struktur der GCN4 bZIP Domäne. Die $\alpha$-Helices bilden eine doppelt gewundene Struktur (coiled coil). Die basische Domäne ist blau markiert, die Leucin Wiederholungen sind rot markiert (Ellenberger et al., 1992). C) Heptamere Wiederholung in der Aufsicht. Die Reste der Aminosäuren in Position a oder d formen die hydrophobe Interaktionsfläche, während die Reste der Aminosäuren $g$ und e über unterschiedliche Ladungen eine Spezifität der Interaktion vermitteln können.

\subsection{Die Gruppen C und S der AtbZIP-Transkriptionsfaktoren}

Die in dieser Arbeit analysierten AtbZIP-Transkriptionsfaktoren gehören $\mathrm{zu}$ den Gruppen C und S (Abbildung 2.1 A). Die Gruppe S umfasst kleine (small) Transkriptionsfaktoren mit einer Masse von 15-20 kDa . Sie bestehen hauptsächlich aus der basischen Domäne und einem langen Leucin-Zipper. Neben diesen Domänen sind nur kurze N- und C-terminale Bereiche vorhanden, weitere gemeinsame konservierte Domänen wurden nicht gefunden. Die Gene verfügen über keine Introns (Jakoby et al., 2002). Zur Gruppe C gehören 4 Transkriptionsfaktoren mit einer Masse von 30-40 kDa. Sie verfügen über putative Phosphorylierungsstellen, die einen Einfluss auf DNABindung und Kerntransport haben könnten (Jakoby et al., 2002).

Für die zur Gruppe S gehörenden bZIP Transkriptionsfaktoren BZI-2, BZI-3 und BZI-4 aus Nicotiana tabacum wurde eine spezifische Heterodimerisierung mit dem bZIP Transkriptionsfaktor BZI-1 gezeigt. BZI-1 ist homolog zu der Gruppe C von bZIP 
Transkriptionsfaktoren (Strathmann et al., 2001). Vergleichbare Interaktionen zwischen bZIP-Transkriptionsfaktoren der Gruppen $\mathrm{C}$ und $\mathrm{S}$ wurden auch für Transkriptionsfaktoren aus Petroselinum crispum gefunden. CPRF2, der Namensgeber der Gruppe C, interagiert spezifisch mit den Gruppe S bZIP-Transkriptionsfaktoren CPRF6 und CPRF7 (Rugner et al., 2001). Diese C/S Heterodimerisierungen scheinen konserviert zu sein, da für BZI-1 aus Tabak auch eine Heterodimerisierung mit CPRF6 und CPRF7 aus Petersilie gezeigt werden konnte (Strathmann, 2003). Ein gemeinsames Merkmal von AtbZIP-Transkriptionsfaktoren der Gruppen $\mathrm{C}$ und S, das in Zusammenhang mit der Heterodimerisierung stehen könnte, ist ein ungewöhnlich langer Leucin-Zipper mit 8 heptameren Wiederholungen (Jakoby et al., 2002).

Die durch die Fähigkeit Heterodimere zu bilden möglichen verschiedenen Kombinationen von bZIP-Proteinen können sich in ihrem DNA-Bindungsverhalten und ihren Aktivierungseigenschaften unterscheiden (Lamb und McKnight, 1991; Pysh et al., 1993). Auf diese Weise kann eine begrenzte Zahl von bZIP-Transkriptionsfaktoren eine Vielzahl von regulatorischen Einflüssen ausüben. Die daraus entstehende Komplexität lässt sich vielleicht dadurch erklären, dass die Heterodimerisierung ein Mechanismus der Signalintegration ist, und macht heterodimerisierende AtbZIPTranskriptionsfaktoren $\mathrm{zu}$ einem interessanten, aber auch schwierigen Forschungsthema.

Obwohl die Gruppe S die größte Gruppe von AtbZIP-Transkriptionsfaktoren in Arabidopsis thaliana ist, ist bisher lediglich ein Mitglied, AtbZIP11 ( ATB2 ), näher untersucht worden (Rook et al., 1998b). AtbZIP11 wird in Sink-Geweben bevorzugt im Leitgewebe exprimiert und ist durch Licht induzierbar. Des weiteren verfügt AtbZIP11 über einen ungewöhnlich langen 5'-untranslatierten Bereich mit einen offenen Leserahmen (uORF), für den gezeigt werden konnte, dass er an einer Repression der Translation durch Saccharose beteiligt ist (Rook et al., 1998a; Wiese et al., 2004). Es ist bekannt, das uORFs die Translation regulieren können (Geballe und Morris, 1994). Dieser uORF, dessen Aminosäuresequenz stark konserviert ist, findet sich in Arabidopsis thaliana in den 5' untranslatierten Bereichen von fünf Mitgliedern der Gruppe S (Abbildung 2.2), die aufgrund von Sequenzhomologien in eine Untergruppe, S1, eingeteilt werden. Für andere Mitglieder der Gruppe S1 konnte eine Saccharosespezifische Repression der Translation ebenfalls gezeigt werden (Wiese et al., 2005). 


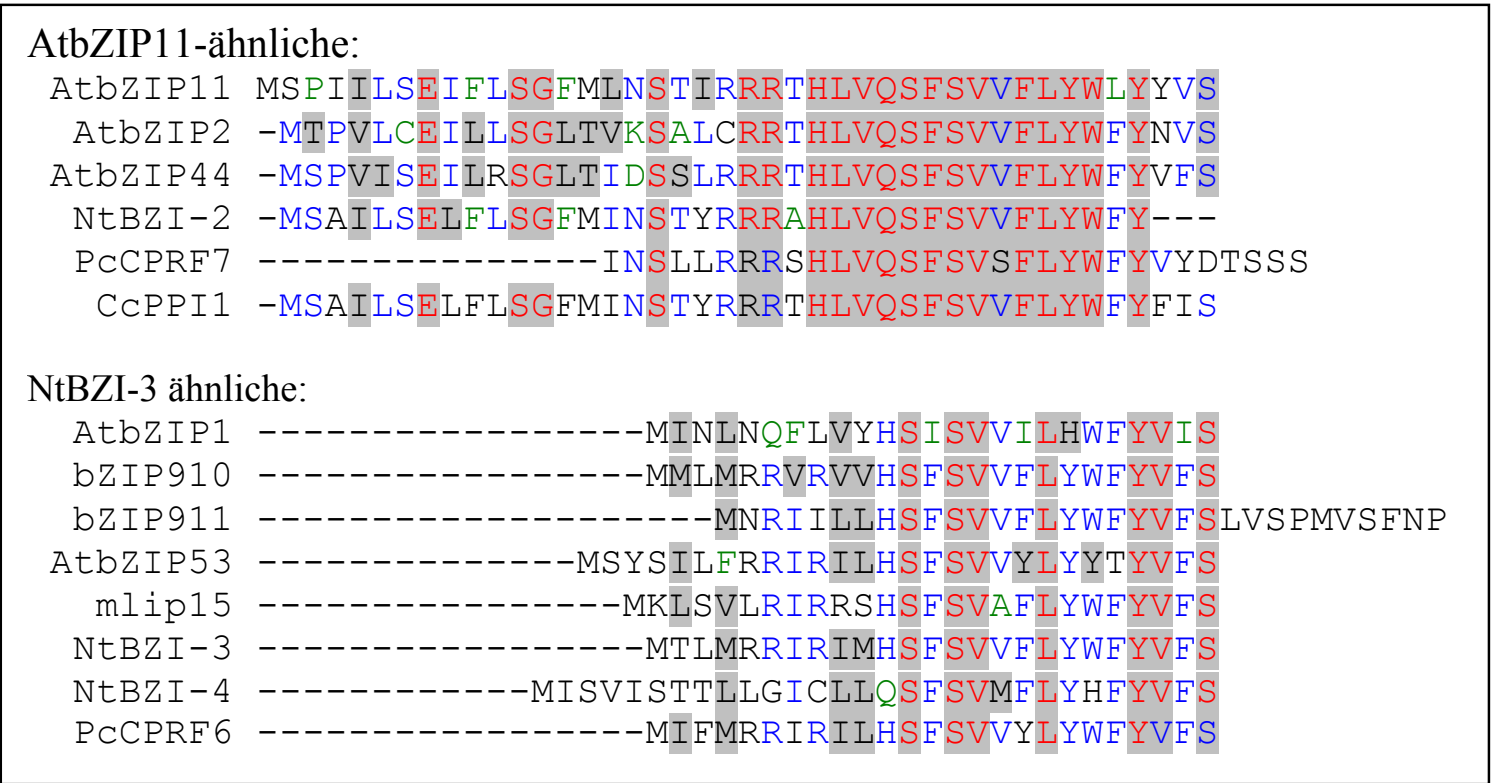

Abbildung 2.2: Konservierte uORFs von Gruppe S1 bZIP-Transkriptionsfaktoren verschiedener Pflanzenspezies. Anhand der Länge der uORFs lässt sich die Gruppe S1 in die Untergruppen der AtbZIP1-ähnlichen und der NtBZI-3 ähnlichen unterteilen. Rot auf Grau: identische Aminosäuren (AS); Blau: konservierte AS; Schwarz auf Grau: ähnliche AS; Grün: schwach ähnliche AS.

Die Gruppe S1 lässt sich in zwei weitere Untergruppen unterteilen. Die Untergruppe der AtbZIP11-ähnlichen Transkriptionsfaktoren, zu der AtbZIP2, AtbZIP11 und AtbZIP44 gehören, unterscheidet sich durch einen längeren uORF sowie das Vorhandensein einer kurzen, serinreichen N-terminalen Sequenz im eigentlichen Kodierbereich von der Untergruppe der NtBZI-3-ähnlichen Transkriptionsfaktoren, zu der AtbZIP1 und AtbZIP53 gehören (Strathmann et al., 2001).

\subsection{Zucker und Zucker-abhängige Signalwege}

Pflanzen müssen wie andere Organismen ihre Entwicklung und ihren Metabolismus abhängig von der Verfügbarkeit der Energiequelle Zucker regulieren. Beispiel für solche Zucker-regulierten Prozesse sind Samenentwicklung (Borisjuk et al., 2004), Pollenentwicklung (Zhang et al., 2001) oder Seneszenz (Paul und Pellny, 2003). Für die Wahrnehmung verfügbarer Zucker haben Pflanzen verschiedene Zucker-abhängige Signalwege (zur Übersicht siehe Roland et al. (2002); Smeekens, (2000)). Zucker wie Glukose und Saccharose können wahrscheinlich direkt wahrgenommen werden. Der Nachweis einer Signalwirkung von Saccharose ist schwierig, da Saccharose von 
Pflanzen schnell zu Hexosen hydrolysiert werden kann. Jedoch konnte gezeigt werden, dass die Translation von Gruppe S1 AtbZIP-Transkriptionsfaktoren spezifisch durch Saccharose, nicht durch Glukose oder Fruktose reguliert wird (Rook et al., 1998a; Wiese et al., 2004). Für Zuckerrüben konnte eine Saccharose-spezifische Repression der Transkription eines Gens, dass einen Saccharose-Transporter codiert, gezeigt werden (Chiou und Bush, 1998). Da Glukose und Fruktose von der Pflanze leicht in Saccharose umgewandelt werden können, wird vermutet, dass nicht die zelluläre Saccharosekonzentration wahrgenommen wird, sondern der Import von Saccharose durch die Zellmembran (Smeekens, 2000).

Für die Glukose-Wahrnehmung existieren wahrscheinlich mindestens zwei unabhängige Systeme. Am besten untersucht ist die Hexokinase-abhängige Signaltransduktion (Moore et al., 2003; Xiao et al., 2000). Hexokinase katalysiert die Phosphorylierung von Glukose und ermöglicht so ihren Eintritt in die Glykolyse. Für die Hexokinase wird zudem eine von der Phosphorylierungsreaktion abhängige Wahrnehmung von Glukose und eine entsprechende Signalweiterleitung postuliert, da Substrate wie 2Deoxyglukose, die wie Glukose phosphorylisiert werden können, Hexokinaseabhängige Signalwege aktivieren können, andere Glukose-Analoga wie 6Deoxyglukose, die zwar in die Zelle transportiert werden können, aber nicht phosphoryliert werden, jedoch nicht dazu in der Lage sind. Für 3-ortho-Methylglukose, die keine Hexokinase-abhängigen Signalwege aktivieren kann und lange als nicht phosphorylierbares Substrat galt, konnte gezeigt werden, dass sie durchaus phosphoryliert werden kann, nicht metabolisiert wird und in der Zelle akkumuliert (Cortes et al., 2003). Jedoch ist die Kinetik dieser Phosphorylierungsreaktion deutlich niedriger als die von Glukose, so dass diese Ergebnisse nicht unbedingt der postulierten Signalfunktion der Hexokinase widersprechen. Neben der Hexokinase-abhängigen Signaltransduktion wird auch noch ein Hexokinase-unabhängiger Signalweg vermutet, da bestimmte Zucker-regulierte Gene wie Pat(B33) auch durch die nicht phosphorylierbaren Glukose-Analoga aktiviert werden können (Martin et al., 1997).

Außerdem gibt es wahrscheinlich auch Signalwege, die nicht über die absoluten ZuckerMengen reguliert werden, sondern zum Beispiel über das Kohlenstoff : Stickstoff Verhältnis (Coruzzi und Bush, 2001). Da Zucker Produkte der Photosynthese sind, überrascht es nicht, dass eine Vernetzung zwischen Zucker- und Lichtabhängigen Signalwegen existiert (Ellis et al., 2002). Darüber hinaus gibt es aber auch eine Vernetzung mit verschiedenen Hormon-Signalwegen (Leon und Sheen, 2003). Ein 
weiterer Faktor, der in Zusammenhang mit Zuckern berücksichtigt werden muss, ist, dass Änderungen von Zuckerkonzentrationen immer auch einen Einfluss auf das osmotische Potential in der Zelle haben.

\subsection{AtbZIP-Transkriptionsfaktoren der Gruppen C und S1 in der Pollen- und Samenentwicklung}

$\mathrm{Zu}$ den Zucker-regulierten Prozessen, für die eine Beteiligung von zu den Gruppen $\mathrm{C}$ und S1 gehörenden bZIP-Transkriptionsfaktoren vermutet wird, gehört die Pollen- und Samenentwicklung.

Die männliche Gametogenese, die Pollenentwicklung, findet in den Staubblättern statt. Staubblätter bestehen aus einem Filament (Stiel), das über das Konnektiv mit den Pollensäcken verbunden ist. Über das Konnektiv und ein an der Innenwand der Pollensäcke existierendes Nährgewebe, das Tapetum, werden die Pollen mit Nährstoffen versorgt (Goldberg et al., 1993; Imlau et al., 1999). In den Pollensäcken entstehen aus Pollenmutterzellen durch Meiose vier haploide Mikrosporen, die einkernigen, primären Pollen. Darauf folgen zwei Mitosen, die zur Bildung des zweikernigen und dreikernigen Pollen führen. Der dreikernige Pollen wird dann tolerant gegen Austrocknung und reift zum fertigen Pollen aus, der nur noch einen Wassergehalt von 15-30\% hat (Crowe et al., 1992; Heslop-Harrison, 1978).

Für Tabak bZIP-Transkriptionsfaktoren der Gruppen C und S1 wird eine Rolle in der Pollenentwicklung diskutiert (Strathmann, 2003). Es konnte gezeigt werden, dass die Überexpression eines dominant-negativen Deletionsderivates des Gruppe C bZIPTranskriptionsfaktors BZI-1, BZI-1 $\Delta \mathrm{N}$, dem der N-Terminus mit der darin enthaltenen Aktivierungsdomäne fehlt, zu einer massiven Störung der Pollenentwicklung führt. Es werden weniger Pollen gebildet, und diese sind zum größten Teil degeneriert. Es konnte gezeigt werden, dass die Antheren-spezifische Invertase NIN88, für die eine Rolle in der Zuckerversorgung der Pollen angenommen wird, in diesen Pflanzen kaum exprimiert wird. Für Pflanzen, in denen die Expression der NIN88 über ein AntisenseKonstrukt unterdrückt wurde, wurde eine vergleichbare Störung der Pollenentwicklung gezeigt (Goetz et al., 2001). Der Phänotyp der BZI-1 $\Delta$ N überexprimierenden Pflanzen ist also möglicherweise auf die gestörte Regulation der NIN88 zurückzuführen. Die Überexpression von BZI-4, einem S1 bZIP-Transkriptionsfaktor, der spezifische 
Heterodimere mit BZI-1 bildet und vorwiegend in Staubblättern exprimiert wird, führt ebenfalls zu einer Repression der NIN88. Für BZI-4 konnte außerdem in GelRetardationsanalysen die Bindung an eine G-Box im NIN-88 Promotor gezeigt werden. Es wird daher vermutet, dass Tabak C/S1 Heterodimere die Invertase NIN88 und damit die Zuckerversorgung der Pollen regulieren.

In Arabidopsis wurde für den S1 Faktor AtbZIP11 mit Hilfe von Promotor-GUS Fusionen eine spezifische Expression im Konnektiv gezeigt. Da Überexpression von AtbZIP11 zu einer verstärkten Expression von Zellwand Invertasen führt, wird für AtbZIP11 ebenfalls eine Rolle in der Zuckerverteilung diskutiert (Rook et al., 1998a). Für die S1 Faktoren bZIP910 und bZIP911 aus Antirrhinum majus wurde in in situ Hybridisierungen eine Expression im Tapetum gezeigt, wo auch sie an der Regulation der Nährstoffversorgung der Pollen beteiligt sein könnten (Martinez-Garcia et al., 1998).

Parallel zur Pollenentwicklung findet im Fruchtknoten die weibliche Gametogenese statt, die zur Bildung der Eizelle und eines Embryosackes führt. Zur Befruchtung wächst aus dem Pollenkorn ein Polenschlauch, und es kommt zur für die Angiospermen typischen doppelten Befruchtung: Ein Pollenkern verschmilzt mit der Eizelle, die sich zum Embryo entwickelt, und ein anderer mit dem Embryosackkern, aus dem sich das Endosperm, ein Nährgewebe, bildet. Während der Samenreifung akkumulieren Samen verschiedene Speicherstoffe, bei Arabidopsis thaliana vorwiegend Lipide und 2S und 12 S Samen-Speicherproteine (SSPs) (Guerche et al., 1990; Mansfield und Briarty, 1992; Pang et al., 1988).

Wichtige cis-Elemente in einem SSP Promotor aus Brassica napus, der zu SSPPromotoren aus Arabidopsis thaliana sehr ähnlich ist, sind eine B-box aus einem DistB (GCCACTTGTC) und einem ProxB (CAAACACC) Element, zwei RY (CATGCA) Elemente und eine G-box (CACGTG). Mutationen in jedem dieser Elemente führen zu einem starken Rückgang der Promotoraktivität in Samen (Ellerstrom et al., 1996; Ezcurra et al., 1999). In Arabidopsis thaliana binden die B3-Transkriptionsfaktoren FUS3 und LEC2 an die $R Y$-Elemente, und die Gruppe C AtbZIP-Transkriptionsfaktoren 10 und 25 an die G-box, und aktivieren die Expression der SSP-Gene. Des weiteren interagieren AtbZIP10 und AtbZIP25 mit ABI3, einem weiteren B3Transkriptionsfaktor, der wahrscheinlich als Koaktivator an der Regulation von SSPGenen beteiligt ist (Kroj et al., 2003; Lara et al., 2003; Abbildung 2.3). 


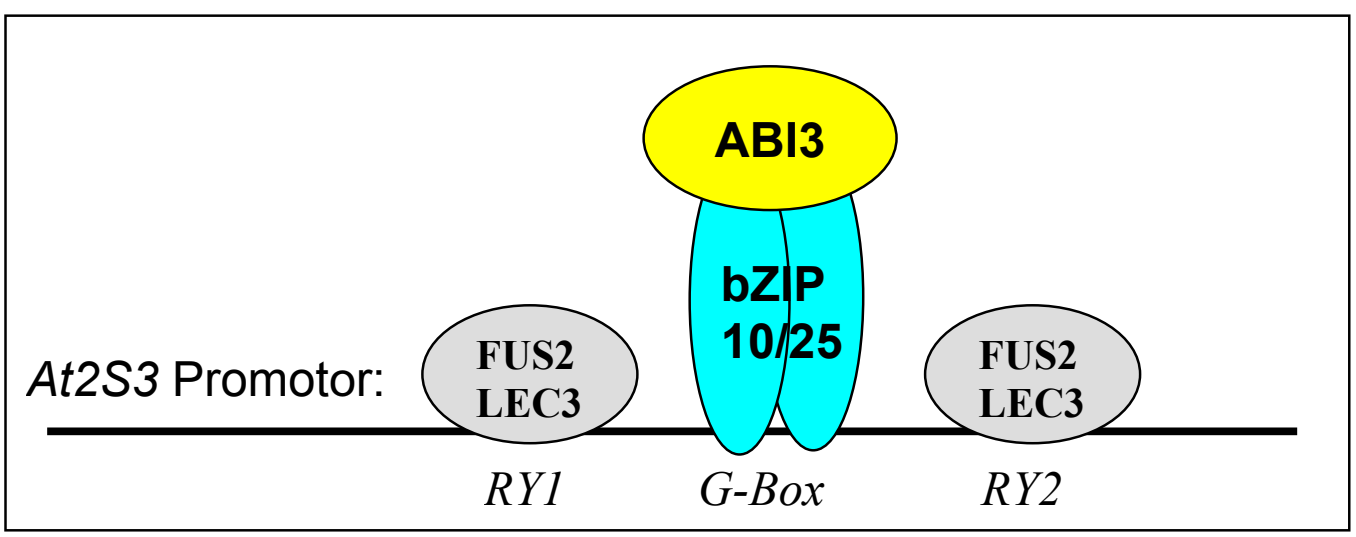

Abbildung 2.3: Modell der SSP-Promotorregulation am Beispiel des At2S3-Promotors. Nach Kroj et al., (2003). FUS3 und LEC2 binden direkt an $R Y$-Elemente in SSP-Promotoren und aktivieren die Transkription, während ABI3 wahrscheinlich über AtbZIP10 oder AtbZIP25 an G-Box Elemente bindet und die Transkription aktiviert.

Transkripte von AtbZIP10 und AtbZIP25 konnten in in situ Hybridisierungen im Embryo und schwächer auch im Endosperm nachgewiesen werden, während die Transkripte der anderen beiden Arabidopsis Gruppe C Faktoren dort nicht nachzuweisen waren. Jedoch wurde für beide Faktoren auch eine deutliche Expression in anderen Geweben, wie Blatt oder Wurzel, gezeigt, sodass sie neben der Samenentwicklung wahrscheinlich auch andere Funktionen haben.

\subsection{Abiotischer Stress und die Funktion von Prolin im Schutz vor Stress}

Kälte, Hitze, Salz oder Trockenheit sind Stresse, an die sich die Pflanze anpassen muss, da sie keine Möglichkeit hat ihnen auszuweichen. Eine wichtige Rolle dabei spielt das Phytohormon Abscisinsäure, das außerdem auch an der späten Phase der Samenentwicklung, in der die Austrocknungstoleranz der Samen ausgeprägt wird, beteiligt ist (Bray, 1993; McCarty, 1995).

Für Homologe der Gruppe S1 aus verschiedenen Spezies, Rdlip, Lip19, tbz17 und mlip15, wurde eine Induktion durch Kältestress gezeigt (Aguan et al., 1993; Ito et al., 1999; Kusano et al., 1998; Yang et al., 2001), für mlip15 außerdem eine Induktion durch Salzstress (Kusano et al., 1995). Des weiteren konnte gezeigt werden, dass in 
Craterostigma plantagineum ein zur Gruppe S1 gehörender bZIP-Transkriptionsfaktor an ein für die Trockenstress-Induktion essentielles, ABA-induzierbares Element aus dem Promotor des LEA-Gens C2, das in hohem Maße bei Trockenstress induziert wird, bindet (Ditzer, 2003). LEA (late embryogenesis abundant) Gene werden durch ihre Expression in der späten Phase der Samenentwicklung definiert, wo sie, wie unter Trockenstress, an der Ausbildung einer Austrocknungstoleranz beteiligt sein können.

Als Reaktion auf Kälte, Salz oder Trocken-Stress akkumulieren viele Pflanzen Prolin (Delauney und Verma, 1993). Unter Stress-Bedingungen fungiert Prolin als kompatibler Osmolyt (Handa et al., 1986), als Schutz vor freien Radikalen (Smirnoff und Cumbes, 1989) und als Puffer des zellulären Redox-Potentials (Hare et al., 1998). Für TabakPflanzen mit gesteigerter Prolin-Biosynthese wurde eine gesteigerte Salztoleranz gezeigt, was auf eine direkte Schutzfunktion von Prolin hindeutet (Kavi Kishor et al., 1995). Andererseits führen auch biotische und abiotische Stresse ohne osmolare Komponente, wie etwa UV-Bestrahlung (Pardha Saradhi et al., 1995) oder Stickstoffmangel (Vaucheret et al., 1992) zu einer Prolin-Akkumulation, was eher für eine andere als die biophysikalische Funktion von Prolin unter Stress spricht. Daher wird von (Hare und Cress, 1997) ein anderer möglicher Mechanismus für die Schutzfunktion von Prolin favorisiert: Prolin ist ein sehr guter Energieträger, die Prolin Biosynthese verbraucht viele Reduktionsäquivalente, und könnte unter Stress an der

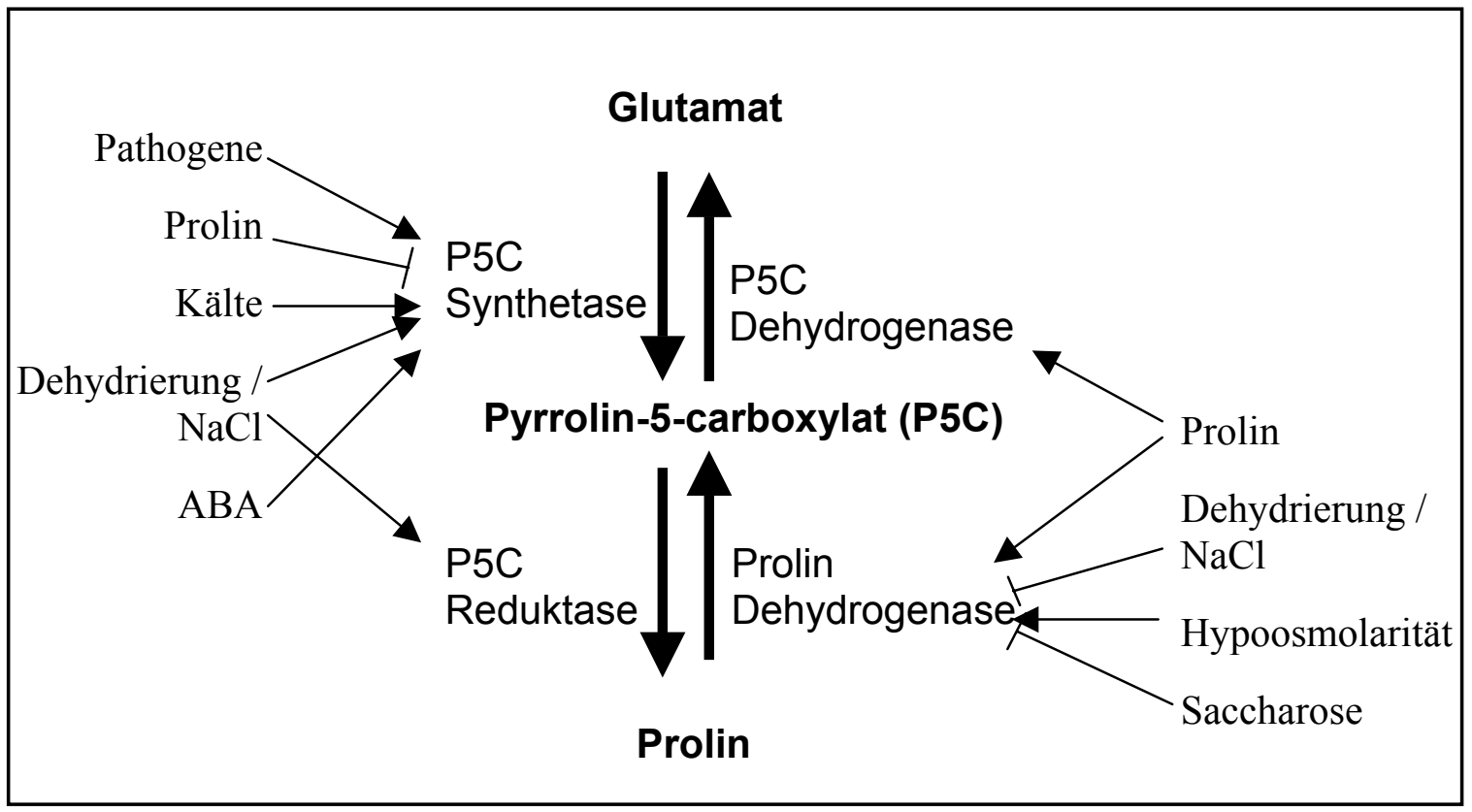

Abbildung 2.4: Übersicht über die Regulation der Biosynthese und Degradation von Prolin. Nach (Abraham et al., 2003; Chiang and Dandekar, 1995; Deuschle et al., 2004; Deuschle et al., 2001; Hellmann et al., 2000; Peng et al., 1996; Satoh et al., 2002). 
Wiederherstellung der terminalen Elektronenrezeptoren der Photosynthese beteilig sein. Nach Ende des Stresses stellt der Abbau von Prolin diese Energie wieder zur Verfügung, die dann für die Regeneration der Pflanze zur Verfügung steht.

Während der Erholung von abiotischem Stress kommt es zur Induktion einer Prolindehydrogenase, die den ersten Schritt des Prolin-Abbaus katalysiert (Kiyosue et al., 1996; Peng et al., 1996; Verbruggen et al., 1996; Abbildung 2.4). Satoh et al., (2002) konnten ein cis-Element identifizieren, das für die Induktion der ProDH bei Erholung von osmotischem Stress verantwortlich ist. In Protoplasten-Assays konnte gezeigt werden, dass die vier S1 AtbZIP-Transkriptionsfaktoren AtbZIP2, 11, 44 und 53 über dieses cis-Element die Transkription eines Reportergens aktivieren können (Satoh et al., 2004). Es gibt also Hinweise für eine Beteiligung von S1 bZIPTranskriptionsfaktoren sowohl in der Anpassung an als auch in der Erholung von abiotischem Stress.

\subsection{Seneszenz und bZIP-Transkriptionsfaktoren}

Die Seneszenz von Blättern ist eine Abfolge von degradativen Prozessen, die zum Abbau von Zellbestandteilen und zu der Mobilisierung der darin enthaltenen Nährstoffe, und letztlich zum Tod des Blattes führen. Die Seneszenz wird von der Pflanze streng reguliert, unter anderem über Zucker- oder ABA-abhängige Signalwege (Fujiki et al., 2001; Pourtau et al., 2004). Sie beinhaltet den Stop der Photosynthese, den Abbau von Proteinen, Membranen, RNA und DNA, sowie die Hydrolyse von Polysacchariden und die Oxidation von Fettsäuren (Smart, 1994). Viele verschiedene Seneszenz-assoziierte Gene wurden identifiziert, darunter Proteasen, RNasen, Glutamin Synthetase, Metallothionine, Lipasen, Enzyme des Glyoxylat-Zyklus, Katalasen, Endoxyloglucan Transferasen, PR-Proteine, Glutathione $S$-transferase, Cyt P450 und Polyubiquitin (Buchanan-Wollaston und Ainsworth, 1997; Weaver et al., 1998).

Während die natürliche Seneszenz vom Blattalter und der reproduktiven Phase der Pflanze abhängt, gibt es viele Faktoren wie Trockenstress, Licht- bzw. Zuckermangel oder Pathogenbefall, die eine vorzeitige Seneszenz auslösen können (Smart, 1994). Transkriptomanalysen von dunkelinduzierter und natürlicher Seneszenz haben gezeigt, dass es neben deutlichen Gemeinsamkeiten auch klare Unterschiede zwischen diesen 
beiden Formen von Seneszenz gibt (Buchanan-Wollaston et al., 2005). Dunkelinduzierte Seneszenz ist wahrscheinlich auf Zucker-Mangel zurückzuführen, und das Transkriptom von durch andauernde Dunkelheit seneszenten Pflanzen zeigt deutliche Parallelen zu dem von einer durch Zucker-Verarmung in die Seneszenz getriebenen Zellkultur.

Die Transkription des Gruppe S1 bZIP-Transkriptionsfaktors BZI-3/TBZF wird durch Seneszenz hochreguliert, und findet vor allem in den Nebenzellen des Spaltöffnungsapparates seneszenter Blätter statt (Yang et al., 2001). Die Transkriptmenge von mlip15, eines weiteren Gruppe S1 bZIP-Transkriptionsfaktors, steigt ebenfalls während der Seneszenz (Berberich et al., 1999).

\subsection{Fragestellung und Zielsetzung der Arbeit}

In Tabak und Petersilie wurde eine spezifische Heterodimerisierung zwischen bZIPTranskriptionsfaktoren der Gruppen $\mathrm{C}$ und $\mathrm{S}$ beschrieben. Über die Funktion dieser Faktoren ist jedoch wenig bekannt, und die biologische Bedeutung der Heterodimerisierung ist bisher nicht untersucht worden.

Erstes Ziel der Arbeit ist, die Heterodimerisierung zwischen Arabidopsis thaliana bZIPTranskriptionsfaktoren der Gruppen C und S auf genomischer Basis zu zeigen. Können spezifische Heterodimerisierungen gezeigt werden, so soll im folgenden die biologische Funktion der einzelnen Heterodimerisierungspartner sowie die funktionelle Bedeutung der Heterodimerisierung untersucht werden. Dafür werden zunächst für die heterodimerisierenden Faktoren die Expressionsmuster untersucht. Mit Hilfe von Promotor-GUS Fusionen kann die für die Heterodimerisierung notwendige gewebespezifische Kolokalisation analysiert werden. Durch Northern-Analysen und Daten aus Mikroarraydatenbanken wird außerdem die stressabhängige Regulation der AtbZIP-Transkriptionsfaktoren untersucht. Anhand dieser Daten können Vorhersagen getroffen werden, welche Heterodimere unter bestimmten Bedingungen in bestimmten Geweben entstehen können, und wo ihre biologische Funktion liegen könnte.

Transgene Pflanzen mit einer konstitutiven ektopischen Expression der AtbZIPTranskriptionsfaktoren, die im Rahmen der Dissertation erzeugt werden, können durch den Vergleich der Transkriptome dieser Pflanzen mit dem Wildtyp-Transkriptom helfen 
mögliche Zielgene zu identifizieren. Neben den Überexpressionslinien werden auch TDNA Insertionsmutanten der AtbZIP-Transkriptionsfaktoren charakterisiert, um mit diesen Pflanzen ebenfalls Transkriptomanalysen durchzuführen und den Einfluss der fehlenden Expression der bZIP-Faktoren auf mögliche Zielgene zu untersuchen. Direkte Zielgene sollen mittels Chromatin-Immunopräzipitation bestätigt werden. Um die Bedeutung der untersuchten AtbZIP-Transkriptionsfaktoren für bestimmte biologische Funktionen zu analysieren, werden die Überexpressions- und Knock Out Pflanzen phänotypisch charakterisiert. Modellhaft soll für ein direktes Zielgen der Einfluss der Heterodimerisierung auf dessen Transkription in Protoplasten-Assays untersucht werden. Die so gesammelten Daten dienen als Basis für Aussagen über die biologische Funktion der einzelnen AtbZIP-Transkriptionsfaktoren, sowie die biologische Funktion der Heterodimerisierung. 


\section{Material}

\subsection{Organismen}

\subsubsection{Hefestämme (Saccharomyces cerevisiae)}

\begin{tabular}{|c|c|c|}
\hline Stamm & Eigenschaften & Referenz \\
\hline $\mathrm{MaV} 203$ & 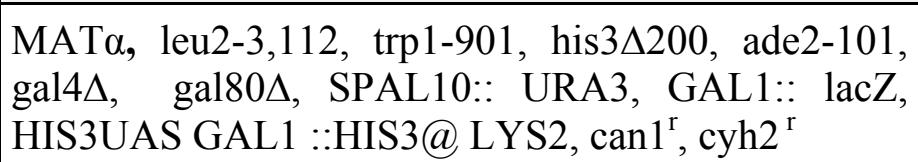 & (Vidal, 1997) \\
\hline
\end{tabular}

\subsubsection{Bakterienstämme}

\begin{tabular}{|c|c|c|}
\hline Stamm & Eigenschaften & Referenz \\
\hline $\begin{array}{l}\text { Agrobacterium } \\
\text { tumefaciens } \\
\text { GV3101 }\end{array}$ & $\begin{array}{l}\text { pMP90RK } \\
\text { Rif }^{\mathrm{r}}, \mathrm{Gm}^{\mathrm{r}}\end{array}$ & (Koncz und Schell, 1986) \\
\hline $\begin{array}{l}\text { Escherichia coli } \\
\text { DH5 } \alpha\end{array}$ & $\begin{array}{l}\text { recAl relA1 thi-1 } \Delta l a c U 169 \quad \phi 80 \\
(\operatorname{lac} Z \Delta M 15) h s d R 17\left(\mathrm{r}_{\mathrm{k}}-\mathrm{m}_{\mathrm{k}}+\right)\end{array}$ & (Hanahan, 1983) \\
\hline $\begin{array}{l}\text { Escherichia coli } \\
\text { DB3.1 }\end{array}$ & 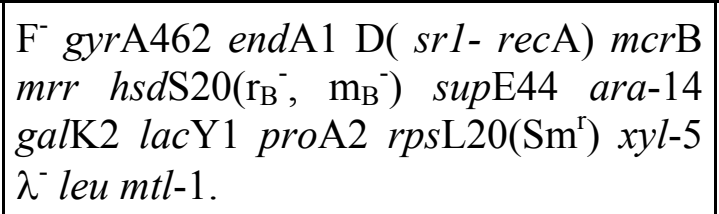 & (Bernard et al., 1993) \\
\hline
\end{tabular}

\subsubsection{Pflanzenmaterial: Ackerschmalwand (Arabidopsis thaliana)}

\begin{tabular}{|c|c|c|}
\hline Kultivar & Eigenschaften & Herkunft \\
\hline Columbia Col-o N1092 & Wildtyp & Kultursorte \\
\hline Garlic_195_E05.b.1a.Lb3Fa & AtbZIP53 Knock down Linie & Syngenta \\
\hline SALK_059343 & AtbZIP1 Knock out Linie & NASC stock center \\
\hline SALK_069489 & AtbZIP1 Knock out Linie & NASC stock center \\
\hline SALK_093416 & AtbZIP9 Knock out Linie & NASC stock center \\
\hline SALK_069883 & AtbZIP53 Knock down Linie & NASC stock center \\
\hline SALK_066531 & AtbZIP63 Knock out Linie & NASC stock center \\
\hline prom $_{\text {AtbZIP1 } 1}: G U S$ & Promotor-GUS Fusion & (Weltmeier, 2002) \\
\hline $\operatorname{prom}_{\text {AtbZIP53:GUS }}$ & Promotor-GUS Fusion & (Weltmeier, 2002) \\
\hline prom $_{\text {AtbZIP9:GUS }}$ & Promotor-GUS Fusion & Xuan Wang \\
\hline
\end{tabular}




\begin{tabular}{|l|l|l|}
\hline prom $_{\text {AtbZIP11 }}:$ GUS & Promotor-GUS Fusion & $($ Rook et al., 1998b) \\
\hline prom $_{\text {AtbZIP44:GUS }}$ Promotor-GUS Fusion & (Wobbes, 2004) \\
\hline prom $_{\text {AtbZIP2:GUS }}$ & Promotor-GUS Fusion & (Wobbes, 2004) \\
\hline prom $_{\text {AtbZIP10:GUS }}$ Promotor-GUS Fusion & Klaus Harter \\
\hline prom $_{\text {AtbZIP25:GUS }}:$ Promotor-GUS Fusion & Jesus Vincente-Carbajosa \\
\hline prom $_{\text {AtbZIP63:GUS }}$ & Promotor-GUS Fusion & Jesus Vincente-Carbajosa \\
\hline
\end{tabular}

\subsection{Nukleinsäuren}

\subsubsection{Plasmide}

\begin{tabular}{|c|c|c|}
\hline Plasmid & Eigenschaften & Referenz \\
\hline pDEST22 & $\begin{array}{l}\mathrm{GAL}_{(768-881)} \mathrm{AD}, \quad \mathrm{TRP} 1, \quad \text { ARS4/CEN6, } \\
\text { pUC ori, } \mathrm{Amp}^{\mathrm{r}}, a_{t} \mathrm{R} 1, \mathrm{Cm}^{\mathrm{r}}, c c d \mathrm{~B}, a_{t} \mathrm{R} 2\end{array}$ & Invitrogen, 2001 \\
\hline pDEST32 & $\begin{array}{l}\mathrm{GAL}_{(1-147)} \mathrm{DB}, \mathrm{LEU} 1, \mathrm{ARS} 4 / \mathrm{CEN} 6, \mathrm{pUC} \\
\text { ori, } \mathrm{CYH} 2{ }^{\mathrm{S}}, \mathrm{Gm}^{\mathrm{r}}, \operatorname{att\mathrm {R}} 1, \mathrm{Cm}^{\mathrm{r}}, c c d \mathrm{~B}, \operatorname{attR}^{2}\end{array}$ & Invitrogen, 2001 \\
\hline pDONR201 & pUC ori, $\mathrm{Km}^{\mathrm{r}}, a t t \mathrm{~L} 1, \mathrm{Cm}^{\mathrm{r}}, c c d \mathrm{~B}, a t t \mathrm{~L} 2$ & Invitrogen, 2001 \\
\hline $\begin{array}{l}\text { pDON201- } \\
\text { AtbZIP1 }\end{array}$ & pUC ori, Gm ${ }^{r}$, attL1, AtbZIP1, attL2 & (Weltmeier, 2002) \\
\hline $\begin{array}{l}\text { pDON201- } \\
\text { AtbZIP2 }\end{array}$ & pUC ori, $\mathrm{Km}^{\mathrm{r}}$, attL1, AtbZIP2, attL2 & $\begin{array}{l}\text { Sjef Smeekens, REGIA } \\
\text { Projekt }\end{array}$ \\
\hline $\begin{array}{l}\text { pDON201- } \\
\text { AtbZIP11 }\end{array}$ & pUC ori, $\mathrm{Km}^{\mathrm{r}}$, attL1, AtbZIP11, attL2 & $\begin{array}{l}\text { Sjef Smeekens, REGIA } \\
\text { Projekt }\end{array}$ \\
\hline $\begin{array}{l}\text { pDON201- } \\
\text { AtbZIP44 }\end{array}$ & pUC ori, $\mathrm{Km}^{\mathrm{r}}$, attL1, AtbZIP44, attL2 & $\begin{array}{l}\text { Sjef Smeekens, REGIA } \\
\text { Projekt }\end{array}$ \\
\hline $\begin{array}{l}\text { pDON201- } \\
\text { AtbZIP53 }\end{array}$ & pUC ori, Gm ${ }^{\mathrm{r}}$, attL1, AtbZIP53, attL2 & (Weltmeier, 2002) \\
\hline $\begin{array}{l}\text { pDON207- } \\
\text { AtbZIP9 }\end{array}$ & pUC ori, Gm ${ }^{\mathrm{r}}$, attL1, AtbZIP9, attL2 & (Weltmeier, 2002) \\
\hline $\begin{array}{l}\text { pDON201- } \\
\text { AtbZIP10 }\end{array}$ & pUC ori, $\mathrm{Gm}^{\mathrm{r}}$, attL1, AtbZIP10, attL2 & $\begin{array}{l}\text { Jesus Vincente-Carba } \\
\text { josa, REGIA Projekt }\end{array}$ \\
\hline $\begin{array}{l}\text { pDON201- } \\
\text { AtbZIP25 }\end{array}$ & pUC ori, $\mathrm{Gm}^{\mathrm{r}}$, attL1, AtbZIP25, attL2 & $\begin{array}{l}\text { Jesus Vincente-Carba } \\
\text { josa, REGIA Projekt }\end{array}$ \\
\hline $\begin{array}{l}\text { pDON201- } \\
\text { AtbZIP63 }\end{array}$ & pUC ori, $\mathrm{Gm}^{\mathrm{r}}$, attL1, AtbZIP63, attL2 & $\begin{array}{l}\text { Jesus Vincente-Carba } \\
\text { josa, REGIA Projekt }\end{array}$ \\
\hline pGEM-T & $\begin{array}{l}\text { f1 ori, colE1 ori, lacZ, MCS, Amp }{ }^{\mathrm{r}} \text {, SP6 } \\
\text { und T-Promotor }\end{array}$ & Promega, 1999 \\
\hline
\end{tabular}




\begin{tabular}{|c|c|c|}
\hline pAlligator2 & $\begin{array}{l}\text { 2S1:GFP, T-DNA Border Sequenzen, } \\
\text { 2x35S-Promotor, 3x HA-tag (N-terminal), } \\
\text { attR1, } \mathrm{Cm}^{\mathrm{r}}, c c d \mathrm{~B}, \text { att } \mathrm{R} 2\end{array}$ & $\begin{array}{l}\text { Parcy, F. ; http://www. } \\
\text { isv.cnrs-gif.fr/JG/ } \\
\underline{\text { alligator/intro.html }}\end{array}$ \\
\hline $\begin{array}{l}\text { pBT10-2xProDH- } \\
\text { GUS }\end{array}$ & $\begin{array}{l}3 \mathrm{x} \text { G/C- Element, pUC ori, } 35 \mathrm{~S}- \\
\text { Minimalpromotor, GUS- Reportergen, } \\
\text { Amp }^{\mathrm{R}} \text {, }\end{array}$ & (Ehlert, 2004) \\
\hline pHBTL- HAGW & $\begin{array}{l}\text { 3x HA- tag, pUC ori, } \mathrm{Amp}^{\mathrm{R}}, \operatorname{attR} 1, c c d B, \\
\mathrm{Cm}^{\mathrm{R}}, \text { attR2 }\end{array}$ & (Ehlert, 2004) \\
\hline
\end{tabular}

\subsubsection{Primer}

\begin{tabular}{|c|c|c|}
\hline Name & $\begin{array}{c}\text { Länge } \\
\text { (bp) }\end{array}$ & Sequenz $\left(5^{\prime} \rightarrow 3^{\prime}\right)$ \\
\hline $2 S 1$ chip F & 19 & GACCGGTGACCTGCGTGTA \\
\hline $2 S 1$ chip R & 21 & GACTTGCATGGAGTTCACGTG \\
\hline $35 \mathrm{SI}$ & 23 & ATTGATGTGATATCTCCACTGAC \\
\hline $5^{\prime}$-GUS & 24 & GGTTTCTACAGGACGTAACATAAG \\
\hline Actin8 3'-anti & 20 & AGGTCTCCATCTCTTGCTCG \\
\hline Actin8 $5^{\prime}$-sense & 20 & GCTGGATTCGCTGGAGATGA \\
\hline ASN1antisense & 20 & CGAAATGCTCACAGTCATCG \\
\hline ASN1chip rev & 21 & GACCAGCTGTTTCCACGTGTT \\
\hline ASN1chip for & 21 & CACGTGTACGGCTCTAAAGCA \\
\hline ASN1sense & 21 & GTGGAATACTTGCCGTGTTAG \\
\hline AtcwINV1gstFOR & 21 & TTCAAAGCCCGTCAAAACAGC \\
\hline AtcwINV1gstREV & 21 & GCTCTTCCCTTTCCACCGAAA \\
\hline AtcwINV2gstFOR & 18 & GAAGGGTTGGGCCGGAAT \\
\hline AtcwINV2gstREV & 20 & TTGCGAAGCTTTCGTCAAAC \\
\hline AtcwINV3for2 & 22 & GACGAGGATTAGCGATTCTTTA \\
\hline AtcwINV3gstFOR & 20 & TGATCACTCGATAGTGGAGA \\
\hline AtcwINV3gstREV & 22 & CAAAACTGATGATTAGGTGAGC \\
\hline AtcwINV4gstFOR & 21 & ACGGTGCTCCTTGATTCAAGC \\
\hline AtcwINV4gstREV & 21 & GCGAGTAAACCCGTGTCTTGC \\
\hline AtcwINV5gstFOR & 25 & CCTAGGAAAGTATGGCTTGATGAAT \\
\hline AtcwINV5gstREV & 25 & GAAGAAAACTTCCACATCTGCTTGT \\
\hline AtcwINV6gstFOR & 25 & GAAGTGACTTTTAATCTGCCTTTCC \\
\hline AtcwINV6gstREV & 19 & TCTTCTCGCTGCTGCACAT \\
\hline BD-GWkasFOR & 36 & AGGTACCAACAATGAAGCTACTGTCTTCTATCGAAC \\
\hline bzip11rev & 20 & GGTTCGAACACATGCCCATG \\
\hline bZIP1pGUSf & 26 & GTCGACCTTGAATTATCCTACGAGTG \\
\hline bZIP1pGUSf2 & 26 & GTCGACACCACAATTTGGAACTAATA \\
\hline bZIP1pGUSf3 & 26 & GTCGACATCATTTCAGATAAGACCCA \\
\hline bZIP1pGUSr & 26 & GAATTCTCAAGAGATAACGTAAAACC \\
\hline bZIP1pGUSr2 & 20 & ACGCTTAACATGGTTGACAA \\
\hline bZIP1TF\#1 & 20 & GGCAAACGCAGAGAAGACAA \\
\hline bZIP1TF\#2 & 20 & GGACGCCATTGGTTGTAGAG \\
\hline bzip2rev & 20 & CAAAACCACAGCCGTCGATC \\
\hline bzip44cDNA\#1 & 22 & ATGGGATCTTCCACAAGTGGAA \\
\hline
\end{tabular}




\begin{tabular}{|c|c|c|}
\hline bzip44cDNA\#2 & 22 & CCTGCTGCGATGATTAGTCTCA \\
\hline bzip44rev & 19 & GCCGTCGAATAATCCACCG \\
\hline bzip53cDNA\#1 & 22 & ATGGGGTCGTTGCAAATGCAAA \\
\hline bzip53cDNA\#2 & 23 & TCAGCAATCAAACATATCAGCCA \\
\hline bZIP53pGUSf & 26 & CTGCAGCTTAGGACAGCTCATCACCA \\
\hline bZIP53pGUSf2 & 26 & CTGCAGAAGTCCAGGTCAAGTTTGTT \\
\hline bZIP53pGUSf3 & 26 & GGATCCATGTTCAGATTCTGCGCTTA \\
\hline bZIP53pGUSr & 26 & GTCGACCTCGTTGACTTTTTGACTTC \\
\hline bZIP53pGUSr2 & 20 & AAAGGCCAAACGAAAGAAGG \\
\hline bZIP53pp antisense & 30 & GCGTTATCATTCTTGGGAAGAGTGACTTCG \\
\hline bZIP53pp sense & 30 & CGAAGTCACTCTTCCCAAGAATGATAACGC \\
\hline bZIP53TF\#1 & 25 & GTGCTTGAGATGGTTGAAGAAATTA \\
\hline bZIP53TF\#2 & 25 & CATACAAAGACACGAACAAATTGAA \\
\hline bzip9cDNA\#1 & 23 & ATGGATAATCACACAGCTAAAGA \\
\hline bzip9cDNA\#2 & 23 & AGAGTCATGGCCAGATGTCTGAG \\
\hline bZIP9TF\#1 & 20 & CGCAACACAACAGTTTCGTA \\
\hline bZIP9TF\#2 & 20 & GCCAGATGTCTGAGACGCAG \\
\hline c63fgw & 51 & $\begin{array}{l}\text { GGGGACAAGTTTGTACAAAAAAGCAGGCTTCGCGTGTGGT } \\
\text { GTTTCCGTCTC }\end{array}$ \\
\hline c63rev2 & 20 & TCTCCGTCGTCTGCAGCGGC \\
\hline c63rgw & 50 & $\begin{array}{l}\text { GGGGACCACTTTGTACAAGAAAGCTGGGTCCTACTGATCC } \\
\text { CCAACGCTTC }\end{array}$ \\
\hline cambia-GUS & 24 & TCGCGATCCAGACTGAATGCCCAC \\
\hline cAtbZIP1FORGW & 60 & $\begin{array}{l}\text { GGGGACAAGTTTGTACAAAAAAGCAGGCTTCATGGCAAAC } \\
\text { GCAGAGAAGACAAGTTCAGG }\end{array}$ \\
\hline cATBZIP1FORGW & 60 & $\begin{array}{l}\text { GGGGACAAGTTTGTACAAAAAAGCAGGCTTCATGGCAAAC } \\
\text { GCAGAGAAGACAAGTTCAGG }\end{array}$ \\
\hline cAtbZIP1REVGW & 59 & $\begin{array}{l}\text { GGGGACCACTTTGTACAAGAAAGCTGGGTTCATGTCTTAA } \\
\text { AGGACGCCATTGGTTGTAG }\end{array}$ \\
\hline cATBZIP1REVGW & 59 & $\begin{array}{l}\text { GGGGACCACTTTGTACAAGAAAGCTGGGTTCATGTCTTAA } \\
\text { AGGACGCCATTGGTTGTAG }\end{array}$ \\
\hline cAtbZIP53FORGW & 60 & $\begin{array}{l}\text { GGGGACAAGTTTGTACAAAAAAGCAGGCTTCATGGGGTCG } \\
\text { TTGCAAATGCAAACAAGTCC }\end{array}$ \\
\hline cATBZIP53FORGW & 60 & $\begin{array}{l}\text { GGGGACAAGTTTGTACAAAAAAGCAGGCTTCATGGGGTCG } \\
\text { TTGCAAATGCAAACAAGTCC }\end{array}$ \\
\hline cAtbZIP53REVGW & 58 & $\begin{array}{l}\text { GGGGACCACTTTGTACAAGAAAGCTGGGTTCAGCAATCAA } \\
\text { ACATATCAGCAGAAGCTC }\end{array}$ \\
\hline cATBZIP53REVGW & 58 & $\begin{array}{l}\text { GGGGACCACTTTGTACAAGAAAGCTGGGTTCAGCAATCAA } \\
\text { ACATATCAGCAGAAGCTC }\end{array}$ \\
\hline CHSA back & 24 & CACTTACTTACACTTGCCTTGGAG \\
\hline CHSA front & 24 & CCAATTAAGATAAAACGTTGAATG \\
\hline CRU3 chip F & 21 & TGACATATGCGGAGAGTGAGC \\
\hline CRU3 chip R & 20 & CAACGAGGAGATTGCTGAGC \\
\hline Gal4AD & 20 & TACCACTACTACAATGGATG \\
\hline Gal4BD & 21 & TCATCGGAAGAGAGTAGTAAC \\
\hline GolS2sense & 22 & CTTGGACGGTGACATACAAGTG \\
\hline GolS2antisense & 20 & TGACATACTGAAGCGCACCG \\
\hline GW32kassettefor & 33 & CATCAATTGACAAGTTTGTACAAAAAAGCTGAA \\
\hline
\end{tabular}




\begin{tabular}{|l|c|l|}
\hline GW32kassetterev & 33 & CATCTCGAGAACCACTTTGTACAAGAAAGCTGA \\
\hline GWkassetteREV & 31 & AGGTACCACCACTTTGTACAAGAAAGCTGAA \\
\hline HA forw & 20 & GCGGCCGCATCTTTTACCCA \\
\hline HA.GWkassetteFOR & 34 & AGGTACCAACAATGGCATACCCATACGACGTTCC \\
\hline LBa1 & 22 & TGGTTCACGTAGTGGGCCATCG \\
\hline LBb1 & 22 & GCGTGGACCGCTTGCTGCAACT \\
\hline LPbZIP1 & 25 & GCAACCTAAAACGAACAACTTCTCC \\
\hline mutZIP53A72Pantis & 44 & CCATTTCAATGTATTTCTTTGATGGTTCATCAACCTGCTCAG \\
\hline mutZIP53A72Psense & 44 & CACTGAGCAGGTTGATGAACCATCAAAGAAATACATTGAAA \\
\hline oligo dT & 20 & TTTTTTTTTTTTTTTTTTTT \\
\hline p63f & 22 & CGTAGCTCGGTCATTGTGTCGG \\
\hline pBD2 & 21 & TCATCGGAAGAGAGTAGTAAC \\
\hline pBD2 & 21 & TCATCGGAAGAGAGTAGTAAC \\
\hline PDHpromfor & 21 & CAAGTCCAGGTCCACATGTTG \\
\hline PDHpromrev & 19 & CAAGGCCCTGACCATAGGA \\
\hline PEPCKsense & 20 & ATGGCGGGAAACGGAAACGA \\
\hline PEPCKantisense & 20 & TCGTACAACTCGGCGGGAGA \\
\hline proDH for & 20 & ATGGCAACCCGTCTTCTCCG \\
\hline proDH rev & 20 & TGGTCGGTCTTTGTCAGCAT \\
\hline REGIA Primer attB1 & 52 & GGGGACAAGTTTGTACAAAAAAGCAGGCTGCCAATTCCAG \\
\hline REGIA Primer attB2 & 51 & GGGGACCACTTTGTACAAGAAAGCTGGGTGCGATCCCCG \\
\hline rev24 & 24 & TTCACACAGGAAACAGCTATGACC \\
\hline SEQL1 pDONR & 25 & TCGCGTTAACGCTAGCATGGATCTC \\
\hline SEQL2 pDONR & 24 & GTAACATCAGAGATTTTGAGACAC \\
\hline shortbzip1cDNA\#1 & 27 & ATGGCAAACGCAGAGAAGACAAGTTCA \\
\hline shortbzip1cDNA\#2 & 27 & TCATGTCTTAAAGGACGCCATTGGTTG \\
\hline T6PPAT4G22590s & 21 & CTTGGATCATCCTTCCCTTCA \\
\hline T6PPAT4G22590as & 19 & TGGCCAGTCCTTCTCGTCA \\
\hline TUP1RD & 20 & AGCCGTCCTAATCTGGTTGG \\
\hline uni24 & 24 & ACGACGTTGTAAAACGACGGCCAG \\
\hline
\end{tabular}

Die Schmelztemperatur wird nach (Bolton und McCarthy, 1962) berechnet:

$$
\mathrm{T}_{\mathrm{m}}\left[{ }^{\circ} \mathrm{C}\right]=69,3+0,41 \times(\% \mathrm{GC})-\frac{650}{\mathrm{n}}
$$

$\mathrm{T}_{\mathrm{m}}=$ Schmelztemperatur, $\mathrm{n}=$ Anzahl der Basen.

\subsubsection{Hybridisierungssonden}

\begin{tabular}{|l|l|l|}
\hline Sonde & Eigenschaften & Referenz \\
\hline AtbZIP1 & $\begin{array}{l}\text { Mit den Primern bZIP1TF\#1 und bZIP1TF\#2 auf } \\
\text { cDNA erhaltenes PCR-Produkt }\end{array}$ & Diese Arbeit \\
\hline AtbZIP53 & $\begin{array}{l}\text { Mit den Primern bZIP53TF\#1 und bZIP53TF\#2 } \\
\text { auf cDNA erhaltenes PCR-Produkt }\end{array}$ & Diese Arbeit \\
\hline
\end{tabular}




\begin{tabular}{|c|c|c|}
\hline AtbZIP9 & $\begin{array}{l}\text { Mit den Primern bZIP9TF\#1 und bZIP9TF\#2 auf } \\
\text { cDNA erhaltenes PCR-Produkt }\end{array}$ & Diese Arbeit \\
\hline AtbZIP63 & $\begin{array}{l}\text { Mit den Primern bZIP63TF\#1 und bZIP63TF\#2 } \\
\text { auf cDNA erhaltenes PCR-Produkt }\end{array}$ & Diese Arbeit \\
\hline AtbZIP10 & $\begin{array}{l}\text { Mit den Primern bZIP10TF\#1 und bZIP10TF\#2 } \\
\text { auf cDNA erhaltenes PCR-Produkt }\end{array}$ & Diese Arbeit \\
\hline AtbZIP25 & $\begin{array}{l}1024 \text { bp Bsp1407I-Fragment aus pHBTL- } \\
\text { HAGW }\end{array}$ & Diese Arbeit \\
\hline ProDH & $\begin{array}{l}\text { Mit den Primern proDH for und proDH rev auf } \\
\text { cDNA erhaltenes PCR-Produkt }\end{array}$ & Diese Arbeit \\
\hline $\begin{array}{l}\text { At4g22590 } \\
\text { (T6PP) }\end{array}$ & $\begin{array}{l}\text { Mit den Primern T6PPAT4G22590s und T6PPA } \\
\text { T4G22590as auf cDNA erhaltenes PCR-Produkt }\end{array}$ & Diese Arbeit \\
\hline GolS2 & $\begin{array}{l}\text { Mit den Primern GolS2sense und GolS2 } \\
\text { antisense auf cDNA erhaltenes PCR-Produkt }\end{array}$ & Diese Arbeit \\
\hline PEP-CK & $\begin{array}{l}\text { Mit den Primern PEPCKsense und PEPCK } \\
\text { antisense auf cDNA erhaltenes PCR-Produkt }\end{array}$ & Diese Arbeit \\
\hline 2S Albumin 1 & $\sim 500$ bp EcoRI-Fragment aus pGEM-2S1 & Vincente-Carbajosa \\
\hline CRU3 & $\sim 500$ bp EcoRI-Fragment aus pGEM-CRU3 & Vincente-Carbajosa \\
\hline ASN1 & $\begin{array}{l}\text { Mit den Primern ASN1antisense und ASN1 } \\
\text { antisense auf cDNA erhaltenes PCR-Produkt }\end{array}$ & Diese Arbeit \\
\hline PR-1 & $\sim 500 \mathrm{bp}$ EcoRI-Fragment aus pSK-AtPR1 & Brenner, 2002 \\
\hline LEA76-like & $\begin{array}{l}\text { Mit den Primern auf cDNA erhaltenes PCR- } \\
\text { Produkt }\end{array}$ & Diese Arbeit \\
\hline
\end{tabular}

\subsection{Nährmedien und Zusätze}

\subsubsection{Hefemedien}

$\underline{\text { SD-Medium }}$

(Clontech, 1996)
$6,7 \mathrm{~g} / 1$ Nitrogen base without amino acids

0,61 g/1 Complete Supplement Mixture (CSM)

$20 \mathrm{~g} / 1$ Glucose

pH 5,8

nach dem Autoklavieren steril hinzufügen:

$25 \mathrm{ml} / 1$ Aminosäure- / Adenin-Stammlösungen (40 x Stocks)

20 g/ 1 Difco Pepton

$10 \mathrm{~g} / 1$ Hefeextrakt

$20 \mathrm{~g} / 1 \quad$ Glucose

$\mathrm{pH} 5,8$

autoklavieren 
3.3.2 Bakterienmedien

$\underline{\text { LB-Medium }}$

(Sambrook et al., 1989)

$\underline{\text { SOC-Medium }}$

(Sambrook et al., 1989)

$\underline{\text { Transformationsmedium }}$

$\underline{\text { YEB-Medium }}$

\subsubsection{Pflanzenmedien}

2MS-Medium

(Murashige und Skoog, 1962)

$$
\begin{array}{rll}
10 \mathrm{~g} / 1 & \text { Trypton } \\
5 \mathrm{~g} / 1 & \text { Hefeextrakt } \\
5 \mathrm{~g} / 1 & \mathrm{NaCl} \\
& & \mathrm{pH} 7,4 \\
& & \text { autoklavieren }
\end{array}
$$

$20 \mathrm{~g} / 1 \quad$ Trypton

$5 \mathrm{~g} / 1$ Hefeextrakt

$10 \mathrm{ml} \quad 1 \mathrm{M} \mathrm{NaCl}$

$2,5 \mathrm{ml} \quad 1 \mathrm{M} \mathrm{KCl}$

$\mathrm{pH} 7,0$

nach dem Autoklavieren steril hinzufügen:

$10 \mathrm{ml} \quad 1 \mathrm{M} \mathrm{MgCl}_{2}$

$10 \mathrm{ml} \quad 1 \mathrm{M} \mathrm{MgSO}_{4}$

$10 \mathrm{ml} 2 \mathrm{M}$ Glucose

$\begin{array}{rll}50 & \mathrm{~g} / 1 & \text { Saccharose } \\ 500 & \mu 1 / 1 & \text { Silwet L-77 }\end{array}$

$10 \mathrm{~g} / 1 \quad$ Fleischextrakt (Lab lemco powder)

$2 \mathrm{~g} / 1 \quad$ Hefe-Extrakt

5 g/l Pepton

$5 \mathrm{~g} / 1 \quad$ Saccharose

$0,5 \mathrm{~g} / 1 \quad \mathrm{MgSO}_{4}$

pH 7 einstellen

autoklavieren

4,59 g/1 Murashige und Skoog Medium

$20 \mathrm{~g} / 1 \quad$ Saccharose

pH 5,8 mit KOH einstellen

$10 \mathrm{~g} / 1 \quad$ Select Agar

Antibiotika nach dem Autoklavieren steril hinzugeben 
Medium für Hydroponische Kultur

Stammlösungen:

Spurenelemente Lösung

$$
\begin{array}{rll}
50 & \mathrm{mM} & \mathrm{KCl} \\
50 & \mathrm{mM} & \mathrm{H}_{3} \mathrm{BO}_{3} \\
10 & \mathrm{mM} & \mathrm{MnSO}_{4} \\
2 & \mathrm{mM}^{2} & \mathrm{ZnSO}_{4} \\
1,5 & \mathrm{mM} & \mathrm{CuSO}_{4}
\end{array}
$$

1:1000 $\mathrm{NaSiO}_{3}$ Stammlsg.

0,1 $\mathrm{M} \quad \mathrm{NaSiO}_{3}$

1:1000 KH $\mathrm{KH}_{2} \mathrm{PO}_{4}$ Stammlsg.

$0,5 \mathrm{M} \quad \mathrm{KH}_{2} \mathrm{PO}_{4}$

1:10000 $\mathrm{Na}_{2} \mathrm{MoO}_{4}$

$0,75 \mathrm{mM} \quad \mathrm{Na}_{2} \mathrm{MoO}_{4}$

$\mathrm{KNO}_{3} \mathrm{Lsg}$.

$1 \mathrm{M} \mathrm{KNO}_{3}$

$\mathrm{MgSO}_{4} \mathrm{Lsg}$.

$1 \mathrm{M} \quad \mathrm{MgSO}_{4}$

$\mathrm{Ca}\left(\mathrm{NO}_{3}\right)_{2} \mathrm{Lsg}$.

$1 \mathrm{M} \quad \mathrm{Ca}(\mathrm{NO})_{3}$

Eisen-EDTA:

$72 \mathrm{mM} \quad \mathrm{FeCl}_{3}$

$72 \mathrm{mM}$ EDTA

unter Rühren aufkochen

hydroponische Lsg.:

41 destilliertes $\mathrm{H}_{2} \mathrm{O}$ vorlegen

(für 121 = einen Kanister)

$12 \mathrm{ml}$ Spurenelemente Lsg.

$12 \mathrm{ml} \mathrm{NaSiO}_{3} \mathrm{Stammlsg}$.

$12 \mathrm{ml} \mathrm{KH}_{2} \mathrm{PO}_{4}$ Stammlsg.

$12 \mathrm{ml}$ Eisen-EDTA

$1,2 \mathrm{ml} \mathrm{Na}_{2} \mathrm{MO}_{4}$ Stammlsg.

$15 \mathrm{ml} \mathrm{KNO}_{3} \mathrm{Lsg}$.

$9 \mathrm{ml} \mathrm{MgSO}_{4} \mathrm{Lsg}$.

$18 \mathrm{ml} \mathrm{Ca}\left(\mathrm{NO}_{3}\right)$

auf 121 mit destilliertem $\mathrm{H}_{2} \mathrm{O}$ auffüllen

Die Vorlage von Wasser verhindert das Ausfallen der Salze. Auf das Autoklavieren wird verzichtet. 


\subsection{Medienzusätze}

\subsubsection{Aminosäuren und Purine}

\begin{tabular}{|l|c|c|}
\hline Aminosäure / Purin & Endkonzentration & Stammlösung (40 x) \\
\hline Adenin & $10 \mathrm{mg} / \mathrm{l}$ & $400 \mathrm{mg} / 1 \mathrm{H}_{2} \mathrm{O}$ \\
\hline Histidin & $20 \mathrm{mg} / 1$ & $800 \mathrm{mg} / 1 \mathrm{H}_{2} \mathrm{O}$ \\
\hline Leucin & $100 \mathrm{mg} / 1$ & $4000 \mathrm{mg} / 1 \mathrm{H}_{2} \mathrm{O}$ \\
\hline Tryptophan & $50 \mathrm{mg} / 1$ & $2000 \mathrm{mg} / 1 \mathrm{H}_{2} \mathrm{O}$ \\
\hline
\end{tabular}

\subsubsection{Antibiotika}

\begin{tabular}{|l|c|c|}
\hline Antibiotikum & Endkonzentration & Stammlösung \\
\hline Ampicillin & $100 \mathrm{mg} / 1$ & $100 \mathrm{mg} / \mathrm{ml} \mathrm{H}_{2} \mathrm{O}$ \\
\hline Gentamycin & $10 \mathrm{mg} / 1$ & $25 \mathrm{mg} / \mathrm{ml} \mathrm{H} \mathrm{O}^{\mathrm{O}}$ \\
\hline Hygromycin & $40 \mathrm{mg} / \mathrm{l}$ & $50 \mathrm{mg} / \mathrm{ml} \mathrm{H}_{2} \mathrm{O}$ \\
\hline Kanamycin & $50 \mathrm{mg} / 1$ & $50 \mathrm{mg} / \mathrm{ml} \mathrm{H}_{2} \mathrm{O}$ \\
\hline Rifampicin & $100 \mathrm{mg} / 1$ & $20 \mathrm{mg} / \mathrm{ml}$ Methanol \\
\hline
\end{tabular}

\subsubsection{Agar}

Festmedien enthalten zusätzlich $14 \mathrm{~g} / 1$ Select Agar, 2MS Medium enthält nur $8 \mathrm{~g} / 1$ Select Agar. Der Agar wird nach dem Einstellen des $\mathrm{pH}$-Wertes, jedoch vor dem Autoklavieren zugefügt.

\subsection{Lösungen und Puffer}

Alle Lösungen werden, soweit nicht anders angegeben, mit $\mathrm{H}_{2} \mathrm{O}$ angesetzt und anschließend autoklaviert (15 min, 2 bar, $121^{\circ} \mathrm{C}$ ).

Ammoniumacetat-Lösung $\quad 8 \mathrm{M} \quad$ Ammoniumacetat

$\underline{\text { Ladepuffer für Agarosegele }} \quad 10 \mathrm{ml} \quad$ TBE

$10 \mathrm{ml}$ Glycerin (87\%)

0,2\% (w/v) Bromphenol-Blau

$0,2 \%(\mathrm{w} / \mathrm{v}) \quad$ Orange $\mathrm{G}$

$0,2 \%(\mathrm{w} / \mathrm{v}) \quad$ Xylencyanol 
DNA-Extraktionspuffer

$$
\begin{array}{rll}
0,35 & \mathrm{M} & \text { Sorbitol } \\
0,1 & \mathrm{M} & \text { Tris } \\
5 & \mathrm{mM} & \text { EDTA } \\
& & \mathrm{pH} 7,5
\end{array}
$$

Extraktionspuffer (Kerne) $\quad 500 \mathrm{mM} \quad$ Hexylenglycol

$50 \mathrm{mM}$ PIPES-KOH pH7,2

$10 \mathrm{mM} \quad \mathrm{MgCl}_{2}$

$5 \mathrm{mM}$ ß-Mercaptoethanol

DNA-Präparationspuffer

$\begin{array}{rll}5 \mathrm{ml} & \text { DNA-Extraktionspuffer } \\ 5 \mathrm{ml} & \text { Kernlysepuffer } \\ 1 \mathrm{ml} & 5 \% \text { Sarkosyl } \\ 30-50 \mathrm{mg} & \mathrm{Na}_{2} \mathrm{SO}_{3}\end{array}$

$\underline{\text { FAA }}$

$50 \% \quad$ Ethanol

$10 \% \quad$ Eisessig

$5 \% \quad$ Formaldehyd

Fällungspuffer

$1,2 \mathrm{M} \quad \mathrm{NaCl}$

$0,8 \mathrm{M}$ tri-Natrium-Citrat

Gradientenpuffer

$$
\begin{array}{rll}
500 & \mathrm{mM} & \text { Hexylenglycol } \\
50 & \mathrm{mM} & \text { PIPES-KOH pH7,2 } \\
10 & \mathrm{mM} & \mathrm{MgCl}_{2} \\
1 & \% & \text { Triton X-100 } \\
5 & \mathrm{mM} & \text { ß-Mercaptoethanol }
\end{array}
$$

GUS-Färbe-Puffer

$$
\begin{array}{lll}
50 \mathrm{mM} & \mathrm{Na}_{2} \mathrm{HPO}_{4} / \mathrm{NaH}_{2} \mathrm{PO}_{4}(\mathrm{pH} 7,2) \\
0,2 \% & \text { Triton X-100 } \\
0,5 \mathrm{mM} & \mathrm{K}_{3} \mathrm{Fe}(\mathrm{CN})_{6} \\
0,5 \mathrm{mM} & \mathrm{K}_{4} \mathrm{Fe}(\mathrm{CN})_{6}
\end{array}
$$

Hybridisierlösung

$$
\begin{array}{rll}
0,5 & \mathrm{M} & \mathrm{Na}_{2} \mathrm{HPO}_{4} / \mathrm{NaH}_{2} \mathrm{PO}_{4}(\mathrm{pH} 7,2) \\
1 & \mathrm{mM} & \text { EDTA } \\
7 & \% & \text { SDS }
\end{array}
$$


Heringssperma-DNA

$\underline{\text { Kernlysepuffer }}$

$\underline{\text { 10x Lithium-Acetat }}$

Lösung I für alkalische Lyse
$10 \mathrm{mg} / \mathrm{ml}$ in TE durch Rühren (1h) lösen

falls nötig: Ultraschallbehandeln

bei $-20{ }^{\circ} \mathrm{C}$ lagern

vor Verwendung 20 Minuten kochen

$\begin{array}{rll}0,2 & \mathrm{M} & \text { Tris } \\ 0,05 & \mathrm{M} & \text { EDTA } \\ 2 & \mathrm{M} & \mathrm{NaCl} \\ 2 & \% & \mathrm{CTAB}\end{array}$

$1 \mathrm{M}$ Lithiumacetat

pH 7,5 mit Essigsäure einstellen

$\begin{array}{rll}50 \mathrm{mM} & \text { Glucose } \\ 10 \mathrm{mM} & \text { EDTA } \\ 25 \mathrm{mM} & \text { Tris- } \mathrm{HCl}(\mathrm{pH} 8,0) \\ 100 \mathrm{mg} / \mathrm{l} & \text { RNase }\end{array}$

$0,2 \mathrm{M} \quad \mathrm{NaOH}$

$2 \% \quad$ SDS

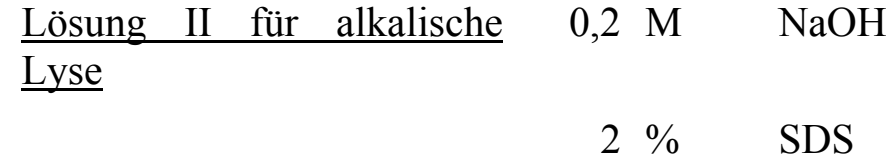

Lösung III für alkalische $294 \mathrm{~g}$ KAc

Lyse

$$
\begin{aligned}
& 50 \mathrm{ml} \quad \mathrm{HCOOH} \\
& \text { mit } \mathrm{H}_{2} \mathrm{O} \text { auf } 11 \text { auffüllen }
\end{aligned}
$$

$10 \times$ MEN-Puffer

$$
\begin{array}{rlllll}
200 \mathrm{mM} & \text { MOPS } & & & \\
50 \mathrm{mM} & \text { NaAc } & & & \\
10 \mathrm{mM} & \text { EDTA } & & \\
& & \text { pH } 7,0 \text { einstellen mit } 1 \mathrm{M} & \mathrm{NaOH}, \\
& & \text { autoklavieren }
\end{array}
$$

$\underline{\text { Na-Acetat-Puffer }}$ 
pH 5,2 (Essigsäure)

oNPG-Lösung

$4 \mathrm{mg} / \mathrm{ml}$ oNPG, gelöst in Z-Puffer

$\underline{\text { PCI-Mix }}$

$250 \mathrm{ml}$ Phenol

$250 \mathrm{ml}$ Chloroform

$10,4 \mathrm{ml}$ Isoamylalkohol

1 Stunden auf dem Magnetrührer mischen

$\underline{\text { PEG/LiAC }}$

$8 \mathrm{ml} \quad 50 \%$ PEG 3350

$1 \mathrm{ml}$ 10x TE

$1 \mathrm{ml} \quad 10 \mathrm{x} \mathrm{LiAc}$

$\underline{35 \% \text { Percoll }}$

$\begin{array}{rll}35 & \% & \text { Percoll } \\ 500 & \mathrm{mM} & \text { Hexylenglycol } \\ 50 & \mathrm{mM} & \text { PIPES-KOH pH7,2 } \\ 10 \mathrm{mM} & \mathrm{MgCl}_{2} \\ 1 & \% & \text { Triton X-100 }^{2} \\ 5 & \mathrm{mM} & \text { ß-Mercaptoethanol }\end{array}$

$75 \%$ Percoll

$\begin{array}{rll}75 & \% & \text { Percoll } \\ 500 & \mathrm{mM} & \text { Hexylenglycol } \\ 50 & \mathrm{mM} & \text { PIPES-KOH pH7,2 } \\ 10 & \mathrm{mM} & \mathrm{MgCl}_{2} \\ 1 & \% & \text { Triton X-100 } \\ 5 & \mathrm{mM} & \text { ß-Mercaptoethanol }\end{array}$

$\underline{\text { P1-Puffer (Qiagen) }}$

$50 \mathrm{mM}$ Tris- $\mathrm{HCl} \mathrm{pH} \mathrm{8,0}$

$10 \mathrm{mM}$ EDTA

$0,1 \mathrm{~g} / 1 \quad$ RNase A

P2-Puffer (Qiagen)

$200 \mathrm{mM} \quad \mathrm{NaOH}$

$1 \% \quad$ SDS

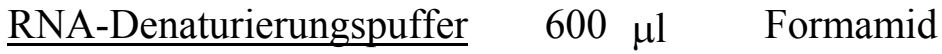




$\begin{array}{rl}180 \mu \mathrm{l} & \text { Formaldehyd } \\ 150 \mu \mathrm{l} & 10 \times \mathrm{MEN} \\ 150 \mu \mathrm{l} & \text { BPB-Auftragspuffer } \\ 6 \mu \mathrm{l} & \text { Ethidiumbromid }\end{array}$

$\underline{20 \times \text { SSC-Puffer }}$

$3 \mathrm{M} \quad \mathrm{NaCl}$

$0,3 \mathrm{M} \quad$ NaCitrat

$20 \times \mathrm{TAE}$

$0,8 \mathrm{M}$ Tris- $\mathrm{HCl}$

$0,2 \mathrm{M} \quad \mathrm{NaAc}$

$20 \mathrm{mM}$ EDTA

pH 7,8 mit Essigsäure einstellen

10x Taq DNA-Polymerase- $\quad 100 \mathrm{mM} \quad$ Tris- $\mathrm{HCl} \mathrm{pH} \mathrm{8,3;20}{ }^{\circ} \mathrm{C}$

$\underline{\text { Puffer (MBI) }}$

$500 \mathrm{mM} \quad \mathrm{KCl}$

$0,8 \% \quad$ Nonidet P40

$\underline{10 \times \text { TE-Puffer }}$

$\begin{aligned} 100 \mathrm{mM} & \text { Tris-HCl } \\ 10 \mathrm{mM} & \text { EDTA } \\ & \text { pH 7,5 }\end{aligned}$

$\underline{\text { Triazolpuffer }}$

$380 \mathrm{ml} / 1 \quad$ Phenol mit 0,1 M Citrat-Puffer gesättigt

0,8 M Guanidiniumthiocynat

0,4 M Ammoniumthiocyanat

$33,4 \mathrm{ml} / 1 \quad$ NaAcetat (aus Stammlösung)

$5 \%$ Glycerin

$\underline{\text { Z-Puffer }}$

$16.1 \mathrm{~g} / \mathrm{l} \quad \mathrm{Na}_{2} \mathrm{HPO}_{4} \bullet 7 \mathrm{H}_{2} \mathrm{O}$

$5.50 \mathrm{~g} / 1 \quad \mathrm{NaH}_{2} \mathrm{PO}_{4} \bullet \mathrm{H}_{2} \mathrm{O}$

$0.75 \mathrm{~g} / 1 \quad \mathrm{KCl}$

$0.246 \mathrm{~g} / 1 \quad \mathrm{MgSO}_{4} \cdot 7 \mathrm{H}_{2} \mathrm{O}$

pH 7,0 mit $\mathrm{NaOH}$, autoklavieren

$\underline{\text { X-Gal Stock }}$

$20 \mathrm{mg} / \mathrm{ml} \quad \mathrm{X}-\mathrm{Gal}$ in DMF

$\underline{\text { X-Gluc Stock }}$

$100 \mathrm{mM} \quad \mathrm{X}$-Gluc in DMF 


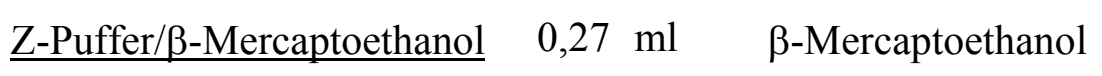

$100 \mathrm{ml}$ Z-Puffer

$\underline{\text { Z-Puffer }+ \text { oNPG }}$

$40 \mathrm{mg}$ oNPG

$10 \mathrm{ml}$ Z-Puffer

\subsection{Geräte}

\begin{tabular}{|l|l|l|}
\hline Gerät & Modell & Hersteller \\
\hline Autoklav & 3870 ELV & Tuttnauer \\
\hline Automatische Pipetten & $2,20,200,1000$ & Gilson \\
\hline Bioimager (Phosphoimager) & BAS-1000 & Fuji \\
\hline Digitalkamera & Coolpix & Nikon \\
\hline Elektroporationsgerät & Gene Pulser & Bio Rad \\
\hline Eismaschine & AF-20 & Scotman \\
\hline Gefriertruhe -80 ${ }^{\circ}$ C & C54285 & New Brunswick Scientific \\
\hline Geldokumentationsanlage & RS1 & Kaiser, Deutschland \\
\hline $\begin{array}{l}\text { Gelelektrophoresekammer } \\
\text { Agarose) }\end{array}$ & & $\begin{array}{l}\text { Werkstatt der Universität } \\
\text { Göttingen }\end{array}$ \\
\hline $\begin{array}{l}\text { Gelelektrophoresekammer } \\
\text { PAGE) }\end{array}$ & I V 15-17 & GIBCO BRL \\
\hline $\begin{array}{l}\text { Gelelektrophoresekammer } \\
\text { (PAGE) }\end{array}$ & $\begin{array}{l}\text { II JoeyTM \#JGC-4 } \\
\text { AGS }\end{array}$ & GIBCO BRL \\
\hline Hybridisierungsschrank & Hy-St-1 & Bachofer \\
\hline Hybridisierungswasserbad & Belly Dancer & Sorvall \\
\hline Heizblock & & Boekel Scientific \\
\hline Heizrührer & RCT basic & IKA Labortechnik \\
\hline Inkubationsschrank & WTC Binder & Memmert \\
\hline Kühlschränke & Sorvall RC 5B Plus & DuPont \\
\hline Kühlzentrifuge & E 323 & Benedikt Heinemann \\
\hline Netzgeräte & EC 105 & EC Apparatus Corporation \\
\hline Netzgeräte & PTC-150 & MJ Research, USA \\
\hline PCR-Gerät, MiniCyclerTM & Hanna Instruments \\
\hline pH-Meter & HI & \\
\hline
\end{tabular}




\begin{tabular}{|l|l|l|}
\hline Photometer & Unikon 720 LC & Kontron \\
\hline Polyacrylamid-Gelkammer & & AGS \\
\hline RNA-/DNA-Calculator & GeneQuant II & Pharmacia \\
\hline Scanner & & Epson \\
\hline Schüttler & 3005 & GFL \\
\hline Semi-Dry-Blot-Apparatur & & Werkstatt der Universität Bielefeld \\
\hline Sequenziergerät & ABI PRISM 310 & Perkin-Elmer Corporation \\
\hline $\begin{array}{l}\text { Spektralphotometer für } \\
\text { Microtiterplatten }\end{array}$ & MRX & Dynex \\
\hline Sterilbank & Microflow & Nunc \\
\hline Tischzentrifuge & Biofuge pico & Heraeus Christ \\
\hline Tischzentrifuge, gekühlt & 5403 & Eppendorf \\
\hline Ultraschallgerät & Soniprep 150 & Scientific Instruments \\
\hline Ultrazentrifuge & Centrikon T-1065 & Kontron \\
\hline Rotoren f. Ultrazentrifuge & $\begin{array}{l}\text { TFT 30.58; TFT } \\
65.13\end{array}$ & Kontron \\
\hline UV-Transilluminator & FLX-20 M & Vilber Lourmat \\
\hline Vortex & L46 & Labinco BV, Niederlande \\
\hline $\begin{array}{l}\text { Waagen } \\
\text { Feinwaage }\end{array}$ & 1207 MP2 & $\begin{array}{l}\text { Scaltec } \\
\text { Sartorius }\end{array}$ \\
\hline Wasseraufbereitungsanlage & Option 4, Maxima & ELGA \\
\hline Wasserbäder & 1086 & GFL \\
\hline Zentrifuge, Ausschwingrotor & Universal 16 A & Hettich \\
\hline
\end{tabular}

\subsection{Verbrauchsmittel}

\begin{tabular}{|l|l|}
\hline Produkt & Hersteller \\
\hline Alufolie & Roth \\
\hline Elektroporationsküvetten & BioRad \\
\hline Fließpapier & Whatman \\
\hline $\begin{array}{l}\text { Glasmaterialien: Flaschen, Pasteurpipetten, } \\
\text { Erlenmeyerkolben usw. }\end{array}$ & Brand, Schott \\
\hline Glasperlen ( 425-600 $\mu \mathrm{m})$ & Sigma \\
\hline Haushaltsfolie & Tip \\
\hline Hybond & TM-N / -N \\
\hline Immobilon-P, PVDF-Transfer Membranen $^{+}$ & Amersham \\
\hline
\end{tabular}




\begin{tabular}{|l|l|}
\hline $\begin{array}{l}\text { Kunststoff-Einwegmaterial: Spitzen, Pipetten, } \\
\text { Reaktionsgefäße, Spritzen, Petrischalen usw. }\end{array}$ & $\begin{array}{l}\text { Eppendorf, Brand, Greiner, Sar- } \\
\text { stedt }\end{array}$ \\
\hline Microtiterplatten & Nunc \\
\hline Miracloth & Calbiochem \\
\hline Nylon-Membran Nytran $® ~ N+$ & Schleicher und Schuell \\
\hline Parafilm N & American National Can ${ }^{\mathrm{TM}}$ \\
\hline Polyacrylamid (PAA)-Mix: $30 \%$ & Roth \\
\hline PVDF-Membran Immobilon-P & Millipore \\
\hline Röntgenfilme Cronex & DuPont \\
\hline Rundfilter $\varnothing 70$ mm & Schleicher \& Schuell \\
\hline Sephadex G50 & Pharmacia \\
\hline
\end{tabular}

\subsection{Chemikalien}

\begin{tabular}{|l|l|}
\hline Chemikalie & Hersteller/Lieferant \\
\hline Agar Bacteriological & GIBCO BRL Life technologies \\
\hline Agarose SeaKem LE & Biozym \\
\hline Aminosäuren & Sigma \\
\hline Ammoniumperoxodisulfat (APS) & Biometra \\
\hline Ampicillin & Sigma \\
\hline BASTA & Hoechst \\
\hline Bovine-Serum-Albumin (BSA) & Serva \\
\hline Bromphenolblau-Natriumsalz & Roth \\
\hline Chloroform & Merck \\
\hline Coomassie Brilliant Blue G-250 & Bio-Rad \\
\hline Complete Supplement Mixture (CSM) & Bio 101 \\
\hline$\left[\alpha-{ }^{32}\right.$ P] dATP, 800 Ci/mmol & Hartmann Analytic \\
\hline Difco Pepton & Difco \\
\hline Dimethylsulfoxid (DMSO) & Sigma \\
\hline dNTPs & MBI; Roth \\
\hline EDTA & AppliChem \\
\hline Essigsäure & Roth \\
\hline Ethanol absolut & Merck \\
\hline Ethidiumbromidlösung 1 \% & Roth \\
\hline Formaldehyd & Roth \\
\hline
\end{tabular}




\begin{tabular}{|c|c|}
\hline Formamid & Roth \\
\hline Glucose & Roth \\
\hline Glycerin $(87 \%)$ & Roth \\
\hline Harnstoff & Roth \\
\hline Heringssperma-DNA (HSP) & Boehringer \\
\hline Hydroxyethyl-Cellulose medium vis. (HEC) & Fluka \\
\hline IPTG & BioTech Trade \\
\hline Kaliumacetat (KAc) & Merck \\
\hline Kaliumchlorid $(\mathrm{KCl})$ & Roth \\
\hline Kanamycin & Duchefa \\
\hline Leupeptin & Sigma \\
\hline Lithiumacetat & Sigma \\
\hline Lyticase & Sigma \\
\hline Magermilchpulver & Glücksklee \\
\hline Magnesiumchlorid $\left(\mathrm{MgCl}_{2}\right)$ & AppliChem \\
\hline Magnesiumsulfat-Heptahydrat $\left(\mathrm{MgSO}_{4} * \mathrm{H}_{2} 0\right)$ & AppliChem \\
\hline Methylumbelliferyl- $\beta$-D-Glucoronid (MUG) & Duchefa \\
\hline Murashige \& Skoog Medium & Duchefa \\
\hline N,N-Dimethylformamid & J.T. Baker Chemicals B. V. \\
\hline $\mathrm{NaOH}$ & Merck \\
\hline Natriumcarbonat & Merck \\
\hline Natriumchlorid $(\mathrm{NaCl})$ & Roth \\
\hline Natriumhypochlorid & Roth \\
\hline Natriumlaurylsulfat (SDS) & Roth \\
\hline Oligonucleotide, synthetisch & MWG, Invitrogen \\
\hline o-Nitrophenyl $\beta$-D-Galactopyranosid (oNPG ) & Sigma \\
\hline Orange G & Sigma \\
\hline Pepton & Roth \\
\hline Percoll & Pharmacia \\
\hline Phenol & AppliChem \\
\hline Phenyl-Methyl-Sulfonyl-Fluorid (PMSF) & Sigma \\
\hline Polyethylenglycol (PEG) 4000 & Fluka \\
\hline Ponceau rot & Sigma \\
\hline Rifampicin & Duchefa \\
\hline
\end{tabular}




\begin{tabular}{|l|l|}
\hline Saccharose & Roth \\
\hline Salzsäure & Merck \\
\hline Select Agar & Life Technologies \\
\hline Select Yeast Extract & Life Technologies \\
\hline Silwet L77 & Lehle Seeds \\
\hline TEMED (N,N,N',N'-Tetramethylethylendiamidin) & Roth \\
\hline Thiamin-HCl & Sigma \\
\hline Trishydroxymethylaminomethan (Tris) & Roth \\
\hline Triton X-100 & Roth \\
\hline Trypton & Oxoid \\
\hline Tween & Sigma \\
\hline X-Gal & BioTech Trade \\
\hline X-Gluc & Roth \\
\hline Xylencyanol & Roth \\
\hline Yeast nitrogen base without amino acids & Difco \\
\hline$\beta$-Mercaptoethanol & Roth \\
\hline
\end{tabular}

\subsection{Enzyme}

\begin{tabular}{|l|l|}
\hline Enzym & Hersteller \\
\hline Cellulase Onozuka R-10 & Serva \\
\hline Klenow Polymerase & Promega \\
\hline Macerocym R-10 & Serva \\
\hline Pfu DNA Polymerase & Promega \\
\hline Restriktionsenzyme & MBI Fermentas \\
\hline RNase A (DNase-frei) & Sigma; Qiagen \\
\hline T4 DNA-Ligase & MBI Fermentas \\
\hline Taq DNA Polymerase & Verschiedene Hersteller \\
\hline
\end{tabular}

\subsection{Antikörper}

\begin{tabular}{|l|l|}
\hline Antikörper & Hersteller \\
\hline$\alpha$-HA IgG, monoklonal & Santa Cruz \\
\hline$\alpha$-HA IgG, polyklonal & Santa Cruz \\
\hline$\alpha$-rabbit IgG polyklonal, Peroxidase gekoppelt & Amersham \\
\hline
\end{tabular}


$\alpha$ - mouse IgG polyklonal, Peroxidase gekoppelt

Amersham

\subsection{Kits}

\begin{tabular}{|l|l|}
\hline Kit & Hersteller \\
\hline BigDye $^{\mathrm{TM}}$ Terminator Ready Reaction Kit & Perkin-Elmer Corporation \\
\hline Enhanced Chemiluminescence $^{\mathrm{TM}}$ Plus Kit $(\mathrm{ECL}+)$ & AmershamPharmacia \\
\hline Gateway Cloning Kit $^{\text {Invisorb }}{ }^{\circledR}$ Spin Plant RNA Mini Kit & Invitrogen \\
\hline Megaprime $^{\mathrm{TM}}$ DNA Labelling Systems & Invitek \\
\hline pGEM $^{\circledR}$-T Vector Systems & AmershamPharmacia \\
\hline QIAprep Spin Miniprep Kit $^{\text {Q }}$ Promega \\
\hline QIAquick Gel Extraction Kit & Qiagen \\
\hline
\end{tabular}

\subsection{DNA-Marker}

$$
\lambda / P s t \mathrm{I}
$$

( $\lambda$-DNA gespalten mit Pst $)$

Größenangaben in bp:

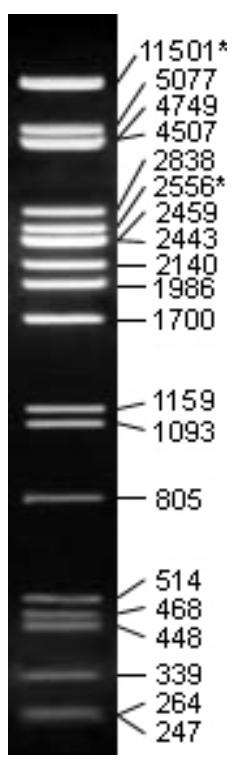

MBI GeneRuler 100bp DNA ladder plus Größenangaben in bp:

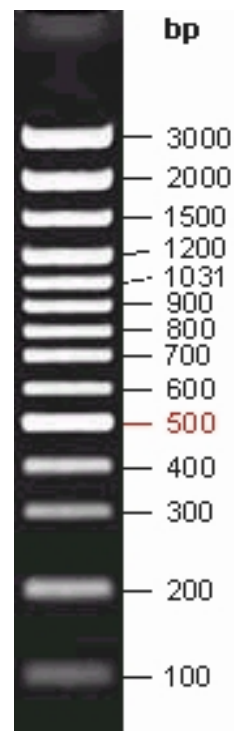

pUC19/HpaII (pUC19 gespalten mit HpaII) Größenangaben in bp:

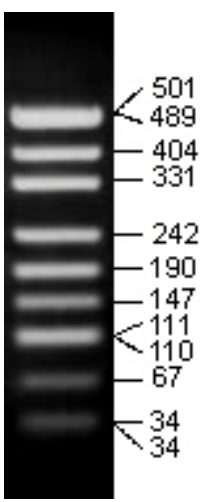




\section{Methoden}

\subsection{Anzucht und Transformation von Arabidopsis thaliana}

\subsubsection{Anzucht der Pflanzen}

Die Pflanzen werden auf Erde angezogen. Vor der Aussaat wird die Erde zweimal im Abstand von zwei Tagen für 30 Minuten bei $80^{\circ} \mathrm{C}$ autoklaviert. Die Samen werden zwei Tage im Dunkeln bei $4^{\circ} \mathrm{C}$ stratifiziert, um eine gleichmäßigere und bessere Keimung zu erreichen.

Die Kultivierung der Pflanzen findet in einer Klimakammer unter LangtagBedingungen (16 Stunden Licht, 8 Stunden Dunkel) statt.

\subsubsection{Floral-dip Transformation}

Ein klassischer Weg zur Transformation von Pflanzen ist der Agrobakterien-vermittelte Gentransfer. Agrobacterium tumefaciens hat die Fähigkeit einen durch zwei BorderSequenzen definierten Abschnitt des so genannten Ti-Plasmids in eine Pflanzenzelle zu transportieren und dort an einer zufälligen Stelle eines Pflanzen-Chromosoms einzufügen (Herrera-Estrella et al., 1992).

Das Ti-Plasmid wurde speziell für die gezielte Integration von Genen in das pflanzliche Genom modifiziert. So werden z.B. die für den Transfer notwendigen Funktionen auf zwei Plasmide aufgeteilt. Die zu übertragenden DNA-Sequenzen lassen sich mit molekularbiologischen Methoden zwischen die Border-Sequenzen inserieren. Agrobacterium tumefaciens ist so zu einem hervorragenden Hilfsmittel geworden, um Pflanzen gezielt zu transformieren.

Für die Agrobakterien-vermittelte Transformation von Arabidopsis thaliana wurde eine sehr einfache Methode entwickelt (Clough und Bent, 1998). Pflanzen, die gerade begonnen haben zu blühen, werden in Medium mit den entsprechenden Agrobakterien und einem Benetzungsmittel getaucht. Dabei scheinen sich entwickelnde Eizellen das bevorzugte Ziel produktiver Transformationen zu sein (Bent, 2000). Aus diesen Zellen entstehen hemizygote Samen. Für die Transformation werden pro Topf ( $\varnothing 6 \mathrm{~cm}$ ) bis zu 20 Samen ausgesät. Gesunde und kräftige Pflanzen erhöhen die Transformationsrate. Durch das Abschneiden der ersten Blütenstände lässt sich die Bildung vieler sekundärer Blütenstände anregen, was die Ausbeute an transgenen Samen erhöhen kann.

1) Mit einer $25 \mathrm{ml}$ Vorkultur $400 \mathrm{ml}$ YEB + entsprechende Antibiotika animpfen und bis zu einer $\mathrm{OD}_{600}$ von $\sim 2.0$ wachsen lassen

2) Die Agrobakterien 10 min. bei 1000xg abzentrifugieren und bis zum Erreichen einer $\mathrm{OD}_{600}$ von etwa 0,8 in Transformationsmedium resuspendieren

3) Pflanzen für einige Sekunden bis zur Rosette in die Agrobakterien-Lösung dippen, anschließend zurück in die Klimakammer stellen und 1-2 Tage mit einer Haube abdecken 
Die Pflanzen werden bis zur Samenreife (2-3 Wochen) weiterkultiviert. Die Blütenstände lässt man dann in Papiertüten trocknen. Die trockenen Pflanzen werden vorsichtig mit den Fingern zerrieben um die Schötchen aufzubrechen, und die Samen durch sieben grob von den übrigen Pflanzenteilen getrennt. Sie können bei $4^{\circ} \mathrm{C}$ trocken gelagert werden.

\subsubsection{Selektion auf Basta ${ }^{\circledR}$-Resistenz}

Die Samen werden zunächst wie gewohnt auf Erde ausgesät und kultiviert. Wenn die Pflanzen 2-4 vegetative Blätter gebildet haben werden sie mit $1 \mathrm{mM}$ Basta besprüht (etwa $1 \mathrm{ml}$ / Topf). Basta bzw. Phosphinothricin (auch Glufosinat = L-Homoanalin-4yl-(methyl)-phosphinsäure) wirkt als Strukturanalogon des L-Glutamat und inhibiert dadurch die Glutaminsynthetase. Die Pflanzen können bei Behandlung mit Basta Glutamat nicht mehr in Glutamin umwandeln. Dadurch häuft sich Ammonium zu einer letalen Konzentration in der Pflanze an und führt zusammen mit dem Glutaminmangel zum raschen Absterben der behandelten Pflanzen. Pflanzen, die als Resitenzmarker das bar-Gen tragen, sind unempfindlich gegenüber Phosphinothricin (White et al., 1990). Nach 3-4 Tagen sind die nicht resistenten Pflanzen abgestorben. Um auszuschließen, dass nicht resistente Pflanzen überleben, werden die Pflanzen noch einmal nach 3-4 Tagen mit Basta besprüht.

\subsubsection{Selektion auf Kanamycin- / Hygromycin-Resistenz}

Transgene Samen, die Antibiotika-Resistenzgene als Selektionsmarker enthalten, werden steril auf 2MS-Medium mit dem entsprechenden Antibiotikum angezogen. Die dafür notwendige Oberflächensterilisation findet mit Chlorgas statt (Clough und Bent, 1998). Die Samen werden in einem unverschlossenen Eppendorfgefäß in den Exsikkator gestellt. Außerdem werden $100 \mathrm{ml} 12 \%$ Hypochlorit-Lösung in einem Becherglas in einen Exsikkator gestellt und $3 \mathrm{ml} 37 \% \mathrm{HCl}$ zu der Hypochlorit-Lösung gegeben. Dabei werden die Lösungen mit der Glaspipette vorsichtig gemischt. Der Exsikkator wird möglichst schnell geschlossen und etwas Luft wird mit einer VakuumPumpe abgesaugt, um einen Luftdichten Verschluss des Exsikkators sicherzustellen. Nach 8-16 Stunden wird der Exsikkator unter der Sterilbank geöffnet und die Samen vorsichtig herausgenommen. Der Exsikkator wird so schnell wie möglich wieder geschlossen und anschließend unter dem Abzug ausgelüftet. Die Samen werden

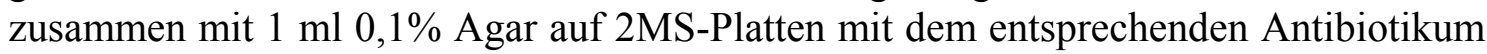
gebracht und dort mit einer sterilen Pipette verteilt.

\subsection{Anzucht und Lagerung von Bakterien und Hefen}

\subsubsection{Anzucht von Escherichia coli}

Die Anzucht von E. coli erfolgt entweder auf LB-Festmedium oder in LB-Flüssigmedium über Nacht bei $37{ }^{\circ} \mathrm{C}$ mit einem geeigneten Antibiotikum zur Selektion (Sambrook et al., 1989). 


\subsubsection{Anzucht von Agrobacterium tumefaciens}

Die Anzucht von Agrobacterium tumefaciens erfolgt entweder auf YEB-Festmedium oder in YEB-Flüssigmedium im Schüttler bei $30^{\circ} \mathrm{C}$ mit geeigneten Antibiotika zur Selektion.

\subsubsection{Anzucht von Saccharomyces cerevisiae}

Die Anzucht von Saccharomyces cerevisiae erfolgt bei $30^{\circ} \mathrm{C}$. Stämme ohne Plasmide werden auf YPD-Medium angezogen. Stämme, die Plasmide enthalten, werden auf den entsprechenden SD-Medien angezogen.

\subsubsection{Lagerung der Bakterien}

Die Bakterien können auf den Platten bei $4{ }^{\circ} \mathrm{C}$ mittelfristig gelagert werden. Für längere Lagerung müssen Gefrierkulturen angelegt werden.

Anlage einer Gefrierkultur:

1) $750 \mu 1$ einer frischen ü.N.-Kultur mit $250 \mu 187 \%$ Glycerin versetzen

2) kräftig vortexen

3) schockgefrieren in Flüssigstickstoff

4) Lagerung bei $-80{ }^{\circ} \mathrm{C}$

\subsubsection{Lagerung der Hefen}

Die Hefen können auf den entsprechenden Platten mit Parafilm bis zu einem Monat bei $4{ }^{\circ} \mathrm{C}$ gelagert werden. Für das Arbeiten mit Hefe sollten die Platten aber frisch sein. Um Hefen längerfristig zu lagern, müssen Gefrierkulturen angelegt werden.

Anlage einer Gefrierkultur:

1) $750 \mu \mathrm{l}$ einer frischen Kultur im entsprechenden SD-Medium mit $250 \mu 187 \%$ Glycerin versetzen

2) kräftig vortexen

3) langsam bei $-80^{\circ} \mathrm{C}$ einfrieren

4) Lagerung bei $-80^{\circ} \mathrm{C}$

\subsection{Methoden zur Isolierung von genomischer DNA aus Arabidopsis}

\subsubsection{DNA-Extraktion aus Arabidopsis thaliana nach (Fulton et al., 1995)}

$100 \mathrm{mg}$ Pflanzenmaterial werden in $200 \mu 1$ Präparationspuffer aufgenommen und mit der Bohrmaschine zerkleinert. Anschließend werden weitere $550 \mu 1$ Präparationspuffer dazugegeben. Die Suspension wird gut durchmischt und 30-120 Minuten bei $65{ }^{\circ} \mathrm{C}$ inkubiert. Danach werden $700 \mu$ l Chloroform / Isoamylalkohol (24:1) dazugegeben und die Lösung gut durchmischt. Nach der Zentrifugation bei $10000 \mathrm{rpm}$ für 5 Minuten wird die wässrige Phase in ein neues Gefäß überführt, und 2/3 bis 1 Volumen kaltes Isopropanol werden dazugegeben. Es folgt wieder eine Zentrifugation von 5 Minuten bei $10000 \mathrm{rpm}$. Der Überstand wird verworfen und das Pellet mit $70 \%$ Ethanol 
gewaschen. Die Zentrifugation wird wiederholt, der Überstand abgenommen und das Pellet getrocknet. Die saubere DNA wird in $50 \mu 1 \mathrm{TE}$ aufgenommen.

\subsubsection{Schnelle Präparation von genomischer DNA}

Die erhaltene DNA ist sehr unrein und lässt sich nur für PCR einsetzen. 10-100mg Blattmaterial werden in $400 \mu 1$ Extraktionspuffer mit einer Bohrmaschine aufgeschlossen. Die Suspension wird bei maximaler Geschwindigkeit für 5 Minuten zentrifugiert. $300 \mu \mathrm{l}$ des Überstandes werden in ein neues Reaktionsgefäss gegeben, in dem $300 \mu$ Isopropanol vorgelegt sind. Die Lösung wird bei maximaler Geschwindigkeit für 5 Minuten zentrifugiert. Der Überstand wird abgenommen und verworfen. Das Pellet wird mit $70 \%$ Ethanol gewaschen. Die Lösung wird bei maximaler Geschwindigkeit für 5 Minuten zentrifugiert. Das Pellet wird getrocknet und in $100 \mu \mathrm{l}$ TE aufgenommen. $1 \mu \mathrm{l}$ wird für die PCR eingesetzt.

\subsection{RNA-Extraktion aus Arabidopsis thaliana}

\subsubsection{RNA-Extraktion aus Arabidopsis thaliana mit dem "Invisorb ${ }^{\circledR}$ Spin Plant RNA Mini Kit"}

RNA Präparationen mit dem "Invisorb Spin Plant RNA Mini Kit" werden nach Angaben des Herstellerprotokolls durchgeführt.

\subsubsection{RNA Extraktion aus Arabidopsis thaliana mit Trizol}

Die Methode basiert auf einer Phenol/Chloroform Extraktion, die die Tatsache ausnutzt, dass RNA sich besser in der hydrophilen, wässrigen Phase löst, während Chlorophyll und andere Bestandteile besser in der hydrophoben Chloroform-Phase gelöst werden. Die beiden Thiocyanat-Salze im Extraktionspuffer inhibieren RNasen und verhindern damit eine Degradation der RNA (Chomczynski, 1993; Chomczynski und Sacchi, 1987).

0,5 g Blattmaterial wird in $\mathrm{N}_{2}$ aufgemörsert und in ein Zentrifugationsgefäß überführt (Sarstedt 13ml 101x16,5mmPP60.540.500). $5 \mathrm{ml}$ Trizolpuffer werden hinzugeben und das Gefäß wird auf dem Vortexer fixiert und 5 Minuten geschüttelt. Dann wird $1 \mathrm{ml}$ Chloroform hinzugeben und erneut 5 Minuten geschüttelt. Anschließend wird 30 Minuten bei $4^{\circ} \mathrm{C} / 10.000 \mathrm{~g}$ abzentrifugiert . Der Überstand wird in ein neues Gefäß überführt, es werden 1,25ml Fällungspuffer und 1,25ml Isopropanol zugegeben. Nach mehrmaligem, Invertieren wird 10 Minuten bei RT inkubiert und 15 Minuten bei $4^{\circ} \mathrm{C} / 10.000 \mathrm{~g}$ abzentrifugiert. Der Überstand wird abgenommen, das Pellet in $70 \% \mathrm{EtOH}$ resuspendiert, 10 Minuten bei $4^{\circ} \mathrm{C} / 10.000 \mathrm{~g}$ abzentrifugiert, 5 Minuten luftgetrocknet und in $100 \mu 1 \mathrm{H}_{2} \mathrm{O}$ gelöst (Inkubation 2 Stunden bei $4^{\circ} \mathrm{C}$ ).

\subsection{Gateway-Rekombination}

Bei Gateway-Klonierungen werden DNA-Segmente über ortsspezifische Rekombination zwischen verschiedenen Plasmiden transferiert. Das System basiert auf der ortsspezifischen Integration des Phagen Lambda in das Genom von E.coli. Um für die Rekombination verfügbar zu sein, müssen Erkennungssequenzen an das gewünschte 
DNA-Segment angefügt werden. Dies geschieht, indem man das gewünschte DNAStück mit Primern amplifiziert, die an den 5'-Enden die Erkennungssequenzen enthalten. Bei Gateway-Klonierungen werden zwei Reaktionen verwendet. Das DNASegment kann aus dem PCR-Produkt in der BP-Reaktion in einen Eingangs-Vektor rekombiniert werden. Von dort aus kann es in der LR-Reaktion in verschiedene ZielVektoren transferiert werden. Außerdem besteht die Möglichkeit, das DNA-Segment aus dem Ziel-Vektor in einer weiteren BP-Reaktion in einen anderen Eingangs-Vektor zu transferieren.

\subsubsection{Aufreinigung von attB-PCR Produkten}

Die Aufreinigung des PCR-Produktes ist notwendig, um Primer-Dimere zu entfernen, die in den Eingangs-Vektor rekombiniert werden könnten.

1) zu einem $50 \mu 1$ PCR-Ansatz $150 \mu 1 \mathrm{TE}$ zugeben

2) $100 \mu 130 \%$ PEG $8000 / 30 \mathrm{mM} \mathrm{MgCl} 2$ zugeben

3) gründlich vortexen und sofort 15 Minuten bei 10.000xg und RT abzentrifugieren

4) Pellet in TE aufnehmen

\subsubsection{BP-Reaktion}

Die BP-Reaktion dient dazu, den DNA-Abschnitt zwischen den attB-sites in einen Donor-Vektor mit attP-sites zu transferieren. Dabei entsteht ein Eingangsplasmid mit attL-sites.

1) 50-200 ng attB-PCR-Produkt (oder linearisierter Ziel-Vektor) in ein $1,5 \mathrm{ml}$ Eppendorfgefäß geben

2) 150 ng Eingangs-Vektor zugeben

3) $2 \mu 15 x$ BP Reaktions-Puffer zugeben

4) mit TE auf $9 \mu 1$ auffüllen

5) $1 \mu 1$ BP ClOnASE Enzym Mix zugeben

6) kurz vortexen und ü.N. bei $25^{\circ} \mathrm{C}$ inkubieren

7) $1 \mu 1$ Proteinase $\mathrm{K}$ zugeben und 10 Minuten bei $37^{\circ} \mathrm{C}$ inkubieren

$5 \mu \mathrm{l}$ des Ansatzes werden in $100 \mu 1$ chemisch kompetente DH5 $\alpha$-Zellen transformiert.

\subsubsection{LR-Reaktion}

Die LR-Reaktion dient dazu, die DNA zwischen den attL-sites eines Eingangsplasmids in einen Ziel-Vektor mit attR-sites zu transferieren. Sie läuft am effizientesten ab, wenn beide Vektoren linearisiert werden.

1) 100-200 ng Eingangs-Vektor in ein 1,5 ml Eppendorfgefäß geben

2) $200 \mathrm{ng}$ Ziel-Vektor zugeben

3) $2 \mu 15 x$ LR Reaktions-Puffer zugeben

4) mit TE auf $9 \mu 1$ auffüllen

5) $1 \mu 1$ LR Clonase Enzym Mix zugeben

6) kurz vortexen und ü.N. bei $25^{\circ} \mathrm{C}$ inkubieren

7) $1 \mu 1$ Proteinase $\mathrm{K}$ zugeben und 10 Minuten bei $37^{\circ} \mathrm{C}$ inkubieren 
Anschließend werden $5 \mu 1$ des Ansatzes in $100 \mu 1$ chemisch kompetente DH5 $\alpha$-Zellen transformiert.

\subsection{Isolation von Plasmiden aus $E$. coli}

\subsubsection{Alkalische Lyse}

Zur schnellen Präparation von Plasmid-DNA zu analytischen Zwecken wird eine modifizierte alkalische Lyse der Bakterien (Le_Gouill et al., 1994) vorgenommen. 1,5 $\mathrm{ml}$ einer stationären $E$. coli-Kultur werden pelletiert ( $3 \mathrm{~min}, 5000 \mathrm{rpm}$ ) und die Zellen nach Dekantieren des Überstandes in $100 \mu 1$ P1 resuspendiert. Die Lyse der Bakterien erfolgt im alkalischen Milieu durch Zugabe von $200 \mu 1$ P2 und $150 \mu 1$ Chloroform. Nach 1 Minuten Inkubation wird zur Neutralisation $150 \mu 1$ P3 zugegeben, der Ansatz gemischt und die Präzipitate durch Zentrifugation (2 min, $15000 \mathrm{rpm}, 4{ }^{\circ} \mathrm{C}$ ) sedimentiert. Die obere, wässrige Phase wird zur Fällung der DNA mit 2,5 Volumen Ethanol $\left(-20{ }^{\circ} \mathrm{C}\right)$ gemischt und $2 \mathrm{~min}, 15000 \mathrm{rpm}, 4{ }^{\circ} \mathrm{C}$ zentrifugiert. Die pelletierte DNA wird mit $70 \%$ Ethanol gewaschen und für 10 Minuten bei $37{ }^{\circ} \mathrm{C}$ getrocknet. Die gewonnene DNA wird in $20 \mu \mathrm{l} \mathrm{EB}$ oder $\mathrm{H}_{2} \mathrm{O}$ gelöst und kann zur Restriktionsanalyse eingesetzt werden.

\subsubsection{Plasmidpräparation für Sequenzierung}

Für Sequenzierreaktionen wird hochreine DNA mit Hilfe des QIAprep Spin MiniprepKits isoliert. Das Prinzip entspricht der alkalischen Lyse, die Durchführung erfolgte nach dem Protokoll des Herstellers.

\subsubsection{Schnellyse von E.coli Zellen für eine anschliessende PCR}

Die einzelnen Kolonien werden in $20 \mu \mathrm{H} 2 \mathrm{O}$ resuspendiert und für 5 Minuten bei $95^{\circ} \mathrm{C}$ erhitzt und anschließend für eine PCR eingesetzt.

\subsubsection{DNA-Elution aus Agarosegelen}

Für die Isolierung von DNA-Fragmenten aus Agarosegelen wird der QIAquick Gel Extraction Kit von Qiagen verwendet. Die Aufreinigung erfolgte nach dem Protokoll des Herstellers.

\subsection{Phenol-Chloroform Extraktion}

Zur Aufreinigung von Nukleinsäurelösungen von Protein-Verschmutzungen, wird die Phenol-Chloroform Extraktion benutzt. Dabei wird die Nukleinsäurelösung nacheinander mit einem Volumen Phenol, mit einem Volumen Phenol-ChloroformIsoamylalkohol-Gemisch (25:24:1, v/v) und einem Volumen Chloroform ausgeschüttelt. Dazwischen wird jeweils zentrifugiert und die obere wässerige Phase in ein neues Gefäß überführt. Die Proteine werden denaturiert und sammeln sich in der organischen Phase und in der Grenzschicht an. Die Nukleinsäuren können aus der wässerigen Phase durch eine Alkoholfällung isoliert werden. 


\subsection{Ethanolfällung von DNA aus wässerigen Lösungen}

Um DNA aus wässrigen Lösungen von Salzen zu reinigen und um eine definierte Konzentration zu erreichen, wird sie einer Ethanolfällung unterzogen. Dabei wird der DNA-Lösung 1/10 Volumen $3 \mathrm{M}$ Natriumacetat, $\mathrm{pH}$ 5,2 zugegeben und mit zwei Volumen $100 \%$ Ethanol gemischt. Die DNA fällt aus, während Salze und Verunreinigungen gelöst bleiben. Die Fällung erfolgte bei $-20{ }^{\circ} \mathrm{C}$ für mindestens zwei Stunden. Danach wird die DNA für 20 Minuten bei $13.000 \mathrm{rpm}$ pelletiert, mit $70 \%$ Ethanol gewaschen, getrocknet und in einem definierten Volumen $\mathrm{H}_{2} \mathrm{O}$ gelöst.

\subsection{Konzentrationsbestimmung von Nukleinsäuren}

Die Konzentration von DNA oder RNA wird photometrisch bei einer Wellenlänge von $260 \mathrm{~nm}$ mit dem Spektrometer GeneQuant II ermittelt. Ein Aliquot der Probe wird mit TE-Puffer 1:100 verdünnt und gegen TE-Puffer gemessen. Eine $\mathrm{OD}_{260}$ von 1,0 entspricht einer Nukleinsäurekonzentration von $50 \mu \mathrm{g} / \mathrm{ml}$ dsDNA bzw. $40 \mu \mathrm{g} / \mathrm{ml}$ RNA oder ssDNA. Kontaminationen mit Proteinen werden über die Absorption bei $\lambda=$ $280 \mathrm{~nm}$ erfasst. Salzrückstände werden durch positive Werte bei $\lambda=320 \mathrm{~nm}$ angezeigt.

Der Quotient $\mathrm{OD}_{260}: \mathrm{OD}_{280}$ gibt zusätzlich Aufschluß über Verunreinigungen. Idealerweise liegt dieser Wert zwischen 1,8 für DNA und 2,0 für RNA. Alternativ kann die DNA-Konzentration nach Auftrennung in einem Agarosegel und Anfärbung mit Ethidiumbromid im Vergleich mit DNA bekannter Konzentration abgeschätzt werden.

\subsection{Restriktionsspaltung von DNA}

Restriktionsendonukleasen (Desoxyribonukleasen) vom Typ II spalten PhosphodiesterBindungen doppelsträngiger DNA an spezifischen Basensequenzen (Smith und Wilcox, 1970). Es gibt eine große Anzahl verschiedener Restriktionsendonukleasen, die jeweils bestimmte Erkennungssequenzen haben (Roberts, 1985). Je nach Enzym entstehen glatte DNA-Enden (,,blunt ends“) oder 5'- bzw. 3'-überhängende Enden (,sticky ends“). Die zur Restriktionsspaltung eingesetzte DNA (ca. 0,5-2 $\mu$ g Plasmid-DNA) sollte frei von Kontaminationen wie hohen Salzkonzentrationen, EDTA oder organischen Lösungsmitteln sein, um die Enzymaktivität nicht zu mindern. Die Reaktionen finden für 2-16 Stunden bei den für jedes Enzym optimalen Temperatur- und Pufferbedingungen (Spaltungspuffer von MBI oder Boehringer) statt. Es werden Enzymmengen von mindestens $1 \mathrm{U}$ Restriktionsenzym pro $\mu \mathrm{g}$ DNA eingesetzt. Weil die Enzymlösungen Glycerin enthalten, wird nicht mehr Restriktionsenzym als höchstens $10 \%$ des Endvolumens zugesetzt, da Glycerinkonzentrationen von mehr als 5 $\%$ die Spezifität herabsetzen. Die meisten Restriktionsenzyme können durch eine Hitzebehandlung für 10 Minuten bei $65^{\circ} \mathrm{C}$ inaktiviert werden.

Die Kontrolle der Spaltung erfolgt durch Agarosegelelektrophorese mit einem Aliquot des Ansatzes. Restriktionsspaltungen können zur Klonanalyse eingesetzt werden. Außerdem sind sie die Grundlage der Klonierungen (Cohen et al., 1973).

\subsection{Ligation}

Das Enzym T4-DNA-Ligase katalysiert die Bildung einer Phosphodiesterbindung zwischen der 3'-OH-Gruppe am Ende eines DNA-Stranges und der 5'-Phosphatgruppe am Ende eines anderen. Bei Anwesenheit von ATP erfolgt zunächst eine Aktivierung 
des Enzyms durch eine Adenylierung unter Abspaltung von Pyrophosphat gefolgt von einer Übertragung der AMP-Einheit auf das $5{ }^{`}$-Ende des einen Stranges, wodurch eine Aktivierung des 5'-Phosphoratoms erfolgt. So kann ein nucleophiler Angriff der 3'-OHGruppe auf dieses aktivierte Phosphoratom erfolgen, wobei der Strang geschlossen und AMP freigesetzt wird. Die Ligation wird in T4-DNA-Ligasepuffer mit 2 u T4-DNALigase über Nacht bei $15^{\circ} \mathrm{C}$ in einem Gesamtvolumen von 20-30 $\mu$ d durchgeführt.

\subsection{TA-Klonierung}

Die Taq-Polymerase produziert keine Fragmente mit glatten Enden, sondern schafft einen Überhang von einer Base, wobei es sich in den meisten Fällen um ein Adenosin handelt (Clark, 1988). Daher lassen sich Taq-amplifizierte PCR-Produkte gut in Vektoren mit Thymin-Überhang klonieren. Ein solcher Vektor ist $\mathrm{pGEM}^{\circledR}-\mathrm{T}$ von Promega.

1) $5 \mu 12 \mathrm{x}$ rapid ligation buffer in ein $1,5 \mathrm{ml}$ Eppendorfgefäß geben

2) $1 \mu 1$ (50 ng) pGEM $^{\circledR}$-T Vektor zugeben

3) PCR-Produkt zugeben (das Verhältnis Insert:Vektor sollte etwa 5:1 betragen)

4) Mit $\mathrm{H}_{2} \mathrm{O}$ auf $9 \mu 1$ auffüllen

5) $1 \mu 1 \mathrm{~T} 4$ DNA Ligase (4 Weiss units/ $\mu$ l) zugeben

6) 2 Stunden bei RT inkubieren (für maximale Effizienz ü. N. bei $4^{\circ} \mathrm{C}$ )

Es werden $5 \mu \mathrm{l}$ des Ansatzes in $100 \mu \mathrm{l}$ chemisch kompetente DH5 $\alpha-Z$ ellen transformiert.

\subsection{Blau-Weiß-Selektion}

Bei der Blau-Weiß-Selektion liegt die Klonierungsstelle innerhalb des lacZ-Gens. lacZ codiert für die ersten 146 aminoterminalen Aminosäuren ( $\alpha$-Peptid) der $\beta$ Galaktosidase. Sie können zusammen mit einem inaktiven Enzym, dem die Aminosäuren 11-41 fehlen, eine funktionierende $\beta$-Galaktosidase bilden $(\alpha-$ Komplementation). Das aktive Enzym hydrolysiert das Substrat X-Gal, das daraufhin durch Luftoxidation eine blaue Färbung zeigt. Bakterienstämme mit dem inaktiven Enzym können durch Aufnahme eines Plasmids, das das lacZ-Gen trägt, nach Induktion mit IPTG X-Gal umsetzen. Wird die Sequenz des lacZ-Gens jedoch durch den Einbau von fremder DNA in das Plasmid unterbrochen, so bleibt die Bakterienkolonie weiß. Dieses Verfahren erleichtert die Selektion der Kolonien mit rekombinanten Plasmiden.

Die Platten, auf denen eine Blau-Weiß-Selektion durchgeführt wird, werden mit $60 \mu 1$ X-Gal-Lösung (20 mg / ml) und $60 \mu 1$ 0,1 M IPTG-Lösung beschichtet, Animpfen und Inkubation finden wie gewohnt statt.

\subsection{Agarosegelelektrophorese von DNA-Molekülen}

Mit Hilfe der Agarosegelelektrophorese werden DNA-Moleküle nach ihrer Größe aufgetrennt (McDonell et al., 1977; Southern, 1979). DNA ist aufgrund des ZuckerPhosphat-Rückgrats negativ geladen. Im elektrischen Feld wandert sie somit zur Anode. Die Wanderungsgeschwindigkeit ist um so größer, je kleiner die DNA-Moleküle sind. Als Gelmatrix dient Agarose, ein gelierfähiges Polysaccarid, welches aus sich abwechselnden Einheiten von $\beta$-1,3-verknüpfter D-Galaktopyranose und $\alpha-1,4-$ verknüpfter 3,6-Anhydro-L-Galaktopyranose besteht. Der Trennbereich ist abhängig 
von der Agarosekonzentration, da sie die Porengröße beeinflusst. Je höher die Agarosekonzentration, desto kleiner die Poren, desto besser werden kleine Moleküle aufgetrennt. Die Zugabe von Hydroxyethylencellulose (HEC) kann hohe Agarosekonzentrationen ersetzen. Zur Auftrennung großer Fragmente wird ein 0,7 prozentiges Gel benutzt. Kleine Fragmente, wie PCR-Produkte, werden in Gelen aufgetrennt, die $1 \%$ Agarose und 0,7 \% HEC enthalten.

Ethidiumbromid (3,8-Diamino-6-ethyl-5-phenylphenantridiumbromid) dient zum Anfärben der DNA. Es bindet an die DNA, indem es zwischen die Basenpaare interkaliert. Der Komplex aus DNA und Ethidiumbromid fluoresziert unter UV-Licht und wird damit auf dem Transilluminator sichtbar.

\subsection{DNA Sequenzierung}

Zum Sequenzieren der DNA wird ein Verfahren benutzt, das auf der kontrollierten Unterbrechung der DNA-Synthese beruht. Diese Methode wurde von (Sanger et al., 1977) entwickelt. Einzelsträngige DNA dient als Template für die Synthese eines neuen Stranges. Es wird ein Primer zugegeben, der mit der DNA hybridisieren kann. Die DNA-Polymerase I benötigt für ihre Syntheseaktivität einen kurzen Abschnitt doppelsträngiger DNA. Zusätzlich $\mathrm{zu}$ den Desoxyribonukleotiden werden auch Didesoxyribonukleotide (ddNTPs) in den Reaktionsansatz gegeben. Diesen fehlt die Hydroxylgruppe am 3'-C-Atom des Zuckers. Werden die ddNTPs in den neuen DNAStrang eingebaut, so stoppt das Kettenwachstum, da keine weitere Phosphodiesterbindung gebildet werden kann. Über die unterschiedliche Länge der neu entstandenen DNA-Stränge läßt sich die Basenabfolge nach einer gelelektrophoretischen Auftrennung ermitteln. Längenunterschiede von einem Basenpaar können aufgelöst werden. Die ddNTPs sind unterschiedlich fluoreszenz-markiert, sodass nach einer Kapillar-Gelelektrophorese jeder DNA-Strang mit einer Laserapparatur detektiert wird. Bei dem Cycle Sequencing wird durch zyklisches Denaturieren und anschließende Neusynthese die Menge an $\mathrm{zu}$ analysierender DNA erhöht.

Cycle Sequencing und Aufreinigung der DNA erfolgen mit dem ABI PRISM ${ }^{\mathrm{TM}}$ BigDye $^{\mathrm{TM}}$ Terminator Cycle Sequencing Ready Reaction Kit. Die eingesetzte DNA wird mit dem Qiaprep Spin Miniprep-Kit isoliert.

In ein PCR-Gefäß werden pipettiert:

- $2 \mu 1$ ET-Mix

- etwa 800 ng DNA

- 5 pmol Primer

- $\mathrm{H}_{2} \mathrm{O}$ ad $10 \mu \mathrm{l}$

Im Thermocycler wird folgendes Programm benutzt:
$1.96^{\circ} \mathrm{C}$
15 Sekunden
2. $55^{\circ} \mathrm{C}$
20 Sekunden
3. $60^{\circ} \mathrm{C}$
60 Sekunden

25 Zyklen 1-3 


\subsubsection{Aufreinigung der Sequenzierreaktion}

Damit die DNA sequenziert werden kann, muß sie gereinigt werden. Alle Verunreinigungen, vor allem aber ungebundene Terminatoren, stören die Sequenzierung.

1) $1 \mu 1$ Ammoniumacetat $(7 \mathrm{M})$ in $1,5 \mathrm{ml}$ Eppendorfgefäße geben

2) Reaktionsansatz zugeben

3) $41 \mu 195 \%$ Ethanol zugeben

4) vortexen

5) Inkubation: 1 Stunde auf Eis

6) Zentrifugation: 15 Minuten / $13.000 \mathrm{rpm} / \mathrm{RT}$

7) Überstand vollständig abnehmen

8) Pellet mit $100 \mu 170 \%$ igem Ethanol waschen

9) Zentrifugation: 15 Minuten / $13000 \mathrm{rpm} / \mathrm{RT}$

10) Überstand sauber abnehmen

11) Pellet 1 Minuten bei $95{ }^{\circ} \mathrm{C}$ trocknen

12) Pellet in $20 \mu 1$ Template Suppression Reagent aufnehmen

13) denaturieren der DNA: 2 Minuten $/ 95^{\circ} \mathrm{C}$, danach sofort auf Eis überführen

14) luftblasenfrei in spezielle Sequenziergefäße des Sequenziergerätes umfüllen

\subsection{Polymerase-Kettenreaktion}

Die Polymerase-Kettenreaktion (PCR $=$ Polymerase Chain Reaction) ist eine Methode, um DNA-Fragmente in vitro zu amplifizieren. Die Technik wurde zuerst von (Mullis und Faloona, 1987) beschrieben. Grundlage ist die Fähigkeit der DNA-Polymerase, einzelsträngige DNA zu einem Doppelstrang aufzupolymerisieren, wenn ein kurzer doppelsträngiger Startbereich vorliegt. Deshalb sind zwei Oligonukleotid-Primer erforderlich, die komplementär zu Bereichen der zu amplifizierenden DNA sind und die als Startpunkt für die Tochterstrang-Synthese dienen. Die beiden Primer begrenzen so auch das zu amplifizierende Fragment. Sie werden im Überschuss zugegeben. Zunächst wird die doppelsträngige DNA durch Erhitzen in Einzelstränge aufgetrennt. Beim anschließenden Abkühlen können sich die Primer an die DNA anlagern (Annealing). Es folgt dann die Aufpolymerisierung durch die DNA-Polymerase bei mittlerer Temperatur. Durch Verwendung der Taq-Polymerase bleibt die Aktivität des Enzyms über den Hitzeschritt erhalten. Die zyklische Wiederholung der Schritte führt zur Anreicherung des gewünschten Fragmentes.

Beispiel für einen Reaktionsansatz:

- 2,5 $\mu 110 \times$ PCR-Puffer $+\mathrm{MgCl}_{2}(\mathrm{MBI})$

- $\quad 0,5 \mu 1 \mathrm{dNTPs}(\mathrm{je} 10 \mathrm{mM})$

- $\quad 1,25 \mu 1$ Primer $1(10 \mu \mathrm{M})$

- $\quad 1,25 \mu 1$ Primer $2(10 \mu \mathrm{M})$

- DNA-Template

- $\quad \mathrm{H}_{2} \mathrm{O}$ ad $49,5 \mu \mathrm{l}$

- $\quad$ 0,5 $\mu 1$ Taq DNA-Polymerase 
Das verwendete PCR-Programm hängt von den Primern und dem verwendeten Template ab und muss für jede PCR individuell erstellt werden.

\subsection{Colony-Screen mittels PCR}

Wird die Plasmid-DNA benötigt, um Klone in einer PCR zu testen, kann eine Schnelllyse mittels Kochen durchgeführt werden.

1) $11 \mu 1 \mathrm{H}_{2} \mathrm{O}$ in ein PCR-Cup geben

2) Kolonien mit einem sterilen Zahnstocher picken

3) auf eine Masterplatte überimpfen

4) den restlichen Teil der am Zahnstocher befindlichen Zellen in den $11 \mu 1 \mathrm{H}_{2} \mathrm{O}$ resuspendieren

5) 10 Minuten $/ 95^{\circ} \mathrm{C}$ (Zellen lysieren, DNasen denaturieren)

6) auf Eis lagern

7) entsprechenden Mastermix zugeben

\subsection{Transformation von Mikroorganismen}

\subsubsection{Herstellung kompetenter Escherichia coli}

Für die Herstellung kompetenter Zellen nach einer modifizierten Methode von (Inoue et al., 1990) werden Bakterien des E. coli-Stammes DH5a verwendet. 0,8 ml einer Übernachtkultur werden in $40 \mathrm{ml}$ LB-Medium überimpft. Die Anzucht der Kultur erfolgte bis zum Erreichen einer OD600 von 0,5. Jeweils $10 \mathrm{ml}$ der Kultur werden in Greiner-Röhrchen überführt und abzentrifugiert (5 Minuten, $6000 \mathrm{x} \mathrm{g,} 4^{\circ} \mathrm{C}$ ). Das Pellet wird in $5 \mathrm{ml} 50 \mathrm{mM} \mathrm{CaCl} 2\left(4^{\circ} \mathrm{C}\right)$ resuspendiert, für 30 Minuten auf Eis inkubiert und abzentrifugiert $\left(5 \mathrm{~min}, 6000 \mathrm{x} \mathrm{g}, 4^{\circ} \mathrm{C}\right)$. Die Zellen werden in $2 \mathrm{ml} 50 \mathrm{mM} \mathrm{CaCl}_{2}\left(4^{\circ} \mathrm{C}\right)$

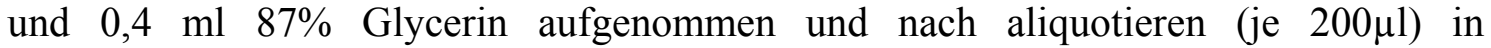
Eppendorfgefäßen in flüssigem Stickstoff schockgefroren. Die Aufbewahrung erfolgt bis zur weiteren Verwendung bei $-80^{\circ} \mathrm{C}$.

\subsubsection{Transformation von Escherichia coli}

Kompetente E. coli-Zellen sind in der Lage, DNA aus dem Umgebungsmedium aufzunehmen. Mit Hilfe der nachfolgenden Methode werden E. coli-Zellen mit PlasmidDNA transformiert (Hanahan, 1983). Die kompetenten Zellen werden auf Eis aufgetaut, dann erfolgt die Zugabe der Plasmid-DNA und Inkubation für 10 Minuten auf Eis (Anheftung der DNA an die Zellen). Durch einen Hitzeschock der Zellen für 2 Minuten bei $42^{\circ} \mathrm{C}$ erfolgt die Aufnahme der DNA. Eine Regeneration der Zellen schließt sich nach Zugabe von $0,8 \mathrm{ml}$ LB-Medium für 40 Minuten bei $37^{\circ} \mathrm{C}$ an. Danach wird der Transformationsansatz auf LB-Selektionsmedium ausplattiert.

\subsubsection{Herstellung kompetenter Agrobakterien}

Für die Herstellung kompetenter Zellen werden Agrobakterien des Stammes LBA 4404 verwendet. $5 \mathrm{ml}$ einer Agrobakterienflüssigkultur werden abzentrifugiert (5 min, 5000 rpm, RT) und dreimal durch Resuspendieren und erneutes Abzentrifugieren in sterilem 
Wasser gewaschen. Das Pellet wird in $500 \mu 1$ sterilem Wasser aufgenommen und in 100 $\mu 1$ Aliquots in flüssigem $\mathrm{N}_{2}$ eingefroren.

\subsubsection{Transformation von Agrobacterium tumefaciens}

Durch Erzeugen kurzer Spannungspulse wird die Membran kompetenter Bakterienzellen permeabilisiert. Dadurch wird die Aufnahme von freier DNA aus dem Medium in die Zelle ermöglicht. Nach der Zugabe der zu transformierenden DNA zu den kompetenten Zellen wird der Transformationsansatz in sterile Elektroporationsküvetten (Elektrodenabstand: $2 \mathrm{~mm}$ ) überführt. Die Elektroporation erfolgt am GenePulser mit 2,5kV, 25 $\mathrm{F}, 400 \Omega$. Der Transformationsansatz wird anschließend in ein Eppendorfgefäß überführt und mit $1 \mathrm{ml}$ LB-Medium aufgefüllt. Die Regeneration der Agrobakterien erfolgte für 2 Stunden bei $28^{\circ} \mathrm{C}$, danach werden sie auf YEB-Selektionsmedium ausplattiert.

\subsubsection{Herstellung kompetenter Hefezellen}

Die Kompetenz von Hefezellen zur DNA-Aufnahme läßt sich durch das Alkalimetallion $\mathrm{Li}^{+}$induzieren. Dabei ist desweiteren PEG (Polyethylenglykol) erforderlich. Wahrscheinlich kommt es zu Spannungsänderungen an der Membran durch Wechselwirkungen zwischen dem negativ geladenen PEG, dem monovalenten Ion $\mathrm{Li}^{+}$ und der Zelloberfläche. Die höchste Transformationseffizienz läßt sich in Zellen erreichen, die sich in der Mitte der logarithmischen Wachstumsphase befinden (Ito et al., 1983). Durch Zugabe von DMSO lässt sich die Transformationseffizienz deutlich steigern (Hill et al., 1991).

1) animpfen von $20 \mathrm{ml}$ YPD-Medium mit den Hefezellen einer einzelnen Kolonie

2) Wachstum ü.N. bei $30^{\circ} \mathrm{C}$ bis zu einer $\mathrm{OD}_{600}$ von etwa 1,5

3) ü.N.-Kultur in $300 \mathrm{ml}$ YPD überimpfen, die $\mathrm{OD}_{600}$ sollte etwa 0,2 betragen

4) Hefen bis zu einer $\mathrm{OD}_{600}$ von 0,4-0,6 anziehen

5) Zentrifugation: 5 Minuten / $1000 \mathrm{xg} / \mathrm{RT}$

6) Überstand verwerfen

7) Pellet in $40 \mathrm{ml} \mathrm{H}_{2} \mathrm{O}$ resuspendieren

8) Zentrifugation: 5 Minuten / $1000 \mathrm{xg} / \mathrm{RT}$

9) $1 \times$ TE / LiAc-Lösung aus den $10 \times$ Stocklösungen frisch ansetzen

10) Überstand verwerfen

11) Pellet in 1,5 $\mathrm{ml} 1 \mathrm{x}$ TE / LiAc-Lösung resuspendieren

12) Inkubation: mindestens 5 Minuten / RT

\subsubsection{Transformation der kompetenten Hefezellen}

1) PEG-LiAc-Lösung aus den Stocklösungen frisch ansetzen

2) Heringssperma-DNA (HSP) für 20 Minuten abkochen, dann auf Eis

3) jeweils ca. $0,25 \mu \mathrm{g}$ der jeweiligen Plasmid DNA, $100 \mu \mathrm{g}$ HSP sowie $100 \mu \mathrm{l}$ kompetenter Zellen mischen

4) $400 \mu 1$ PEG-LiAc-Lösung zufügen

5) vortexen 
6) Inkubation: 30 Minuten / $30{ }^{\circ} \mathrm{C}$, unter Schütteln (200 rpm)

7) DMSO zufügen (Endkonzentration $10 \%$ )

8) Hitzeschock bei $42^{\circ} \mathrm{C}$ für $15 \mathrm{~min}$

9) kurz auf Eis abkühlen lassen

10) $1 \times$ TE-Puffer aus dem $10 \times$ Stock herstellen

11) Zentrifugation der Zellen: $5 \mathrm{~s} / 13000 \mathrm{rpm} / \mathrm{RT}$

12) Zellen in $500 \mu 1$ TE-Puffer resuspendieren

13) $100 \mu 1$ davon auf dem entsprechenden SD-Medium ausplattieren

\subsection{Transformation von Arabidopsis thaliana-Protoplasten}

\subsubsection{Protoplastengewinnung}

Von 3- 4 Wochen alten Pflanzen werden das 2te oder 3te Blattpaar entnommen und von der Blattunterseite fein eingeritzt. Mit der angeritzten Unterseite werden die Blätter auf die Enzymlösung in eine Petrischale gelegt (10- 20 Blätter auf 5- $10 \mathrm{ml}$ Enzymlösung) und über Nacht verdaut. Durch leichtes schwenken der Petrischale fallen die Protoplasten in die Enzymlösung. Die Protoplastensuspension wird mit einem Metallnetz $(35-75 \mu \mathrm{m})$ filtriert und bei $100 \mathrm{~g}$ für $1 \mathrm{~min}$ (RT) zentrifugiert. Das Protoplastenpellet wird vorsichtig durch leichtes Schwenken in 2ml kalte W5- Lösung resuspendiertund für 6- 15h auf Eis inkubieren (max. 24h).

\subsubsection{Protoplasten- PEG- Transformation}

Vor der Transformation erfolgt ein erneutes resuspendieren der abgesetzten Protoplasten und anschließendes auszählen der Lebendzellzahl mit Hilfe einer Zählkammer. Nach Zentrifugation bei $100 \mathrm{~g}$ für $1 \mathrm{~min}$ (RT) wird das Pellet in 1-2 ml MMg- Lösung je $10^{5}$ Zellen vorsichtig durch Schwenken resuspendieren.

In $2 \mathrm{ml}$ Eppendorfgefäße mit rundem Boden werden $20 \mu 1$ DNA (20-40 $\mu \mathrm{g})$ vorgelegt und $200 \mu 1$ Protoplasten vorsichtig mit einer abgeschnittenen blauen Spitze hinzugefügt. Nach vorsichtigem mischen werden $220 \mu$ l PEG- Lösung hinzufügt und erneut vorsichtig gemischt. Dann folgte eine Inkubation für 30 Minuten bei RT. Es werden $800 \mu \mathrm{l}$ W5- Lösung hinzugefügt und nach vorsichtigem mischen folgt eine Zentrifugation bei $100 \mathrm{~g}$ für $1 \mathrm{~min}$ (RT). Mit einer blauen Spitze werden vorsichtig ca. $800 \mu \mathrm{l}$ vom Überstand abgenommen. Nach einer weiteren Zentrifugation bei $100 \mathrm{~g}$ für $1 \mathrm{~min}$ (RT) werden mit einer gelben Spitze vorsichtig ca. $300 \mu 1$ vom Überstand abgenommen. Der restliche Überstand wird nach einer weiteren Zentrifugation bei $100 \mathrm{~g}$ für 1min (RT) mit einer Insulin-Spritze abgenommen. 500 $\mu 1$ WI- Lösung werden vorsichtig hinzugefügt und dabei wird das Protoplastenpellet resuspendiert. Nach Inkubation für $8-16 \mathrm{~h}$ bei RT werden $450 \mu 1$ des Überstandes mit einer gelben Spitze entfernt. Nach Zentrifugation bei 100g für $1 \mathrm{~min}$ (RT) wird der restliche Überstand mit einer Insulinspritze vorsichtig entfernt.

\subsubsection{Messung der ß-Glucuronidase (GUS)- Aktivität}

Die $\beta$-Glucuronidase (GUS) ist das Genprodukt des GUS-Reportergens. Das GUSEnzym ist in der Lage $\beta$ - Glucuronide in D-Glucuronsäuren und einem aglyconischen 
Rest zu spalten. Setzt man das künstliche Substrat 4-Methylumbeliferyl-ß-D-Glucuronid (4-MUG) ein, so erhält man nach der Hydrolyse das fluoreszierende Molekül Methylumbeliferon (MU). Die Anregung des MU erfolgt bei 360nm, die Emission bei $460 \mathrm{~nm}$.

Die transformierten Protoplasten werden in $150 \mu 1$ GUS-Extraktionspuffer mit ßMercaptoethanol aufgenommen und $100 \mu 1$ der Proteinsuspension in ein Well einer Mikrotiterplatte überführt. $100 \mu 1$ MUG-Gebrauchslösung werden zugeben. Nach mischen wird $10 \mathrm{~min}$ bei $37^{\circ} \mathrm{C}$ inkubiert. $100 \mu 1$ des Reaktionsansatzes in ein neues Well überführen und die Reaktion durch Zugabe von $100 \mu$ l GUS-Stop-Puffer abgestopt $\left(\mathrm{t}_{0}\right)$. Weitere $100 \mu 1$ des Reaktionsansatzes werden für $60 \mathrm{~min}$ bei $37^{\circ} \mathrm{C}$ inkubiert, und dann ebenfalls gestoppt $\left(\mathrm{t}_{60}\right)$. Die Quantifizierung der Fluoreszenz erfolgt im CytoFluor II Plate Reader, die GUS-Aktivität wird nach folgender Formel berechnet.

GUS-Aktivität $[\mathrm{pmol} /(\mathrm{min} * \mathrm{mg})]=\frac{\Delta \mathrm{F} / 10}{\mathrm{t}^{*} \mathrm{mg}}$

$\Delta \mathrm{F}=$ Differenz der Floureszenz $\mathrm{t}_{60}-\mathrm{t}_{0}$

10 Fluoreszenzeinheiten entsprechen 1pmol MUG-Umsatz.

$\mathrm{t}=60 \mathrm{~min}$

$\mathrm{mg}=$ eingesetzte Gesamtproteinmenge in $\mathrm{mg}$

\subsection{GUS-Färbung}

Promotoren werden oft durch transskriptionale Fusionen mit Reportergenen untersucht. Eines der Weitverbreitesten Reportergene ist das uidA-Gen aus E.coli, welches das GUS-Enzym kodiert (Jefferson et al., 1987). Die GUS-Aktivität kann durch Färbung mit dem chromogenen Substrat X-Gluc nachgewiesen werden. Dieses Substrat kann in das Pflanzengewebe hinein diffundieren, das aktive Enzym spaltet den GlucuronsäureRest $a b$, und nach Oxidation durch das im Färbepuffer enthaltene $\mathrm{K}_{3} \mathrm{Fe}(\mathrm{CN})_{6}$ / $\mathrm{K}_{4} \mathrm{Fe}(\mathrm{CN})_{6}$ entsteht ein blauer Indolfarbstoff, der ausfällt. Höhere $\mathrm{K}_{3} \mathrm{Fe}(\mathrm{CN})_{6} /$ $\mathrm{K}_{4} \mathrm{Fe}(\mathrm{CN})_{6}$-Konzentrationen führen $\mathrm{zu}$ einem schnelleren Ausfallen des IndolFarbstoffes und damit zu präziser abgegrenzten Färbungen, hemmen aber die Enzymaktivität, sodass die Intensität der Färbung abnimmt.

1) Gewebe-Proben (z.B. Blätter, Blüten) sammeln und sofort in 1,5 ml Eppendorfgefäße mit eiskaltem $90 \%$ Aceton geben. Auf Eis lagern bis alle Proben gesammelt sind.

2) 20 Minuten bei RT inkubieren. In der Zwischenzeit die benötigten Lösungen frisch ansetzen und auf Eis lagern

3) Aceton von den Proben entfernen, mit GUS-Färbe-Puffer waschen (auf Eis)

4) Färbelösung durch Zugabe von $2 \mathrm{mM}$ (Endkonzentration) X-Gluc in GUS-FärbePuffer ansetzen

5) GUS-Färbe-Puffer von den Proben entfernen, Färbelösung zugeben

6) Proben 15-20 Minuten im Vakuum mit der Färbelösung infiltrieren. Vakuum langsam ablassen.

7) Übernacht bei $37^{\circ} \mathrm{C}$ inkubieren (kann bis zu 2 Tagen verlängert werden)

8) Färbelösung entfernen, der Reihe nach je 30 Minuten mit 20\%, 35\% und 50\% Ethanol bei RT waschen

9) Mindestens 30 Minuten in FAA fixieren 
10) FAA entfernen, $70 \%$ Ethanol zugeben. Bei $4{ }^{\circ} \mathrm{C}$ können die Proben länger gelagert werden

\subsection{Northernblot / Kapillarblot}

Im Northernblot-Verfahren wird die zu analysierende RNA durch eine denaturierende Agarosegelelektrophorese aufgetrennt. Nach Kontrolle des Gellaufs auf dem Transilluminator erfolgt der Transfer der RNA auf eine Nylonmembran mittels Kapillarblot. Durch Hybridisierung des Filters mit radioaktiv markierten einzelsträngigen DNA-Sonden ist es möglich diejenigen RNA-Transkripte durch Autoradiographie sichtbar zu machen, die komplementär zu der eingesetzten Sonde sind.

\subsubsection{Denaturierende Agarosegelelektrophorese von RNA-Molekülen}

Um die elektrophoretische Grössenauftrennung von RNA-Molekülen zu ermöglichen muss die Elektrophorese unter denaturierenden Bedingungen stattfinden, da sonst die Sekundärstrukturen das Laufverhalten beeinflussen. Die Elektrophorese findet in einem Formaldehyd-haltigen Agarosegel (1\% (w / v) Agarose, 5,5\% (v / v) Formaldehyd in 1 $\mathrm{x}$ MEN-Puffer , $200 \mathrm{mM}$ MOPS, $50 \mathrm{mM} \mathrm{NaAc,} 10 \mathrm{mM}$ EDTA, pH 7,0 mit NaOH) statt, wobei 1 x MEN als Laufpuffer dient. Die je $8 \mu \mathrm{g}$ der RNA-Proben werden auf das gleiche Volumen abgeglichen und mit 2,5 x Probenpuffer $(2,5 \times \mathrm{MEN}, 5,55 \%$ (v / v) Formaldehyd, $48 \%$ deionisiertes Formamid, 10,44 \% (v / v) Glyzerin, 0,5 \% EtBr, $0,001 \%$ (v / v) BPBLösung) versetzt. Die Denaturierung der Proben erfolgt bei $65{ }^{\circ} \mathrm{C}$ für $10 \mathrm{~min}$. Bis zum Auftragen der Proben werden diese auf Eis gehalten. Die Elektrophorese erfolgt bei $120 \mathrm{~V}$ bis die BPB-Bande $2-3 \mathrm{~cm}$ vom unteren Gelrand entfernt ist. Die Kontrolle und Dokumentation der RNA erfolgt am UVTransilluminator mit Hilfe der Geldokumentationsanlage.

\subsubsection{Kapillarblot}

Mittels Kapillar-Blot wird die durch eine denaturierende Agarosegelektrophorese aufgetrennte RNA auf eine Nylonmembran transferiert. Dazu werden zwei Lagen Fließpapier mit 10 x SSC äquilibriert und so auf einer ebenen Glasplatte aufgebracht, dass die Enden in ein 10 x SSC-Pufferreservoir tauchen. Das RNA-Gel wird luftblasenfrei mit der Oberseite nach unten auf das Fließpapier gelegt. Die Kanten und Taschen des Gels werden mit Haushaltsfolie abgedeckt. Die Nylonmembran wird luftblasenfrei auf das Gel aufgelegt, mit zwei Lagen Fließpapier und Papiertüchern bedeckt und mit einem Gewicht (ca. 500 g) gleichmäßig beschwert. Der Kapillarblot erfolgt für mindestens $14 \mathrm{~h}$. Die RNA wird durch kurze UV-Bestrahlung auf dem Transilluminator und durch zweistündige Inkubation bei $80^{\circ} \mathrm{C}$ auf der Filteroberfläche fixiert.

\subsubsection{Herstellen einer radioaktiv markierten DNA-Sonde}

Für die Herstellung radioaktiv markierter Hybridisierungssonden wird ein DNA Fragment nach Restriktionsspaltung oder ein PCR-Produkt aus einem Agarosegel eluiert. Die Markierungsreaktion erfolgt nach der Random-Prime-Labeling-Methode nach (Feinberg und Vogelstein, 1983; Feinberg und Vogelstein, 1984), bei der Hexanukleotide zufälliger Sequenz an die Matrizen-DNA binden: Die gebundenen 
Hexanukleotide dienen dann als Primer für die Neusynthese eines komplementären Stranges durch die Klenow-Polymerase unter Einbau von radioaktiven Nukleotiden. Die verwendete Klenow-Polymerase ist modifiziert, so dass sie keine Exonucleaseaktivität (exo-) mehr besitzt. Die Markierungsreaktion wird mit Hilfe des Megaprime DNA labeling system Kits von Amersham Pharmacia vorgenommen. Die Durchführung erfolgt nach dem Protokoll des Herstellers.

\subsubsection{Hybridisierung der Northern Blot Membran}

Durch Hybridisierung der Membran mit radioaktiv markierten, einzelsträngigen DNASonden lassen sich komplementäre RNA-Transkripte auf der Membran lokalisieren. Die Spezifität, mit der die Sonde an die RNA bindet, ist abhängig von der Salzkonzentration und der Temperatur. Bei hoher Salzkonzentration und niedriger Temperatur ist die Stabilität unspezifischer DNA-RNA-Hybride größer als in Lösungen niederer Salzkonzentration und höherer Temperatur. Durch die Absenkung der Salzkonzentration in den Waschlösungen erhöht man die Stringenz. Bei einer detektierbaren Strahlung auf dem Filter von ca. 100 cps ist der Filter auswertbar. Die Methode ist modifiziert nach (Church und Gilbert, 1984). Die zu analysierende Membran wird in einer Hybridisierungsröhre 30 Minuten bei $65{ }^{\circ} \mathrm{C}$ in einer Hybridisierungslösung (0,5 M Na-Phosphatpuffer, 1mM EDTA, $7 \%$ SDS) inkubiert. Die Sonden-DNA wird 10 Minuten bei $100{ }^{\circ} \mathrm{C}$ denaturiert und 5 Minuten auf Eis inkubiert. Nach der Zugabe der Sonden-DNA zu ca. $10 \mathrm{ml}$ Hybridisierungslösung in der Hybridisierungsröhre erfolgt die Hybridisierung bei $65{ }^{\circ} \mathrm{C}$ ü.N. im Roller. Zur Abtrennung unspezifisch gebundener Sonden-DNA wird die Membran zweimal mit $2 \mathrm{x}$ SSC (20x SSC: $2 \mathrm{M} \mathrm{NaCl}, 0,3 \mathrm{M}$ Na-Citrat) / 0,1\% SDS und einmal mit 1x SSC / 0,1\% SDS und optional mit 0,5x SSC / 0,1\% SDS für 15 - 30 Minuten gewaschen. Für den Nachweis der Radioaktivität wird die Membran in Folie eingeschweißt und mit einem IP-Screen exponiert. Die Dauer der Exposition hängt von der Menge der nachweisbaren Radioaktivität ab. Die Auswertung erfolgt mit Hilfe des Bioimagers (BAS-1000 von Fuji). Zur Quantifizierung werden die Programme PCBAS ${ }^{2} 2.09$ und TINA ${ }^{\circledR} 2.0$ der Firma Raytest verwendet. Die Normalisierung der detektierten Signale wird über den Vergleich mit der dokumentierten Ethidiumbromid-Färbung der RNA erreicht.

\subsubsection{Rehybridisierung}

Die auf der Filteroberfläche fixierte RNA kann nacheinander mit mehreren verschiedenen Sonden hybridisiert werden. Dazu müssen die auf dem Filter befindlichen radioaktiven Sonden aus der vorhergehenden Hybridisierung durch Denaturierung der RNA-DNA-Hybride in Waschlösungen mit geringer Salzkonzentration bei hoher Temperatur abgelöst werden. Die Membran wird durch Zugabe kochendheißer 0,1\%iger SDS-Lösung für 1 Stunde bei $65{ }^{\circ} \mathrm{C}$ gewaschen. Danach war der Filter für eine erneute Hybridisierung einsetzbar.

\subsection{Transkriptomanalyse mit 'ARIZONA whole genome arrays'}

Die für die Transkriptomanalysen verwendeten Microarrays stammen von der Abteilung Pflanzenwissenschaften der Universität Arizona, und werden durch das Spotten des für diesen Zweck von der Firma Operon käuflichen Oligonukleotid-Satzes 'Arabidopsis Genome Oligo Set Version 3.0' auf Glasträger erstellt. Die für die Hybridisierung dieser Microarrays verwendete RNA werden zunächst mit Ambions 'Amino Allyl 
MessageAmp ${ }^{\mathrm{TM}}$ II aRNA Amplification Kit' $\mathrm{zu}$ aRNA amplifiziert und dabei indirekt Fluoreszenzmarkiert.

\subsubsection{Amplifikation der eingesetzten RNA}

Die Amplifikation der RNA wird mit dem Kit der Firma Ambion im wesentlichen nach Herstellerangaben, jedoch mit kleineren Ansätzen durchgeführt. 2,75 $\mu$ l RNA (454 ng/ $\mu \mathrm{l}$ ) wird mit $0,25 \mu \mathrm{l}$ T7 Oligo(dT) Primer im PCR-tube für 10 Minuten auf $70^{\circ} \mathrm{C}$ erhitzt, kurz abzentrifugiert, und auf Eis gestellt. Für die reverse Transkription wird ein Mastermix $(0,5 \mu 1$ 10x First strand buffer / $1 \mu \mathrm{l}$ dNTP Mix / 0,25 $\mu 1$ RNase Inhibitor / $0,25 \mu \mathrm{l}$ Arrayscript Polymerase pro Ansatz) angesetzt, davon jeweils $2 \mu 1 \mathrm{zu}$ den RNAProben gegeben, durch Pipettieren gemischt und $2 \mathrm{~h}$ bei $42^{\circ} \mathrm{C}$ inkubiert.

Für die Zweitstrang Synthese wird ein Mastermix (15,75 $\mu 1$ RNase-freies Wasser / 2,5 $\mu 1$ 10x Second strand buffer / $1 \mu \mathrm{l}$ dNTP mix / 0,5 $\mu 1$ DNA Polymerase / 0,25 $\mu 1$ RNase H pro Ansatz) angesetzt, davon jeweils $20 \mu \mathrm{lu}$ den Proben geben, durch Pipettieren gemischt und $2 \mathrm{~h}$ bei $16^{\circ} \mathrm{C}$ inkubiert. Die Proben werden mit $75 \mu 1 \mathrm{RNase}$ freiem Wasser aufgefüllt, die Aufreinigung der cDNA fand mit den dafür vorgesehenen Säulen nach Herstellerprotokoll statt. Die Elution der cDNA findet mit zwei mal $10 \mu 1$ auf $55^{\circ} \mathrm{C}$ vorgewärmtem Wasser statt, und die eluierte cDNA wird in der Vakuumzentrifuge auf ein Volumen von 3,75 $\mu 1$ eingeengt.

Für die in vitro Transkription wird ein Mastermix $(0,75 \mu 1$ Aminoallyl-UTP / $1 \mu 1$ ATP Lösung / $1 \mu$ l CTP Lösung / $1 \mu$ l GTP Lösung / 0,5 $\mu$ l UTP Lösung / $1 \mu 1$ 10x reaction buffer / 1 $1 \mu 1$ T7 Enzym Mix pro Ansatz) angesetzt, davon werden jeweils 6,25 $\mu 1 \mathrm{zu}$ den Proben geben, durch Pipettieren gemischt und $16 \mathrm{~h}$ bei $37^{\circ} \mathrm{C}$ inkubiert. Die Proben werden mit $90 \mu 1$ RNase-freiem Wasser aufgefüllt und die aRNA wird mit den dafür vorgesehenen Säulen nach Herstellerprotokoll aufgereinigt. Die Elution der aRNA findet mit zwei mal $50 \mu 1$ auf $60^{\circ} \mathrm{C}$ vorgewärmtem Wasser statt.

Die Konzentration der eluierten aRNA wird mit dem Nanodrop gemessen, und Qualität der aRNA wird im Bioanalyzer getestet.

\subsubsection{Indirekte Markierung der aRNA}

Während der folgenden Arbeitsschritte werden die Proben vor Licht geschützt um ein Ausbleichen der Fluoreszenzfarbstoffe zu verhindern. Für die indirekte Markierung werden je 7,5 $\mu$ g der Aminoallyl-aRNA auf ein Volumen von $14 \mu 1$ gebracht und mit $2 \mu 1$ $1 \mathrm{M} \mathrm{Na} \mathrm{CO}_{3}$ (pH9) und $4 \mu \mathrm{l}$ Cy5 bzw. Cy3 für 1 Stunde im Dunkeln bei Raumtemperatur inkubiert. Die Kopplungsreaktion wird dann durch Zugabe von $35 \mu 1$ 100mM Natriumacetat (pH5,2) gestoppt. Die Proben werden mit $45 \mu 1$ RNase-freiem Wasser aufgefüllt und die fluoreszenzmarkierte aRNA wird mit den dafür vorgesehenen Säulen nach Herstellerprotokoll aufgereinigt. Die Elution der fluoreszenzmarkierten aRNA findet mit 2 mal $50 \mu \mathrm{l}$ auf $60^{\circ} \mathrm{C}$ vorgewärmtem Wasser statt. Anschließend werden am Nanodrop gemessen wie viel pmol Fluorophore pro $\mu 1$ eingebaut werden.

Je nach Ausbeute werden für die Hybridisierung Proben mit 150-300 pmol Fluoreszenzfarbstoff eingesetzt, wobei darauf geachtet wird, dass von beiden auf einen Array hybridisierte Proben beide gleichviel picomol Fluoreszenzfarbstoff enthielten. Die für einen Array verwendeten Volumen Cy3 und Cy5 markierter aRNA werden vereinigt, $1 \mu 1$ polyA $(20 \mu \mathrm{g} / \mu \mathrm{l})$ und $1 \mu \mathrm{l} \mathrm{tRNA}(20 \mu \mathrm{g} / \mu \mathrm{l})$ zugegeben, und das ganze wird in einer Vakuumzentrifuge zur Trockne eingeengt. 


\subsubsection{Hybridisierung der ARIZONA whole genome arrays}

Vor der Verwendung werden die ARIZONA whole genome arrays ,hydratisiert“, das heißt, sie werden dreimal kurz über ein $60^{\circ} \mathrm{C}$ Wasserbad gehalten, so dass ihre Oberfläche leicht beschlagen. Dabei laufen die aufgrund von Pufferresten hygroskopischen Spots etwas auseinander, werden dadurch größer und lassen sich später besser auswerten. Anschließend werden die Oligonukleotide durch Bestrahlung mit 120 Millijoule UV-Licht kovalent an die Oberfläche des Glasträgers gebunden. Danach werden die Arrays 4 Minuten mit 0,1\% SDS, dreimal 2 Minuten mit $\mathrm{H}_{2} \mathrm{O}$ (demin) und dann 30 Sekunden in 100\% Ethanol gewaschen und anschließend durch Abzentrifugieren oder Abpusten getrocknet.

Die Vorhybridisierungslösung besteht aus $300 \mu 120 x$ SSC, $575 \mu 1 \mathrm{H}_{2} \mathrm{O}, 100 \mu 110 \%$ BSA und $25 \mu 120 \%$ SDS. Zur Vorhybridisierung werden $80 \mu 1$ Vorhybridisierungslösung auf ein Deckglas gegeben, der Array umgedreht an das Deckglas gehalten und mit dem nun durch Adhäsion anhaftenden Deckglas angehoben. Anschließend wird der Array mit Deckglas in die Hybridisierungskasette geschlossen und $1 \mathrm{~h}$ bei $42^{\circ} \mathrm{C}$ inkubiert.

In der Zwischenzeit werden die getrocknete aRNA in $9 \mu 1 \mathrm{H}_{2} \mathrm{O}$ resuspendiert und $1 \mu \mathrm{l}$ $10 \mathrm{x}$ fragmentation buffer wird zugegeben. Dann wird $15 \mathrm{~min}$ bei $70^{\circ} \mathrm{C}$ inkubiert und $1 \mu 1$ fragmentation stop zugegeben. $\mathrm{Zu}$ jeder Probe werden 56,4 $\mu 1$ einer Hybridisierungslösung (350 $\mu 1$ Formamid, $210 \mu 1$ 20x SSC, 70 $\mu 1$ 50X Denhardts, 17,5 $\mu 1$ $20 \%$ SDS und $52,5 \mu 1 \mathrm{H}_{2} \mathrm{O}$ ) gegeben, das ganze gevortext, 5 Minuten auf $95^{\circ} \mathrm{C}$ erhitzt und 5 Minuten bei $10.000 \mathrm{~g}$ abzentrifugiert.

Die vorhybridisierten Glasträger werden mit $\mathrm{H}_{2} \mathrm{O}$ gewaschen, und die in der Hybridisierungslösung aufgenommene aRNA wird zwischen den Glasträger und einen darauf platzierten Liftslip laufengelassen. Der Glasträger mit Probe wird in wasserdichte Hybridisierungsgefäße eingeschlossen und anschließend über Nacht bei $37^{\circ} \mathrm{C}$ in einem Wasserbad inkubiert. Nach der Inkubation wird der Glasträger 5 Minuten bei $37^{\circ} \mathrm{C}$ mit $0,5 \mathrm{x}$ SSC $+1 \% \mathrm{SDS}$, zweimal 5 Minuten bei RT mit $0,5 \mathrm{x} \mathrm{SSC}+1 \% \mathrm{SDS}$, viermal 5 Minuten bei RT mit $0,5 \mathrm{x}$ SSC und 5 Minuten bei RT mit $0,1 \mathrm{x}$ SSC gewaschen und anschließend durch Abzentrifugieren oder Abpusten getrocknet.

Anschließend werden die Fluoreszenzsignale mit einem GenePix 4000B Microarray Scanner eingelesen.

\subsubsection{Auswertung der ARIZONA whole genome arrays}

Die Auswertung erolgt mit der GenePix Pro 4.0 Software von Axon Instruments. Die richtige Platzierung der Felder für das Auslesen der Signalstärken der einzelnen Spots wird von Hand überprüft und gegebenenfalls korrigiert. Nach dem Auslesen der Fluoreszenzsignale werden die mit den 3 biologischen Replikaten erhaltenen Datensätze mit der Software S.O.L.A.R. integriert.

\subsection{Herstellung von Chloroform / Methanolextrakten zur Bestimmung des Zuckergehaltes}

$300 \mathrm{mg}$ Pflanzenmaterial werden unter Kühlung mit flüssigem Stickstoff zu einem feinen Pulver aufgemörsert. Das Pulver wird in ein $12 \mathrm{ml}$ Greinerröhrchen mit $5 \mathrm{ml}$ Chloroform/Methanol $(1,5: 3,5)$ gegeben. Nach gründlichem Schütteln erfolgte für 30 Minuten eine Inkubation auf Eis. Danach werden $4 \mathrm{ml}$ steriles Millipore-Wasser zugegeben, 2 Minuten geschüttelt und 5 Minuten bei $5000 \mathrm{rpm}$ zentrifugiert. Die wässrige Phase wird mit einer Transferpipette in einen auf Eis gekühlten Rotationskolben gegeben. Die organische Phase wird nochmals mit $3 \mathrm{ml}$ sterilem 
Millipore-Wasser ausgeschüttelt, wieder zentrifugiert und die abgetrennte wässrige Phase wieder in den Rotationskolben überführt. Die Probe wird am Rotationsverdampfer bei $34^{\circ} \mathrm{C}$ im Wasserbad bis zur Trocknung eingeengt. Die getrockneten Proben werden mit $1 \mathrm{ml}$ HPLC Wasser gelöst, über eine Nitrocellulosemembran gefiltert und in einem Eppendorfgefäß aufgefangen. Nach Schockgefrieren in flüssigem Stickstoff erfolgt die Lagerung bei $-80^{\circ} \mathrm{C}$. Die Messung erfolgte durch G. Lohaus (Universität Göttingen).

\subsection{Nachweis der $\beta$-Galaktosidaseaktivität in Hefen mit einem oNPG-Test}

Der oNPG-Test erlaubt eine quantitative Bestimmung der $\beta$-Galaktosidaseaktivität. Die $ß$-Galaktosidase ist ein hydrolytisches Enzym, welches das Disaccharid Lactose in Glucose und Galaktose spaltet. Die ß-Galactosidase kann auch chromogene Substratanaloga wie X-Gal oder oNPG umsetzen und ist somit ein geeignetes Reporterenzym. Der oNPG-Test erlaubt eine qualitative und quantitative Bestimmung der ß-Galaktosidaseaktivität. Er beruht auf der Hydrolyse des Substrates oNPG unter Freisetzung des Farbstoffes o-Nitrophenol, der eine gelbe Färbung aufweist. Die Anzucht der Hefe erfolgt über Nacht in $3 \mathrm{ml}$ SD Medium bei $30^{\circ} \mathrm{C}$. Am nächsten Morgen wird die OD600 bestimmt. $2 \mathrm{ml}$ der Kultur werden pelletiert und in $665 \mu 1 \mathrm{H}$ Puffer (100mM HEPES / KOH, pH 7,0; $150 \mathrm{mM} \mathrm{NaCl;} 2 \mathrm{mM} \mathrm{MgCl}_{2}, 1 \%$ BSA) resuspendiert. Eine Nullkontrolle wird parallel behandelt. Durch Zugabe von $55 \mu 1$ Chloroform und $55 \mu \mathrm{l}$ SDS und nach einer Minute vortexen sind die Zellen lysiert. Dann wird als Substrat $125 \mu 1$ oNPG-Lösung $(4 \mathrm{mg} / \mathrm{ml}$ oNPG gelöst in H-Puffer) zugegeben. Die Reaktion läuft für 30 Minuten bei $37^{\circ} \mathrm{C}$ ab. Zum Abstoppen der Reaktion werden $400 \mu l$ Natriumcarbonatlösung (1 M) zugegeben. Die genaue Reaktionszeit wird notiert. Die festen Bestandteile werden durch Zentrifugation für 5 Minuten in der Tischzentrifuge pelletiert. Der klare Überstand wird abgenommen und die OD420 wird bestimmt. Dieses Protokoll (Strathmann, persönliche Mitteilung) ist eine Modifikation des Originalprotokolls nach (Miller et al., 1999).

Die Berechnung der $\beta$-Galaktosidaseaktivität erfolgt nach folgender Formel:

$\beta$-Galaktosidaseaktivität [units] $=\frac{\left(1000 \times O D_{420}\right)}{\left(V \times t \times O D_{600}\right)}$

$\mathrm{V}=$ Für die Messung eingesetztes Volumen der Kultur (0,5 ml)

$\mathrm{t}=$ Reaktionszeit in Minuten

\subsection{Chromatin-Immunopräzipitation}

Die Chromatin-Immunopräzipitation ist eine Methode, mit der die in vivo Bindung von Proteinen an DNA gezeigt werden kann (Hecht et al., 1996; Johnson et al., 2001).

\subsubsection{Chromatinpräparation}

Zur Kreuzvernetzung der DNA-Proteinkomplexe (Solomon et al., 1988; Solomon und Varshavsky, 1985) werden je $10 \mathrm{~g}$ Blattmaterial in Einmachgläser überführt und mit 
Crosslinkingpuffer (50mM Kaliumphosphatpuffer, 1\% Formaldehyd) überschichtet. Dann wird ein Vakuum angelegt, bis die Blätter mit dem Crosslinkingpuffer vollgesogen sind. Für 30 Minuten wird bei Raumtemperatur inkubiert, dann werden die Blätter nacheinander in eiskalter 0,3M Glycinlösung und dann dreimal in 1x TBS gewaschen. Die Blätter werden dann trockengetupft und in flüssigem Stickstoff tiefgefroren. Von jetzt an alle Schritte auf Eis durchführen.

Das Blattmaterial wird in Stickstoff aufgemörsert und in 20ml Extraktionspuffer aufgenommen. Dort wird es mit einem Homogenisator (Miccra) auf Stufe B für etwa 4 Minuten weiter homogenisiert. Anschließend wird durch 2 Lagen Miracloth filtriert, das Volumen mit Extraktionspuffer auf $24 \mathrm{ml}$ gebracht, und unter langsamen Rühren langsam $1 \mathrm{ml} \mathrm{25 \%}$ Triton zugetropft. Anschließend wird 15 Minuten weiter gerührt. Ein Percoll-Gradient aus 6ml 75\% Percoll / 6ml 35\% Percoll wird mit den 24ml Kernen überschichtet und bei $2000 \mathrm{xg}$ (3500 rpm), soft start\&stop, 30min abzentrifugiert. Extraktionspuffer und 35\% Percoll werden abgenommen, die Zwischenphase in ein neues Greiner überführt und mit 20ml Gradientenpuffer verdünnt. Dieses wird auf ein neues $6 \mathrm{ml} \mathrm{35 \%} \mathrm{Percollkissen} \mathrm{gegeben} \mathrm{und} \mathrm{bei} \mathrm{2000g} \mathrm{(3500rpm),} \mathrm{soft} \mathrm{stop,} 10$ Minuten abzentrifugiert. Der Überstand wird abgenommen und die Kerne werden in $1 \mathrm{ml}$ TE mit $0,25 \%$ SDS aufgenommen.

Die Ultraschallbehandlung zur Fragmentierung des Chromatins findet für 4 x 12 Sekunden auf Eis statt. Anschließend wird 15 Minuten bei $13.000 \mathrm{rpm}$ und $4^{\circ} \mathrm{C}$ abzentrifugiert, und das Pellet in $500 \mu 1$ sonication buffer aufgenommen. 2 Aliquots von $200 \mu \mathrm{l}$ werden bei $-80^{\circ} \mathrm{C}$ weggefroren, der Rest wird genommen um die DNAKonzentration $\mathrm{zu}$ bestimmen. Dazu wird die Quervernetzung durch ÜbernachtInkubation bei $65^{\circ} \mathrm{C}$ rückgängig gemacht, anschließend wird die Probe RNAse und ProteinaseK (je $1 \mu \mathrm{l}$ ) verdaut. Anschließend wird die DNA PCI-Aufgereinigt und unter Zugabe von $1 \mu \mathrm{l}$ Glycogen $(10 \mathrm{mg} / \mu \mathrm{l}) 4 \mathrm{~h}$ bei $-80^{\circ} \mathrm{C}$ gefällt. Die gefällte DNA wird in $25 \mu \mathrm{H}_{2} \mathrm{O}$ aufgenommen, die Ausbeute sollte $30-200 \mathrm{ng} / \mu \mathrm{l}$ sein.

\subsubsection{Immunopräzipitation}

Die Chromatin-Proteinkomplexe werden nun für die Immunopräzipitation eingesetzt. Die aufgetauten Proben werden 10 Minuten bei 13.000rpm abzentrifugiert und mithilfe der zuvor bestimmten DNA-Konzentrationen auf die gleiche Konzentration eingestellt. $200 \mu 1$ Chromatin werden mit $300 \mu 1$ RIPAF ohne SDS und $30 \mu 1$ gewaschenen Protein A beads 1 Stunde bei $4^{\circ} \mathrm{C}$ im Intellimixer inkubiert. Die Protein $\mathrm{A}$ beads werden abzentrifugiert und der Überstand mit $8 \mu$ l HA-Antikörper mindestens $4 \mathrm{~h}$ (oder ü.N.) bei $4^{\circ} \mathrm{C}$ inkubiert. Dann werden $30 \mu \mathrm{l}$ gewaschene Protein A beads zugeben, $1 \mathrm{~h}$ bei $4^{\circ} \mathrm{C}$ im intellimixer inkubiert, und anschließend werden die beads abzentrifugiert und 4 mal mit RIPAF gewaschen. Die Elution erfolgt mit $200 \mu 1$ Glycin elution buffer, anschließend werden $50 \mu \mathrm{l} 1 \mathrm{M}$ Tris-HCl pH 9,7 zum Neutralisieren zugegeben. Der Erfolg der IP wird im Western mit je $40 \mu$ Überstand und Eluat überprüft. Nachdem die DNA mit einer Phenol-Chloroformfällung aufgereinigt wird, kann sie in einer PCR getestet werden.

\subsection{Herstellung denaturierender Gesamtzellextrakte aus Pflanzen}

Das Blattgewebe wird unter flüssigem Stcikstoff aufgemörsert, 50 - $200 \mathrm{mg}$ des Pulvers im gefrorenen Zustand in ein Eppendorfgefäß eingewogen, in der doppelten Menge 
(w/v) Harnstoffextraktionspuffer (4 M Harnstoff, 16,6\% (v/v) Glycerin, 5\% (v/v) ßMercaptoethanol, 5\% (w/v) SDS, 0,5\% (w/v) Bromphenolblau) aufgenommen, gevortext und bei $65^{\circ} \mathrm{C}$ für 10 Minuten inkubiert. Nach 5 Minuten Inkubation werden die Eppendorfgefäße mehrmals invertiert. Anschließend wird der Rohextrakt 15 Minuten bei $15000 \mathrm{rpm}$ und RT zentrifugiert um Zelltrümmer und DNA abzutrennen. 2/3 Volumen des Überstandes werden in ein neues Eppendorfgefäß überführt. Die Proteinextrakte werden bis zur weiteren Verwendung bei $-80^{\circ} \mathrm{C}$ gelagert. Vor Auftragung in der SDS-PAGE werden sie 5 Minuten bei $65^{\circ} \mathrm{C}$ inkubiert. Die Proben können direkt auf das Gel appliziert werden.

\subsection{Western Blot Analyse}

\subsubsection{SDS-Polyacrylamidgelelektrophorese}

Die SDS-Polyacrylamidgelelektrophorese (SDS-PAGE, (Laemmli, 1970)) dient der Auftrennung von Proteinen nach ihrer Molekularmasse. Die Polyacrylamidmatrix wird durch Polymerisation von Acrylamid mit dem Quervernetzer N,N'Methylenbisacrylamid (BIS) hergestellt. Die Porengröße im Gel kann durch die Wahl der Acrylamidkonzentration sowie des Verhältnisses Acrylamid/BIS verändert werden. Die Polymerisation wird durch Zugabe von Ammoniumpersulfat (APS) durch Erzeugung freier Radikale gestartet. Als Katalysator wird N,N,N',N'Tetramethylethylendiamin (TEMED) zugefügt. In dieser Arbeit werden SDS-Gele verwendet, die sich aus einem Trenngel aus 10\% (w/v) Acrylamid/Bis (19:1), 0,4 M Tris/HCl pH 8,8, 0,1\% (w/v) SDS, 0,1\% (v/v) TEMED, 0,1\% (w/v) APS sowie einem Sammelgel aus \% (w/v) Acrylamid/BIS (19:1), $125 \mathrm{mM}$ Tris/HCl pH 6,8, 0,1\% (w/v) SDS, 0,2\% (v/v) TEMED, 0,1 \% (w/v) APS zusammensetzen. Nach Beladen der Taschen des Gels mit je $10 \mu 1$ Proteinextrakt aus denaturierten Harnstoffextrakten erfolgte der Gellauf bei $20 \mathrm{~mA}$ für 2 Stunden. Als Laufpuffer diente $25 \mathrm{mM}$ Tris, 190mM Glycin, 0,1\% (w/v) SDS.

\subsubsection{Coomassie-Färbung}

Um Proteinbanden in SDS-PAGE-Gelen sichtbar zu machen, werden diese mit dem Farbstoff Coomassie Brilliant Blue G-250 angefärbt. Hierfür wird das Gel 30 Minuten in der Fixierlösung $(25 \%(\mathrm{v} / \mathrm{v})$ Isopropanol, 10\% (v/v) Essigsäure) geschwenkt. Nach Verfärbung des Bromphenolblau ins Gelbliche wird das Gel in der Färbelösung $(0,006 \%$ (w/v) Coomassie Brilliant Blue G-250, 10\% (v/v) Essigsäure) 30 bis 60 Minuten inkubiert. Die Entfärbung des Gels erfolgt in dem Entfärbebad (10\% (v/v) Essigsäure) unter wiederholtem Wechsel der Lösung für mehrere Stunden. Optional kann der Vorgang durch kurzes Erwärmen in der Mikrowelle beschleunigt werden.

\subsubsection{Proteintransfer auf PVDF-Membranen}

Der Transfer der im SDS-Gel aufgetrennten Proteine auf eine PVDF-Membran erfolgt mittels der „Semi-Dry-Blotting“-Methode (Kyhse-Anderson, 1984). Dazu werden drei Lagen Fließpapier in Transferpuffer (192mM Glycin, $25 \mathrm{mM}$ Tris, 20\% (v/v) Methanol, $0,01 \%(\mathrm{w} / \mathrm{v})$ SDS) angefeuchtet und auf die Blottingapparatur aufgelegt. Die PVDFMembran wird in Methanol aktiviert, mit Transferpuffer äquilibriert und luftblasenfrei auf die Schicht Fließpapier gelegt. Das PAA-Gel wird auf dem Filter positioniert und 
mit drei Lagen in Transferpuffer äquilibriertem Fließpapier bedeckt. Der Elektrotransfer läuft für 45 Minuten bei $5 \mathrm{~mA} / \mathrm{cm}^{2}$ Filterfläche. Nach dem Transfer wird der Filter kurz in TBS gewaschen und zwischen zwei Lagen Fließpapier getrocknet. Die Membran wird vor der Weiterbehandlung wieder mit Methanol aktiviert.

\subsubsection{Immunodetektion mit dem ECL+ System}

Bei der hier angewendeten indirekten Nachweismethode werden die auf der Membran immobilisierten Proteine zuerst mit einem Primärantikörper immunodetektiert. Dieser Antikörper ist spezifisch gegen ein Epitop des nachzuweisenden Proteins gerichtet. Unter Verwendung eines Peroxidase-gekoppelten zweiten Antikörpers wird der Primärantikörper erkannt. Der Nachweis erfolgt mit Hilfe des ECL+-Kits der Firma Amersham. Nach Inkubation des Filters mit einem Substrat-Mix kann die bei der Peroxidase-katalysierten Oxidation des Substrates Luminol entstehende Chemilumineszenz durch Exposition eines Röntgenfilms nachgewiesen werden. Das Absättigen freier Stellen auf der Membran (Blocken) erfolgt durch 1 Stunde Inkubation mit $5 \%$ Milchpulver in TBST. Danach erfolgt für 2 Stunden die Inkubation mit $5 \%$ Milchpulver in TBST und Primärantikörper. Die Membran wird dreimal 10 Minuten mit 1 x TBST zum Entfernen von nicht gebundenem Antikörper gewaschen. Die Inkubation mit dem Sekundärantikörper erfolgte in $5 \%$ Milchpulver in TBST für $1 \mathrm{~h}$. Nichtgebundener Antikörper wird wieder entfernt durch 5 x 5 Minuten Waschen mit 1 x TBS. Das ECL-Substratmix wird frisch aus den Lösungen 1 und 2 im Verhältnis 1:1 angesetzt, für eine Membran $(9,5 \times 6,5 \mathrm{~cm})$ werden $3 \mathrm{ml}$ Substratmix benötigt. Die Membran wird mit der Proteinseite nach oben auf ein Stück Haushaltsfolie gelegt, und mit dem Substratmix 1 Minuten inkubiert. Überschüssiger Substratmix wird abgeschüttet und die Membran in Haushaltsfolie eingeschlagen. Die Detektion der Chemilumineszenssignale erfolgt durch Exposition eines Röntgenfilms, je nach Signalstärke für $15 \mathrm{~s}$ bis $10 \mathrm{~min}$. Der Autoradiographiefilm wird dann für 1-5 Minuten entwickelt, kurz gewässert und 3 Minuten fixiert.

\subsection{Verwendete Computerprogramme}

VectorNTI Suite V 6.0 (InforMax, 2000)

BLAST (Altschul et al., 1997; Madden et al., 1996)

PCBAS 2.09 und TINA 2.0 (Raytest)

POBO (Kankainen und Holm, 2004)

Genevestigator (Zimmermann et al., 2004)

Coils, Version 2.2 (Lupas, 1996)

Bioprospektor (Liu et al., 2001) 


\subsection{Mathematische Formeln}

Formel zur Berechnung des Mittelwertes:

$\langle x\rangle=\frac{\sum_{i=1}^{n} x_{i}}{n}$

Formel zur Berechnung der Standardabweichung:

$\sigma=\sqrt{\frac{n \sum x^{2}-\left(\sum x\right)^{2}}{n^{2}}}$ 


\section{Ergebnisse:}

\subsection{AtbZIP-Transkriptionsfaktoren der Gruppe C bilden spezifische Heterodimere mit AtbZIP-Transkriptions- faktoren der Gruppe S1}

Protein-Protein Interaktionen zwischen bZIP-Transkriptionsfaktoren der Gruppe $\mathrm{C}$ und bZIP-Transkriptionsfaktoren der Gruppe S1 sind bereits für die Spezies Tabak und Petersilie gezeigt worden (Rugner et al., 2001; Strathmann et al., 2001). Solche Interaktionen auch für bZIP-Transkriptionsfaktoren aus Arabidopsis zu zeigen, und zu quantifizieren, war das erste Ziel dieser Arbeit. In Arabidopsis sind zudem alle Mitglieder dieser beiden Gruppen bekannt (Jakoby et al., 2002), sodass es möglich ist, eine Interaktionsmatrix auf genomischer Basis zu erstellen.

Die Fähigkeit der AtbZIP-Transkriptionsfaktoren zur Homodimeriserung oder Heterodimerisierung mit anderen AtbZIP-Transkriptionsfaktoren, sowie ihre Aktivierungseigenschaften, wurden mit dem ProQuest-System in "Yeast One-Hybrid" bzw. "Yeast Two-Hybrid" Tests untersucht (INVITROGEN, 2001).

Das "Yeast Two-Hybrid" System ist ein klassisches System zur Analyse von in vivo Protein-Protein Interaktionen. Es basiert auf dem modularen Aufbau des Transkriptionsfaktors GAL4 aus einer DNA-Bindedomäne (BD) und einer Aktivierungsdomäne (AD) (Brent und Ptashne, 1985; Ma und Ptashne, 1987). Die DNA-Bindedomäne interagiert mit der GAL4-UAS (upstream activating sequence) der DNA und positioniert den Transkriptionsfaktor in der Nähe des Transkriptionsstartpunktes, die Aktivierungsdomäne wird benötigt, um die Transkription durch Interaktion mit dem RNA-Polymerase II Komplex einzuleiten (Giniger et al., 1985).

In "Yeast Two-Hybrid" Tests untersucht man die Interaktion zwischen zwei Proteinen, indem man das eine Protein an die GAL4-BD und das andere Protein an die GAL4-AD fusioniert. Wenn die Proteine miteinander interagieren, wird der GAL4 Transkriptionsfaktor rekonstituiert und aktiviert die Expression eines Reportergens, dass 
unter der Kontrolle eines GAL4-UAS abhängigen Promotors steht (Fields und Song, 1989).

Die für die "Yeast One-Hybrid" bzw. "Yeast Two-Hybrid" Tests notwendigen Expressionsvektoren stammen aus dem REGIA-Projekt und wurden durch Rekombination der AtbZIP-Gene in die Gateway-Plasmide pDEST22 (AD) bzw. pDEST32 (BD) erzeugt (siehe Material und Methoden 4.5 Gateway Rekombination). Zur Kontrolle wurden die AD- und BD-Vektoren mit den Primern Gal4AD und Gal4BD sequenziert. Dabei konnte die Sequenz sowie die Einhaltung des Leserasters mit der GAL4-Domäne bestätigt werden.

\subsubsection{AtbZIP-Transkriptionsfaktoren der Gruppen S1 und C zeigen unterschiedliche Aktivierungseigenschaften}

In dem "Yeast One-Hybrid" System wird lediglich das GAL4-BD Fusionsprotein in Hefe exprimiert, das über die Gal4-BD an die Reportergen-Promotoren binden kann. Eine Aktivierung des Reportergens sollte hier ausschließlich auf den Aktivierungseigenschaften des fusionierten AtbZIP-Proteins beruhen, und deren Stärke wiedergeben.

Um quantitative Werte für die Aktivierungseigenschaften der AtbZIP-Proteine zu erhalten, wurden oNPG-Tests mit jeweils drei unabhängigen Kolonien durchgeführt (Abbildung 5.1). Der oNPG-Test erlaubt eine quantitative Bestimmung der Aktivität der vom lacZ-Reportergen kodierten $\beta$-Galaktosidase. Als Negativ-Kontrolle wurde der leere BD-Vektor pDEST32 verwendet. AtbZIP9 ist ein starker, AtbZIP1, 2, 11, 44 vergleichsweise schwache Transkriptionsaktivatoren in Hefe. Für AtbZIP53 und 63 konnten keine Aktivierungseigenschaften gezeigt werden. Die Ergebnisse wurden durch Verwendung verschiedener Methoden und Reportergenkonstrukte (Filter-lift assay, Wachstum auf Selektivmedium ohne Uracil oder ohne Histidin) verifiziert (nicht gezeigt).

Im Rahmen ihrer Diplomarbeit wurden diese Ergebnisse der oNPG-Tests von Andrea Ehlert reproduziert, außerdem wurden hier auch die Aktivierungseigenschaften von AtbZIP10 und 25 quantifiziert (Ehlert, 2004). Dabei wurde gezeigt, dass AtbZIP10 im Vergleich zu AtbZIP9 eine mehr als doppelt so starke Aktivierung des Reportergens bewirkt, während AtbZIP25 in Hefe keine Aktivierungseigenschaften zeigt. 


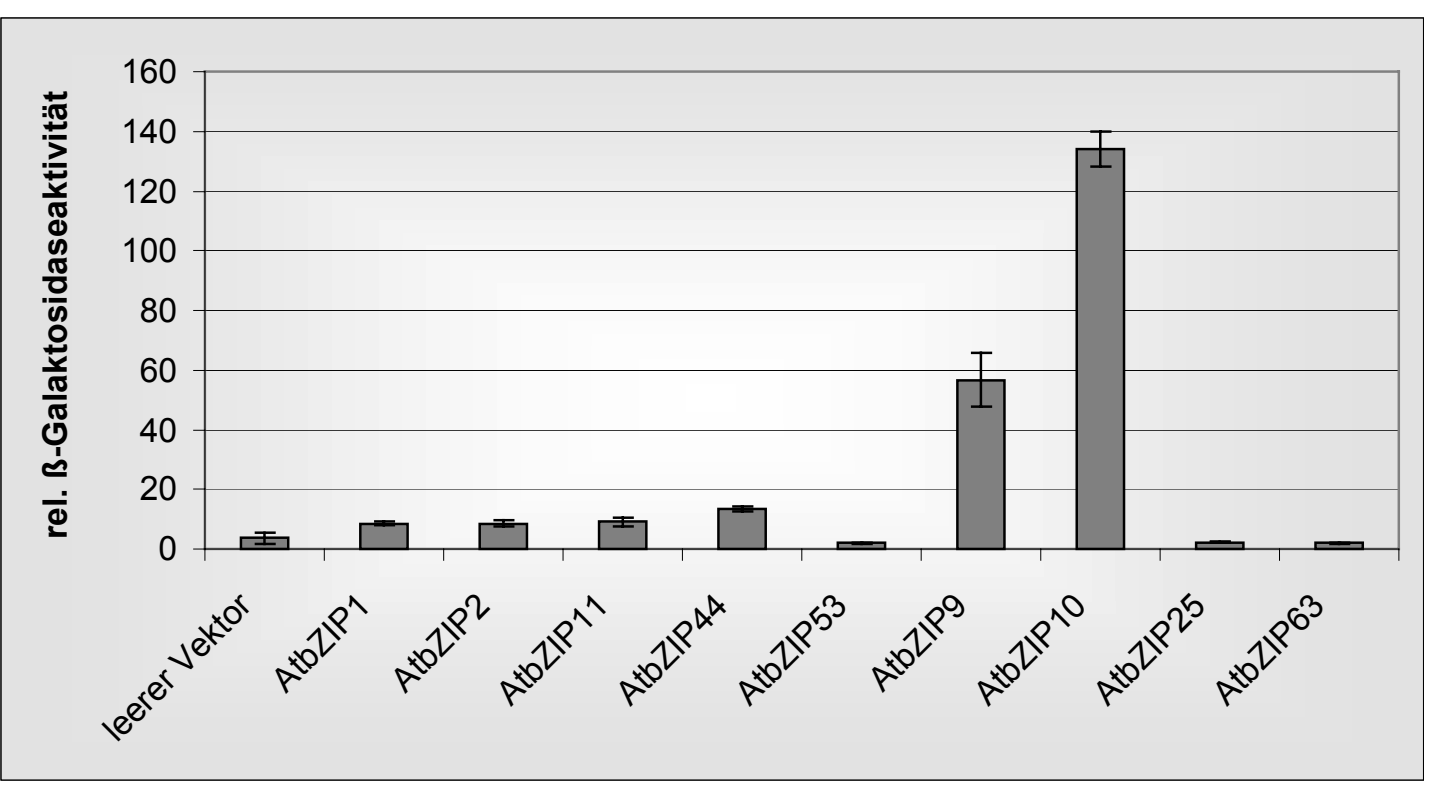

Abbildung 5.1: Analyse der Aktivierungseigenschaften der Gruppe C/S1 AtbZIPTranskriptionsfaktoren im "Yeast One-Hybrid" System. Die $\beta$-Galaktosidaseaktivität entspricht der Aktivität des lacZ-Reportergens, dessen Aktivierung hier ausschließlich über das Aktivierungspotential der durch die BD-Fusion an den Reportergen-Promotor gebrachten Transkriptionsfaktoren erfolgt. Die $\beta$ Galaktosidaseaktivitäten wurden jeweils für drei Klone bestimmt und werden mit Standardabweichungen dargestellt. Als Hefestamm wurde MaV203 verwendet, die BD-Fusionen wurden mit dem Plasmid pDEST32 erzeugt.

\subsubsection{AtbZIP-Transkriptionsfaktoren der Gruppe C heterodimerisieren in Hefe bevorzugt mit AtbZIP-Transkriptionsfaktoren der Gruppe S1}

Mit Hilfe des "Yeast Two-Hybrid" Systems (Y2H) sollten Interaktionen zwischen Mitgliedern der Gruppen S1 und Mitgliedern der Gruppe C identifiziert und quantifiziert werden. Dabei wurde die durch Interaktionen entstehende Aktivierung des Reportergens mit Hilfe aller drei im verwendeten Stamm MaV203 zur Verfügung stehenden Reporterkonstrukte analysiert.

AtbZIP9 hat zu starke Aktivierungseigenschaften, um sinnvoll als BD-Fusion verwendet zu werden. Daher wurde ein Deletionsderivat, AtbZIP9 $\Delta$ N, verwendet, das reduzierte Aktivierungseigenschaften zeigt (Weltmeier, 2002).

Zunächst wurden mit Hilfe des URA-Reportergenkonstruktes Tests auf Interaktionen durchgeführt (Abbildung 5.2). Hierbei führt eine Interaktion zur Aktivierung eines Gens für die Uracil-Synthese, das Wachstum auf Platten ohne Uracil erlaubt. 


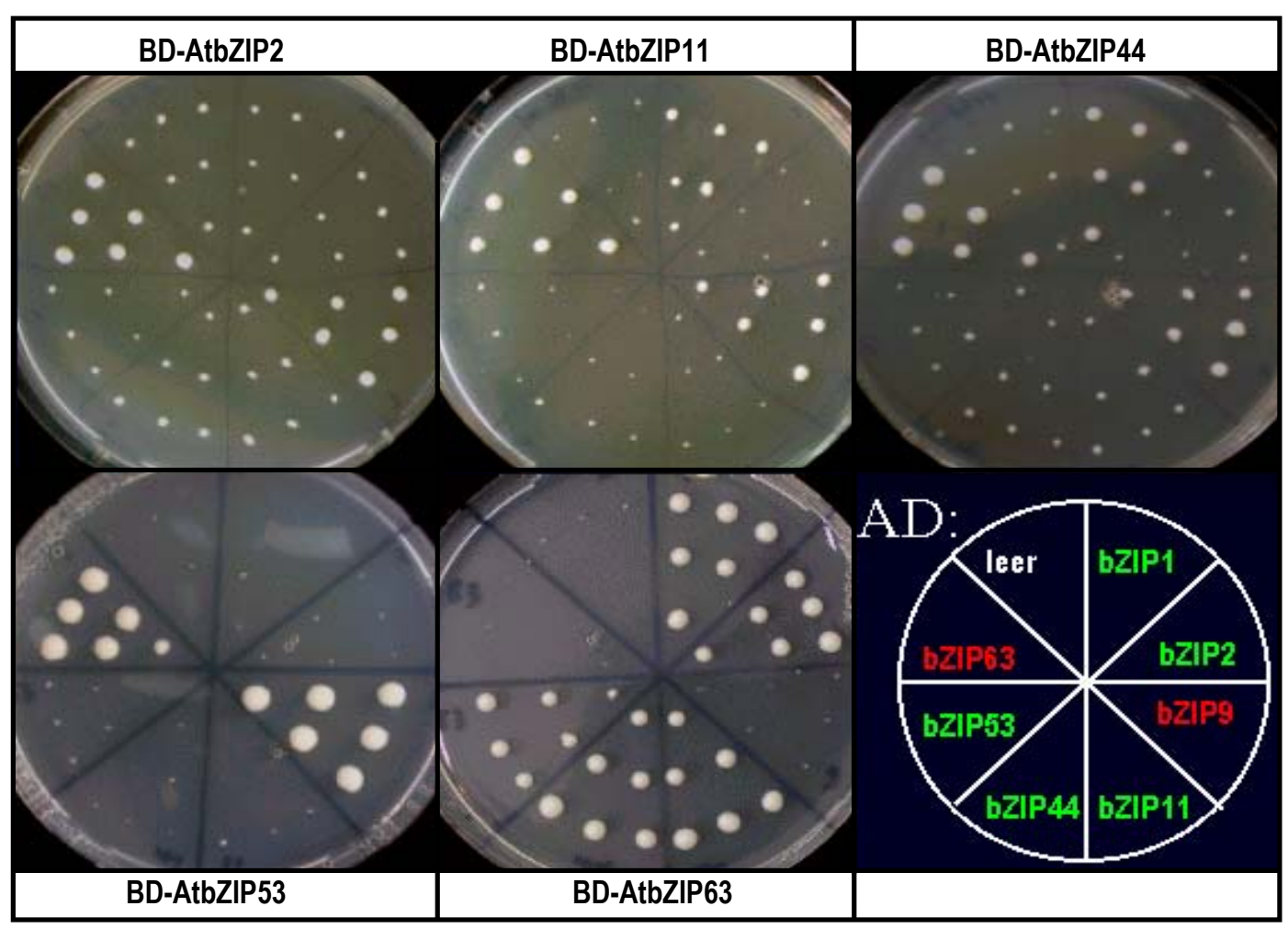

Abbildung 5.2: "Yeast Two-Hybrid" (Y2H)-Tests zur Identifizierung von Protein-Protein Interaktionen zwischen AtbZIP-Transkriptionsfaktoren der Gruppen C und S1. Auf den Platten wurden Kotransformanden der angegebenen BD-AtbZIP Fusionen mit verschiedenen AD-AtbZIP Fusionen angeimpft. Die Positionen der verschiedenen AD-AtbZIP Fusionen sind rechts unten wiedergebeben, jede Kombination wurde aus drei unabhängigen Kolonien angeimpft. Y2H-Tests mit den BD-Fusionen von AtbZIP53 bzw. 63 wurden auf SD-Medium ohne Uracil, Y2H-Tests mit den leicht aktivierenden BD-Fusionen von AtbZIP2, 11 und 44 wurden auf SD-Medium ohne Histidin und mit 100mM 3-AT durchgeführt. Als Hefestamm wurde MaV203 verwendet, die BD-Fusionen wurden mit dem Plasmid pDEST32 erzeugt, die AD-Fusionen mit dem Plasmid pDEST22.

Für AtbZIP53-BD Fusionen konnten dabei spezifische Interaktionen mit den Gruppe C Mitgliedern AtbZIP9 und AtbZIP63 gezeigt werden, und für AtbZIP63-BD Fusionen spezifische Interaktionen mit allen Gruppe S1 Mitgliedern.

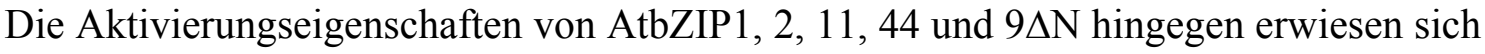
als zu stark, um mit diesem Reporterkonstrukt als BD-Fusionen eingesetzt werden zu können. Daher wurden sie mit dem HIS-Reporterkonstrukt getestet, das ein Unterdrücken der Hintergrundaktivität durch Zugabe von 3-Amino-1,2,4-Triazol (3AT) in das Medium erlaubt. Bei einer sehr hohen 3-AT Konzentration von 100mM konnten so für AtbZIP2, 11 und 44 spezifische Interaktionen mit AtbZIP9 und 63 gezeigt werden, AtbZIP11 und AtbZIP44 interagierten außerdem mit AtbZIP1 (Abbildung 5.2). BD-Fusionen von AtbZIP1 und AtbZIP9 $\Delta \mathrm{N}$ verursachten auch hier noch eine zu starke Hintergrundaktivität, um klare Ergebnisse zu erhalten. 
Im folgenden wurden die Interaktionen unter Verwendung des lacZReporterkonstruktes in oNPG-Tests untersucht, die den Vorteil bieten, dass sie quantitative Werte liefern. Die Messungen der $\beta$-Galaktosidase Aktivität wurden für jede AtbZIP-Kombination mit zwei biologischen und jeweils zwei technischen Replikaten durchgeführt, und die so erhaltenen Werte wurden mit Standardabweichungen in Diagramme aufgenommen, die in Abbildung 5.3 dargestellt sind.
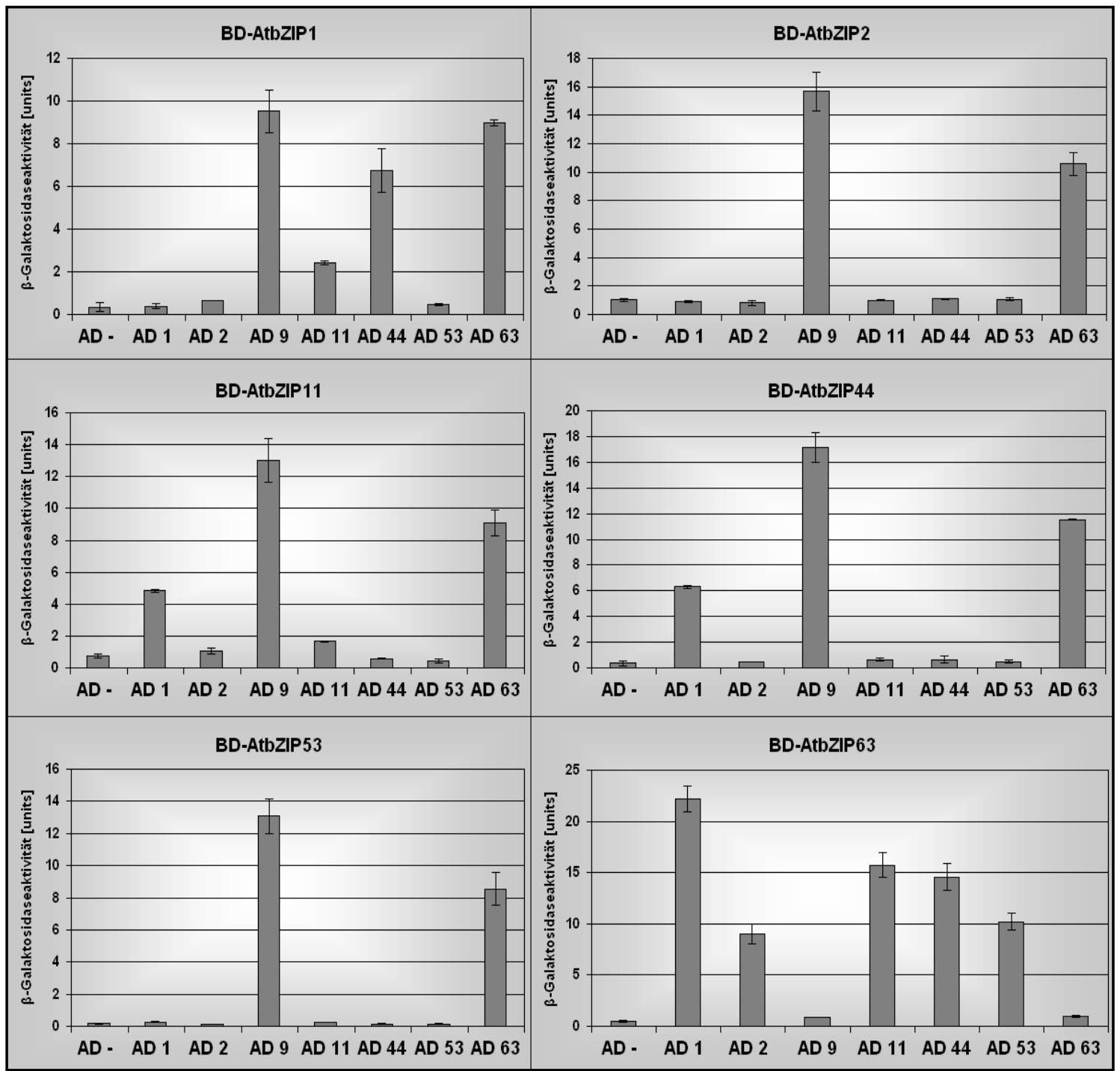

Abbildung 5.3: oNPG-Tests zur Quantifizierung von Protein-Protein Interaktionen zwischen AtbZIP-Transkriptionsfaktoren der Gruppen C und S1. Die verwendeten BD-Fusionen wurden mit dem Plasmid pDEST32 erzeugt, die AD-Fusionen mit dem Plasmid pDEST22. Die über den einzelnen Diagrammen angegebenen BD-Fusionen wurden mit AD-Fusionen von AtbZIP1 (AD1), AtbZIP2 (AD2), AtbZIP11 (AD11), AtbZIP44 (AD44), AtbZIP53 (AD53) und AtbZIP63 (AD63) in den Hefestamm MaV203 kotransformiert, und die Aktivität des lacZ-Reportergens wurde in oNPG-Tests für jeweils zwei unabhängige Kolonien in je zwei Messungen bestimmt. oNPG-Tests unter Verwendung einer BDAtbZIP9 $\Delta$ N Fusion lieferten keine brauchbaren Resultate (nicht gezeigt). 
In den oNPG-Tests konnten dabei die Ergebnisse der vorherigen Versuche bestätigt werden. Zudem konnten mit dieser Methode für AtbZIP1 neben Interaktionen mit den zur Gruppe C gehörenden Faktoren AtbZIP9 und AtbZIP63 auch deutliche Interaktionen mit den zur Gruppe S1 gehörenden Faktoren AtbZIP11 und AtbZIP44 gezeigt werden. Die Verwendung der AtbZIP9 4 N-BD Fusion lieferte allerdings auch in diesem System keine verwendbaren Daten (nicht gezeigt).

Mögliche Heterodimerisierungen zwischen den bisher untersuchten AtbZIPTranskriptionsfaktoren und den noch fehlenden Mitgliedern der Gruppen C und S wurden von Andrea Ehlert im Rahmen ihrer Diplomarbeit untersucht (Ehlert, 2004). Dort wurden für AtbZIP10 und 25 ebenfalls starke Interaktionen mit allen Gruppe S1 Mitgliedern gefunden. Starke Interaktionen zwischen Gruppe C und den Gruppen S2 oder S3 wurden hingegen nicht gefunden. Auch für die zur Gruppe S1 gehörenden AtbZIP-Transkriptionsfaktoren wurde keine oder nur schwache Interaktionen mit den Gruppen S2 oder S3 gefunden. Eine Übersicht der Interaktionen in Hefe ist in Abbildung 5.4 dargestellt.

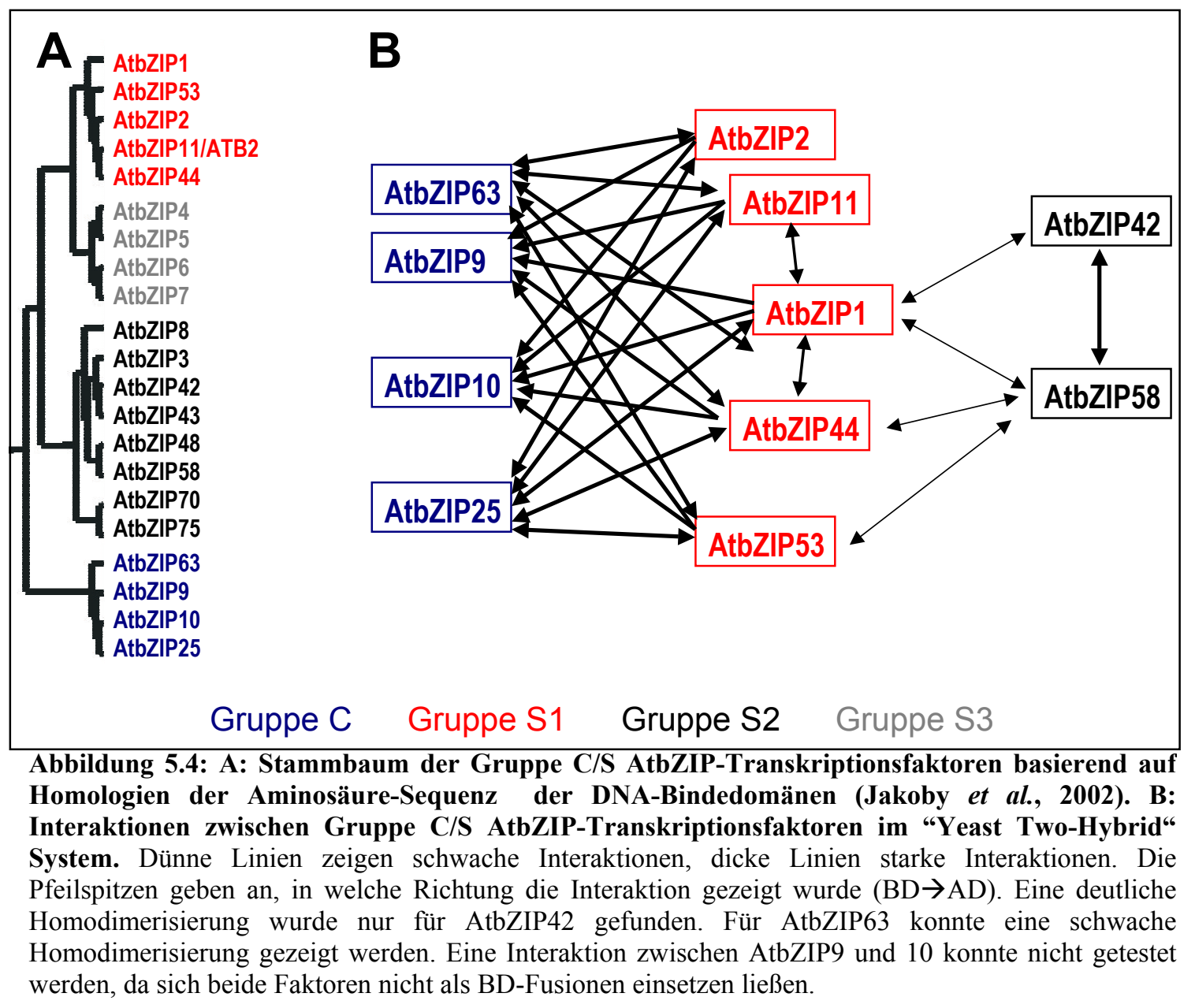


Um zu überprüfen, ob es sich bei den gezeigten Interaktionen wirklich um durch den Leucin Zipper vermittelte Dimerisierungen handelt, wurde ein mutiertes AtbZIP53Protein (AtbZIP53pp) erzeugt, bei dem die in der Leucin Zipper liegenden Aminosäuren Leucin58 und Alanin72 gegen Proline ausgetauscht wurden. Die Proline brechen die $\alpha-$ helikale Struktur des Leucin Zippers und verhindern so die Heterodimerisierung. Exemplarisch wurde die Interaktion dieser Mutante mit AtbZIP9 und AtbZIP10 getestet. Tatsächlich ließ sich hier keine Interaktion mehr nachweisen, was belegt, dass es sich bei den gezeigten Interaktionen wirklich um eine Zipper-vermittelte Heterodimerisierung handelt (Abbildung 5.5).

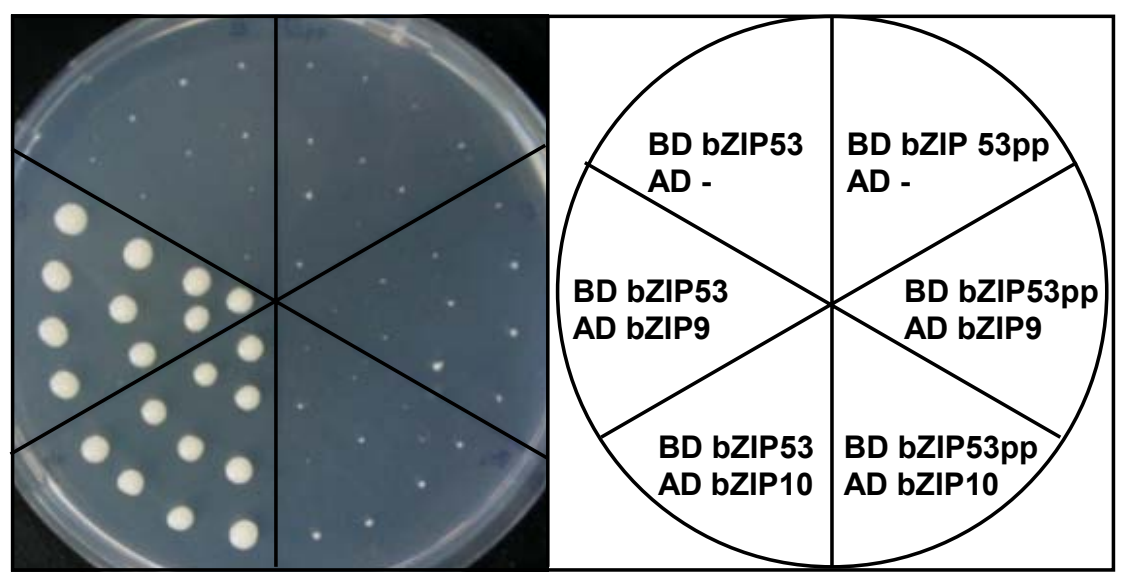

Abbildung 5.5: Tests unter Verwendung des $U R A$-Reportergens zeigen, dass die Zipper-Mutante AtbZIP53pp nicht mehr mit AtbtZIP9 oder AtbZIP10 interagieren kann. Kotransformanden der angegebenen BD- und AD-AtbZIP Fusionen wurden mit einem Zahnstocher angeimpft, auf der rechten Seite wurde AtbZIP53 mit mutierter Zipper-Domäne verwendet, auf der linken Seite als Kontrolle das nicht mutierte AtbZIP53. Als Hefestamm wurde MaV203 verwendet, die BDFusionen wurden mit dem Plasmid pDEST32 erzeugt, die AD-Fusionen mit dem Plasmid pDEST22. 


\subsection{Promotor-GUS Fusionen zeigen eine Kolokalisation von AtbZIP Transkriptionsfaktoren der Gruppen C und S1}

Kolokalisation ist eine Voraussetzung für die Heterodimerisierung. In einem ersten

Experiment wurde die Gewebe-spezifische Expression von AtbZIP Transkriptionsfaktoren der Gruppen C und S1 mit Hilfe von Promotor-GUS Fusionen analysiert. Promotor-GUS Fusionen bieten hier gegenüber Northern-Analysen zwei entscheidende Vorteile. Zum einen lassen Northern-Analysen nur begrenzt Aussagen über die Gewebespezifität zu, da eine Isolation z.B. von Zellen des Phloems oder von Schließzellen technisch kaum $\mathrm{zu}$ realisieren ist. Zum anderen korreliert die Transkriptmenge nicht notwendigerweise mit der Menge an Protein, die letztlich für die Funktion entscheidend ist.

Gerade für die Gruppe S1 trifft dieses in besonderem Maße zu, da für sie eine Saccharose-induzierte Repression der Translation gezeigt wurde (Wiese et al., 2004). Promotor-GUS Fusionen hingegen sind eine Möglichkeit der Expressionsanalyse, die translationale Kontrollmechanismen zumindest zum Teil miteinbezieht, und die im Vergleich zum Northern eine genauere Darstellung der Gewebespezifität der Expression ermöglicht.

Für alle AtbZIP-Transkriptionsfaktoren des Heterodimerisierungsnetzwerkes stehen Linien mit Promotor-GUS Fusionen zur Verfügung. Die Promotor-GUS Linien für AtbZIP1 und AtbZIP53 wurden im Rahmen der vorangegangenen Diplomarbeit erzeugt (Weltmeier, 2002), und im Rahmen der Dissertation wurden mehrere unabhängige Linien mit vergleichbarer GUS-Aktivität identifiziert und über mehrere Generationen weitergezogen, um homozygote Pflanzen zu erhalten.

\subsubsection{AtbZIP-Transkriptionsfaktoren der Gruppen C und S1 zeigen überlappende gewebespezifische Expressionsmuster}

Die verschiedenen Promotor-GUS Linien wurden auf Erde angezogen. Nach 20 Tagen wurden Pflanzen mit 6-8 Blättern an der Wurzel kurz unterhalb der Erde abgeschnitten und mit 1mM X-Gluc / 1mM Kalium-Hexacyanoferrat 24h gefärbt (Abbildung 5.6). 
Während bei allen anderen Linien eine deutliche Färbung zu erkennen war, zeigten die Pro $_{A t b Z I P 25}$ :GUS und Pro ${ }_{A t b Z I P 53}:$ GUS Linien nur eine Färbung der Nebenblätter. Daher wurde für diese Linien die Färbung mit 2 und 4 mM X-Gluc / 1mM KaliumHexacyanoferrat wiederholt.

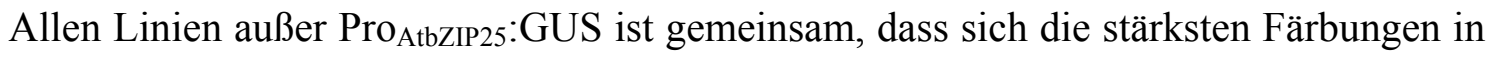
jungen Blattanlagen finden, und dass die GUS-Aktivität während der Entwicklung der Blätter zurückgeht, so dass die ältesten Blätter keine GUS-Aktivität mehr zeigen. Darüber hinaus ist in der Regel die GUS-Aktivität am Blattansatz höher als in der Blattspitze. In Pro AtbZIP9:GUS und Pro $_{A t b Z I P 10}$ :GUS Linien ist die GUS-Aktivität auf das Leitgewebe beschränkt, in den anderen Linien erstreckt sie sich über die ganze Blattspreite, ist aber auch dort im Leitgewebe am stärksten. Für ProAtbZIP9:GUS Pflanzen konnte in mikroskopischen Schnittpräparaten gezeigt werden, das die GUS-Aktivität auf das Phloem beschränkt ist (Xuan Wang, persönliche Mitteilung). Für die

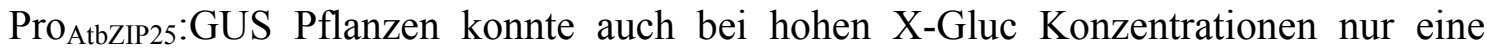

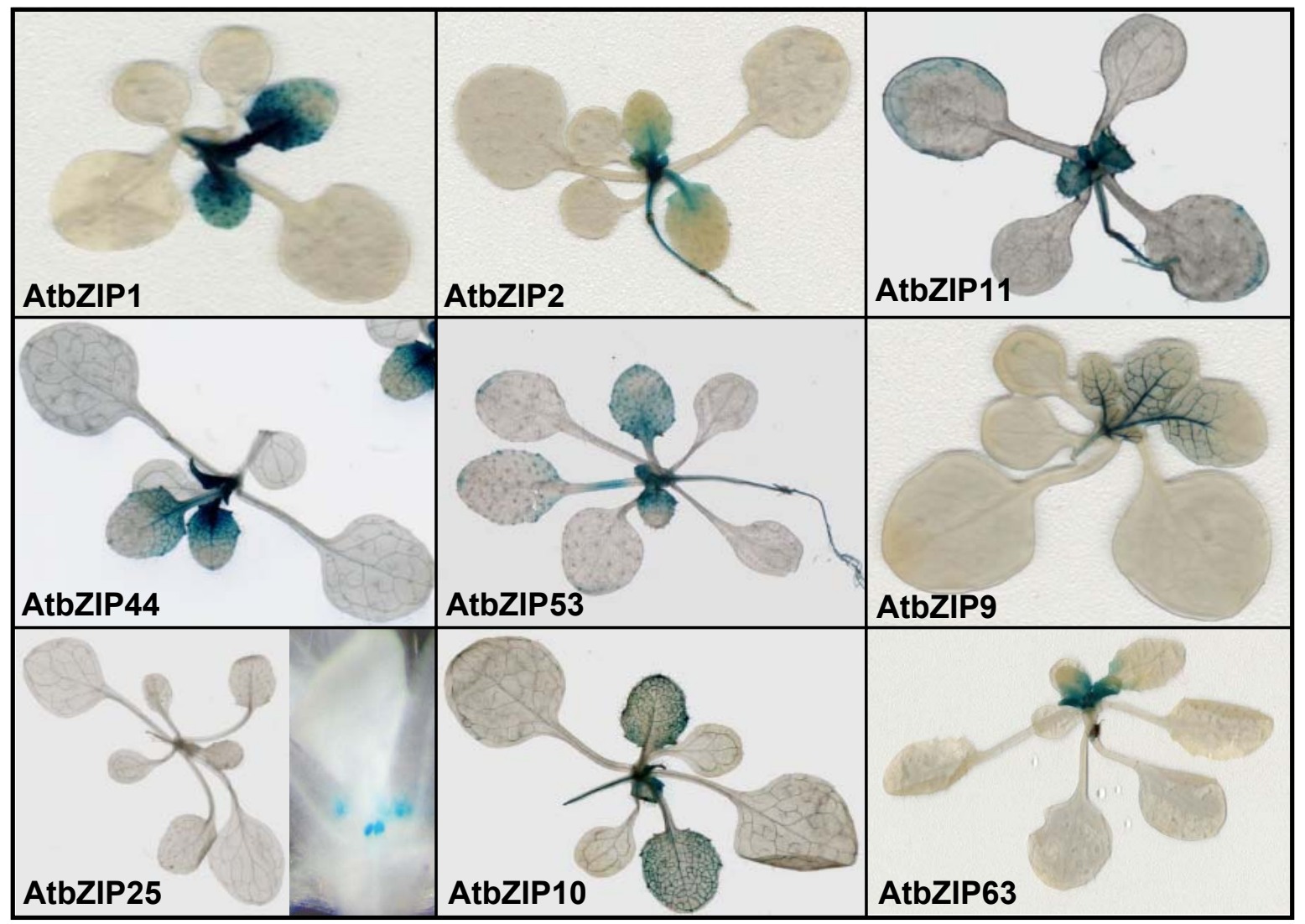

Abbildung 5.6: Histologische Färbungen von 20 Tage alten Promotor-GUS Pflanzen zum Nachweis der $\beta$-Glucuronidase-Aktivität zeigen eine Kolokalisation von AtbZIP-Transkriptionsfaktoren der Gruppen $\mathbf{C}$ und $\mathbf{S 1}$ in sich entwickelnden Blättern. Die Pflanzen wurden auf Erde angezogen, am Hypokotyl abgeschnitten, 20 Minuten in 90\% Aceton fixiert und anschließend 24 Stunden in 1mM X-Gluc /

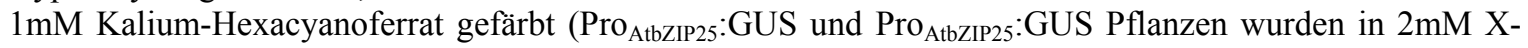
Gluc / 1mM Kalium-Hexacyanoferrat gefärbt). Für jedes Promotor-GUS Konstrukt ist eine repräsentative

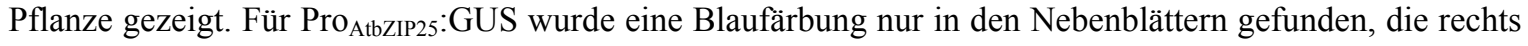
neben der Pflanze vergrößert dargestellt sind. 
Färbung der Nebenblätter gefunden werden. Die Färbungen wurden mit allen zur Verfügung stehenden Linien reproduziert, und vergleichbare Expressionsmuster wurden auch bei 5 Tage (erste echte Blätter erkennbar) oder 28 Tage alten Pflanzen gefunden. Im folgenden wurde untersucht, in welchen Geweben blühender Pflanzen eine GUSAktivität zu beobachten war. Die Daten sind in Tabelle 5.1 zusammengefasst. GUSAktivitäten wurden in praktisch allen Pflanzenteilen mit Ausnahme von älteren Blättern, also mit Ausnahme von Source-Geweben, gefunden. In vielen Geweben schwankten die GUS-Aktivitäten jedoch sehr stark, so dass dort wahrscheinlich andere Faktoren als die Gewebespezifität ausschlaggebend sind.

Tabelle 5.1: Übersicht über die Gewebe, in denen in den Promotor_GUS Linien der AtbZIP-Transkriptionsfaktoren der Gruppen C und S1 eine GUS-Aktivität beobachtet wurde. +: reproduzierbare GUS-Aktivität in diesem Gewebe; -: keine GUS-Aktivität in diesem Gewebe; $(+)$ : Die GUS-Aktivität in diesen Geweben ist starken Schwankung unterworfen; ${ }^{1}$ : GUS-Aktivität vorwiegend im Leitgewebe; ${ }^{2}$ : GUS-Aktivität vorwiegend in den Funikuli; ${ }^{3}$ : GUS-Aktivität vorwiegend in der Schotenhülle; ${ }^{4}$ : GUS-Aktivität vorwiegend Samenanlagen.

\begin{tabular}{|c|c|c|c|c|c|c|c|c|c|}
\hline \multirow{2}{*}{$\begin{array}{l}\text { AtbZIP- } \\
\text { Faktoren: }\end{array}$} & \multicolumn{5}{|c|}{ Gruppe S1 } & \multicolumn{4}{|c|}{ Gruppe C } \\
\hline & 1 & 2 & 11 & 44 & 53 & 9 & 10 & 25 & 63 \\
\hline Junge Blätter & + & + & + & + & + & $+{ }^{1}$ & + & + & + \\
\hline Alte Blätter & - & - & - & - & - & - & - & - & - \\
\hline Nebenblätter & + & + & + & + & + & + & + & + & + \\
\hline Trichome & + & + & $(+)$ & + & $(+)$ & - & + & - & - \\
\hline Hydathoden & $(+)$ & $(+)$ & $(+)$ & $(+)$ & $(+)$ & - & $(+)$ & - & - \\
\hline Stängel & $(+)$ & $(+)$ & $(+)$ & - & $(+)$ & +1 & $(+)$ & + & $(+)$ \\
\hline Wurzel & + & + & + & $(+)$ & $(+)$ & +1 & + & $(+)$ & + \\
\hline Wurzelspitze & + & + & + & + & + & + & + & + & + \\
\hline Blüteknospe & + & + & + & + & + & + & + & + & + \\
\hline Blütenblätter & $(+)$ & $(+)$ & $(+)$ & $(+)$ & $(+)$ & $+{ }^{1}$ & - & $(+)$ & - \\
\hline Kronblätter & + & $(+)$ & $(+)$ & $(+)$ & $(+)$ & $(+)^{1}$ & $(+)$ & - & $(+)$ \\
\hline Fruchtknoten & $(+)$ & + & $(+)$ & + & - & + & $(+)$ & $(+)$ & - \\
\hline Pollen & $(+)$ & $(+)$ & - & - & $(+)$ & - & - & $(+)$ & $(+)$ \\
\hline Konnektiv & - & - & + & + & - & + & + & - & - \\
\hline Junge schoten & 3 & 2,3 & 2,4 & 2,4 & - & 1,2 & 2 & 3 & 2,3 \\
\hline
\end{tabular}




\subsection{Erzeugung und Charakterisierung von Mutanten und ektopischen Überexpressionslinien der AtbZIP. Transkriptionsfaktoren 1, 53, 9 und 63}

Über die Funktion der an dem Heterodimerisierungsnetzwerk beteiligten Transkriptionsfaktoren war zu Beginn dieser Doktorarbeit wenig bekannt, lediglich für AtbZIP11 gab es Publikationen, in denen eine Regulation durch Licht und Zucker, sowie Daten zur gewebespezifischen Expression gezeigt werden konnten (Rook et al., 1998a; Rook et al., 1998b). Da für das Verständnis der Bedeutung der Heterodimerisierung ein Verständnis der Funktion der einzelnen Heterodimerisierungspartner notwendig ist, sollte versucht werden diese zu charakterisieren.

Um Funktionen mit Hilfe von Phänotypen zu belegen wurden mehrere transgene Linien mit einer ektopischen Überexpression der AtbZIP-Transkriptionsfaktoren erzeugt. Darüber hinaus wurden in der SALK Sammlung von T-DNA Insertionslinien Mutanten der AtbZIP-Transkriptionsfaktoren identifiziert und anschließend charakterisiert. Die so erhaltenen Linien sollten neben der phänotypischen Charakterisierung auch zur Identifizierung von Zielgenen durch Mikroarray-Experimente, Chromatin-IP und Northern-Analysen genutzt werden.

Da parallel zu dieser Arbeit eine funktionelle Charakterisierung von AtbZIP10 und AtbZIP25 durch unseren Kollaborationspartner Jesus Vincente-Carbajosa von der Universität Madrid und eine funktionelle Charakterisierung von AtbZIP2, 11 und 44 durch unseren Kollaborationspartner Sjef Smeekens von der Universität Utrecht erfolgen sollte, wurde ein besondere Schwerpunkt auf AtbZIP1, 53, 9 und 63 gelegt.

\subsubsection{Ektopische Expression von AtbZIP-Transkriptionsfaktoren der Gruppen C und S1 unter Kontrolle des 35S-Promotors}

Zur Erzeugung transgener Linien mit einer ektopischen Überexpression wurden AtbZIP1, 2, 11, 44, 53, 9 und 63 mit der Gateway-Technik in den Pflanzen- 
Transformationsvektor pAlligator2 rekombiniert. Dieser Vektor enthält einen $35 S$ Promotor sowie einen HA-tag, der N-terminal an das in den Vektor rekombinierte Gen fusioniert wird. Die so entstandenen Plasmide wurden in den Agrobacterium tumefaciens Stamm GV3101 (Koncz und Schell, 1986) transformiert. Nach der Transformation gewachsene Kolonien wurden per PCR mit dem Primern 35S sowie einem AtbZIP-spezifischen Rückwärtsprimer auf Anwesenheit des Plasmids getestet.

Positiv getestete Agrobacterium-Klone wurden anschließend genutzt, um Arabidopsis thaliana nach der "floral dip" Methode stabil zu transformieren (Clough und Bent, 1998). Der Vektor pAlligator2 verwendet als Selektionsmarker ein unter Kontrolle eines samenspezifischen Promotors stehendes GFP. Dieser Selektionsmarker bewirkt, das transgene Samen grün fluoreszieren. Die nach der Transformation gesammelten Samen wurden unter einem Fluoreszenzmikroskop auf diese Expression des GFP hin untersucht, und für alle transformierten Konstrukte konnten transgene Samen identifiziert werden.

Von den transgenen Samen mit den Konstrukten zur Überexpression von AtbZIP2, 11, 44 oder 53 sind viele deutlich kleiner als nicht transformierte, d.h. keine GFPExpression zeigende, Samen (Abbildung 5.7 A).

Samen mit deutlicher GFP-Aktivität wurden auf Erde ausgelegt. Mehrere der mit dem Konstrukt für eine ektopische Überexpression von AtbZIP11, 44 oder 53 transformierten Linien zeigten einen deutlichen, zum Teil extremen Zwergwuchs (Abbildung 5.7 B-E). Des weiteren sind viele der ausgelegten Samen dieser Linien nicht gekeimt, was dafür sprechen könnte, dass eine starke Überexpression dieser AtbZIPTranskriptionsfaktoren letal ist.

Samen von einer 35S:AtbZIP53 Linie sowie von einer atbzip53 Mutante (siehe 5.3.2) wurden 4 Tage im Dunkeln auf feuchtem Whatman Papier angezogen, um den Effekt der Überexpression auf das Streckungswachstum des Hypokotyls zu beobachten. Dabei zeigten die AtbZIP53 überexprimierende Pflanzen ein deutlich kürzeres Hypokotyl als der Wildtyp. Das Hypokotyl der atbzip53 Mutanten war leicht länger, der Unterschied lag jedoch im Bereich der natürlichen Schwankungen zwischen einzelnen Individuen (Abbildung 5.8). 

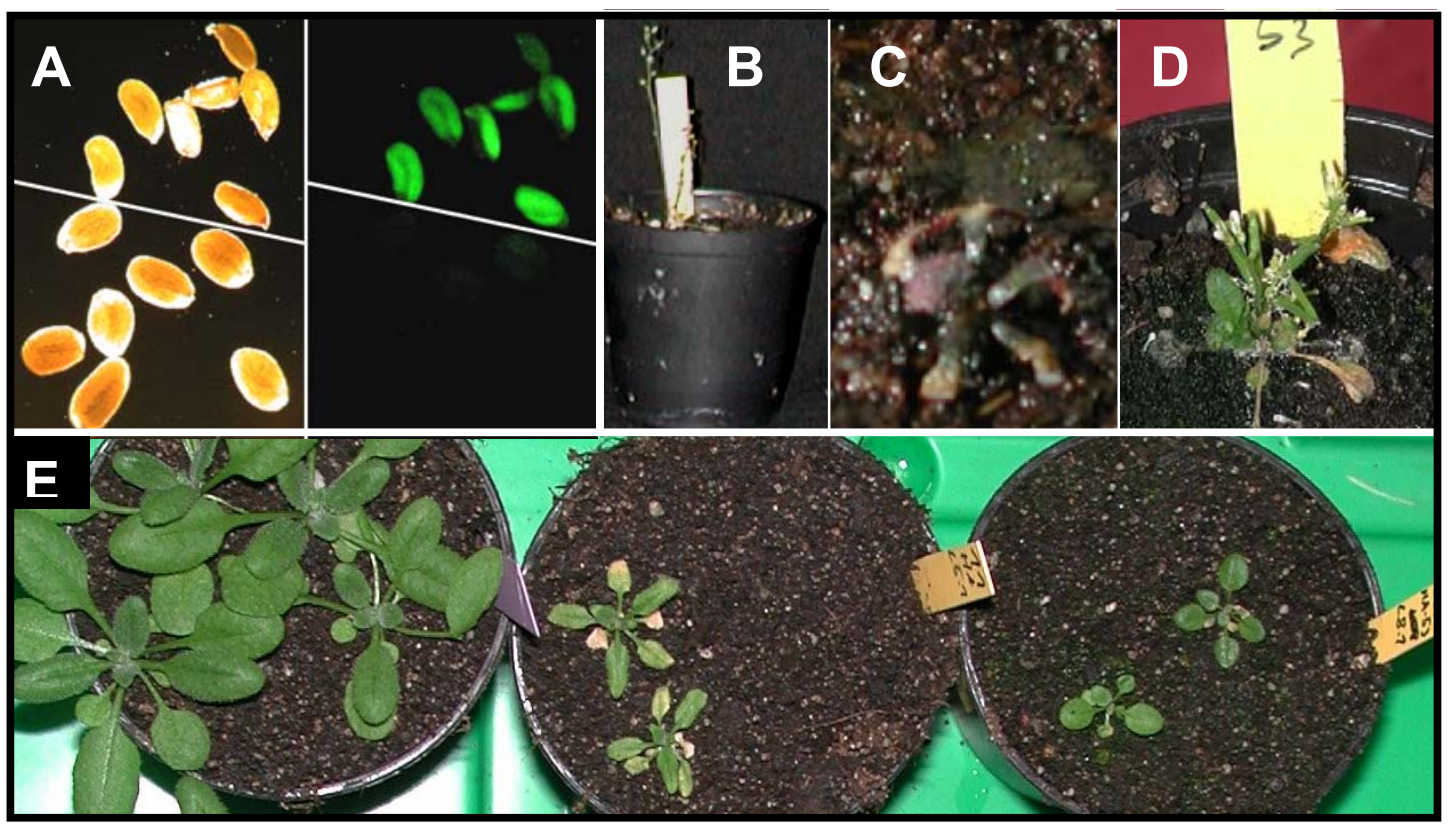

Abbildung 5.7: Phänotypen von Pflanzen mit ektopischer Überexpression von AtbZIP11, 44 oder 53. A: T1-Samen aus der Transformation zur AtbZIP11-Überexpression. Transformierte, GFPExpression zeigende Samen sind kleiner als nicht transformierte Samen. B-D: 6 Wochen alte Überexpressionspflanzen mit extremem Zwergphänotyp, $T_{1}$ Generation. (B:AtbZIP11; C:AtbZIP44; D:AtbZIP53). Diese Pflanzen produzierten keine keimungsfähigen Samen. E: 24 Tage alte Überexpressionspflanzen mit deutlichem Zwergphänotyp, $T_{2}$ Generation. Links Wildtyp; Mitte 35S:AtbZIP11 (Linie 5.1); Rechts 35S:AtbZIP53 (Linie 8.1)

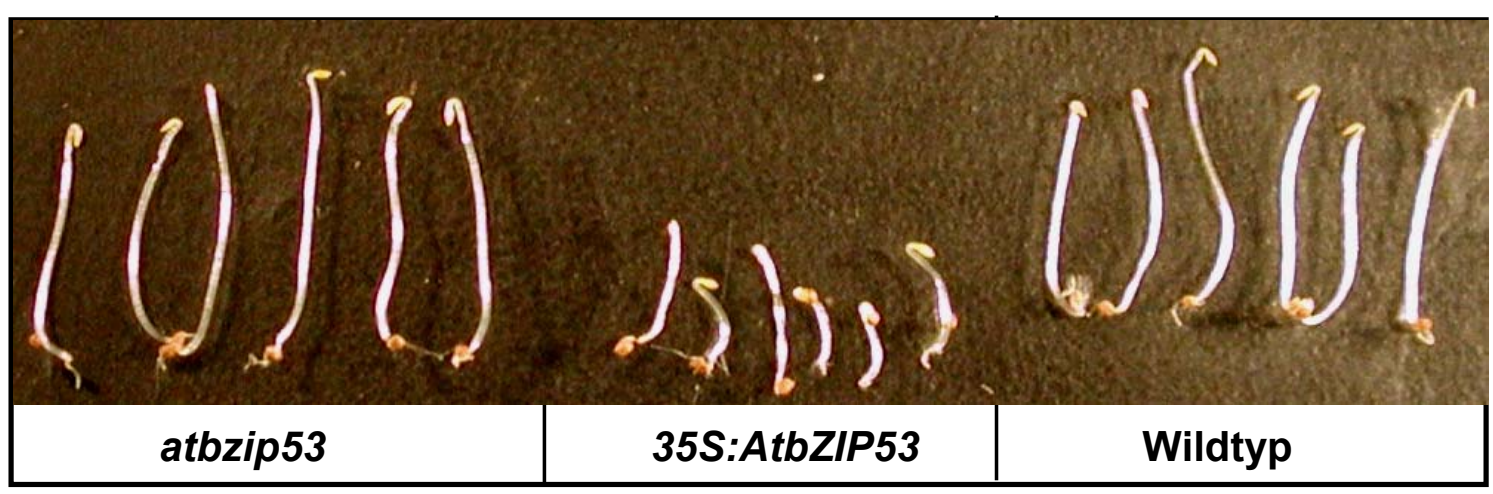

Abbildung 5.8: Reduziertes Streckungswachstum des Hypokotyls in 35S:AtbZIP53 Pflanzen bei Keimung im Dunkeln. Die Samen wurde auf feuchtem Wattman Papier ausgelegt, 3 Tage bei $4^{\circ} \mathrm{C}$ stratifiziert, und anschließend 4 Tage bei Raumtemperatur ausgekeimt. Der Versuch wurde mit zwei unabhängigen AtbZIP53 Überexpressionslinien reproduziert.

Die erhaltenen transgenen Pflanzen wurden in Western-Analysen auf die Expression der HA-AtbZIP Fusionsproteine untersucht. Für AtbZIP1, 53, 9 und 63 konnten mehrer Linien mit einer deutlichen Expression identifiziert werden, wobei die HA-AtbZIP Fusionsprotein langsamer liefen als die berechneten Molekulargewichte erwarten ließen (siehe Abbildung 5.9). Linien mit extremen Phänotypen wie in Abbildung 5.8 B-D 
konnten nicht in Western-Analysen untersucht werden, da nicht genug Pflanzenmaterial vorhanden war. In Überexpressionslinien von AtbZIP2, 11 oder 44, die keinen Phänotyp zeigten, ließ sich in Western-Analysen auch die Expression von HA-getagtem Protein nicht nachweisen, so dass das Überexpressionskonstrukt in diesen Pflanzen wahrscheinlich nicht aktiv war.

Während die meisten der identifizierten HA-AtbZIP1 bzw. HA-AtbZIP9 Überexpressionslinien sich nicht erkennbar vom Wildtyp unterschieden, zeigten die AtbZIP1-Überexpressionslinie $\mathrm{H}$ sowie die AtbZIP9-Überexpressionslinie $\mathrm{X}$ einen buschigen Wuchs und verkümmerte Pollensäcke sowie Schoten (Abbildung 5.10). Dieser Phänotyp fand sich auch bei einem Teil der Nachkommen dieser beiden Linien. Beide Linien zeigten in Western-Analysen eine deutliche Überexpression, jedoch korreliert diese nicht direkt mit dem Phänotyp, da andere Linien mit einer vergleichbaren oder stärkeren Expression diesen Phänotyp nicht zeigten. Somit bleibt es fraglich, ob der beobachtete Phänotyp auf die Überexpression zurückzuführen ist.

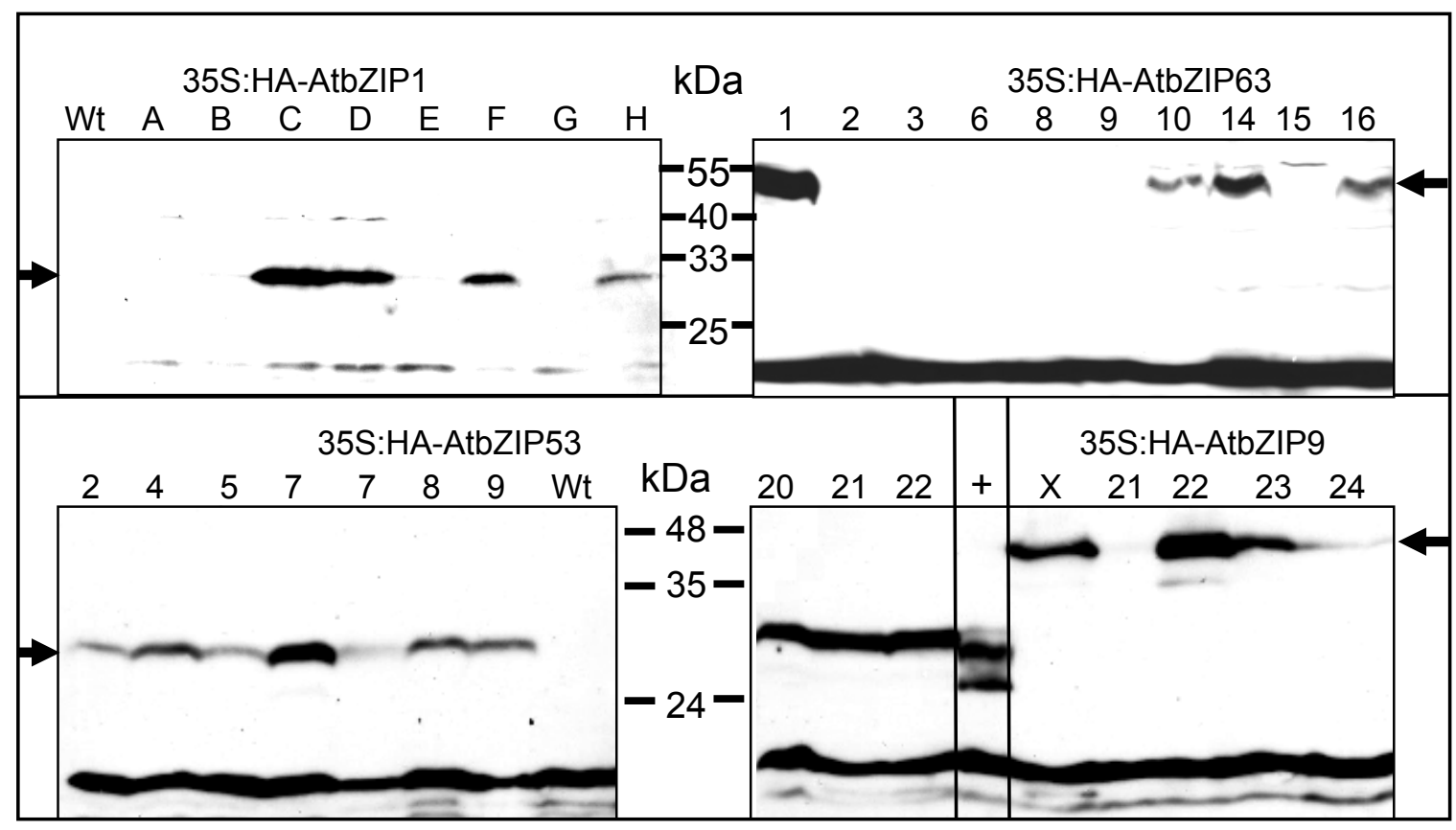

Abbildung 5.9: Western-Analysen verschiedener 35S:HA-AtbZIP Überexpressionslinien. Die Detektion fand mit einem anti-HA Antikörper statt, detektierte HA-AtbZIP Fusionsproteine sind durch schwarze Pfeile gekennzeichnet. Die bei etwa $16 \mathrm{kDa}$ auftretende Bande ist eine für den anti-HA Antikörper typische Hintergrundbande in Arabidopsis. Die Buchstaben und Zahlen über den einzelnen Gelspuren kennzeichnen die verschiedenen Linien, + steht für eine Positivkontrolle. Von auf Erde angezogenen Pflanzen wurde Blattmaterial geerntet und daraus mit Harnstoff-Extraktionspuffer Proteinextrakte gewonnen. Jeweils $30 \mu \mathrm{l}$ Proteinextrakt wurden auf ein 15\% SDS-Gel aufgetragen. (Berechnet Molekulargwichte: HA-AtbZIP1: 24 kDa; HA-AtbZIP53: 24,5 kDa; HA-AtbZIP9: 38,1 kDa; HA-AtbZIP63: 41,8 kDa) 

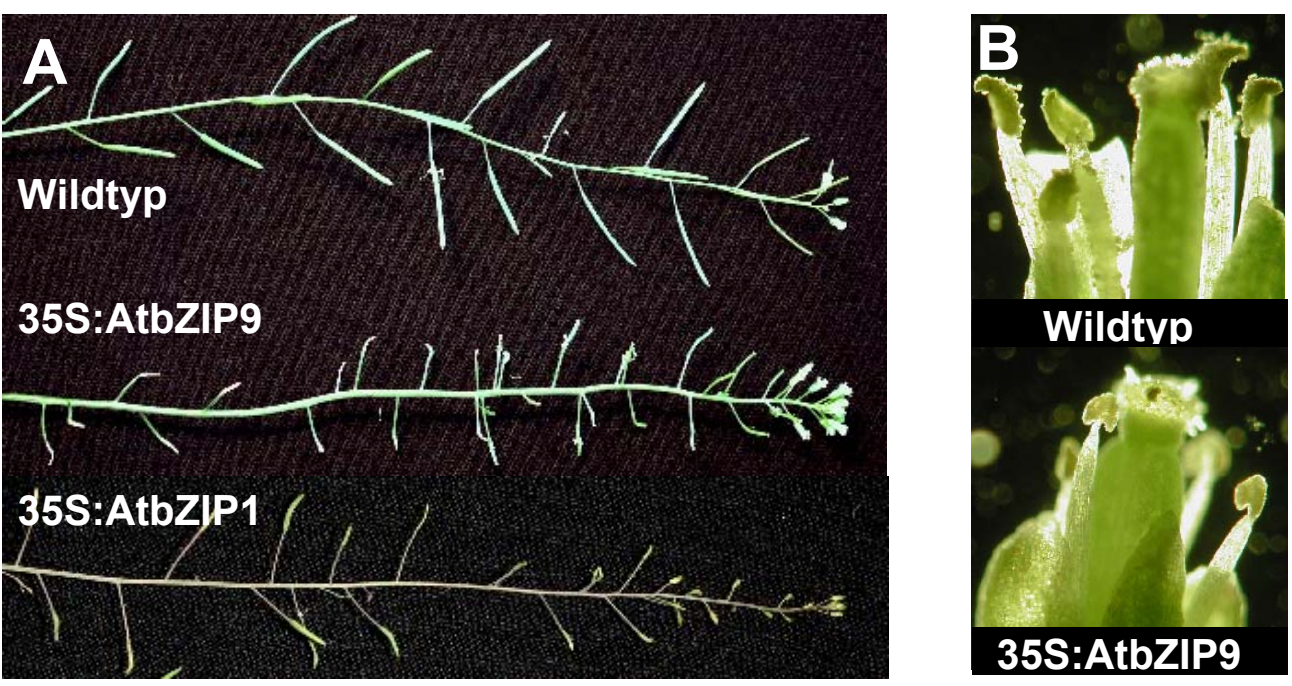

Abbildung 5.10: A: Blütenstände von ektopischen AtbZIP1 oder AtbZIP9 Überexprimierern sowie Wildtyp-Pflanzen. Die Pflanzen waren 7 Wochen alt und wurden unter Langtag angezogen. Die Schoten der Überexpressionspflanzen sind verkümmert und enthalten kaum Samen. B: Nahaufnahme von Blüten zum Zeitpunkt der Bestäubung. Die Pollensäcke der ektopischen AtbZIP9 Überexpressionspflanzen sind verkümmert.

\subsubsection{Identifizierung und Charakterisierung von T-DNA Insertionsmutanten}

Ektopische Überexpression ist ein wertvolles Hilfsmittel für die funktionelle Charakterisierung eines Gens, kann jedoch auch zu irreführenden Ergebnissen führen, z.B. da das ektopisch exprimierte Gen Funktionen in Geweben ausüben kann, in denen es normalerweise gar nicht exprimiert wird. Daher ist es notwendig, neben den ektopischen Überexprimierern auch Mutanten ohne oder mit reduzierter Expression der AtbZIP-Transkriptionsfaktoren zu charakterisieren.

Eine Methode zur Erzeugung solcher Mutanten ist die T-DNA Mutagenese (Alonso et al., 2003). Die Insertion einer T-DNA in ein Gen kann zum Verlust oder zu einer Reduzierung der Genfunktion führen. Da die Integration der T-DNA in das PflanzenGenom zufällig erfolgt, lassen sich Gene auf diese Weise nicht gezielt ausschalten. Es sind jedoch von mehreren Instituten große Sammlungen von T-DNA Insertionsmutanten erstellt worden. Durch TAIL-PCR (Alonso et al., 2003) wurden die an die T-DNA Insertionsstellen angrenzenden Sequenzen gewonnen, die dann mit der Sequenz des $A$. thaliana Genoms verglichen wurden, um den Insertionsort der T-DNA 
und damit das eventuell mutierte Gen zu ermitteln. Diese Daten sind in einer Datenbank zusammengefasst, in der sich nach Mutanten für das gewünschte Gen suchen lässt (SIGnAL "T-DNA Express" Arabidopsis Gene Mapping Tool, (Alonso et al., 2003); http://signal.salk.edu/cgi-bin/tdnaexpress).

Verfügbare Mutanten von AtbZIP-Transkriptionsfaktoren der Gruppen C/S1 im Ökotyp Columbia wurden bei dem NASC stock center bestellt. Da die Angaben in der Datenbank zum Teil fehlerhaft sind, wurde das Vorhandensein der in der Datenbank angegebenen T-DNA Insertionen mit Hilfe von PCR-Analysen verifiziert. Dabei konnten für zwei Linien eine Insertion im Kodierbereich von AtbZIPl bestätigt werden (SALK_059343, SALK_069489), für eine Linie eine Insertion im Kodierbereich von AtbZIP9 (SALK_093416) und für zwei weitere Linien eine Insertion im 5'untranslatierten Bereich von AtbZIP53 (SALK_069883) bzw. AtbZIP63 (SALK_066531). Für die Linien SALK_004675 (AtbZIP53) und SALK_111897 (AtbZIP9) konnten die in der Datenbank angegebenen T-DNA Insertionen nicht bestätigt werden.

Die positiv getesteten Linien wurden bis zur T2-Generation weitergezogen und mittels PCR wurden homozygote Linien identifiziert (Abbildung 5.11). Eine Übersicht über die vorhandenen T-DNA Insertionsmutanten findet sich auf der folgenden Seite (Abbildung 5.12).

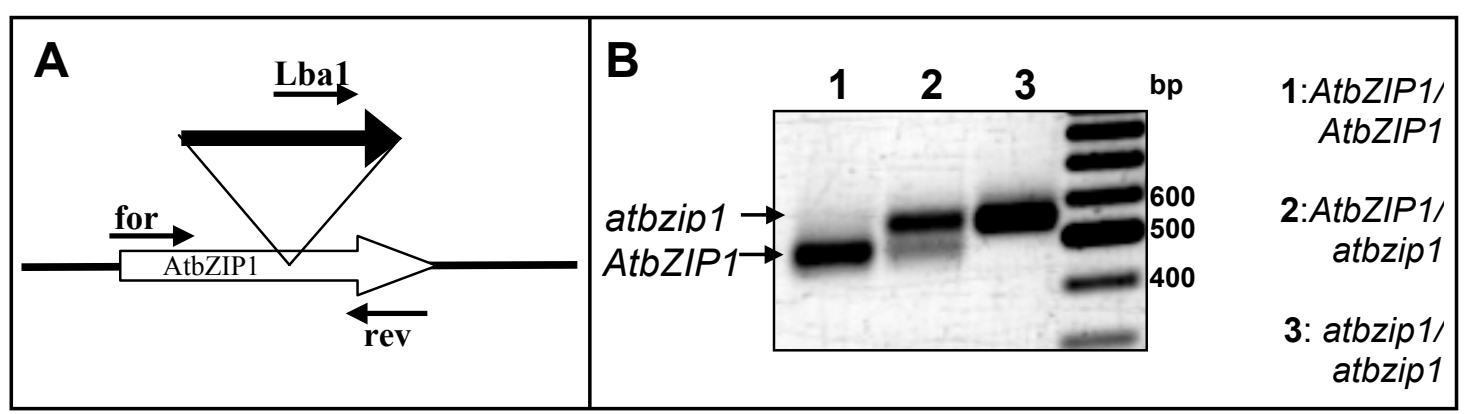

Abbildung 5.11: 3-Primer PCR zur Charakterisierung einer atbzip1 T-DNA Insertionsmutante. A: Die drei verwendeten Primer sind ein genspezifischer Vorwärtsprimer (for), ein genspezifischer Rückwärtsprimer (rev) sowie ein T-DNA spezifischer Primer (Lba1). Im Wildtyp bilden nur for und rev ein PCR-Produkt (hier 500bp), in der homozygoten Mutante nur Lbal und rev (hier 550bp). In Heterozygoten Pflanzen treten beide Banden auf. B: Agarosegel mit den PCR-Produkten von Wildtyp, einer heterozygoten sowie einer homozygoten T-DNA Insertionsmutante. 
Arabidopsis T-DNA Insertionsmutanten:

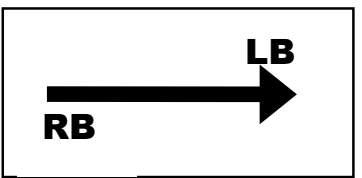

AtbZIP1:

SALK_059343: ORF, 300 Basenpaare hinter dem ATG

SALK_069489: ORF, 342 Basenpaare hinter dem ATG

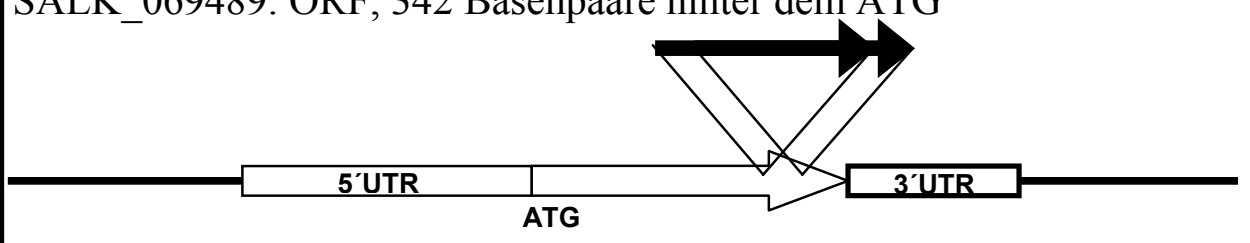

AtbZIP53:

SALK_069883: 5'UTR, 430 Basenpaare vor dem ATG

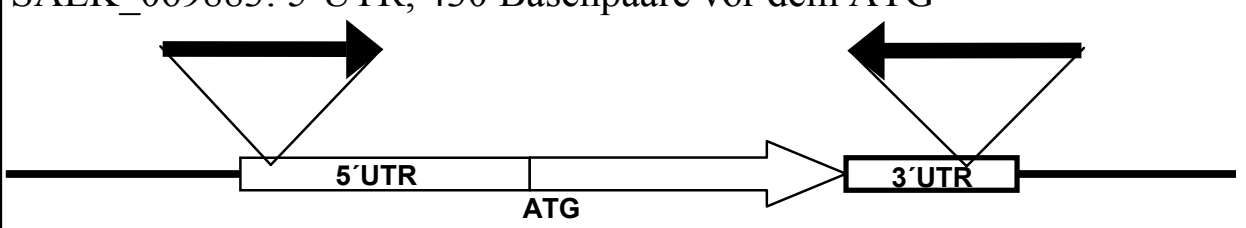

AtbZIP9:

SALK_093416: 3. Exon, 554 Basenpaare hinter dem ATG

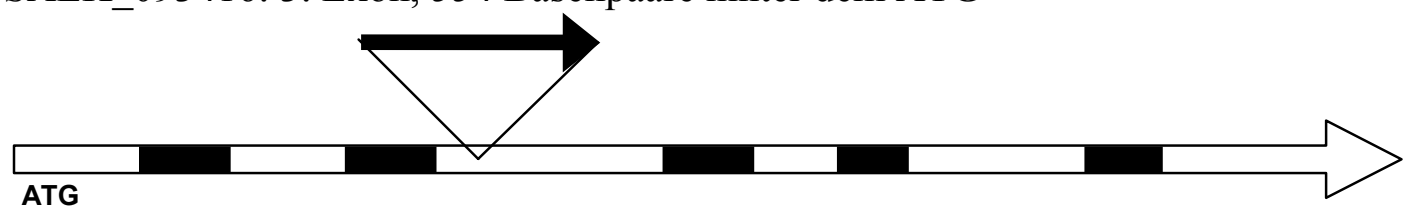

AtbZIP63:

SALK_066531: 5'UTR, 49 Basenpaare vor dem ATG

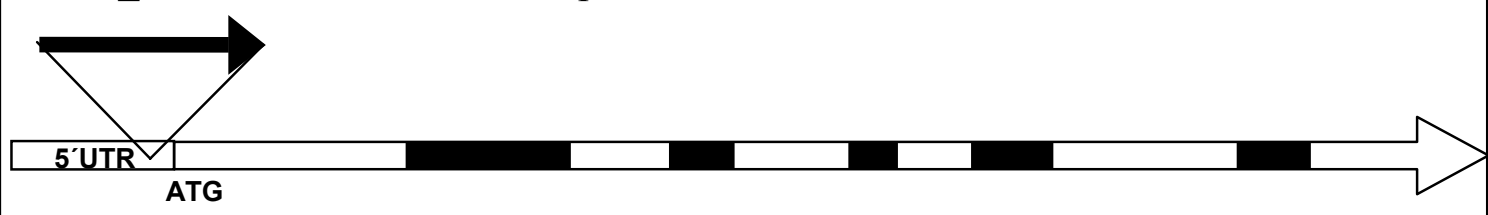

Abbildung 5.12: Übersicht über die in dieser Arbeit charakterisierten T-DNA Insertionsmutanten. Exons sind weiß dargestellt, Introns schwarz, 3' und 5' untranslatierte Bereiche sind beschriftet (3'UTR, 5'UTR). Die T-DNA ist als schwarzer Pfeil dargestellt, die Pfeilspitze gibt die Position der linke TDNA Grenz Sequenz an. Die T-DNA ist nicht maßstabsgerecht wiedergegeben. Zu jeder T-DNA Insertionslinie ist der Insertionsort sowie der Abstand zum ATG angegeben. LB: linke T-DNA Grenz Sequenz; RB: rechte T-DNA Grenz Sequenz; ORF: offenes Leseraster; UTR: Untranslatierter Bereich. 
Die Transkriptmengen der AtbZIP-Transkriptionsfaktoren in den homozygoten T-DNA Insertionsmutanten, im Wildtyp und in verschiedenen Überexpressionslinien wurden in Northern Analysen verglichen (Abbildung 5.13). Dazu wurden zwei Wochen alte Pflanzen aus Sterilkultur verwendet. Für AtbZIP1, 9 und 63 konnte in den Mutanten kein Transkript mehr detektiert werden, während in den Überexpressionslinien ein deutlich stärkeres Signal als im Wildtyp detektiert wurde.

Mit 1242 Basenpaaren ist die AtbZIP53 mRNA deutlich länger als der eigentliche Kodierbereich (441bp), was auf den langen 5'UTR zurückzuführen ist. Da dieser 5'UTR im Transkript des AtbZIP53 Überexpressionskonstruktes fehlt, ist es deutlich kürzer. Für AtbZIP1 ist dieser Unterschied nicht so deutlich, da hier die mRNA nur 907bp lang ist, während der Kodierbereich mit 474bp sogar länger als der von AtbZIP53 ist. In Northern-Analysen zur Expression von AtbZIP53 wurden meistens zwei Banden detektiert, die auch hier zu sehen sind.

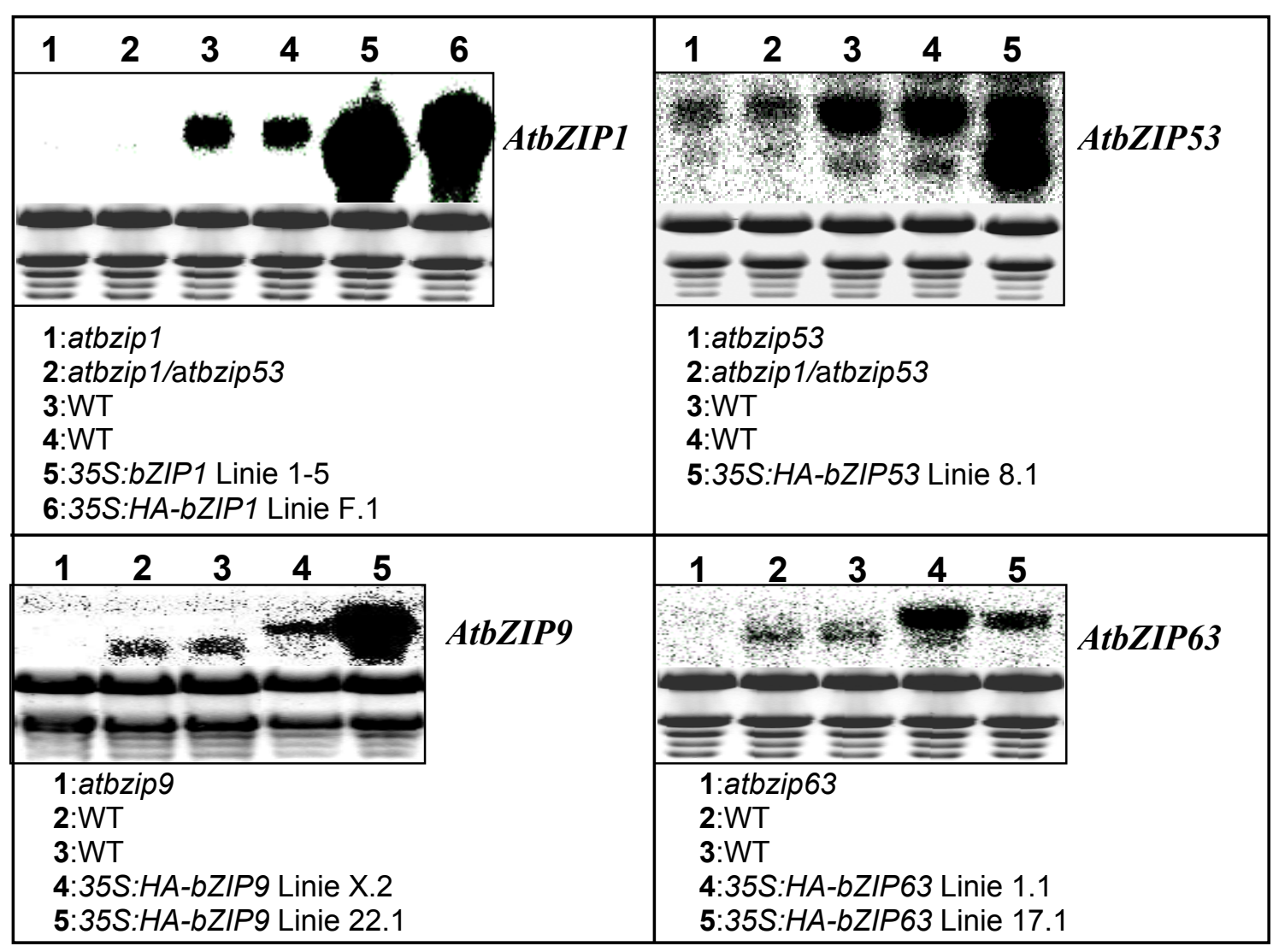

Abbildung 5.13: Charakterisierung homozygoter T-DNA Insertionsmutanten sowie einzelner Überexpressions- Linien von AtbZIP1, 53, 9 und 63 durch Northern Analysen. Die RNA wurde aus 2 Wochen alten, in Sterilkultur auf 2MS Medium angezogenen Pflanzen isoliert. Die verwendeten T-DNA Insertionsmutanten sind SALK_059343 (atbzip1), SALK_069883 (atbzip53), SALK_066531 (atbzip63) und SALK_93416 (atbzip9). 
Die obere, stärkere Bande läuft deutlich langsamer als die des Überexpressionskonstruktes, und ist damit eher dem erwarteten Transkript zuzuordnen. Die schwächere, untere Bande läuft etwa auf einer Höhe mit Transkript des Überexpressionskonstruktes. Interessanterweise sind beide Banden in der atbzip53Mutante deutlich schwächer, so dass es sich bei der unteren Bande möglicherweise um ein kürzeres Transkript von AtbZIP53 handelt. Da das AtbZIP53-Transkript noch detektierbar ist, ist die Linie als Knock-down einzustufen.

Die Mutanten zeigten keine offensichtlichen Phänotypen. Da dies möglicherweise auf eine funktionelle Redundanz der Faktoren zurückzuführen ist, wurden durch Kreuzung der Mutanten der jeweils ähnlichsten AtbZIP-Transkriptionsfaktoren atbzip1/atbzip53 und atbzip9/atbzip63 Doppel-Mutanten erzeugt. Jedoch zeigten auch diese Linien keine auffälligen Phänotypen. 


\subsection{Prolindehydrogenase ist ein Zielgen von AtbZIP. Transkriptionsfaktoren der Gruppen C und S1}

Prolindehydrogenase (ProDH) ist ein Enzym, welches den ersten Schritt der Degradation der Aminosäure Prolin katalysiert. Prolin wird als kompatibles Osmolyt unter osmotischem Stress akkumuliert, wo es außerdem als Schutz vor Hydroxylradikalen dienen könnte (Delauney und Verma, 1993; Schobert und Tschesche, 1978; Smirnoff und Cumbes, 1989). Unter hypoosmolaren Bedingungen wie etwa nach Ende von osmotischem Stress wird die ProDH induziert und katalysiert den Abbau von Prolin (Peng et al., 1996).

Neben der Funktion unter hypoosmotischem Stress wird für die ProDH auch eine Funktion in der Pollen- und Samenentwicklung vermutet (Nakashima et al., 1998; Verbruggen et al., 1996). Hier könnte Prolin als eine schnell verfügbare Quelle von Stickstoff, Kohlenstoff und Reduktionsequivalenten dienen (Blum und Ebercon, 1976; Skubatz et al., 1989). In einem transienten Expressionssystem in Protoplasten konnten (Satoh et al., 2004) zeigen, dass AtbZIP2, 11, 44 und 53, nicht jedoch AtbZIP1, an ein ACTCAT-Motiv aus dem ProDH-Promotor binden und die Transkription aktivieren.

\subsubsection{AtbZIP53 und AtbZIP1 regulieren die Expression der ProDH}

Um zu überprüfen, ob die Transkriptionsfaktoren AtbZIP1 und AtbZIP53 in planta die Expression der ProDH regulieren können, wurden durch Northern Analysen die Transkriptmenge der ProDH in Pflanzen mit veränderter Expression von AtbZIPl oder AtbZIP53 quantifiziert. Dabei wurde eine konstitutive Expression der ProDH nicht nur in 35S:AtbZIP53 Pflanzen, sondern, im Widerspruch zu den Daten von Satoh et al. (2004), auch in 35S:AtbZIP1 Pflanzen gefunden (Abbildung 5.14). Die konstitutive Expression der ProDH in 35S:AtbZIP53 oder 35S:AtbZIP1 Pflanzen konnte sowohl mit Pflanzen aus Sterilkultur auf 2MS-Medium, als auch mit auf Erde angezogenen Pflanzen, mehrfach reproduziert werden.

Für die ProDH wird eine Induktion innerhalb einer Stunde durch eine Hypoosmolaritätsbehandlung beschrieben, bei der Pflanzen aus 2MS-Sterilkultur in Wasser transferiert werden (Nakashima et al., 1998). AtbZIP1 und AtbZIP53 werden 


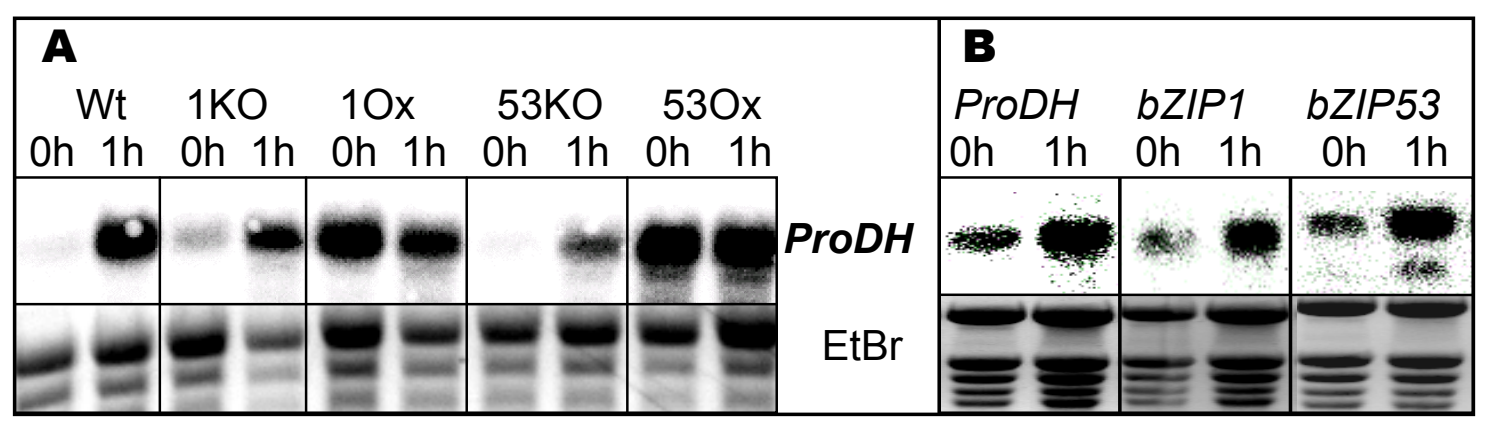

Abbildung 5.14: AtbZIP53 und AtbZIP1 regulieren die Expression der ProDH. A: Induktion der ProDH in Wildtyp (Wt), atbzipl (1KO), 35S:AtbZIP1 (1Ox), atbzip53 (53KO) und 35S:AtbZIP53 (530x) Pflanzen nach Hypoosmolaritäts-Behandlung. Die Pflanzen wurden in Sterilkultur auf MS Medium mit 2\% Saccharose angezogen und für eine Stunde in destilliertes Wasser transferiert. In Northern Analysen sieht man die von Satoh et al. beschriebene Induktion. Bei den Null Stunden Werten (0h) sieht man eine konstitutive Expression der $P r o D H$ in den beiden Überexpressionslinien, im Vergleich der 1 Stundenwerte (1h) eine schwächere Induktion der ProDH in den beiden Mutanten. Die Resultate wurden mehrfach reproduziert. EtBr: Etidiumbromid-Färbung der verwendeten RNA-Gele zum Nachweis gleichmäßiger Beladung. B: AtbZIP1 und AtbZIP53 werden nach HypoosmolarotätsBehandlung innerhalb einer Stunde induziert. Wildtyppflanzen wurden in Sterilkultur auf MS Medium mit $0,5 \%$ Saccharose angezogen $(0 \mathrm{~h})$ und für eine Stunde in destilliertes Wasser transferiert (1h). In Northern-Analysen zeigt sich parallel zur Induktion der ProDH auch eine Induktion von AtbZIPl und AtbZIP53. Die Resultate wurden mehrfach reproduziert.

unter diesen Bedingungen ebenfalls induziert und kommen somit als Aktivatoren der ProDH nach Hypoosmolaritäts-Induktion in Frage (Abbildung 5.14). Die Induktion der ProDH durch Hypoosmolarität ist in atbzipl bzw. atbzip53 Mutanten gegenüber Wildtyp-Pflanzen reduziert, was ein weiterer Hinweis auf die Beteiligung dieser Faktoren an der Induktion ist.

\subsubsection{AtbZIP1, 53, 9, 63 und die ProDH werden durch Zuckermangel, AtbZIP53 und die ProDH auch durch Hypoosmolarität induziert}

Bei der von Nakashima et al. (1998) beschriebenen Hypoosmolaritätsbehandlung werden die Pflanzen nicht nur hypoosmolarem Stress ausgesetzt, ihnen wird auch der zuvor aus dem Medium verfügbare Zucker entzogen. Daher ist zu klären, ob die gesehenen Effekte wirklich auf der Änderung der Osmolarität beruhen, oder ob sie auf die Zuckerverarmung zurückzuführen sind. Dazu wurden Pflanzen in Sterilkultur auf MS-Medium angezogen, das neben Zucker auch PEG1000 als Osmotikum enthielt. Dadurch war es möglich, Hypoosmolarität (durch Transfer in entsprechendes Medium ohne PEG) von der Zuckerverarmung (durch Transfer in equimolares Medium ohne 
Zucker) zu trennen. Als Zucker wurden sowohl Glukose als auch Saccharose verwendet. Da die Translation von AtbZIP1 und AtbZIP53 durch Saccharose, aber nicht durch Glukose reguliert wird (Anika Wiese, persönliche Mitteilung), war es interessant, ob eine Unterscheidung zwischen Glukose und Saccharose auch auf Transkriptionsebene stattfindet. Die Regulation der Gruppe C Heterodimerisierungspartner AtbZIP9, 10, 25 und 63 wurde ebenfalls untersucht. Zunächst ist zu erkennen, dass AtbZIP53 und die ProDH ähnlich reguliert werden (Abbildung 5.15). Beide Gene zeigen eine Induktion sowohl durch Hypoosmolarität als auch durch Zuckermangel, sind aber auch im Kontrollmedium induziert. Da die Medien, in welche die Pflanzen transferiert wurden, im Gegensatz zu dem Anzuchtmedium der Agar fehlt, haben sie alle eine niedrigere Osmolarität als das Anzuchtmedium, sodass es in allen Proben zu einer hypoosmolaren Induktion gekommen ist. Da jedoch die Induktion in dem Medium ohne Zucker (-Z) sowie in dem Medium mit niedriger Osmolarität $(\mathrm{H})$ stärker ist als in dem Kontrollmedium, ist anzunehmen, dass AtbZIP53

\begin{tabular}{|c|c|c|c|c|c|}
\hline $\begin{array}{c}\text { Oh } \\
\mathbf{G} \mathbf{S}\end{array}$ & \begin{tabular}{rrr|} 
& & \\
& $\mathbf{G}$ & \\
$-\mathrm{Z}$ & $\mathrm{K}$ & $\mathrm{H}$ \\
\end{tabular} & $\begin{array}{c}\mathbf{S} \\
-\mathrm{Z} K \mathrm{~K}\end{array}$ & 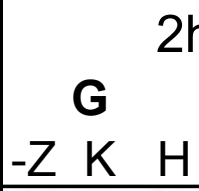 & $\begin{array}{c}\mathbf{S} \\
-\mathrm{Z} K \mathrm{~K}\end{array}$ & $\begin{array}{l}\text {-Z: Zuckerentzug } \\
\text { K: (Kontrolle) } \\
\text { H: Hypoosmolarität }\end{array}$ \\
\hline & & & - & - & $\begin{array}{l}\text { ProDH } \\
\text { EtBr }\end{array}$ \\
\hline & $=$ & -5 & 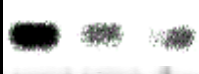 & 10 & AtbZIP53 \\
\hline & 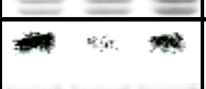 & $\begin{array}{l}\equiv \equiv \equiv \\
\equiv\end{array}$ & $=1$ & $\frac{\equiv}{\equiv}$ & AtbZIP1 \\
\hline$=$ & $\equiv=$ & 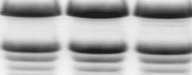 & $=0$ & $=-2$ & $\mathrm{EtBr}$ \\
\hline 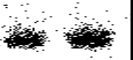 & \% & $1 \%$ & he $/ 6$ & $64 k$ & AtbZIP63 \\
\hline & & & & & EtBr \\
\hline
\end{tabular}

Abbildung 5.15: Northern Analysen zur Differenzierung zwischen einer Induktion durch Hypoosmolarität oder durch Zuckerverarmung. In der ersten Zeile über den Northern ist der Zeitpunkt der Probennahme angegeben, in der zweiten Zeile, ob die Anzucht auf MS-Medium mit 70,8 mM PEG1000 und entweder 29,2 mM Glukose (G) oder 29,2 mM Saccharose (S) erfolgte. In der dritten Zeile ist angegeben ob die Induktion mit $100 \mathrm{mM}$ PEG1000 (-Z; weniger Zucker, gleiche Osmolarität), einer dem Anzuchtmedium entsprechenden Kontrolle (K; 70,8mM PEG1000 und 29,2 mM des jeweiligen Zuckers), oder 29,2mM Glukose bzw. Saccharose (H; Hypoosmolarität bei gleichbleibender Zuckerkonzentration) erfolgte. EtBr: Etidiumbromid-Färbung der verwendeten RNA-Gele zum Nachweis gleichmäßiger Beladung. 
und die ProDH sowohl durch Zuckermangel als auch durch Hypoosmolarität induziert werden.

Für AtbZIP1 und AtbZIP63 ist zu erkennen, dass der Transfer von auf Glukose oder Saccharose gewachsenen Pflanzen in Medium ohne Zucker, aber mit hoher Osmolarität, nach zwei Stunden zu einer deutlichen Induktion führt, während der Transfer in die beiden zuckerhaltigen Lösungen mit vergleichbarer oder niedrigerer Osmolarität sogar $\mathrm{zu}$ einer Repression führt (Abbildung 5.15). Dies zeigt, dass eine Induktion der Transkription von AtbZIP1 und 63 durch Zuckerverarmung, nicht durch Hypoosmolarität erfolgt. Dass in der Kontroll- und der Zuckerlösung sogar eine Repression zu sehen ist, mag darauf zurückzuführen sein, das in Anzuchtmedium schon ein Teil des Zuckers verbraucht war, wodurch der Transfer in frisches 2MS Medium bzw. 29,2mM Zucker ein plus an Zucker bedeutet.

Die Expression von AtbZIP9, AtbZIP25 und AtbZIP10 unter den getesteten Bedingungen wurde ebenfalls durch Northern analysiert. AtbZIP9 und AtbZIP25 zeigten jedoch keine Regulation durch Zucker oder Hypoosmolarität, während für AtbZIP10 in keiner der Proben ein Transkript zu detektieren war.

\subsubsection{Eine Dunkel-induzierte Expression von ProDH, AtbZIP1, AtbZIP53, AtbZIP9 und AtbZIP63 wird durch Zucker reprimiert.}

Im Gegenzug zur gezeigten Induktion durch Zuckermangel sollte getestet werden, ob die Transkription von AtbZIP-Transkriptionsfaktoren der Gruppen C und S1 sowie die Transkription der ProDH auch durch Zucker reprimiert werden kann. Dazu wurden drei Wochen alte, in Hydroponik angezogene Pflanzen für 24 Stunden dunkel gestellt, um sie an Zuckern zu verarmen. Sowohl die ProDH als auch AtbZIP1, 53, 9 und 63 werden deutlich durch Dunkelheit induziert. Diese Induktionen könnten direkt auf die Abnahme der Zuckerkonzentration in den Blättern während der Dunkelheit zurückzuführen sein (Fujiki et al., 2001).

Die Pflanzen wurden anschließend in Hydroponikmedium mit 167mM 3-orthomethylglukose (3-OMG), Glukose, Saccharose oder PEG1000 transferiert und dabei weiter im Dunkeln gehalten. 3-OMG ist ein Glukose-Derivat, das von der Zelle aufgenommen wird, aber nicht zur Aktivierung des Hexokinase1 (HXK1) -abhängigen Zuckersignalwegs führt (Cortes et al., 2003). AtbZIP1, AtbZIP63 und AtbZIP9 werden 
spezifisch durch Zucker, nicht aber durch Hyperosmolarität, reprimiert. Da 3-OMG nicht zu einer Repression führt, scheint die Glukose-vermittelte Repression über einen HXK1-abhängigen Signalweg stattfindet (Abbildung 5.16).

AtbZIP53 und die ProDH hingegen werden auch durch 167mM PEG, dass heißt durch Hyperosmolarität, reprimiert. Die Repression der ProDH durch Saccharose ist jedoch stärker als die durch equimolare Glukose oder PEG-Lösungen, was auf einen zusätzlichen, Saccharose-spezifischen Repressionsmechanismus hindeutet, der additiv mit der osmotischen Repression arbeitet. Ein solcher Effekt ist für AtbZIP53 nicht deutlich zu erkennen. 3-OMG zeigt trotz gleicher Konzentrationen einen schwächeren Effekt als Glukose. Dies könnte darauf zurückzuführen sein, dass 3-OMG ebenso wie Glukose in die Zelle aufgenommen wird, dort aber nicht metabolisiert wird, sondern in der Vakuole akkumuliert (Cortes et al., 2003). Dadurch steigt der osmotische Wert in der Zelle, und die Differenz zum Medium wird kleiner.

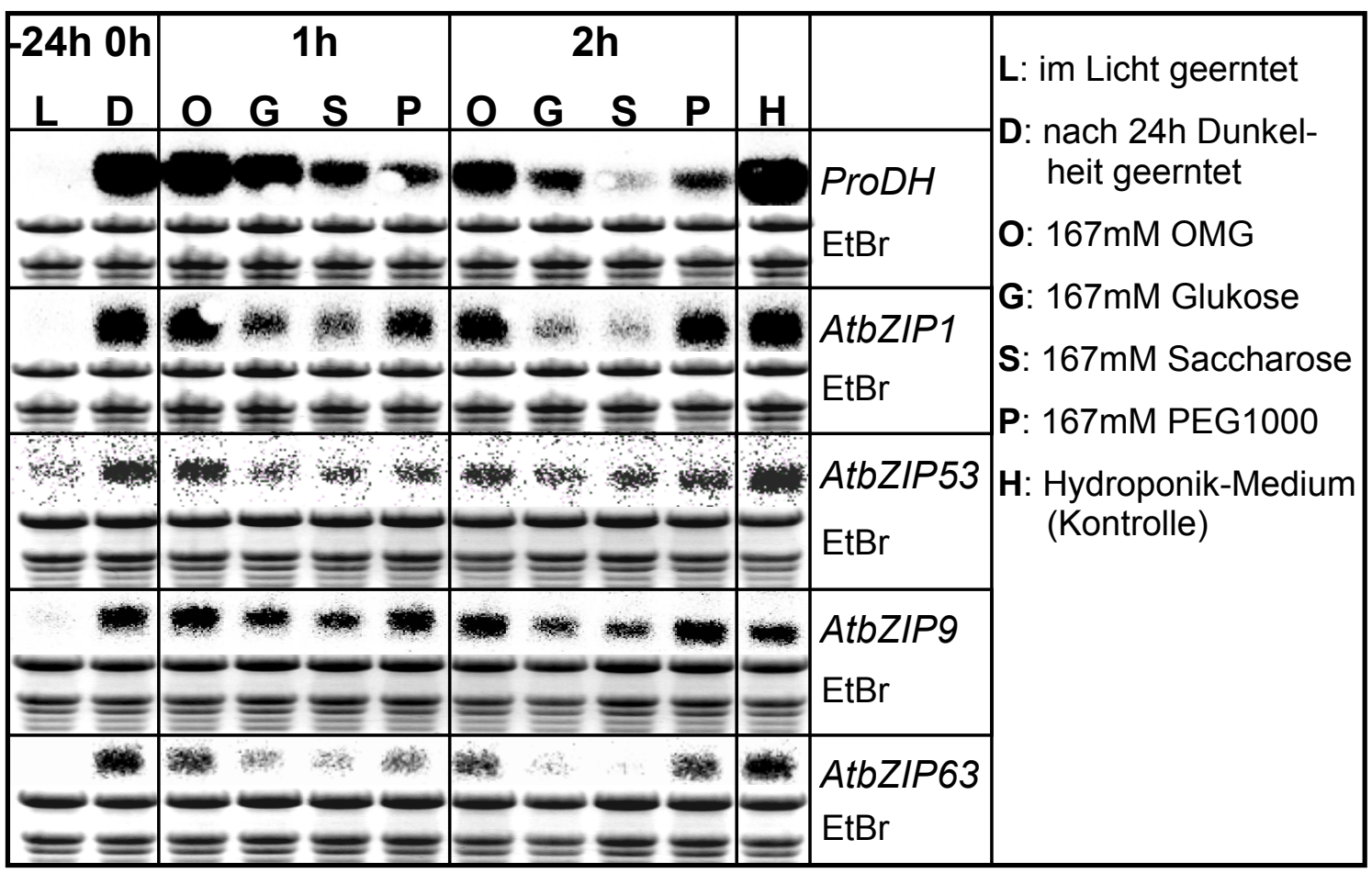

Abbildung 5.16: Northern-Analysen zeigen eine Repression von AtbZIP1, 9 und 63 durch Zucker und eine Repression von AtbZIP53 und der ProDH durch Zucker oder Hyperosmolarität. Pflanzen wurden auf Netzen in hydroponischer Kultur (ohne Zucker) im Kurztag angezogen. 3 Stunden nach Beginn der Lichtphase wurde die erste Probe (L, -24h) geerntet, danach wurden die Pflanzen für 24 Stunden dunkel gestellt. Nach dem Ernten einer weiteren Probe (D, 0h) wurden die Pflanzen mit Netz in Gefäße mit Hydroponikmedium mit 167mM 3-Orthomethylglukose (O), Glukose (G), Saccharose (S) oder PEG1000 (P) transferiert und dabei weiter im Dunkeln gehalten. Nach 1 bzw. 2 Stunden wurden die Pflanzen mit Wurzeln geerntet. Als Kontrolle wurde ein Netz in Hydroponik Medium umgesetzt und nach 2 Stunden geerntet $(\mathrm{H})$. EtBr: Etidiumbromid-Färbung der verwendeten RNA-Gele zum Nachweis gleichmäßiger Beladung. 


\subsubsection{Die Induktion von AtbZIP53 durch Hypoosmolarität findet vorwiegend in Blättern statt}

Eine Induktion von AtbZIP53 durch Hypoosmolarität konnte auch mit Hilfe von Promotor-GUS Fusionen gezeigt werden (Abbildung 5.17). Dazu wurden

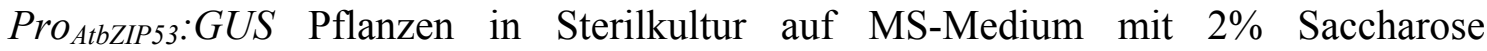
angezogen. Nach 8 Tagen wurden ganze Pflanzen in $\mathrm{H}_{2} \mathrm{O}$, in MS Medium mit 2\% Saccharose oder in MS Medium mit 300mM Mannitol transferiert und nach einer Inkubation über Nacht histochemisch gefärbt. Dabei zeigten die in Wasser transferierten Pflanzen eine deutliche Zunahme der GUS-Aktivität. Die Induktion findet dabei hauptsächlich in den Blättern statt, im Hypokotyl und in den Wurzeln waren keine deutlichen Unterschiede $\mathrm{zu}$ sehen. Bei den in Mannitol transferierten Pflanzen ist ebenfalls eine leichte Zunahme der GUS-Aktivität zu sehen, die auf die Abnahme der Saccharose-induzierten Repression der Translation zurückzuführen sein könnte. Der Versuch wurde zweimal unter der Verwendung von zwei unabhängigen Pro $_{\text {AtbZIP53: }}$ GUS Linien reproduziert.

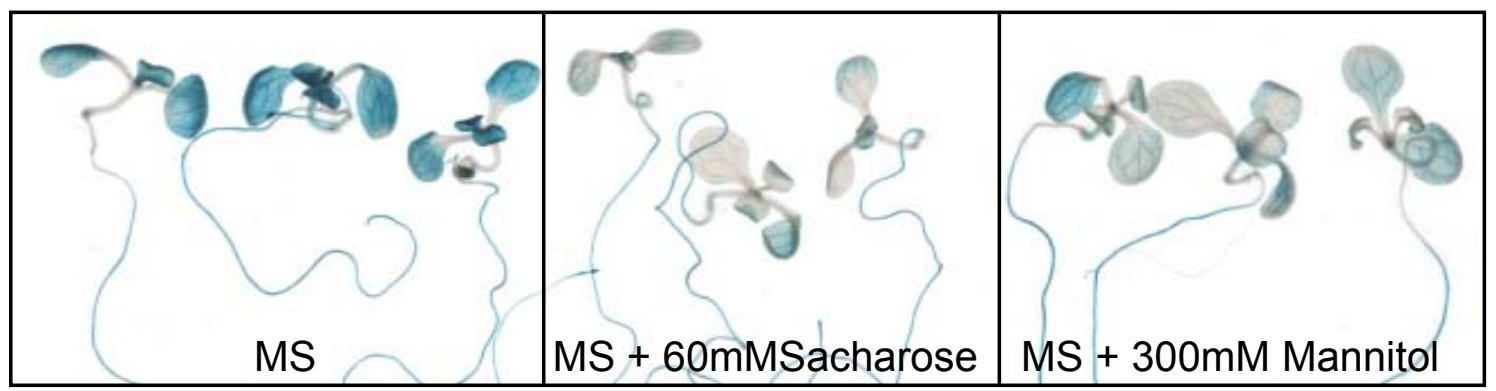

Abbildung 5.17: AtbZIP53 wird durch Hypoosmolarität induziert. Pflanzen mit einer Pro $_{A t b Z I P 53}$ : GUS Fusion wurden für 8 Tage auf MS-Medium mit 60mM Saccharose angezogen und über Nacht in MS-Medium, MS-Medium mit 60mM Saccharose oder MS-Medium mit 300mM Manitol inkubiert. Anschließend wurden sie mit 2mM X-Gluc / 1mM Hexacyanoferrate für 24 Stunden histochemisch gefärbt. Der Versuch wurde mit zwei unabhängigen Pro $_{A t b z I P 53}$ : GUS Linien reproduziert.

\subsubsection{AtbZIP53 wird durch Prolin induziert}

Die ProDH wird neben Hypoosmolarität auch stark durch Prolin induziert (Nakashima et al., 1998). Um zu überprüfen, ob AtbZIP-Transkriptionsfaktoren der Gruppen C und S1 neben Osmolaritäts- und Zucker-Signalen auch Prolin-abhängige Signale vermitteln 
könnten, wurde getestet, ob sie durch Prolin induziert werden können. Dazu wurden 2 Wochen alte Pflanzen, die in Sterilkultur auf MS Medium mit 2\% Saccharose angezogen worden waren, mit Wurzel in flüssiges MS Medium mit 2\% Saccharose und 100mM Prolin bzw. 100mM Mannitol umgesetzt. Mannitol diente dabei als osmotische Kontrolle. Nach 0, 1, 2 und 4 Stunden wurden Proben genommen, und die Expression von AtbZIP1, 53, 9, 63, 25 und 10 in diesen Proben wurde in Northern Analysen getestet. AtbZIP53 wird dabei sehr schnell stark induziert (Abbildung 5.18). Vergleicht man die Kinetik der Induktion von AtbZIP53 mit der der ProDH, so scheint AtbZIP53 früher induziert zu werden, was dafür spricht, dass die Prolin-abhängige Induktion der ProDH über AtbZIP53 erfolgen könnte. Die Transkription von AtbZIP1, 9, 63 und 25 wird nicht durch Prolin induzieren (nicht gezeigt).

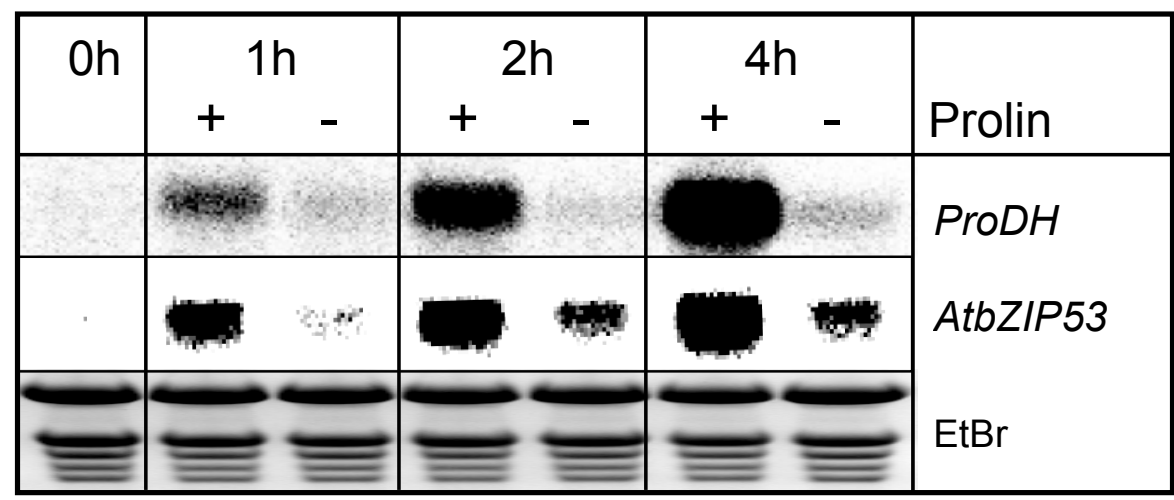

Abbildung 5.18: Die Transkription von AtbZIP53 wird durch Prolin induziert. Zwei Wochen alte, in Sterilkultur auf MS-Medium mit 2\% Saccharose angezogene ganze Pflanzen wurden in MS-Medium mit 100mM Prolin (+) oder MS-Medium mit 100mM Mannitol (-; Mannitol dient als osmotische Kontrolle) inkubiert. Anschließend wurde aus den ganzen Pflanzen RNA extrahiert und in Northern auf die Expression von der ProDH und von AtbZIP1, 53, 9, 63, 25 und 10 analysiert. AtbZIP1, 9, 63, und 25 zeigten keine Unterschiede zwischen den mit Mannitol oder Prolin behandelten Proben, das Transkript von AtbZIP10 war nicht nachzuweisen. EtBr: Etidiumbromid-Färbung der verwendeten RNA-Gele zum Nachweis gleichmäßiger Beladung. 


\subsubsection{Die ProDH ist ein direktes Zielgen von AtbZIP53}

Um zu überprüfen, ob AtbZIP53 direkt an den ProDH-Promotor bindet, oder ob die in Protoplasten- und Northern Analysen gesehenen Einflüsse indirekt sind, wurde eine Chromatin-Immunopräzipitation (ChIP) durchgeführt (Johnson et al., 2001). Diese Methode war im Labor zuvor nur für Tabak etabliert, und musste für Arabidopsis modifiziert werden. Für die ChIP Experimente wurden Pflanzen mit einer ektopischen Expression eines HA-markierten AtbZIP53 verwendet. Als Kontrolle dienten WildtypPflanzen. Zunächst wurden DNA-bindende Proteine und DNA durch eine Formaldehydbehandlung quervernetzt. Hierfür wurde ein 50mM Kaliumphosphatpuffer mit 1\% Formaldehyd eingesetzt, wie er für Tabak bereits erfolgreich verwendet wurde. Für die folgende Kernpräparation wurden verschiedene Protokolle getestet, und ihr Erfolg kontrolliert, in dem die mit Propidiumiodid gefärbten Kerne unter dem Fluoreszenzmikroskop betrachtet wurden. Ein Percoll-basiertes Protokoll (Dr. Corinna Thurow, persönliche Mitteilung) erwies sich als am besten geeignet.

Das mit den Kernen isolierte Chromatin wurde anschließend durch Ultraschall fragmentiert. Dabei wurde empirisch eine Dauer von vier mal 12 Sekunden für die Ultraschallbehandlung ermittelt, die eine ideale Fragmentgröße von etwa 500 Basenpaaren lieferte. Um die Effizienz der Quervernetzung sowie der Fragmentierung zu überprüfen, wurde für ein Aliquot des fragmentierten Chromatins die Quervernetzung rückgängig gemacht, und dieses zusammen mit einem zweiten Aliquot in einem Agarose-Gel aufgetrennt (Abbildung 5.19 B). Das langsamere Laufverhalten der quervernetzten Proben ist auf die an die DNA gebundenen Proteine zurückzuführen und bestätigt den Erfolg der Vernetzungsreaktion.

Anschließend wurde mit den quervernetzten Chromatin-Fragmenten und einem HAAntikörper eine Immunopräzipitation (IP) durchgeführt. Um sicherzustellen, dass gleiche Mengen von Chromatin eingesetzt wurden, wurde für einen Teil des Chromatins die Quervernetzung rückgängig gemacht, und die DNA-Konzentration photometrisch bestimmt. Für die Immunopräzipitation wurden dann die DNA-Konzentrationen der HA-AtbZIP53-Probe und der Wildtyp-Kontrolle aneinander angepasst. Die gleiche Konzentration von ProDH-Promotor Fragmenten wurde über eine PCR mit für den ProDH-Promotor spezifischen Primern, die zu beiden Seiten des von Satoh et al. beschriebenen $c i s$-Elements binden, bestätigt (Abbildung 5.19 C, Input). 
Die Anreicherung des HA-markierten AtbZIP53 Proteins durch die IP wurde durch eine Western Analyse bestätigt (Abbildung 5.19 A). Während im Überstand kein HAmarkiertes AtbZIP53 Protein detektiert wurde, war es im Eluat deutlich nachzuweisen. Eine Ponceau Rot Färbung des für den Western verwendeten Filters zeigte, dass sich der Großteil des Gesamtproteins im Überstand befand, während über die Färbung im Eluat kein Protein nachzuweisen ist. Verschiedene Protokolle schlagen für die Immunopräzipitation zwei Elutionschritte vor. Da die Western Analysen jedoch kein HA-markiertes AtbZIP53 Protein im zweiten Eluat zeigen, wurde im folgenden nur das erste Eluat verwendet.

Bindet das HA-AtbZIP53 Protein in der Pflanze an den ProDH-Promotor, so werden DNA-Fragmente aus dem Promotor mit präzipitiert und so angereichert. Über eine PCR mit für den ProDH-Promotor spezifischen Primern konnte eine deutliche Anreicherung von Fragmenten der Promotor-Region detektiert werden, was belegt, dass die ProDH ein direktes Zielgen von AtbZIP53 ist. Als Kontrolle wurden Wildtyppflanzen ohne HA-markiertes AtbZIP53 Protein parallel mitbehandelt.

Um zu überprüfen, ob der Hintergrund an unspezifische präzipitierter DNA in den ChIP-Proben der Pflanzen mit einer ektopischen Expression des HA-markierten AtbZIP53 mit dem in den ChIP-Proben der Wildtyp-Pflanzen vergleichbar ist, wurde eine PCR mit den Kontrollprimern cwINV2for und cwINV2rev durchgeführt, die ein Stück aus dem Kodierbereich eines Genes amplifizieren, dass nicht von AtbZIP53 gebunden wird. Bei dieser PCR konnte auch ein Produkt amplifiziert werden, was einen Hintergrund an unspezifische präzipitierter DNA belegt. Jedoch ist dieser Hintergrund in beiden Proben vergleichbar. 


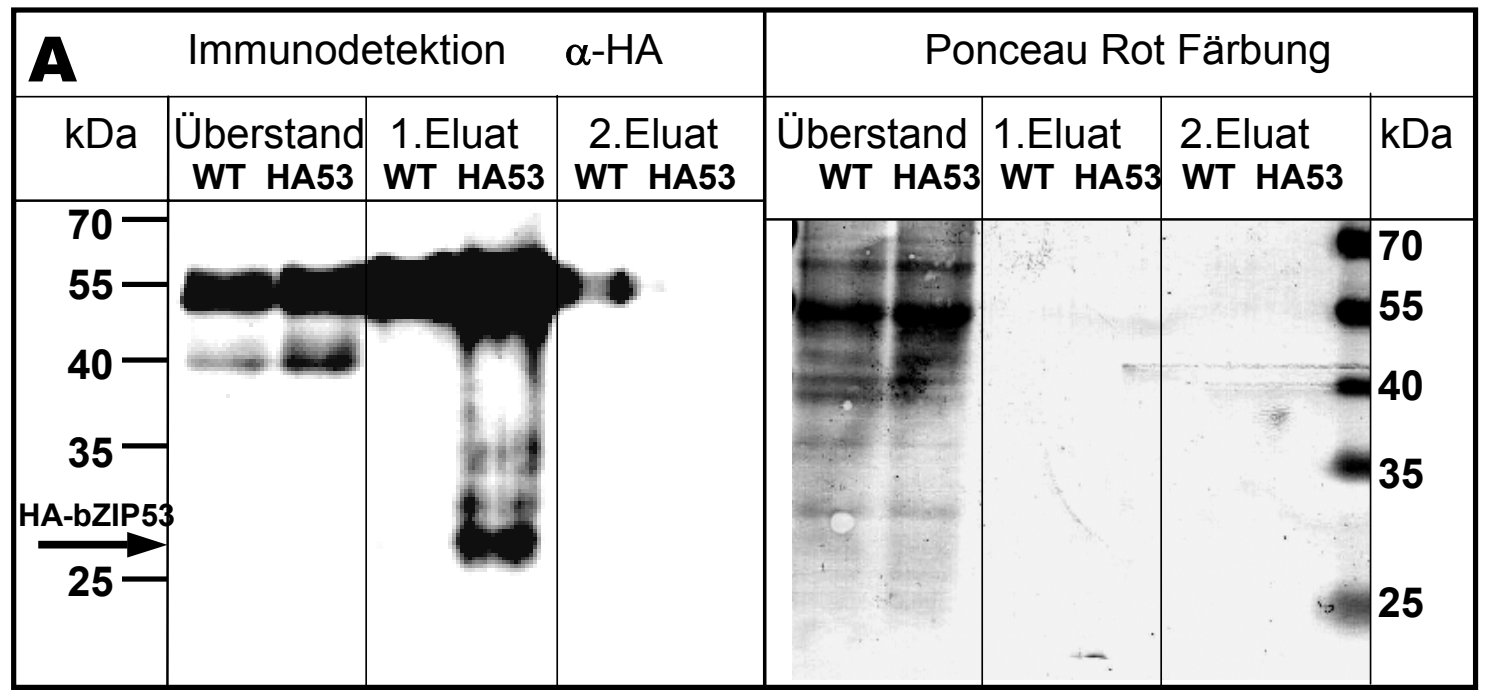

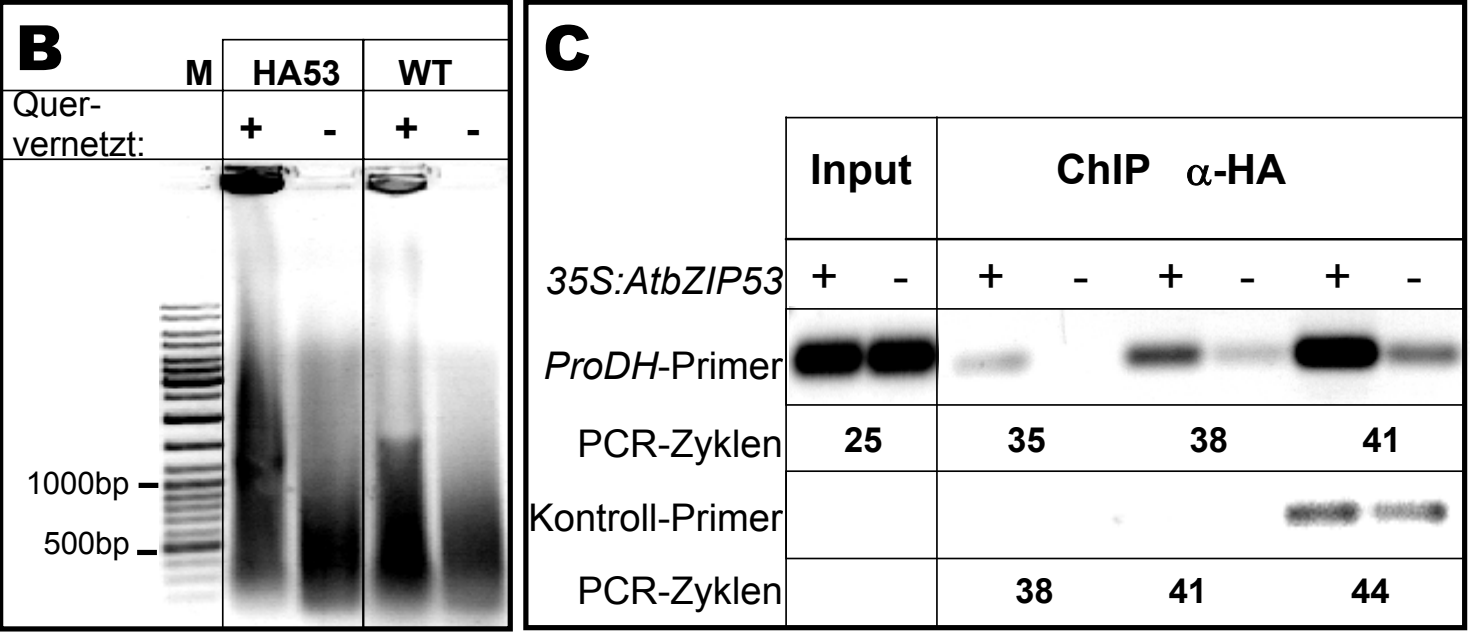

Abbildung 5.19: ChIP-Analysen bestätigen die Bindung von AtbZIP53 an den ProDH-Promotor. 4 Wochen alte auf Erde angezogene Wildtyp und 35S:HA-AtbZIP53 Pflanzen wurden für 30 min mit Formaldehyd behandelt, um Protein und DNA querzuvernetzen. A: Aus diesen Pflanzen wurde das Chromatin isoliert und dieses durch Ultraschallbehandlung fragmentiert, so dass DNA-Bruchstücke von durchschnittlich 500bp Länge entstanden. In einem Agarose-Gel zeigt die vernetzten DNA-Probe in Vergleich zu der Probe bei der die Vernetzung rückgängig gemacht wurde eine Retardation, die die Effizienz der Vernetzung anzeigt. B: Mit den vernetzten DNA-Fragmente wurde eine CoImmunopräzipitation durchgeführt. Der Erfolg der Immunopräzipitation wurde im Western überprüft. C: Für die präzipitierten Chromatin-Fragmente wurde die Vernetzung aufgehoben, und die Menge des enthalten ProDH-Promotors über eine quantitative PCR mit den Primern PDHpromfor und PDHpromrev ermittelt. Der Abgleich des DNA-Hintergrundes erfolgt über eine quantitative PCR mit den Kontrollprimern AtcwINV2gstFOR und AtcwINV2gstREV. Input: Für die Immunopräzipitation eingesetztes Chromatin. 


\subsubsection{Heterodimere von AtbZIP53 mit Gruppe C AtbZIP. Transkriptionsfaktoren führen zu einer synergistischen Aktivierung der ProDH}

Im folgenden wurde der Einfluss der Heterodimerisierung von AtbZIP53 mit Gruppe C AtbZIP Faktoren auf die Expression der ProDH untersucht. Diese Analysen wurden in Mesophyll-Protoplasten an dem von (Satoh et al., 2002, siehe Einleitung) identifizierten cis-Element ACTCAT durchgeführt.

$9 \mu \mathrm{g}$ eines Reporterplasmid (pBT10-2xProDH-GUS), welches dieses cis-Element 2-fach vor ein GUS-Reportergen fusioniert enthielt, wurde zusammen mit jeweils $14 \mu \mathrm{g}$ von den Effektor-Plasmiden 1 und 2 (pHBTL-HAGW), welche die AtbZIPTranskriptionsfaktoren der Gruppen $\mathrm{C}$ und S1 unter Kontrolle des 35S-Promotors exprimieren, transient in Arabidopsis Mesophyll-Protoplasten transformiert.

Werden nur einzelne AtbZIP-Transkriptionsfaktoren in den Mesophyll-Protoplasten exprimiert, zeigt vor allem die Expression von AtbZIP53 eine deutliche Aktivierung des Reportergens, während diese durch die Expression von einzelnen Gruppe C AtbZIPTranskriptionsfaktoren kaum gesteigert wird (Abbildung 5.20). Bei der Betrachtung dieser Ergebnisse muss berücksichtigt werden, dass es in Mesophyll-Protoplasten auch zu einer endogene Expression von AtbZIP-Transkriptionsfaktoren der Gruppen $\mathrm{C}$ und S1 kommt. Die Aktivierung, die bei der Transformation nur mit AtbZIP53 als Effektor $\mathrm{zu}$ sehen ist, kann also durchaus auf Heterodimeren von AtBZIP53 mit endogenen Gruppe C AtbZIP-Transkriptionsfaktoren beruhen.

Wird, gegenüber der Expression von AtbZIP53 alleine, die Hälfte des Effektors durch den für die Expression von z.B. AtbZIP25 ersetzt, würde man eine ReportergenAktivität zwischen der bei der alleinigen Expression der beiden AtbZIPTranskriptionsfaktoren erhaltenen erwarten. Diese fällt jedoch deutlich stärker aus, was einen synergistischen Effekt der Heterodimerisierung auf die Aktivierung des ACTCAT Motivs belegt.

Detailiertere Analysen der Regulation dieses Motivs durch verschieden Heterodimere sowie eine genauere Analyse des cis-Elements durch verschiedene Mutationen werden von Andrea Ehlert im Rahmen ihrer Dissertation durchgeführt. Dabei konnten die synergistischen Effekte bei der Aktivierung durch $\mathrm{C} / \mathrm{S} 1$ Heterodimere bestätigt werden (Weltmeier et al., zur Veröffentlichung eingereicht). 


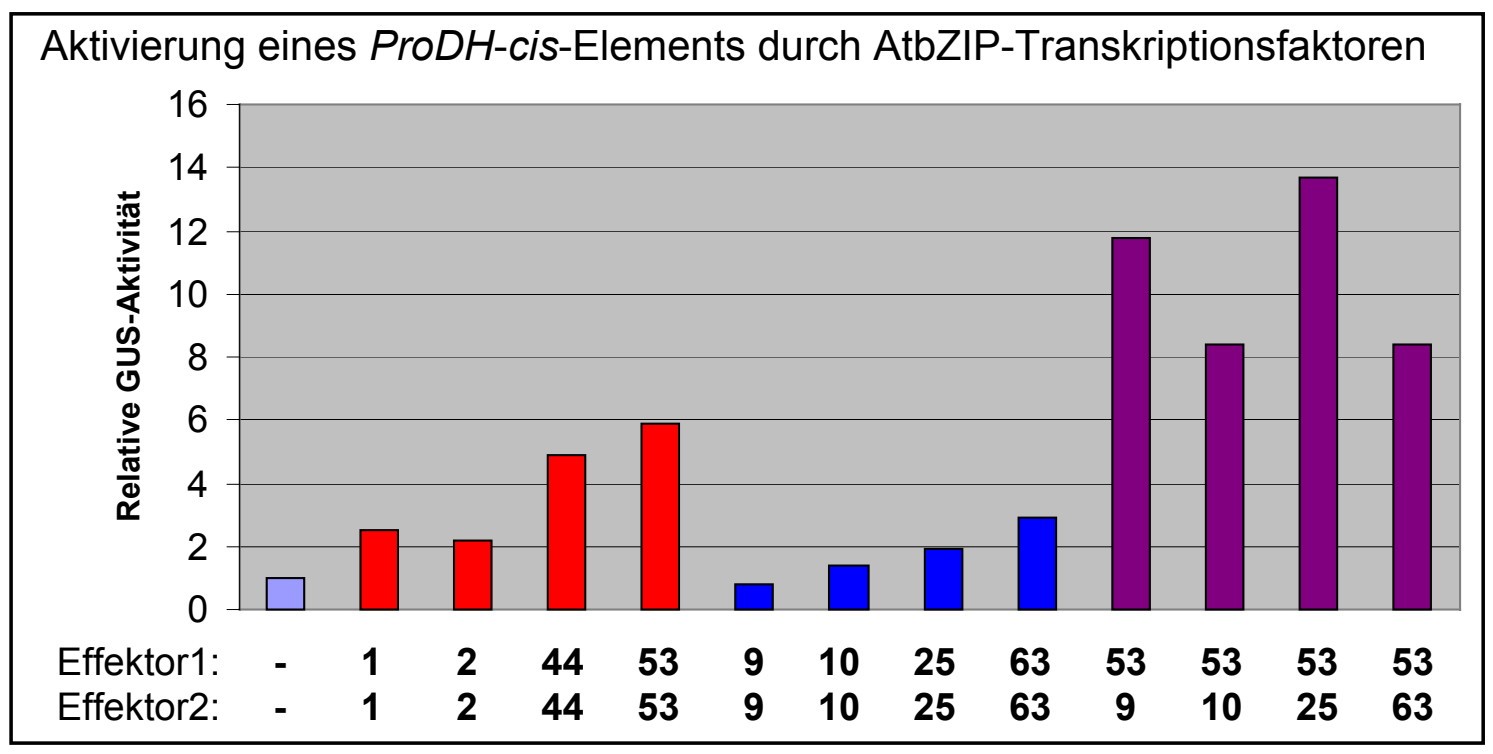

Abbildung 5.20: AtbZIP53 enthaltende Heterodimere führen zu einer stärkeren durch das ACTCAT-Motiv vermittelten Expression als einzelne C/S1 AtbZIP-Transkriptionsfaktoren. Gezeigt ist die Aktivität eines GUS-Reportergens in transient transformierten Arabidopsis MesophyllProtoplasten. Das Reportergen steht unter der Kontrolle eines doppelten ACTCAT-Motivs aus dem ProDH-Promotor. Die Zahlen unter dem Diagramm (Effektor1 und Effektor2) geben an, welcher AtbZIP-Transkriptionsfaktor von den mit dem Reporterplasmid kotransformierten Effektorplasmiden exprimiert wurde, der Strich steht für ein leeres Effektorplasmid. Von den Effektorplasmiden wurden jeweils gleiche Mengen $(14 \mu \mathrm{g})$ eingesetzt, von dem Reporterplasmid $9 \mu \mathrm{g}$.

\subsubsection{Einzelne AtbZIP-Transkriptionsfaktoren der Gruppen C und S1 werden wie die ProDH stark in Pollen exprimiert}

Die ProDH wird nicht nur durch Osmolarität reguliert, sondern zeigt auch gewebespezifische Expressionsmuster. So konnten Verbruggen et al. (1996) eine blütenspezifische Expression der ProDH zeigen, die von Nakashima et al. (1998) mit Hilfe von Promotor-GUS Fusionen auf die Pollen und in Samen eingegrenzt werden konnte. Verschiedene Publikationen zeigen hohe Konzentrationen von Prolin in reproduktiven Geweben wie Samen und Pollen (Chiang und Dandekar, 1995; Zhang und Croes, 1983). Die starke Expression der ProDH mag also auf die Induktion durch die hohe Prolin-Konzentration zurückzuführen sein. Jedoch wird für diese Gewebe auch über eine Funktion von Prolin als Energiequelle spekuliert (Nakashima et al., 1998).

Für S1 bZIP-Transkriptionsfaktoren aus Tabak, BZI3/tbzF und BZI4, wurde ebenfalls eine spezifische Expression in Blüten gezeigt, und es gibt Hinweise auf eine Funktion 
von BZI-1 und BZI-4 in der Pollen-Entwicklung (Strathmann et al., 2001; Yang et al., 2001; Yang et al., 2002). Für AtbZIP11 konnte durch Promotor-GUS Fusionen eine spezifische Expression im Konnektiv gezeigt werden (Rook et al., 1998).

Daher wurde im folgenden die Expression der AtbZIP-Transkriptionsfaktoren der Gruppen S1 und C in Blüten mit Hilfe der Promotor-GUS Linien untersucht. Dazu wurden die Pflanzen bis zu Blüte auf Erde angezogen, und komplette Blütenstände mit 2mM X-Gluc / 2mM Kalium-Hexacyanoferrat für 24 Stunden gefärbt. Vergleicht man Blüten in einem Entwicklungsstadium etwa zur Zeit der Pollination miteinander, so lassen sich hier deutlich zwei Gruppen voneinander unterscheiden, die unterschiedliche Expressionsmuster in den Antheren zeigen: GUS-Fusionen mit den Promotoren von AtbZIP9, 11, 44 und 10 zeigten eine GUS-Aktivität, die auf das Konnektiv beschränkt war, während solche mit den Promotoren von AtbZIP1, 2, 53, 25 und 63 eine deutliche GUS-Aktivität in den Pollen zeigten (Abbildung 5.21). Während die Expression im Konnektiv sehr stabil und in vielen GUS-Färbungen nachzuweisen wahr, unterlag die Pollen-spezifische GUS-Aktivität insbesondere von AtbZIP53 und 63 Promotor-GUS Fusionen Schwankungen, sodass oft an einer Blüte ein Teil der Antheren Blau gefärbt war, ein anderer nicht, oder dass nur ein Teil der Staubbeutel eine Blaufärbung zeigte. In den von (Nakashima et al., 1998) für die ProDH veröffentlichten GUS-Färbungen ist ebenfalls eine pollenspezifische Expression zu sehen. Es liegt daher nahe zu vermuten, dass AtbZIP1, 2, 53, 25 oder 63 auch an der Regulation der Pollen-spezifischen Expression der ProDH beteiligt sind, während AtbZIP9, 11, 44 und 10 möglicherweise andere Funktionen in der Pollenentwicklung übernehmen. Eine Analyse der zur Expression in Pollen erhältlichen Mikroarray-Daten zeigt ebenfalls eine pollenspezifische Koexpression. Eine ähnliche Koexpression von der ProDH mit AtbZIP-Transkriptionsfaktoren der Gruppen S1 und C findet sich auch in Samen. Auf diese wird in Kapitel 5.8 eingegangen. 


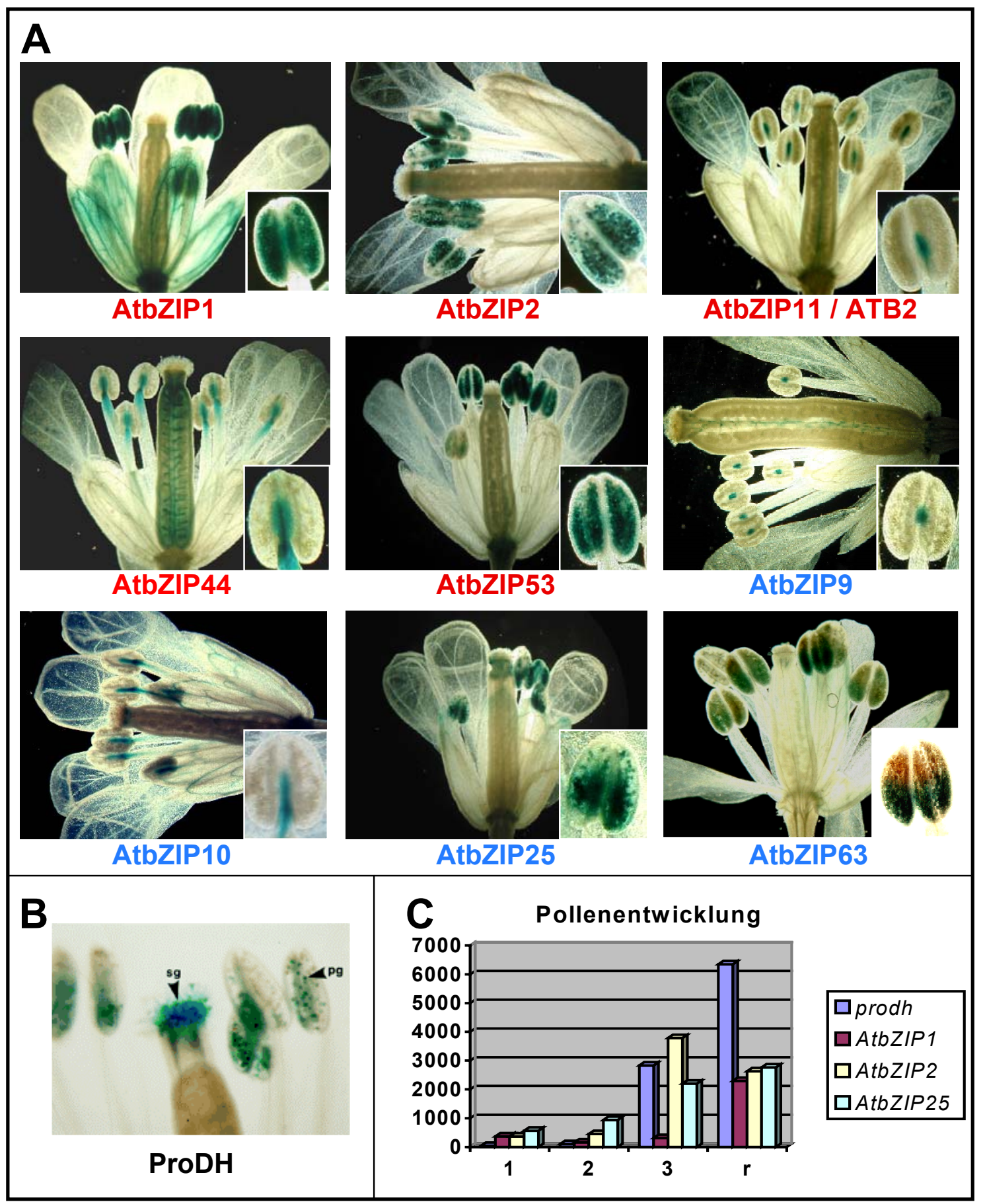

Abbildung 5.21: A: Gruppe C/S1 AtbZIP-Transkriptionsfaktoren zeigen zwei distinkte Expressionsmuster in Antheren. Von 8 Wochen alten, auf Erde im Langtag angezogenen Pflanzen mit Promotor-GUS-Fusionen der verschiedenen AtbZIP-Transkriptionsfaktoren wurden sechs Stunden nach Beginn der Lichtphase Blüten geerntet und 24 Stunden mit $1 \mathrm{mM}$ X-Gluc / $2 \mathrm{mM}$ Kalium-Hexacyanoferrat histochemisch gefärbt. B: Histochemische Färbung einer Pro $_{P r o D H}: G U S$ Pflanze (aus Nakashima et al. (1998)). C: Pollen-spezifische Expression von AtbZIP1, 2, 25 und der ProDH in verschiedenen Entwicklungsstadien der Pollen. 1: Einzell-Stadium; 2: ZweikernStadium; 3: Zweikern-Stadium; r: reifes Pollenkorn. Die Werte stammen aus der Genevestigator Datenbank, die Signalstärke der ProDH wurde zugunsten der besseren Darstellbarkeit jeweils um den Faktor 10 reduziert. 


\subsection{Eine Regulation von AtbZIP-Transkriptionsfaktoren der Gruppen C/S1 durch Zucker lässt sich durch Transkriptom- analyse-Daten und Promotor-GUS Fusionen bestätigen}

In den vorangegangenen Kapiteln wurde gezeigt, dass die ProDH sowie die Mehrheit der Gruppe AtbZIP-Transkriptionsfaktoren der Gruppen C und S1 durch Zucker reprimiert und durch Dunkelheit induziert werden. Dunkelheit führt zu einer Abnahme der Zuckerkonzentration in den Blättern (Gibon et al., 2004), und viele der bekannten dunkelinduzierten Gene werden durch Zucker reprimiert (Fujiki et al., 2000; Fujiki et al., 2001), sodass diese beiden Prozesse eng miteinander verwandt sind.

Um zusätzliche Daten zu erhalten, wurde nach veröffentlichten Transkriptomanalysen zur Zuckerregulation gesucht und die Regulation aller AtbZIP-Transkriptionsfaktoren der Gruppen C und S1 in diesen Expressionsprofilen betrachtet.

\subsubsection{Transkriptionelle Regulation von AtbZIP-Transkriptionsfaktoren der Gruppen C und S1 durch Saccharose}

In der NASCArray Datenbank (Craigon et al., 2004) sind Daten aus einem Experiment veröffentlicht, in dem 3 Tage alte Keimlinge aus Sterilkultur auf MS-Medium mit oder ohne Saccharose verglichen wurden (Karen Greville und Mark Hooks, 2004).

In diesem Experiment wird in Abwesenheit von Saccharose die Expression von AtbZIP63 um mehr als das Zehnfache, die von AtbZIP1 um mehr als das Fünffache, und die von AtbZIP9 und AtbZIP2 um das Zwei- bis Dreifache induziert. Auf die Expression der anderen AtbZIPs sind hier keine signifikanten Effekte zu sehen (Abbildung 5.22). In zwei weiteren, ähnlichen Experimenten (Malcolm Campbell und AtGenExpress, 2005), wo 7 bzw. 8 Tage alte Pflanzen aus Sterilkultur auf MS-Medium mit oder ohne Saccharose getestet wurden, wird die Repression von AtbZIP63, 9 und 1 durch Saccharose bestätigt, allerdings sind die Effekte zu dieser Zeit nicht mehr so deutlich. Dafür findet sich nun eine leichte Induktion von AtbZIP2 und AtbZIP11 (Daten nicht gezeigt). 


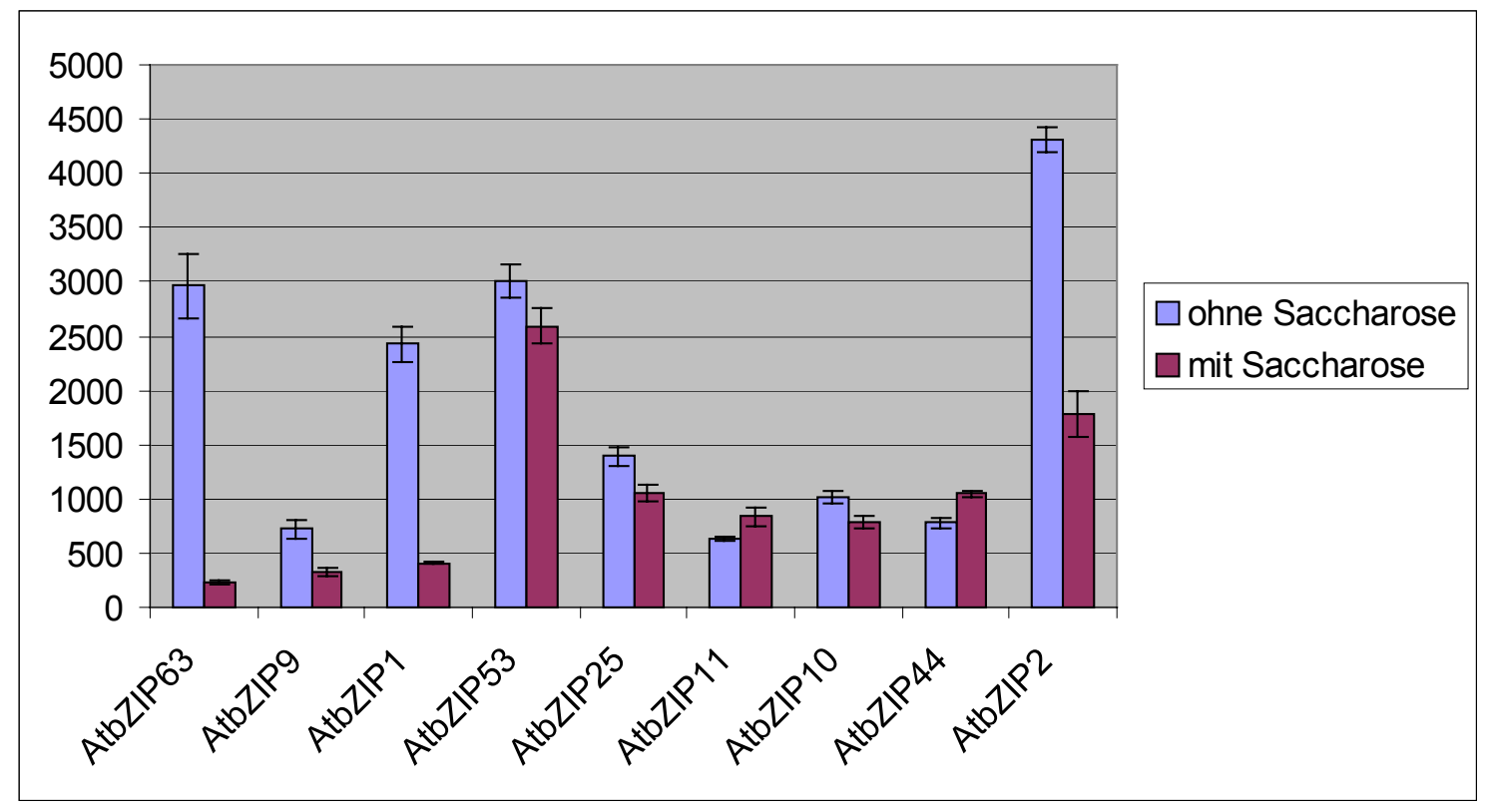

Abbildung 5.22: AtbZIP1 und AtbZIP63 werden durch Saccharose reprimiert. Expression der AtbZIP-Transkriptionsfaktoren des Gruppen C und S1 in drei Tage alte Keimlingen, die auf MS-Medium mit oder ohne Saccharose angezogen wurden (Karen Greville und Mark Hooks, 2004). Auf der X-Achse sind die Mittelwerte mit Standardabweichung von in 3 biologischen Replikaten gemessenen Signalstärken wiedergegeben.

Ein anderer experimenteller Ansatz wurde von Contento et al. (2004) veröffentlicht. Hier wurden Arabidopsis Zellkulturen vor und nach Transfer in ein Medium, in dem Saccharose durch PEG ersetzt wurde (um osmotische Effekte auszuschließen), miteinander verglichen. Innerhalb von 24 Stunden wurden auch hier sowohl AtbZIP1 (14fach) als auch AtbZIP63 (8fach) deutlich induziert.

\subsubsection{Transkriptionelle Regulation von AtbZIP-Transkriptionsfaktoren der Gruppen C und S1 durch Glukose}

Die Regulation durch Glukose wurde ebenfalls in verschiedenen Experimenten untersucht. In einem der interessantesten dieser Experimente wurden Pflanzen in Hydroponik-Medium mit 167mM Glukose bzw. 167mM 3-ortho-Methylglukose (3OMG) transferiert (Price et al., 2004). Zusätzlich wurde hier der Einfluss der Verfügbarkeit von Stickstoff untersucht, und eine Wiederholung des Experiments nach Vorbehandlung mit Cycloheximid durchgeführt. Cycloheximid inhibiert die Proteinsynthese, so dass sich hier transkriptionelle Regulationen, die die Neusynthese 
von Proteinen erfordern, von solchen, bei denen dieses nicht der Fall ist, unterscheiden lassen. Parallel zur Glukose-Behandlung wurden Pflanzen auch mit 3-OMG behandelt. 3-OMG ist ein Glukose-Analogon, welches wie Glukose in die Zelle aufgenommen wird, aber nicht zur Aktivierung des Hexokinase-Signalweges führt. Es ermöglicht die Unterscheidung zwischen Hexokinase-abhängigen und Hexokinase-unabhängigen Signalen (Xiao et al., 2000). Die Glukose-Behandlung führt zu einer deutlichen Repression von AtbZIP1 und AtbZIP63 so wie einer leichten Repression von AtbZIP2, 53 und 9, für AtbZIP11 hingegen sieht man eine Induktion durch Glukose.

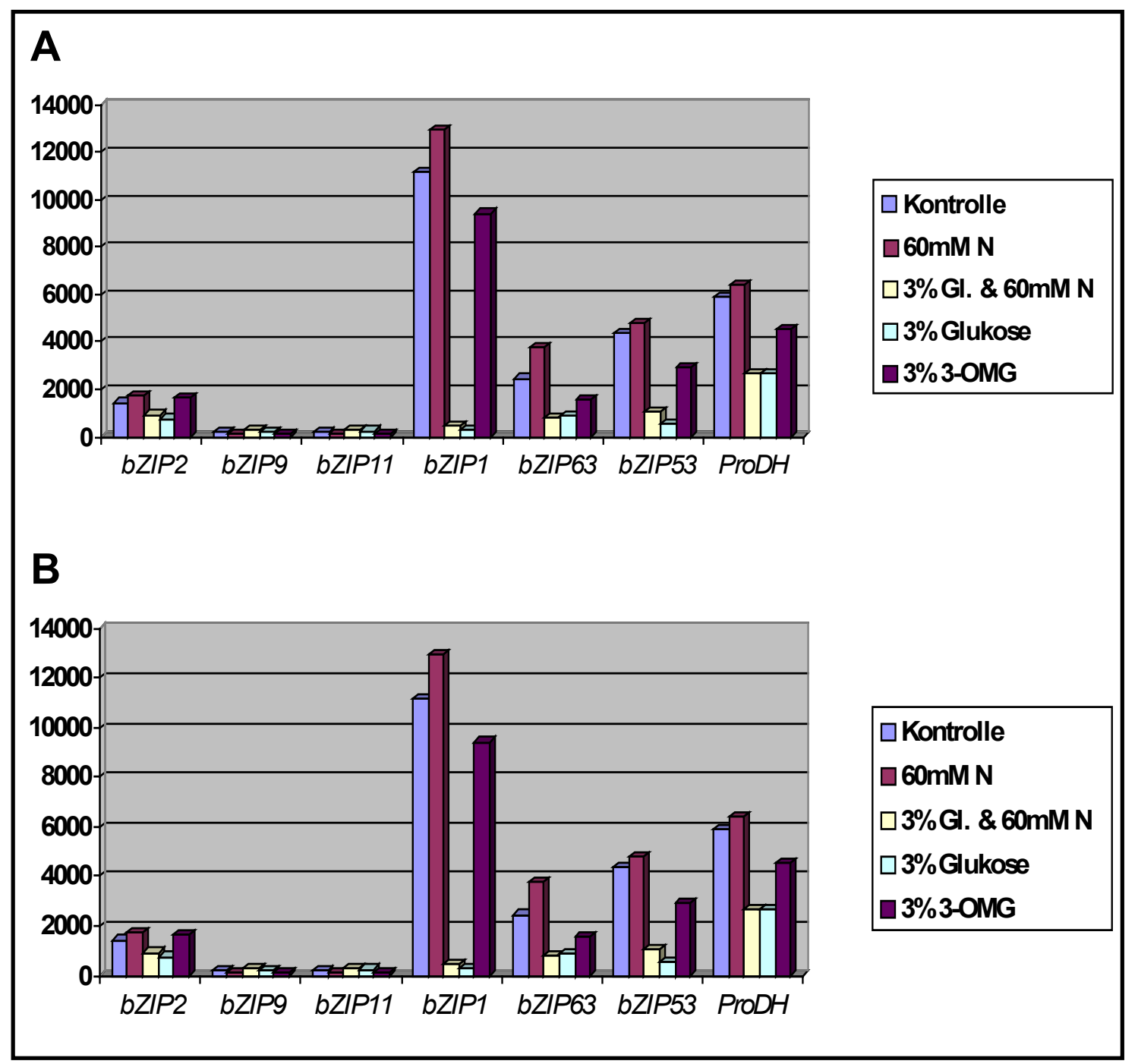

Abbildung 5.23: Die Transkription von AtbZIP-Transkriptionsfaktoren der Gruppen C und S1 wird durch Glukose reguliert. A: Arabidopsis Wildtyp Pflanzen wurden für 5 Tage in flüssigem MSMedium mit 58,4 mM Saccharose angezogen und dann für 24 Stunden im Dunkeln in MS-Medium ohne Saccharose gehalten, um sie an Zuckern zu verarmen. Anschließend wurden die Pflanzen bei Dunkelheit für 3 Stunden in Wasser (Kontrolle), 20mM NH $\mathrm{mO}_{3}$ und $20 \mathrm{mM} \mathrm{KNO}$ (60mM N), 3\% Glukose mit $20 \mathrm{mM} \mathrm{NH}_{4} \mathrm{NO}_{3}$ und $20 \mathrm{mM} \mathrm{KNO}_{3}(3 \%$ Gl. \& $60 \mathrm{mM} \mathrm{N}), 3 \%$ Glukose oder $3 \%$ OMG transferiert. B: Gleiche Durchführung wie unter A, jedoch wurden die Pflanzen vor dem Transfer in die verschiedenen Lösungen mit Cycloheximid behandelt. Die Diagramme beruhen auf Mikroarraydaten von (Price et al., 2004), AtbZIP44, 10 und 25 zeigten in dem Experiment keine signifikante Regulation. 
Da die mit 3-OMG induzierten Proben diese Effekte nicht zeigen, findet die Repression/Induktion wahrscheinlich über einen Hexokinase-abhängigen Signalweg statt.

Das Experiment wurde nach Vorbehandlung mit Cycloheximid wiederholt, um herauszufinden, ob eine de novo Proteinsynthese notwendig für die gezeigten Regulationen ist. Die Repression von AtbZIP1, 253 und 63 wurden durch die Vorbehandlung mit Cycloheximid nicht beeinflusst, sodass hier ein sehr direkter Signalweg von Zucker zu ihrer Regulation vermutet werden kann. Eine Induktion von AtbZIP11 hingegen fand nicht mehr statt, daher sind am Signalweg zur Induktion wohl Proteine beteiligt, die erst neu synthetisiert werden müssen. AtbZIP9 war nach Vorbehandlung mit Cycloheximid per se nur sehr schwach exprimiert, sodass hier keine Aussage getroffen werden kann.

In einem in der Genevestigator-Datenbank verfügbaren Experiment (Dorthe Villadsen, 2004) finden sich vergleichbare Ergebnisse (nicht gezeigt).

\subsubsection{Saccharose reprimiert die Translation von AtbZIP1 und AtbZIP53}

Rook et al. (1998) konnten zeigen, dass die Translation des S1 AtbZIPTranskriptionsfaktors AtbZIP11 spezifisch durch Saccharose reprimiert wird (SIRT: sucrose induced repression of translation). Dieser Mechanismus wird durch einen konservierten uORF vermittelt, der in den $5^{\prime}$ untranslatierten Bereichen von allen 5 Mitgliedern der Gruppe S1 vorkommt (Siehe Einleitung, Abbildung 2.2). Daher wurde getestet, ob Saccharose einen vergleichbaren Einfluss auf die Translation von AtbZIP1 und AtbZIP53 hat. Hierzu wurden Pflanzen auf MS-Medium mit 10 oder $100 \mathrm{mM}$ Saccharose angezogen. Wie erwartet, zeigten die Pflanzen in Gegenwart höherer Saccharose-Konzentrationen eine reduzierte GUS-Aktivität (Abbildung 5.24). Für AtbZIP1 wurde in Abbildung $5.22 \mathrm{im}$ Gegensatz zu AtbZIP53 unter vergleichbaren Bedingungen auch eine Repression of Transkriptionsebene gezeigt, sodass sich nicht ohne weiteres feststellen lässt, ob der hier gezeigte Effekt bei AtbZIPl wirklich auf den SIRT-Mechanismus zurückzuführen ist. Jedoch wurden hierzu von der Arbeitsgruppe von Professor Dr. Sjef Smeekens (Universität Utrecht) detailliertere Analysen durchgeführt, und Sie konnten inzwischen bestätigen, dass alle 5 Mitglieder der Gruppe 
S1 durch SIRT reguliert werden (persönliche Mitteilung). Daher ist anzunehmen, dass in Gegenwart hoher Saccharose-Konzentrationen das Vorhandensein von C/S1Heterodimeren generell abnimmt.

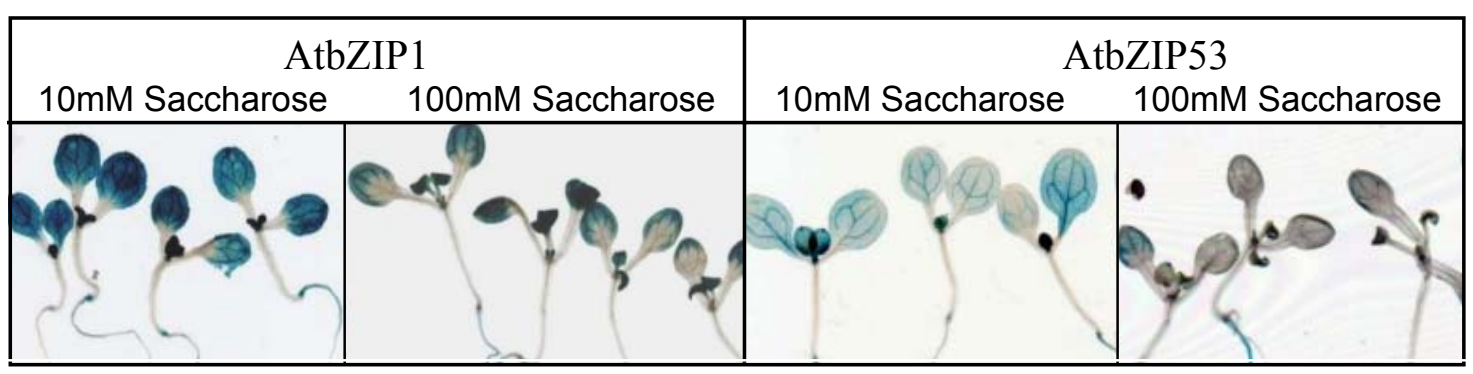

Abbildung 5.24: GUS-Färbungen zeigen eine Repression der Expression von AtbZIP1 und AtbZIP53 durch Saccharose. Samen der AtbZIP1 und AtbZIP53 Promotor-GUS Linien wurden Gasphasensterilisiert und in Sterilkultur auf MS-Medium mit 10 bzw. 100 mM Saccharose angezogen. Nach 8 Tagen wurden die Pflanzen geerntet und 24 Stunden mit 1mM X-Gluc / 1mM KaliumHexacyanoferrat gefärbt. 


\subsection{Transkriptomanalyse einer 35S:AtbZIP53 Linie zur Identifizierung von Zielgenen}

Um direkt oder indirekt regulierte Zielgene von AtbZIP53 zu identifizieren sollten die Transkriptome von ektopischen AtbZIP53-Überexprimierern und Wildtyp Pflanzen mit Hilfe von "Arizona whole-genome microarrays" miteinander verglichen werden. Die Mikroarray Experimente wurden in den Laboren von Jesus Vicente-Carbajosa und Roberto Solano in Madrid / Spanien durchgeführt.

$\mathrm{Da}$ in Northern Analysen für Pflanzen aus Sterilkultur auf MS Medium mit 2\% Saccharose bereits eine erhöhte Expression der ProDH in 35S:AtbZIP53 Pflanzen gezeigt werden konnte, wurden dieselben Bedingungen auch für die Mikroarray Experimente gewählt. Außerdem bietet die Anzucht auf MS Medium mit 2\% Saccharose die Vorteile, dass die Wuchsbedingungen sehr vergleichbar sind, die Pflanzen mit Wurzel geerntet werden können, und dass eine große Zahl von Pflanzen gleichzeitig geerntet werden kann, so dass zufällige Schwankungen besser herausgemittelt werden.

Die Transkriptomanalyse wurde mit 3 biologischen Replikaten durchgeführt, und für jedes Replikat wurden Pflanzen von 2 Petrischalen verwendet, so dass in jede Probe etwa 4g Pflanzenmaterial bzw. 200 Pflanzen einflossen. Die Proben wurden im Langtag angezogen und etwa 8 Stunden nach Beginn der Lichtphase komplett mit Wurzeln geerntet. Nach der Isolation der RNA wurde deren Qualität im Bioanalyzer überprüft (Abbildung 5.25).

Im Anschluss wurde die RNA zu Antisense RNA (aRNA) amplifiziert. Der Prozess der aRNA-Amplifikation beginnt mit einer reversen Transkription der zu untersuchenden RNA-Extrakte mit einem Oligo(dT)-Primer, der am 5'-Ende einen T7-Promotor enthält. Mit der nach der Zweitstrangsynthese erhaltenen cDNA wird dann eine in vitro Transkription mit T7 RNA Polymerase durchgeführt, wobei tausende Antisense RNA Kopien von jeder mRNA im Ausgangsmaterial erstellt werden. Die Qualität der so erhaltenen aRNA wurde ebenfalls im Bioanalyzer überprüft (Abbildung 5.26).

Für aRNA Proben wird eine erhöhte Zuverlässigkeit der mit ihnen erhaltenen Array Ergebnisse beschrieben, unabhängig davon, ob eine Amplifikation des Ausgangsmaterials notwendig ist oder nicht (Feldman et al., 2002; Polacek et al., 2003). 


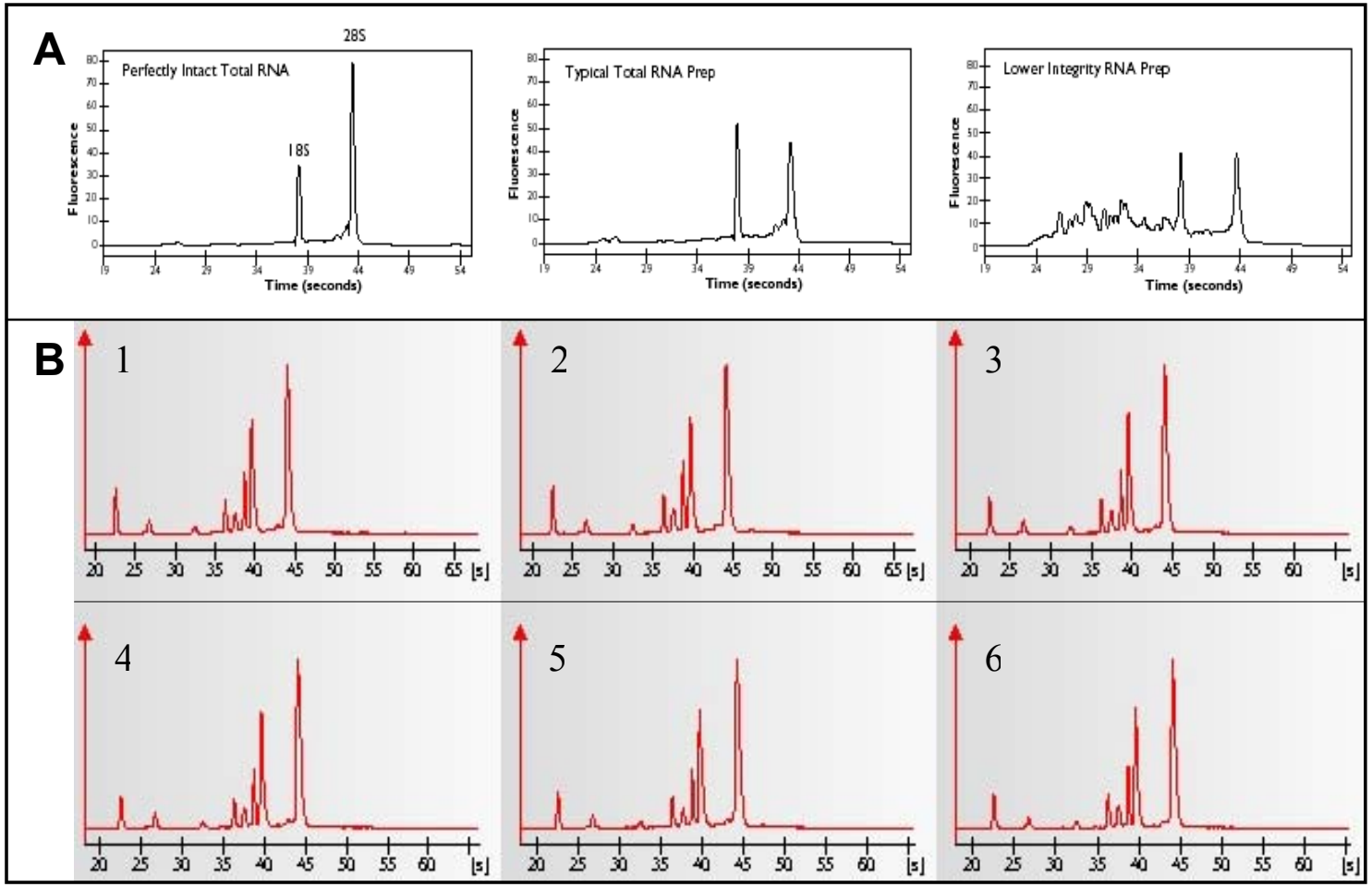

Abbildung 5.25: Qualitätskontrolle der für die Transkriptomanalyse eingesetzten Gesamt-RNA Extrakte mit dem Bioanalyzer. Die X-Achse gibt die Zeit an, die die RNA zum Durchwandern einer Gelmatrix benötigt, die Y-Achse die zum jeweiligen Zeitpunkt gemessene RNA-Menge. A: Beispiele für vollständig intakte RNA (links), eine durchschnittliche RNA-Präparation (Mitte) sowie teilweise degradierte RNA. B: Mit den drei biologischen Replikaten von Wildtyp (1-3) sowie 35S:HA-AtbZIP53 (4-6) Pflanzen erhaltene RNA-Profile. Die distinkten rRNA-Peaks sowie der sonstige Verlauf der Kurve nah an der Null-Linie lassen eine gute Qualität der RNA-Proben erkennen. Hier sind mehr Peaks zu erkennen als in den Beispielen unter (A), da diese Beispiele tierische RNA-Proben zeigen, denen die chloroplastidären rRNAs fehlen.

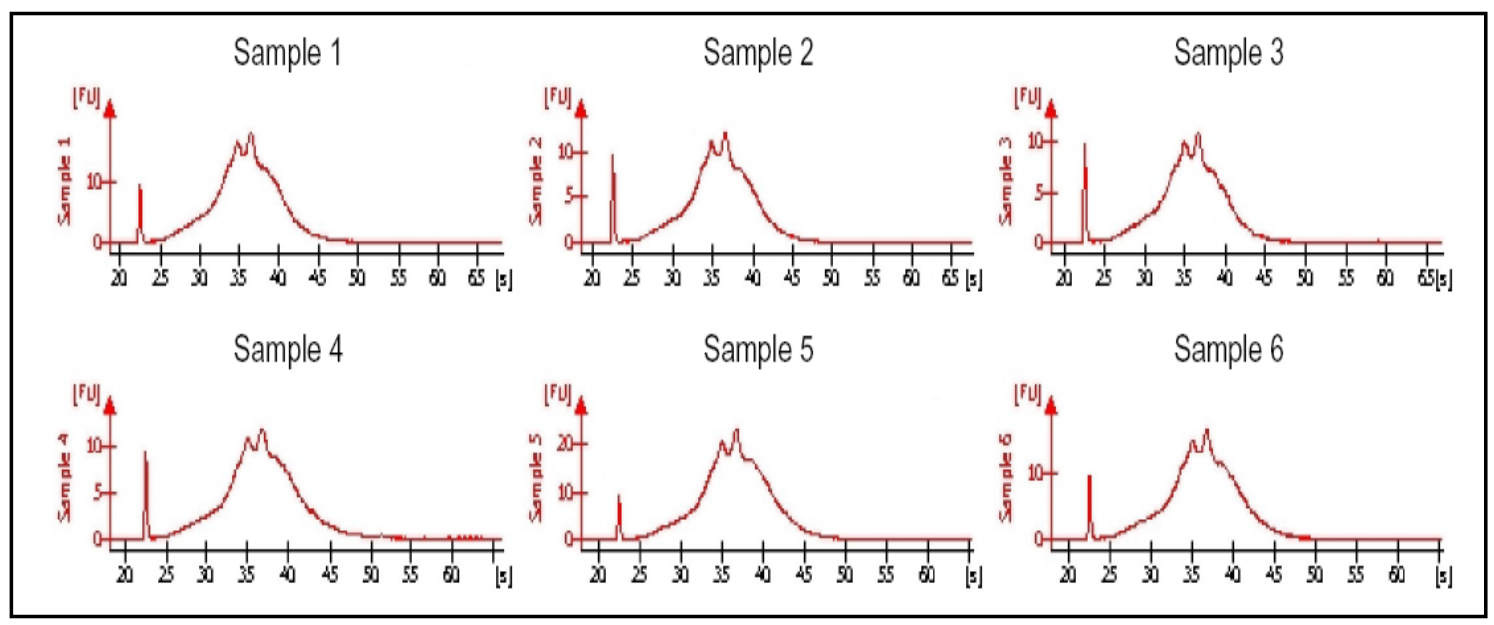

Abbildung 5.26: Qualitätskontrolle der aRNA im Bioanalyzer. Die Peaks der rRNAs sind verschwunden, dafür ist jetzt der hügelartige Verlauf der aRNAs, der equivalent zu dem von mRNAs ist, zu erkennen. Die Kurven belegen den Erfolg der aRNA-Synthese. Der Peak nach etwa 22 Sekunden stammt von einem in dem System verwendeten Farbmarker. Sample 1-3: Wildtyp aRNAs; Sample 4-6: 35S:HA-AtbZIP53 aRNAs. 
Das Markieren der aRNA fand indirekt statt, d.h., dass während der aRNA Synthese zunächst Aminoally-UTP eingebaut wurden, an das anschließend chemisch die Fluoreszenzfarbstoffe Cy3 bzw. Cy5 gekoppelt wurden. Dieses indirekte Fluoreszenzmarkieren bietet den Vorteil dass der Einbau von Aminoally-UTP während der aRNA-Synthese durch die T7-Polymerase wesentlich effizienter abläuft als der Einbau von bereits kovalent an die Fluoreszenzfarbstoffe gekoppelten UTPs.

Die fluoreszenzmarkierte Wildtyp- bzw. 35S:AtbZIP53 aRNA wurde anschließend auf "ARIZONA whole genome arrays" hybridisiert, und die hybridisierten Arrays mit einem "GenePix 4000B Microarray Scanner" eingelesen. Die richtige Platzierung der Felder für das Auslesen der Signalstärken der einzelnen Spots wurde von Hand überprüft und gegebenenfalls korrigiert, und die aus den 3 biologischen Replikaten erhaltenen Daten wurden mit der Software S.O.L.A.R. System der Firma Bioalma integriert.

Für jedes auf dem Array vertretene Gen wurde das Maß der differentiellen Regulation (Y-Achse) gegen die mittlere Signalstärke (X-Achse) aufgetragen (Abbildung 5.27). Die große Mehrheit der Punkte liegt dicht an der Nulllinie, was für einen niedrigen Hintergrund und für eine hohe Reproduzierbarkeit zwischen den Proben spricht, die wohl durch die große Zahl von Pflanzen in jeder Probe zu erklären ist.

Für die Identifizierung von in der 35S:AtbZIP53 Linie im Vergleich zum Wildtyp signifikant unterschiedlich exprimierten Genen wurden zunächst als Schwellenwerte ein P-Wert von höchstens 0,07 , eine Signalstärke von mindestens 50 sowie ein Unterschied in der Signalstärke (Ratio) von mindestens Faktor 2,4 festgesetzt.

In der Übersicht ist deutlich zu erkennen, dass nach diesen Definitionen in AtbZIP53 überexprimierenden Pflanzen im Vergleich zum Wildtyp mehr Gene induziert als reprimiert sind, und dass die Induktionen stärker sind als die Repressionen (Abbildung 5.27). Dies ist ein Ergebnis wie man es für die Überexpression eines Transkriptionsaktivators erwarten würde. In Zahlen sind nach diesen Definitionen 71 Gene in der 35S:AtbZIP53 Linie signifikant herauf reguliert (Tabelle 5.2) und 30 Gene signifikant herunter reguliert (Tabelle 5.3). Das am stärksten heraufregulierte Gen zeigt in der 35S:AtbZIP53 Linie ein 13,93fach stärkeres Signal als im Wildtyp, das am stärksten herunterregulierte Gen ein 5,13fach schwächeres Signal. 


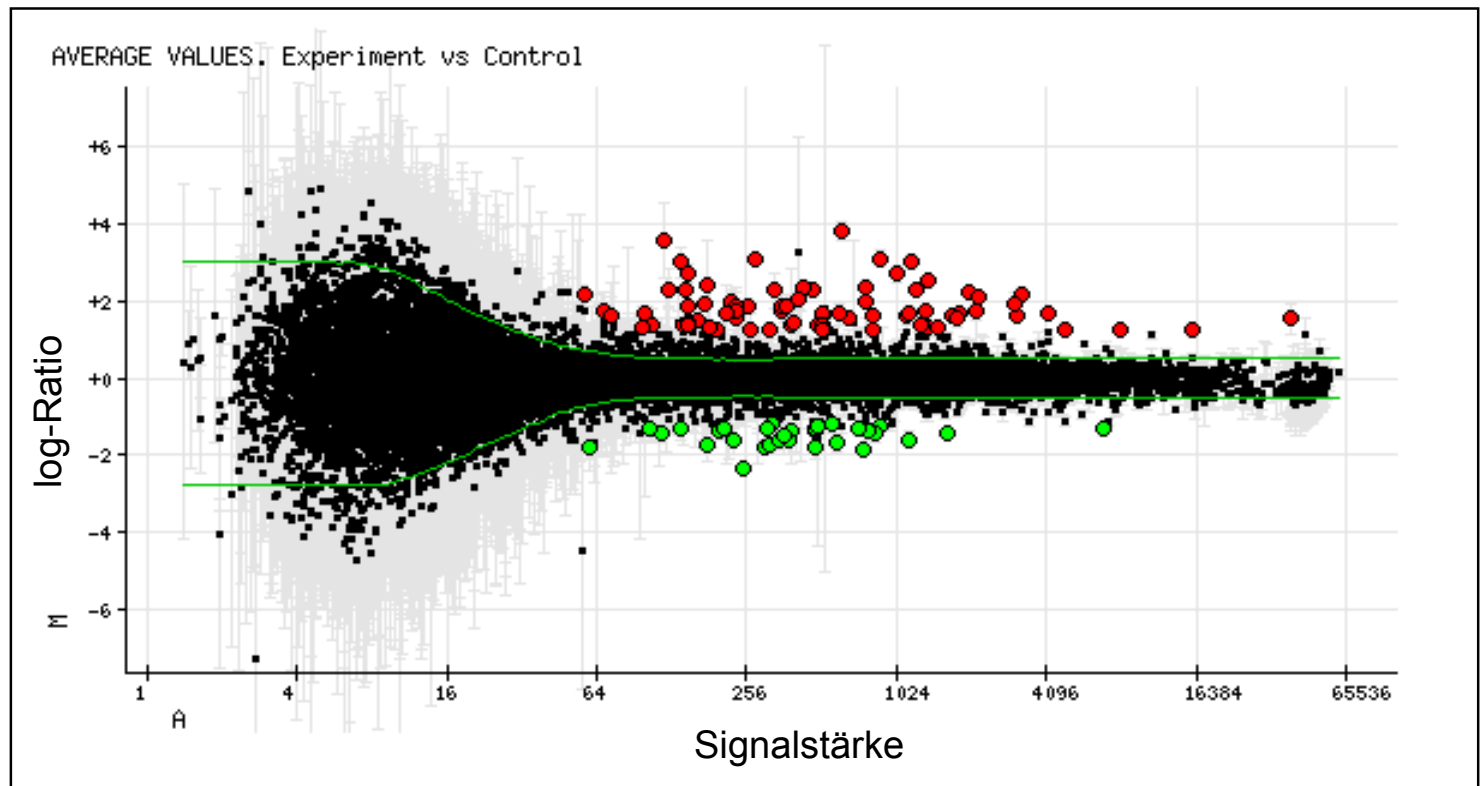

Abbildung 5.27: Verteilung nach Signalstärke und dem Logarithmus des Quotienten (log-Ratio) der Signale von 35S:HA-AtbZIP53 und Wildtyp Pflanzen. Die hellgrauen Balken geben die p-Werte der einzelnen Datenpunkte wieder. Rote Punkte: In 35S:HA-AtbZIP53 Pflanzen hochregulierte Gene mit einer Signalstärke von mindestens 50, einem p-Wert von höchstens 0,07, sowie einem log-Ratio von mindestens 1,25. Grüne Punkte: In 35S:HA-AtbZIP53 Pflanzen herunterregulierte Gene mit einer Signalstärke von mindestens 50, einem p-Wert von höchstens 0,07 , sowie einem log-Ratio von höchstens $-1,25$.

Tabelle 5.2: In 35S:AtbZIP53 Pflanzen stärker als im Wildtyp exprimierte Gene. In der Genevestigator-Analyse am stärksten in Samen exprimierte Gene sind grün gekennzeichnet, am stärksten in Pollen exprimierte Gene blau, am stärksten in seneszenten Blättern exprimierte Gene gelb und am stärksten in den Wurzeln exprimierte Gene braun. Gene in den weißen Feldern fallen in keine dieser Gruppen, kursiv geschriebene Gene sind in der GenevestigatorDatenbank nicht vorhanden und können deshalb nicht zugeordnet werden. Das Ratio gibt den Quotienten der für 35S:AtbZIP53 und Wildtyp Pflanzen erhaltenen Signale an, der p-Wert ihre statistische Signifikanz (je niedriger der $p$-Wert, desto zuverlässiger die Daten). Mit \# gekennzeichnete Gene enthalten ein ACGTGGC-Motiv in ihrem Promotor (siehe 5.6.3)

\begin{tabular}{|r|c|l|l|l|}
\hline Signal & Ratio & p-Wert & Beschreibung & AGI-Code \\
\hline 614 & 13,93 & 0,001 & legumin-like protein & At5g44120\# \\
\hline 13557 & 11,82 & 0,024 & unknown protein & At1g68250 \\
\hline 27975 & 8,22 & 0,000 & similar to myo-inositol oxygenase & At4g26260\# \\
\hline 1172 & 8,01 & 0,001 & 12S cruciferin seed storage protein & At4g28520\# \\
\hline 2110 & 7,94 & 0,006 & splicing factor SF3a like protein & At4g16200 \\
\hline 1014 & 6,47 & 0,002 & trehalose-6-phosphate phosphatase-like protein & At4g22590\# \\
\hline 149 & 6,43 & 0,002 & similar to PEP-carboxykinase (ATP) -like protein & At5g65690 \\
\hline 1379 & 5,65 & 0,001 & NWMU1 - 2S albumin 1 precursor & At4g27140 \\
\hline 177 & 5,32 & 0,067 & putative cruciferin 12S seed storage protein & At1g03880 \\
\hline 763 & 5,11 & 0,001 & NWMU2 - 2S albumin 2 precursor; protein id & At4g27150 \\
\hline 432 & 5,01 & 0,003 & NWMU4 - 2S albumin 4 precursor; protein id & At4g27170 \\
\hline 126 & 4,88 & 0,016 & glycosyl hydrolase family protein 17 & At5g63240 \\
\hline 1220 & 4,86 & 0,001 & Prolindehydrogenase & At3g30775 \\
\hline 146 & 4,85 & 0,013 & acireductone dioxygenase (ARD/ARD') family protein & At2g26400 \\
\hline 475 & 4,82 & 0,001 & NWMU3 - 2S albumin 3 precursor & At4g27160 \\
\hline 1993 & 4,54 & 0,001 & unknown protein & At1g14880 \\
\hline 3243 & 4,4 & 0,003 & glutamine-dependent asparagine synthetase & At3g47340 \\
\hline 58 & 4,4 & 0,000 & peroxiredoxin & At1g48130\# \\
\hline 2182 & 4,28 & 0,002 & pathogenesis-related PR-1-like protein & At2g14610 \\
\hline & & & & \\
\hline
\end{tabular}




\begin{tabular}{|c|c|c|c|c|}
\hline 220 & 3,96 & 0,008 & RNA polymerase II fifth largest subunit like protein & At4g14660 \\
\hline 769 & 3,96 & 0,001 & putative $\mathrm{Fe}(\mathrm{II}) /$ ascorbate oxidase & At4g10500 \\
\hline 174 & 3,76 & 0,002 & 11-beta-hydroxysteroid dehydrogenase-like & At5g50600 \\
\hline 356 & 3,66 & 0,008 & disease resistance protein (TIR class), putative & At1g19960 \\
\hline 149 & 3,65 & 0,011 & hypothetical protein & At1g13470 \\
\hline 259 & 3,58 & 0,003 & galactinol synthase & At1g56600 \\
\hline 234 & 3,54 & 0,015 & MADS-box protein & At5g65080 \\
\hline 373 & 3,52 & 0,013 & putative trehalose-6-phosphate phosphatase (AtTPPA); & At4g12430\# \\
\hline 57 & 3,38 & 0,031 & unknown protein & At3g07600 \\
\hline 355 & 3,37 & 0,003 & lipase class 3-related & At5g24200 \\
\hline 231 & 3,29 & 0,037 & thionin, putative & At2g15010 \\
\hline 2136 & 3,26 & 0,006 & Expressed protein & At3g22231 \\
\hline 69 & 3,25 & 0,028 & oleosin & At3g01570\# \\
\hline 1324 & 3,24 & 0,001 & nucleoid DNA-binding protein cnd41 - like protein & At5g10760 \\
\hline 510 & 3,23 & 0,001 & ankyrin repeat family protein & At1g10340 \\
\hline 1828 & 3,2 & 0,001 & unknown protein & At2g14560\# \\
\hline 101 & 3,18 & 0,002 & AlL1; LEA76 homologue type2 & At3g15670\# \\
\hline 4111 & 3,17 & 0,001 & glycosyl hydrolase family 36 & At3g57520\# \\
\hline 210 & 3,15 & 0,061 & putative protein & At5g45630\# \\
\hline 1136 & 3,14 & 0,004 & germin-like protein (GLP1) (GLP4) & At1g18970 \\
\hline 608 & 3,13 & 0,009 & putative protein & At5g41080\# \\
\hline 511 & 3,09 & 0,000 & branched chain aminoacid transaminase & At1g10070\# \\
\hline 1114 & 3,08 & 0,002 & hypothetical protein & At2g18660 \\
\hline 828 & 3,06 & 0,001 & putative protein & At3g45730 \\
\hline 74 & 3,03 & 0,032 & aminoacid transporter family protein & At2g41190\# \\
\hline 3134 & 3,01 & 0,002 & AtbZIP53 & At3g62420 \\
\hline 1691 & 3,01 & 0,002 & CTP synthase-like protein & At1g30820 \\
\hline 657 & 2,97 & 0,001 & similar to Fructose-2,6-bisphosphatase & At3g60420 \\
\hline 69 & 2,96 & 0,007 & hypothetical protein & At1g56660\# \\
\hline 1768 & 2,96 & 0,008 & Lipoxygenase - defense gene conferring resistance & At1g55020 \\
\hline 230 & 2,93 & 0,005 & ankyrin-repeat-containing protein-like & At5g54610 \\
\hline 39126 & 2,9 & 0,020 & expressed protein & At2g25510 \\
\hline 161 & 2,83 & 0,000 & polygalacturonase, putative & At5g14650 \\
\hline 68 & 2,73 & 0,023 & unknown protein & At1g54095 \\
\hline 398 & 2,66 & 0,014 & protein kinase, putative & At4g23160 \\
\hline 148 & 2,64 & 0,032 & hypersensitive response protein 3 (HR3) & At3g50470 \\
\hline 390 & 2,62 & 0,008 & glycosyl hydrolase family 1, beta-glucosidase & At3g60140 \\
\hline 496 & 2,58 & 0,001 & proline oxidase, mitochondrial precursor -like protein & At5g38710 \\
\hline 515 & 2,58 & 0,001 & cytochrome P450, putative & At1g01190 \\
\hline 1269 & 2,55 & 0,005 & zinc finger family protein / ankyrin repeat family protein & At4g14365 \\
\hline 106 & 2,54 & 0,040 & NAM (no apical meristem)-like protein & At1g02230 \\
\hline 149 & 2,54 & 0,048 & leucine-rich repeat transmembrane protein kinase, putativ & At1g35710 \\
\hline 142 & 2,53 & 0,002 & tonoplast intrinsic protein, alpha (alpha-TIP) & At1g73190 \\
\hline 1504 & 2,51 & 0,003 & flavanone 3-hydroxylase-like protein; & At5g24530 \\
\hline 1369 & 2,49 & 0,002 & glutamine amidotransferase-related; & At1g15045 \\
\hline 180 & 2,49 & 0,004 & oleosin & At3g27660 \\
\hline 97.7 & 2.49 & 0,055 & trehalose-phosphatase, putative & At1g35910 \\
\hline 1369 & 2,49 & 0,002 & hypothetical protein; & At3g27660 \\
\hline 52 & 2,48 & 0,008 & embryo-specific protein 3 (ATS3); & At5g07190 \\
\hline 68 & 2,46 & 0,042 & NAM (no apical meristem)-like protein; & At2g17040 \\
\hline 8064 & 2,4 & 0,002 & calcium binding protein (CaBP-22); & At2g41090 \\
\hline 524 & 2,4 & 0,009 & putative calcium-binding protein; & At3g47480 \\
\hline 4858 & 2,4 & 0,005 & hypothetical protein; & At1g67020 \\
\hline
\end{tabular}




\subsubsection{Gene mit einer erhöhten Expression in der 35S:AtbZIP53 Linie zeigen gewebespezifische Expressionsmuster}

Direkte Zielgene von AtbZIP53 sind am ehesten in der Gruppe der aktivierten Gene zu erwarten. Hier fällt zunächst auf, dass alle $12 S$ und $2 S$ Samenspeicherprotein-Gene in dieser Gruppe vertreten sind. Darüber hinaus finden sich weitere samenspezifische Gene wie Oleosin, Thionin oder ein LEA-Gen.

Um zu prüfen, ob auch andere der induzierten Gene eine samenspezifische Expression zeigen, sowie um einen Überblick über die gewebespezifische Expression der putativen Zielgene $\mathrm{zu}$ erhalten, wurden die 50 am stärksten aktivierten Gene mit dem Metaanalyzer Programm der Genevestigator Software (Zimmermann et al., 2004) auf ihr Expressionsmuster hin analysiert (Abbildung 5.28). Dieses Programm fasst Daten mehrerer Mikroarray-Experimente zur gewebespezifischen Expression zusammen, und ermöglicht so für einzelne Gene die Expression in verschiedenen Geweben miteinander zu vergleichen. Für jedes Gen werden die stärksten gemessenen Expressionen dunkelblau, die schwächsten weiß dargestellt. Da einige der aktivierten Gene auf den Affymetrix Mikroarrays, mit denen die Daten der Genevestigator-Datenbank erzeugt wurden, nicht vorhanden sind, konnten diese nicht analysiert werden.

In der Analyse der Gewebespezifität der Expression der 50 am stärksten aktivierten Gene fällt auf, dass ein Großteil von ihnen in eine von drei Gruppen fällt, die entweder eine starke samenspezifische oder pollenspezifische Expression zeigen, oder deutlich am stärksten in seneszenten Blättern exprimiert werden. Die Gruppe der pollenspezifischen Gene, die auch das bereits bekannte Zielgen ProDH enthält, unterstützt die aufgrund der Promotor-GUS Daten aufgestellte Vermutung, dass AtbZIP-Transkriptionsfaktoren der Gruppen C und S1 an der Pollenentwicklung beteiligt sind. Die anderen Gruppen können als Hinweis auf eine Beteiligung von AtbZIP53 an der Samenentwicklung bzw. Seneszenz gesehen werden.

Neben der Analyse der gewebespezifischen Expressionsmuster wurde mit Genevestigator auch eine Analyse der Stressregulation der in den 35S:AtbZIP53 Pflanzen im Vergleich zum Wildtyp am stärksten aktivierten Gene durchgeführt (Abbildung 5.29). Hier zeigt sich ein wesentlich heterogeneres Bild. Insgesamt sind in der über Genevestigator analysierbaren Datenbank Mikroarray-Experimente zu 76 verschiedenen Stressen vorhanden. Zu Gunsten der Übersichtlichkeit sind hier nur 


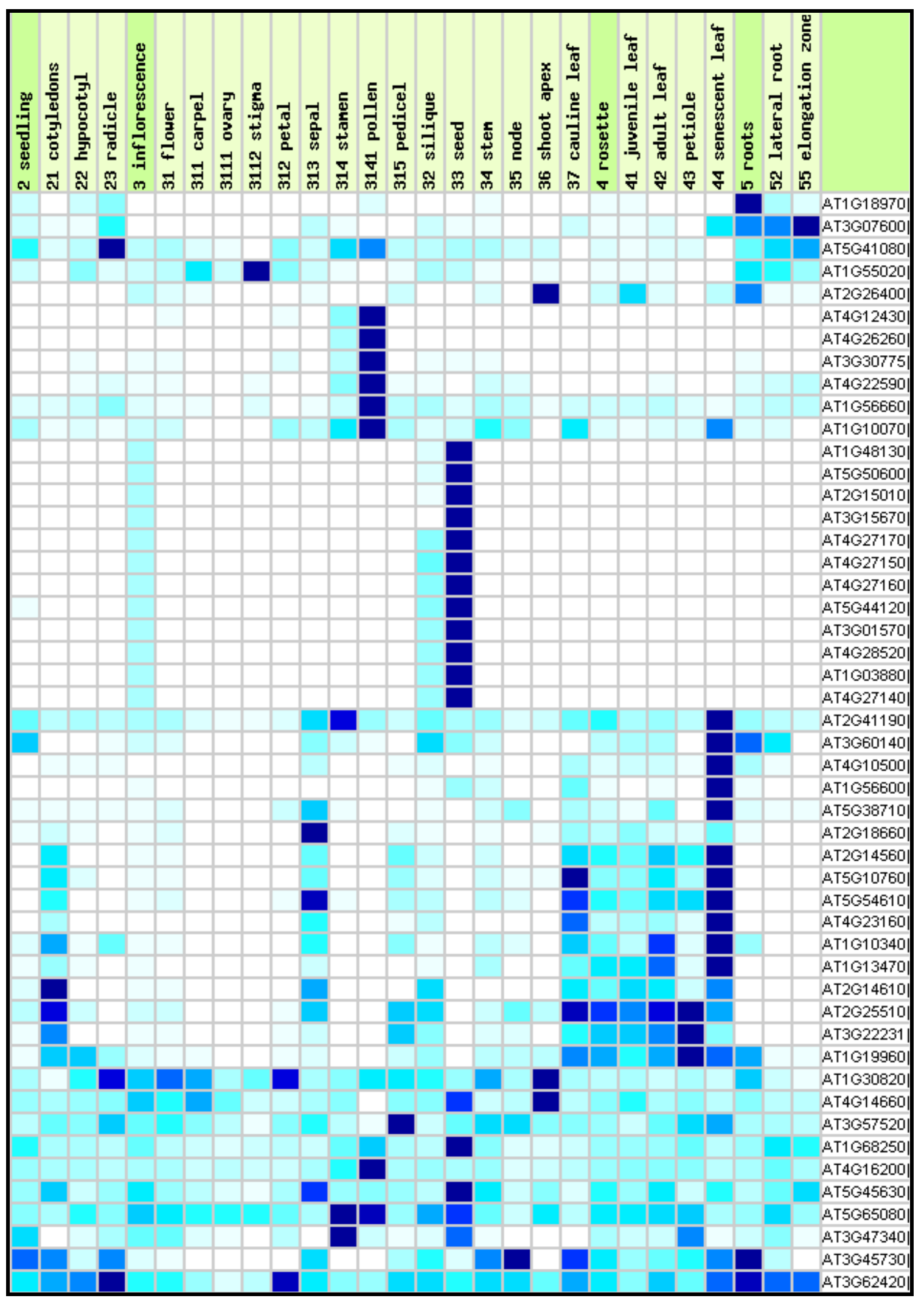

Abbildung 5.28: Genevestigator-Analyse der gewebespezifischen Expressionsmuster der in den 35S:AtbZIP53 Pflanzen im Vergleich zum Wildtyp am stärksten aktivierten Gene. Je dunkler das Blau, desto stärker ist die Expression in dem jeweiligen Gewebe. Für die Darstellung wurden Kallus und Zellkultur von der Liste der Gewebe ausgeschlossen, verwendete Einstellungen für die Berechnung der Cluster waren Euclidean und Average. Entsprechend den Ergebnissen dieser Analyse wurden die Gene in Tabelle 5.2 den jeweiligen Gruppen zugeordnet. 


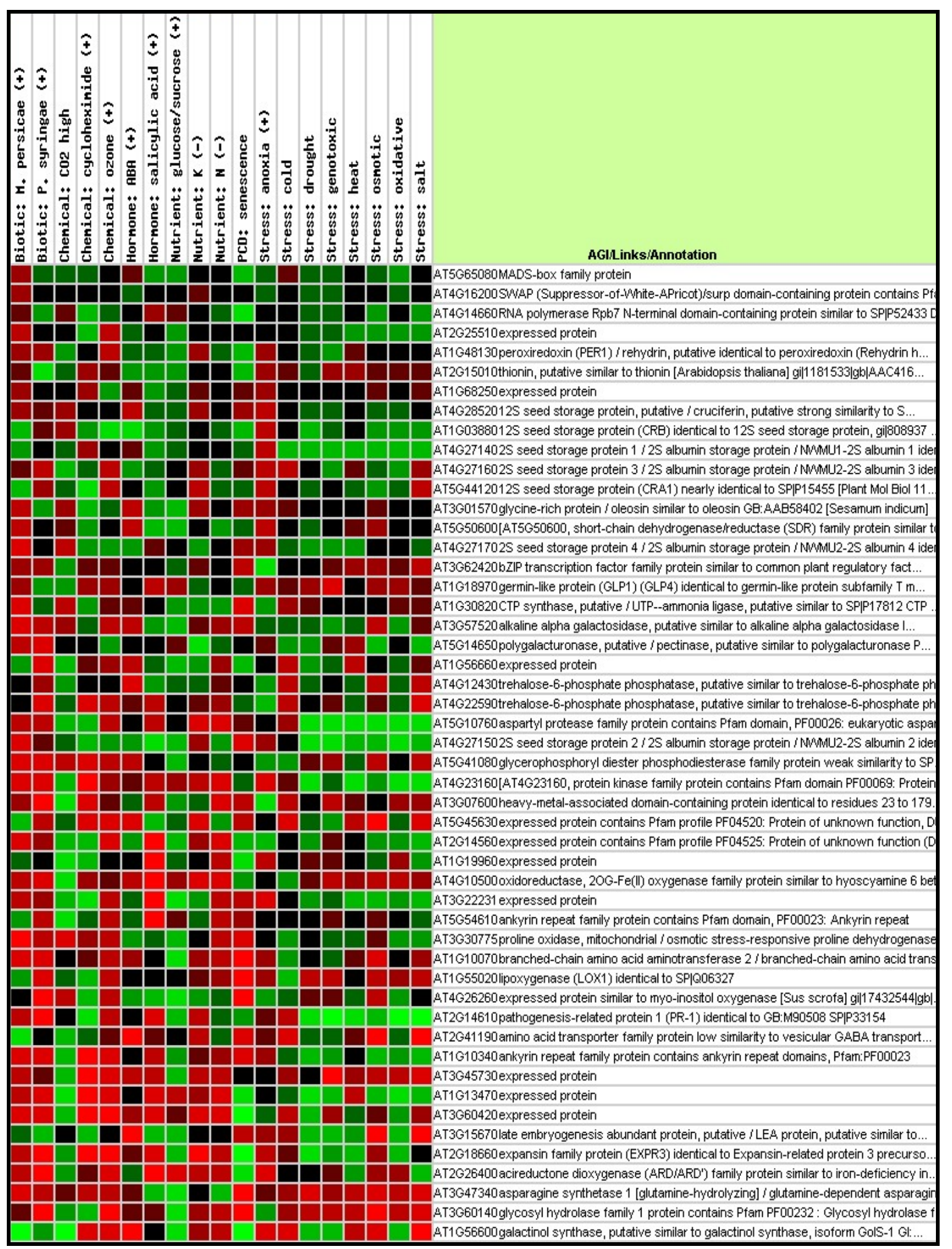

Abbildung 5.29: Übersicht über die Regulation der in 35S:AtbZIP53 Pflanzen aktivierten Gene unter verschiedene Stressbedingungen. Die Beschriftungen oben bezeichnen das jeweilige Experiment, rechts sind verschiedenen aktivierten Gene aufgeführt. Ist ein Feld rot, ist das Gen im Experiment stärker exprimiert, ist es grün, so ist das Gen im Experiment schwächer exprimiert. Je heller die Farben sind, desto stärker ist die Differenz zwischen Experiment und Kontrolle. Schwarze Felder bedeuten eine gleichstarke Expression in Experiment und Kontrolle. 
Experimente gezeigt, in denen ein Grossteil der Gene eine deutliche Regulation zeigt, sowie verschiedene Experimente zu abiotischem Stress, da für AtbZIP53-ähnliche Transkriptionsfaktoren mehrfach eine Beteiligung an der Antwort auf abiotischen Stress postuliert wurde (siehe Einleitung, Kapitel 2.6). Es fällt auf, dass viele Gene durch Infektion mit den Pathogenen M. persicae oder Pseudomonas syringae, oder nach Behandlung mit dem in der Pathogenabwehr wichtigen Hormon Salicylsäure induziert werden. Möglicherweise hat AtbZIP53 also auch eine Funktion in der Pathogenabwehr. Zudem finden sich auch hier viele durch Seneszenz induzierte Gene. In diesem Fall wurde die Seneszenz in einer Zellkultur durch Zucker-Verarmung induziert, weshalb sie als Stress aufgeführt ist.

\subsubsection{Gene mit einer reduzierten Expression in der 35S:AtbZIP53 Linie zeigen keine einheitlichen Expressionsmuster}

Unter den in der 35S:AtbZIP53 Linie reprimierten Gene wird der Anteil an Genen, deren Regulation auf sekundäre und indirekte Effekte zurückzuführen ist, erwartungsgemäß größer sein. Entsprechend fällt hier auch die Zuordnung der Gene in verschiedene Kategorien schwerer. Es fällt auf, dass in dieser Gruppe der Anteil an Transkriptionsfaktoren deutlich größer ist als in der Gruppe der aktivierten Gene. Des weiteren sind auch unter den reprimierten Genen zwei Thionine, die aber nicht in Samen exprimiert werden. Für die reprimierten Gene wurde ebenfalls eine Analyse der Expressionsmuster mit dem Metaanalyzer Werkzeug der Genevestigator Software durchgeführt.

In der Analyse der gewebespezifischen Expression zeigte keines der reprimierten Gene eine nennenswerte Expression in Pollen, jedoch finden sich auch hier 4 vorwiegend in Samen und zwei vorwiegend in seneszenten Blättern exprimierte Gene (Abbildung 5.30). Eine möglicherweise interessante Gruppe sind die vier am stärksten in Blütenblättern exprimierten Gene, von denen drei zu den zehn am stärksten reprimierten Genen gehören. Auch AtbZIP53 wird laut Genevestigator mit am stärksten in den Blütenblättern exprimiert, jedoch zeigt keines der aktivierten Gene eine vergleichbare Expression. In der Analyse der Stressregulation der reprimierten Gene zeichnen sich keine klaren Gruppen ab, die einen Hinweis auf die Funktion von AtbZIP53 geben könnten. 
Tabelle 5.3: In 35S:AtbZIP53 Pflanzen schwächer als im Wildtyp exprimierte Gene. Transkriptionsfaktoren sind blau unterlegt. In der Genevestigator-Analyse am stärksten in Samen exprimierte Gene sind grün gekennzeichnet, und am stärksten in seneszenten Blättern exprimierte Gene gelb. Am stärksten in Blütenblättern exprimierte Gene sind fett geschrieben. Das Ratio gibt den Quotienten der für 35S:AtbZIP53 und Wildtyp Pflanzen erhaltenen Signale an, der $p$-Wert ihre statistische Signifikanz (je niedriger der $p$-Wert, desto zuverlässiger die Daten).

\begin{tabular}{|c|c|c|c|c|}
\hline Signal & Ratio & p-Wert & Beschreibung & AGI-Code \\
\hline 246 & $-5,13$ & 0,000 & cell wall protein precursor & At2g20870 \\
\hline 756 & $-3,62$ & 0,001 & similar to GCN5-related $\mathrm{N}$-acetyltransferase family protein & At2g39030 \\
\hline 483 & $-3,49$ & 0,010 & lipase family protein & At5g14180 \\
\hline 60 & $-3,48$ & 0,039 & putative auxin-induced protein & At2g37030 \\
\hline 303 & $-3,43$ & 0,003 & putative helix-loop-helix DNA-binding protein & At1g73830 \\
\hline 177 & $-3,39$ & 0,016 & expressed protein & At5g22430 \\
\hline 314 & $-3,31$ & 0,004 & MADS-box protein & At1g24260 \\
\hline 586 & $-3,25$ & 0,006 & zinc finger (CCCH-type) family protein & At5g44260 \\
\hline 62 & $-3,21$ & 0,042 & thionin & At1g72260 \\
\hline 343 & $-3,12$ & 0,007 & thionin, putative & At1g66100 \\
\hline 380 & $-3,07$ & 0,016 & putative protein & At5g62280 \\
\hline 224 & $-3,06$ & 0,014 & auxin-responsive family protein & At3g53250 \\
\hline 1148 & $-3,01$ & 0,005 & unknown protein & At2g44080 \\
\hline 364 & $-2,82$ & 0,030 & ribonuclease, RNS1 & At2g02990 \\
\hline 117 & $-2,74$ & 0,006 & RING-H2 finger protein RHA3a, putative & At1g49200 \\
\hline 832 & $-2,72$ & 0,008 & unknown protein & At5g57760 \\
\hline 1641 & $-2,69$ & 0,002 & AP2 domain protein RAP2.8 (RAV2) & At1g68840 \\
\hline 386 & $-2,64$ & 0,005 & member of the ERF subfamily B-3 of ERF/AP2 & At5g51190 \\
\hline 477 & $-2,63$ & 0,006 & nonspecific lipid-transfer protein precursor - like & At5g59310 \\
\hline 782 & $-2,61$ & 0,008 & expressed protein & At1g53870 \\
\hline 197 & $-2,60$ & 0,010 & lipase family protein & At5g14180 \\
\hline 6946 & $-2,53$ & 0,004 & $\begin{array}{l}\text { J8-like protein, DNAJ heat shock N-terminal domain- } \\
\text { containing protein }\end{array}$ & At1g80920 \\
\hline 138 & $-2,52$ & 0,013 & putative protein & At5g03090 \\
\hline 484 & $-2,52$ & 0,018 & putative tyrosine aminotransferase & At2g24850 \\
\hline 83 & $-2,52$ & 0,027 & protochlorophyllide oxidoreductase A (gb|AAC49043.1) & At5g54190 \\
\hline 311 & $-2,50$ & 0,019 & quinone oxidoreductase -like protein & At5g37940 \\
\hline 206 & $-2,49$ & 0,016 & phytochrome kinase substrate 1 - like protein & At5g04190 \\
\hline 105 & $-2,45$ & 0,023 & hypothetical protein & At2g22880 \\
\hline 715 & $-2,44$ & 0,009 & ethylene responsive element binding factor 2 (EREBP-2) & At5g47220 \\
\hline 60 & $-2,43$ & 0,017 & $\begin{array}{l}\text { isopentenyl pyrophosphate:dimethyllallyl pyrophos- } \\
\text { phate isomerase }\end{array}$ & At5g16440 \\
\hline
\end{tabular}




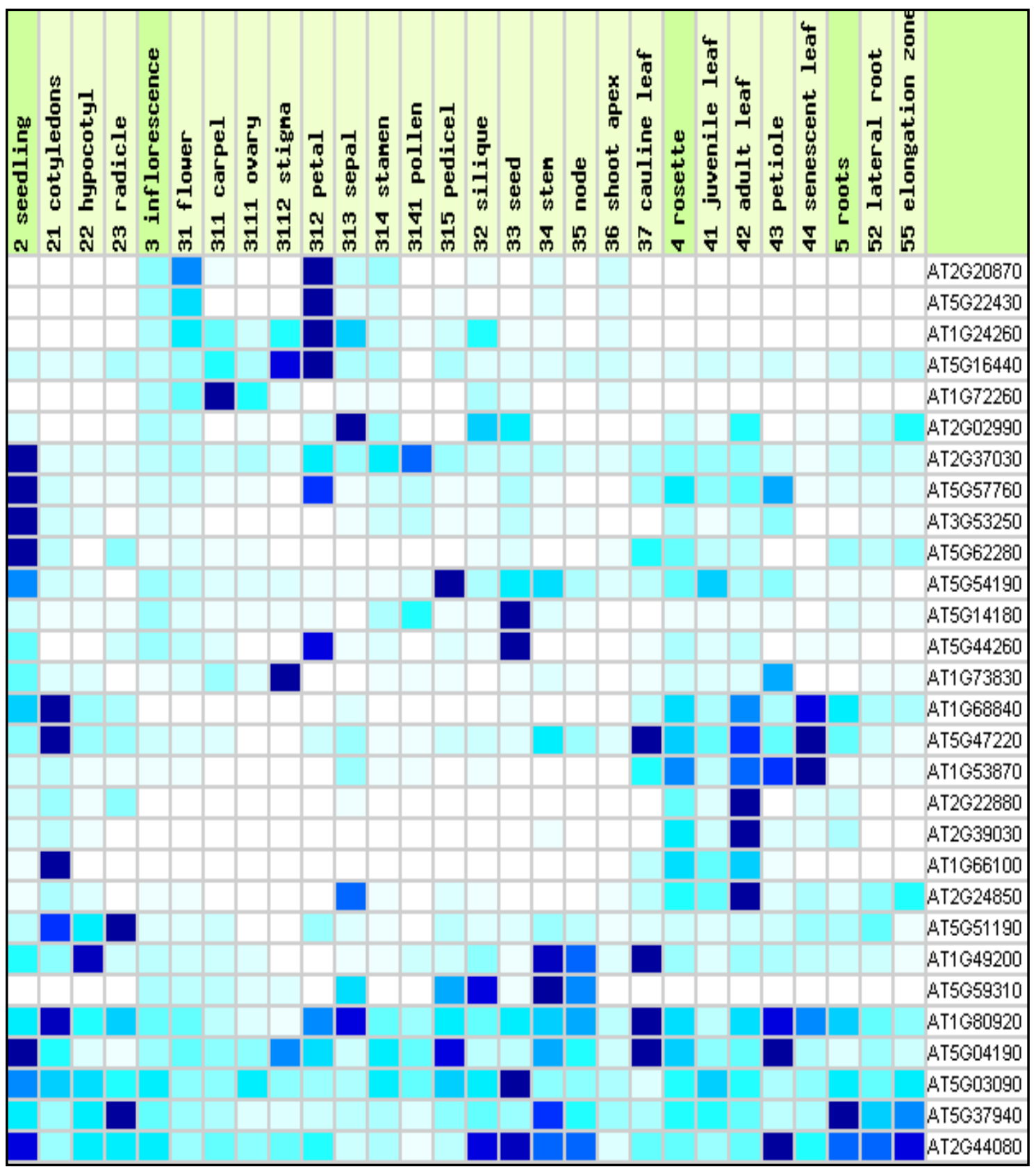

Abbildung 5.30: Genevestigator-Analyse der gewebespezifischen Expressionsmuster der in den 35S:AtbZIP53 Pflanzen im Vergleich zum Wildtyp am stärksten reprimierten Gene. Je dunkler das blau, desto stärker ist die Expression in dem jeweiligen Gewebe. Für die Darstellung wurden Kallus und Zellkultur von der Liste der Gewebe ausgeschlossen, verwendete Einstellungen für die Berechnung der Cluster waren Euclidean und Average. Entsprechend den Ergebnissen dieser Analyse wurde die Gene in Tabelle 5.3 den jeweiligen Gruppen zugeordnet. 


\subsubsection{Die Analyse der Promotoren von in der 35S:AtbZIP53 Linie stärker exprimierten Genen zeigt ein gehäuftes Auftreten eines ACGTGGC- Motivs}

Da AtbZIP53 wahrscheinlich als Heterodimer seine Zielgene reguliert, und die von AtbZIP53 gebundenen cis-Elemente wahrscheinlich auch von dem Heterodimerisierungspartner abhängen (Matsushima-Hibiya et al., 1998), wird es schwierig sein, ein konkretes Bindeelement zu identifizieren. Solche Aussagen anhand der Arraydaten werden zusätzlich erschwert, da die Überexpression über einen langen Zeitraum erfolgte, so dass wahrscheinlich nur ein Teil der aktivierten Gene direkte Zielgene sind.

Nichtsdestotrotz zeigen Promotoranalysen der Gene mit einer erhöhten Expression in der 35S:AtbZIP53 Linie mit dem Programm POBO (promoter bootstrapping program, Kankainen und Holm, 2004) ein deutlich gehäuftes Auftreten von ACGT-Motiven, einer klassischen Erkennungssequenz von bZIP-Transkriptionsfaktoren, ebenso wie von den für die ProDH beschriebenen ACTCAT-Motiv (Abbildung 5.31). Um ein möglicherweise bevorzugt von AtbZIP53 gebundenes cis-Element über das $A C G T$ Motiv hinaus zu definieren wurde analysiert, welche Basen gehäuft vor und hinter der $A C G T$-Sequenz vorkommen.

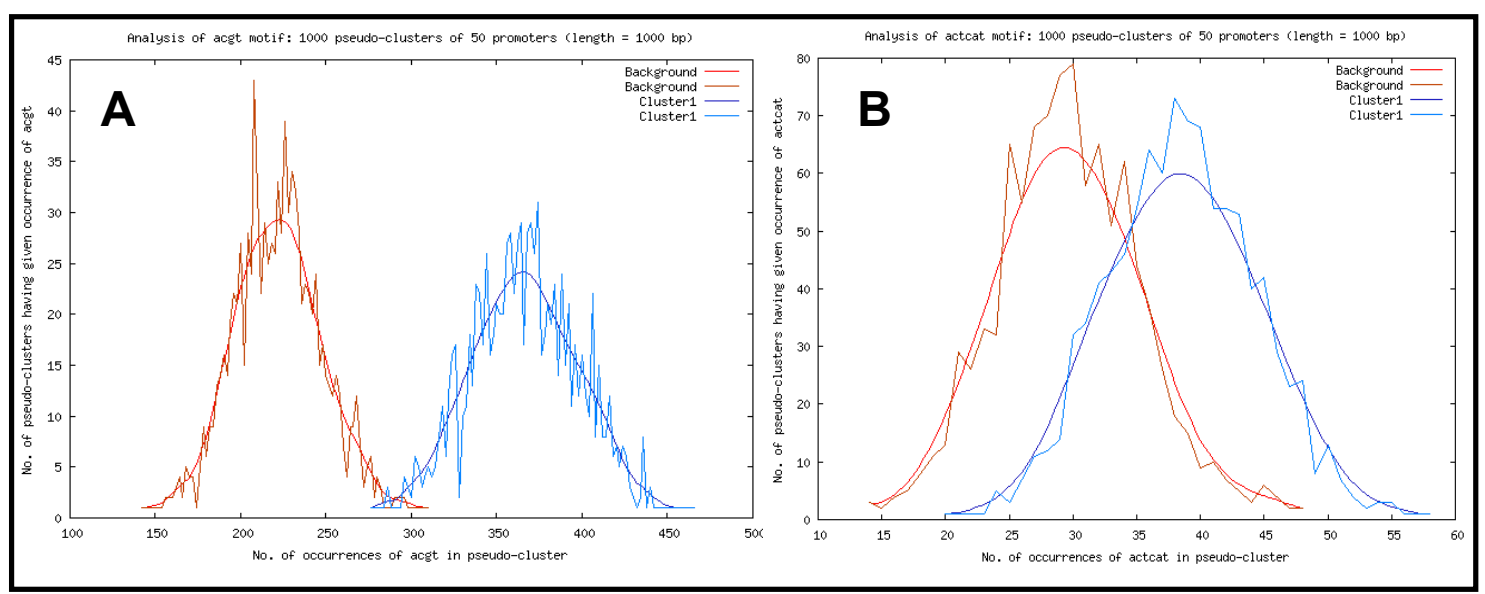

Abbildung 5.31: Analyse der -1 bis -1000 bp Promotorregionen der 57 in 35S:HA-AtbZIP53 Pflanzen am stärksten aktivierten Gene mit dem Programm POBO. A: Häufigkeit des $A C G T$ Motivs; B: Häufigkeit des ACTCAT-Motivs; 52 der 57 aktivierten Promotoren enthielten $A C G T$ Motive, 32 ACTCAT-Motive. Als Kontrolle diente Arabidopsis_thaliana_full, ein Datensatz der die 1000bp Promotorregionen fast aller Gene aus Arabidopsis enthält. Die Bootstrap-Analysen wurden mit jeweils mit 1000 Clustern aus je 50 Promotoren durchgeführt. Die roten Linien zeigen die Häufigkeit des untersuchten Motivs in der Kontrollgruppe, die blau Linie die Häufigkeit des Motivs in den Promotoren der aktivierten Gene (X-Achse: Häufigkeit des Motivs im Pseudo-Kluster; Y-Achse: Zahl der Pseudokluster). 
Als Vergleich diente eine Kontrollgruppe, welche die 1000bp Promotorregionen fast aller Gene aus Arabidopsis enthält. Während alle Basen etwa gleich häufig vor dem $A C G T$-Motiv auftraten (nicht gezeigt), fand sich an der Position hinter dem ACGTMotiv sowohl in absoluten Zahlen als auch relativ zur Kontrolle am häufigsten ein Guanosin (Abbildung 5.32; Von den 57 aktivierten Promotoren enthielten 47 zusammen 137 ACGTG-Motive). Verfolgt man dieses Vorgehen weiter, so ist die häufigste Base nach dem Guanosin ein weiteres Guanosin (23 Promotoren enthielten zusammen 35 ACGTGG-Motive), gefolgt von einem Cytosin. Dieses Motiv, $A C G T G G C$, findet sich in 15 der aktivierten Gene und tritt etwa dreimal häufiger auf als in der Kontrollgruppe. Diese Sequenz ist in der Literatur als ABA-responsive- (ABRE-) Element beschrieben, ein cis-Element, das für die Regulation verschiedener Gene durch das Phytohormon Abscisinsäure verantwortlich ist (Busk und Pages, 1998; Shen et al., 2004; Straub et al., 1994). In der Liste der aktivierten Gene (Tabelle 5.2) wurden diejenigen Gene, die dieses Motiv in ihrem Promotor enthalten, mit einem \# gekennzeichnet. Tatsächlich wird ein Teil der Gene, die dieses Element in ihrem Promotor enthalten, wie zum Beispiel das LEA-Gen AIL1, ein Trehalose-6-Phosphat Phosphatase-Gen, eine branched chain aminoacid transaminase (BCAT) oder ein Gen das einen putativen Aminosäuretransporter codiert (At2g41190), deutlich durch ABA induziert.

Aufgrund des gehäuften Auftretens des ABRE-Motives wurde vermutet, AtbZIP53 oder einer seiner Heterodimerisierungspartner könnte deutlich durch ABA induziert werden. Northern-Analysen zeigten jedoch keine Induzierbarkeit von AtbZIP53 durch ABA (nicht gezeigt), und auch in veröffentlichten Mikroarray-Daten findet sich keine solche Induktion. Unter den potentiellen Heterodimerisierungspartnern zeigt nur AtbZIP9 eine Induktion durch ABA, die zudem sehr schwach ist (nicht gezeigt). 

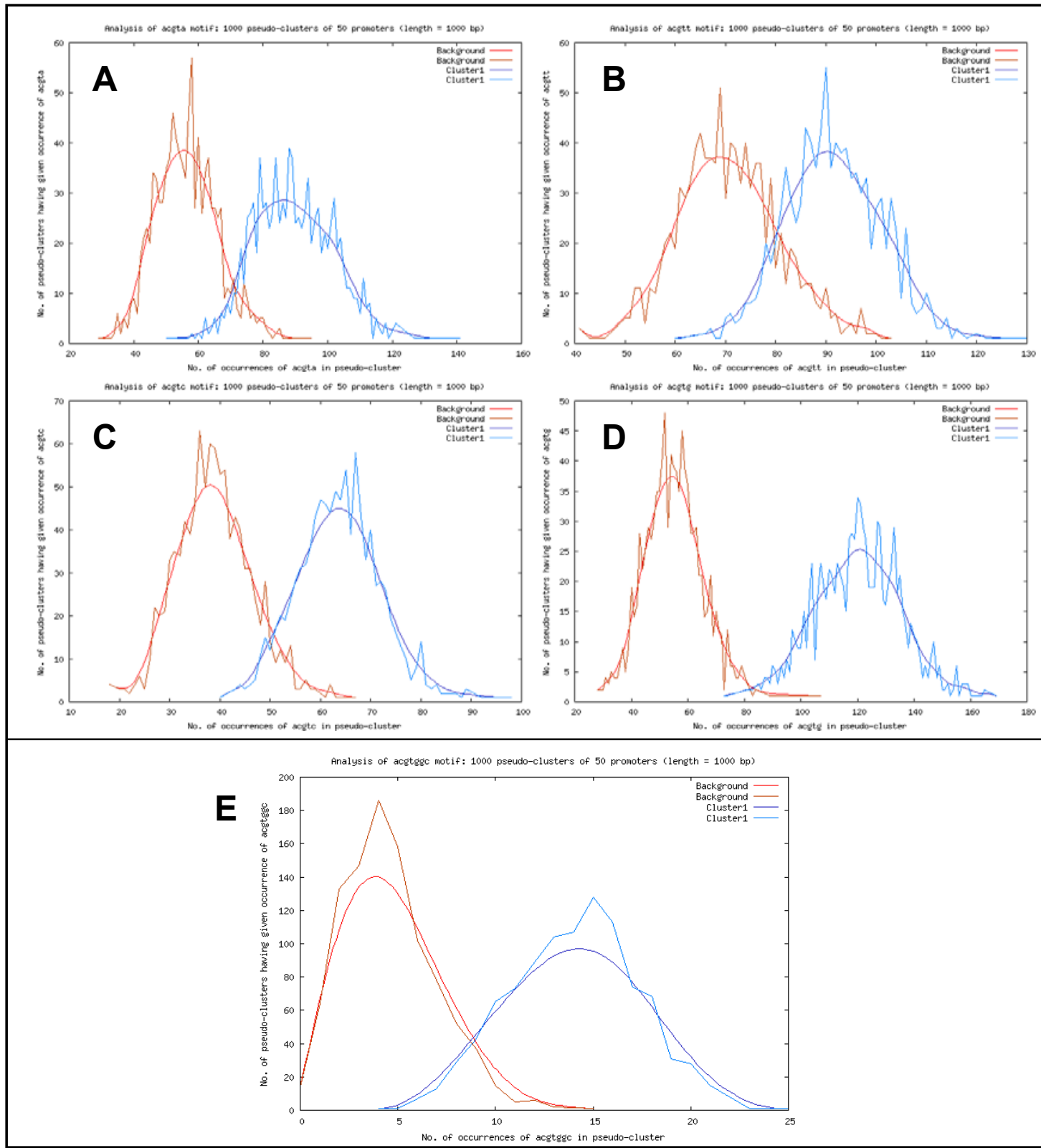

Abbildung 5.32: Analyse der -1 bis -1000 bp Promotorregionen der 57 am stärksten aktivierten Gene mit dem Programm POBO. A: Häufigkeit des $A C G T A$-Motivs; B: Häufigkeit des ACGTTMotivs; C: Häufigkeit des ACGTC-Motivs; D: Häufigkeit des $A C G T G$-Motivs; E: Häufigkeit des $A C G T G G$-Motivs; 47 der 57 aktivierten Promotoren enthielten ACGTG-Motive, 15 ACGTGGC Motive. Kontrolle und Bootstrap-Analysen wie oben beschrieben. Rote Linien: Häufigkeit des Motivs in der Kontrollgruppe; Blaue Linien: Häufigkeit des Motivs in den Promotoren der aktivierten Gene (X-Achse: Häufigkeit des Motivs im Pseudo-Kluster; Y-Achse: Zahl der Pseudokluster). 


\subsubsection{Verifikation von einzelnen in dem Mikroarrayexperiment durch AtbZIP53 induzierten Genen in Northern Analysen}

Für einen Teil der am stärksten regulierten Gene wurden die Mikroarray Daten in Northern Analysen reproduziert (Abbildung 5.33). Hierfür wurden neu Pflanzen unter denselben Bedingungen angezogen, so dass es sich hier auch um ein weiteres biologisches Replikat handelt.

Da aufgrund der Heterodimerisierungsdaten sowie der in Protoplasten-Assays mit dem ProDH cis-Element erhaltenen Daten angenommen werden kann, dass auch andere Gruppe C/S1 AtbZIP-Transkriptionsfaktoren an der Regulation von putativen Zielgenen von AtbZIP53 beteiligt sind, wurde die Expression der untersuchten Gene auch in Linien mit einer veränderten Expression von AtbZIP1, 9, und 63 untersucht. Desweiteren ist auf den Filtern RNA aus einer AtbZIP10 Überexpressions- und einer atbzip10 Mutante aufgetragen. Die beiden Samenspeicherprotein-Gene CRU3 und 2S1 zeigen eine deutliche Aktivierung in AtbZIP53, 9 und 63 Überexpressionslinien, die mit der Stärke der Überexpression korreliert. Jedoch lässt sich in der AtbZIP9Überexpressionslinie 6-3 keine Aktivierung erkennen.

Für die drei stark in Pollen exprimierten Gene ProDH, ASN1 und T6PP konnte die Aktivierung im 35S:AtbZIP53 Hintergrund ebenfalls reproduziert werden. Die ProDH zeigt in diesen Proben einen hohe Hintergrundaktivität, so dass die Aktivierung weniger deutlich ist, dafür lässt sich aber eine Repression in der atbzip53 Mutante und der atbzip1/atbzip53 Doppelmutante erkennen. ASN1 zeigt neben der deutlichen Aktivierung in der AtbZIP53 Überexpressionslinie auch eine leichte Aktivierung in der stärkeren AtbZIP63 Überexpressionslinie. Dies entspricht Daten von Dr. Jesús VicenteCarbajosa, der in einer Transkriptomanalyse einer 35S:AtbZIP63 Linie ebenfalls eine Aktivierung der ASN1 zeigen konnte (persönliche Mitteilung).

Die Seneszenz-induzierten Gene PRI und GolS2 zeigen auch die erwartet Aktivierung in der starken AtbZIP53-Überexpressionslinie, jedoch sind beide auch in den sehr schwachen Überexpressionslinien HA9 22 und HA53 21.4 aktiviert. Dies wirft die Frage auf, ob diese Unterschiede auf zufällige Schwankungen zurückzuführen sind. Für das Seneszenz-induzierte Gen PEPCK ließ sich die Induktion durch AtbZIP53 reproduzieren, eine leichte Aktivierung ist auch in der schwachen AtbZIP53Überexpressionslinie sowie der AtbZIP10-Überexpressionslinie zu erkennen. 


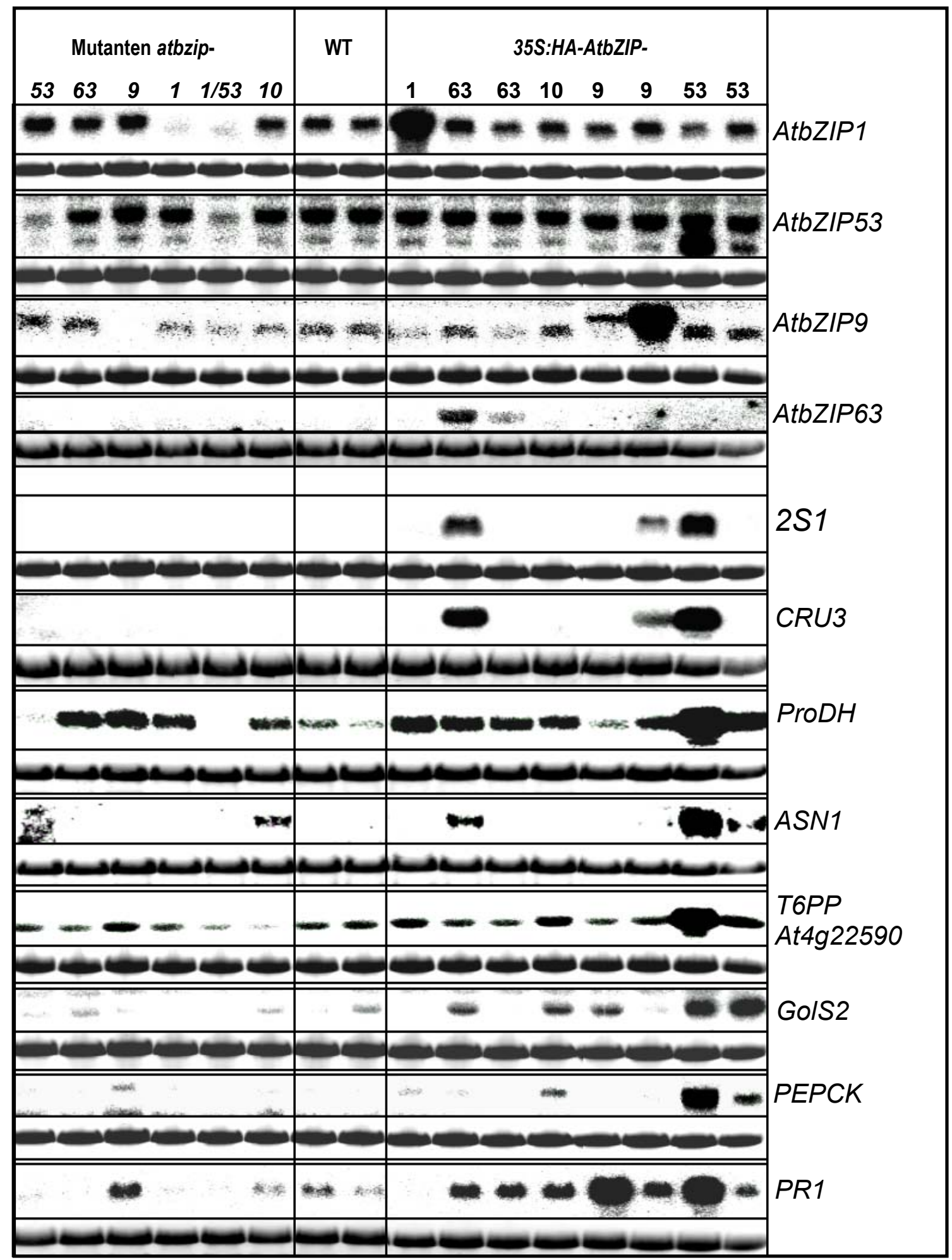

Abbildung 5.33: Northern Analysen der Expression von in dem Mikroarrayexperiment aktivierten Genen in verschiedenen AtbZIP-Überexpressionslinien und atbzip-Mutanten. Die Pflanzen wurden auf MS-Medium mit 2\% Saccharose unter Langtag-Bedingungen angezogen und nach zwei Wochen etwa 8 Stunden nach Beginn der Lichtphase komplett mit Wurzeln geerntet. Jede Probe repräsentiert etwa 100 Pflanzen von einer Petrischale. Unter jedem Northern ist ein Bild der Etidiumbromid Färbung des verwendeten RNA-Gels als Ladeabgleich gezeigt. 


\subsubsection{ASN1 ist ein direktes Zielgen von AtbZIP53}

Für die ProDH wurde bereits durch ChIP-Experimente gezeigt, dass sie ein direktes Zielgen von AtbZIP53 ist. Im folgenden sollten weitere direkte Zielgene von AtbZIP53 identifiziert werden. Ein Kandidat dafür war die Glutamin-abhängige Asparagin Synthetase (ASN1), da sowohl die Überexpression von AtbZIP53 als auch die Überexpression von AtbZIP63 zu ihrer Induktion führt, so dass sie möglicherweise von AtbZIP53/AtbZIP63 Heterodimeren reguliert wird. Des weiteren zeigt ASN1 ein hohes $\mathrm{Maß}$ an Koregulation mit diesen Genen. ASN1 wird durch Zucker reprimiert (Thum et al., 2003), durch Dunkelheit induziert (Fujiki et al., 2001), ist an der Samenentwicklung beteiligt (Lam et al., 2003), und außerdem wird für ASN1 eine Funktion in der Seneszenz vermutet (Lin und $\mathrm{Wu}, 2004$ ).

Im Promotor von ASN1 befinden sich in den 356 Basenpaare in 5' Richtung vor dem Transkriptionsstart 3 potentielle Bindemotive für bZIP-Transkriptionsfaktoren, 2 G-Box und ein C-Box Motiv. Für die ChIP-Analyse wurden zwei Primer zu beiden Seiten von diesen Motiven gewählt (ASN1chip for und ASN1chip rev). Die folgende Analyse durch quantitative PCR wurde mit dem selben immunoprezipitierten Chromatin wie in den entsprechenden Experimenten zur ProDH durchgeführt. Dabei konnte eine deutliche Anreicherung von Fragmenten des ASN1-Promotors gezeigt werden, so dass es sich bei ASN1 wahrscheinlich um ein direktes Zielgen handelt (Abbildung 5.34).

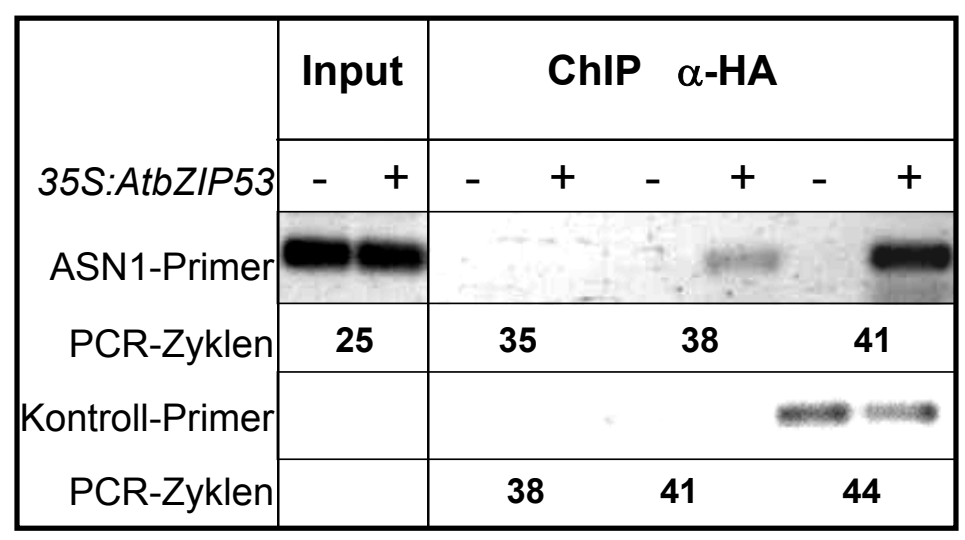

\footnotetext{
Abbildung 5.34: Nachweis der direkten Bindung von AtbZIP53 an den Promotor von ASN1 durch ChIP. Für die präzipitierten Chromatin-Fragmente wurde die Vernetzung aufgehoben, und die Menge von enthaltenen asn1-Promotorfragmenten über eine quantitative PCR mit den Primern ASN1chip for und ASN1chip rev ermittelt. Der Abgleich des DNAHintergrundes erfolgt über eine quantitative PCR mit den Kontrollprimern AtcwINV2gstFOR und AtcwINV2gstREV.
} 


\subsection{AtbZIP-Transkriptionsfaktoren der Gruppen C und S1 sind an der Antwort auf abiotischen Stress beteiligt}

Für Gruppe S1 Homologe aus unterschiedlichen Pflanzenspezies wird eine Beteiligung an der Antwort auf abiotischen Stress vermutet. Viele von ihnen zeigen eine Induktion durch Kälte (Aguan et al., 1993, 223; Ito et al., 1999; Kusano et al., 1998; Yang et al., 2001) oder Salz (Kusano et al., 1995). Für die ProDH hingegen, die in 35S:AtbZIP53 und 35S:AtbZIP1 Pflanzen eine erhöhte Expression zeigt, wird eine Funktion in der Erholung von abiotischem Stressen vermutet (Hare und Cress, 1997), und es wurde eine Repression durch abiotischen Stress gezeigt (Kiyosue et al., 1996; Verbruggen et al., 1996). Für Pflanzen mit einer durch ein Antisense-Konstrukt reprimierten Expression der ProDH wurde eine erhöhte Resistenz gegen Salz- und Kältestress gezeigt (Nanjo et al., 1999), die auf eine verstärkte Prolin-Akkumulation zurückgeführt wird. Es gibt also Hinweise für eine positive wie auch eine negative Funktion der in dieser Arbeit untersuchten AtbZIP-Transkriptionsfaktoren in der Antwort auf abiotischen Stress.

\subsubsection{AtbZIP53 wird in Schließzellen exprimiert}

Histochemische Färbungen von auf MS-Medium mit 2\% Saccharose angezogenen

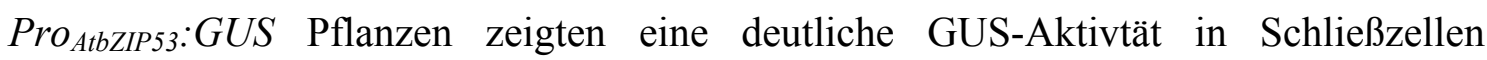
(Abbildung 5.35). Viele abiotische Stresse, wie Trocken- oder Salzstress, führen zu einer Schließung der Stomata, um Wasserverluste zu vermeiden. Das Schließen der Stomata wird durch das Phytohormon Abscisinsäure (ABA) induziert, das bei Wasserstre $\beta$ in den Wurzeln gebildet und in die Blätter transportiert wird, so dass dort der ABA-Gehalt steigt. Möglicherweise ist AtbZIP53 also an der Regulation der Spaltöffnungen durch Wasserstreß beteiligt. Die deutlichsten Färbungen von Stomata fanden sich bei in Sterilkutur angezogenen Pflanzen. In Sterilkulturen herrscht eine sehr hohe Luftfeuchtigkeit und, während der Lichtphase, ein sehr niedriger $\mathrm{CO}_{2}$-Gehalt (Hempel, 1993). Möglicherweise ist einer dieser beiden Faktoren für die GUS-Aktivität in Stomata verantwortlich. Sollte AtbZIP53 an der Regulation von Schließzellen beteiligt sein, könnten Pflanzen mit veränderter Expression von AtbZIP53 Unterschiede in der Trockenstress-Resistenz zeigen. 


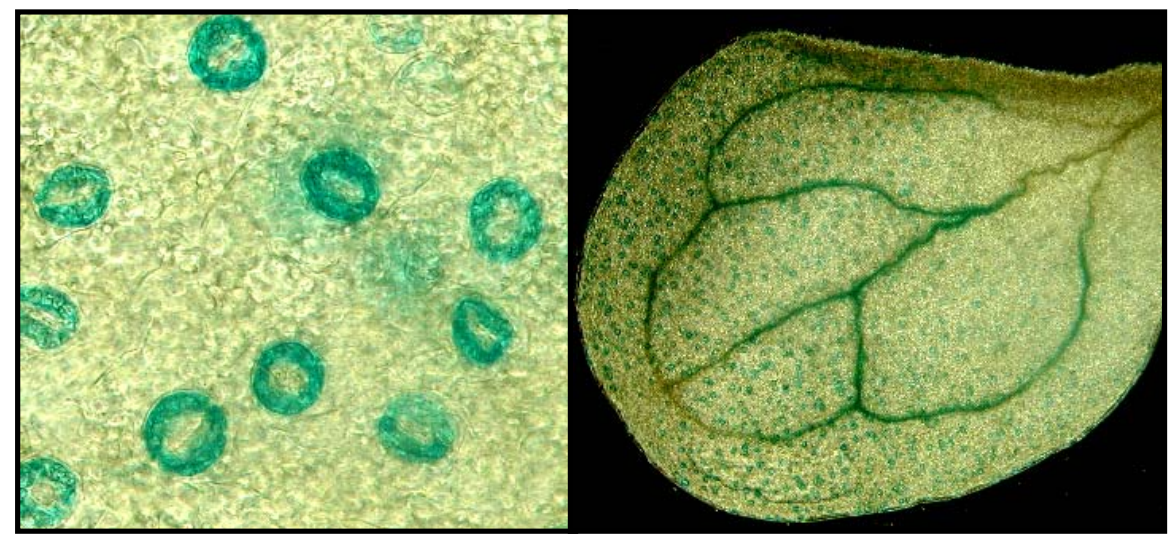

Abbildung 5.35: Histochemische Färbungen von Pro ${ }_{A t b Z I P 53}: G U S$ Pflanzen zeigen eine spezifische Expression in Schließzellen. Zwei Wochen alte Pflanzen aus einer Sterilkultur auf MS-Medium mit 2\% Saccharose wurden über Nacht mit $1 \mathrm{mM}$ Xgluc / 1mM Kaliumhexacyanoferrat gefärbt. Die spezifische Expression in Schließzellen ließ sich mit drei unabhängigen $\operatorname{Pro}_{A t b Z I P 53}$ : GUS Linien reproduzieren.

\subsubsection{Ektopische Expression von AtbZIP53 vermittelt eine erhöhte Resistenz gegen Salzstress}

AtbZIP1, 53, 9 und 63 Überexpressions-Linien und Mutanten wurden phänotypisch auf eine veränderte Toleranz gegenüber Trocken- oder Salzstress hin charakterisiert. Hierzu wurden verschiedene Ansätze verfolgt. Das Verhalten unter Trockenstress wurde untersucht, indem auf Erde angezogene Pflanzen nicht weiter gegossen wurden. Hier ließen sich jedoch in zwei Wiederholungen keine klaren Unterschiede zwischen den transgenen Linien und den Wildtyp-Kontrollen feststellen (nicht gezeigt). Außerdem wurde die Transpirationsrate von AtbZIP1 bzw. AtbZIP53 Überexpressionspflanzen sowie den atbzipl und atbzip53 Mutanten untersucht, in dem ganze Pflanzen am Hypokotyl abgeschnitten wurden, und die Transpiration über die Abnahme des Gewichtes der Pflanze verfolgt wurde (nicht gezeigt). Auch hier zeigten sich keine Unterschiede. Desweiteren wurde die Transpirationsrate mit Hilfe eines Poromometers gemessen. Jedoch zeigten sich auch hier keine deutliche Unterschiede (nicht gezeigt). In allen diesen Versuchen traten Schwankungen auf, sodass eine veränderte Transpirationsrate für die getesteten transgenen Linien nicht mit Sicherheit ausgeschlossen werden kann.

Zur Analyse der Keimung unter Salzstress wurden Samen von Wildtyp, AtbZIP53Überexpressionspflanzen und der atbzip53 Mutante auf MS-Medium mit 0,5\% 
Saccharose und 200mM NaCl zum Keimen ausgelegt. Samen der AtbZIP53Überexpressionslinie zeigten gegenüber dem Wildtyp ein deutlich besseres Wachstum und grünere Blätter (Abbildung 5.36 A). Die Samen der atbzip53 Mutante hingegen keimten deutlich schlechter, und die Keimlinge starben früh ab. Anschließend wurde das Verhalten von auf Erde angezogenen Pflanzen untersucht. Dazu wurden etwa zwei Wochen alten Pflanzen mit einer 500mM NaCl-Lösung gewässert. Die WildtypPflanzen und die atbzip53 Mutante zeigten eine Woche nach Beginn des Salzstresses eine deutliche Chlorosis und starben eine weitere Woche später ab, während dieser Prozess bei den AtbZIP53-Überexpressionspflanzen deutlich langsamer ablief (Abbildung 5.36 B). Parallel wurden auch sechs Wochen alte Pflanzen mit 500mM $\mathrm{NaCl}$ gewässert. Nach drei Tagen fingen die Infloreszenzen der Wildtyp-Pflanzen an

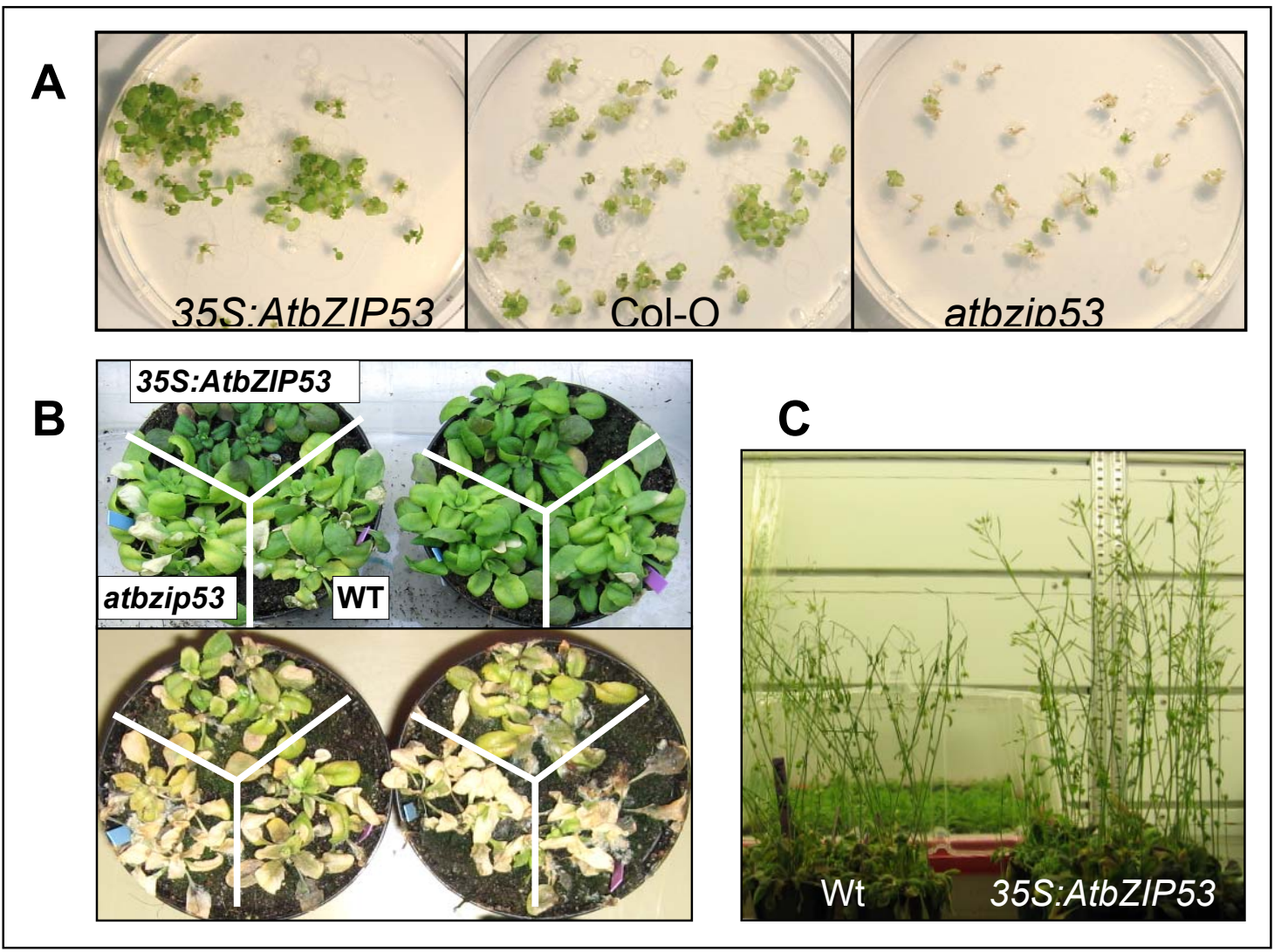

Abbildung 5.36: Ektopische Überexpression von AtbZIP53 führt zu einer erhöhten Toleranz gegen Salzstress. A: Samen von Wildtyp-Pflanzen, einer AtbZIP53 Überexpressionslinien und der atbzip53 Mutante wurden in Sterilkutur auf 0,5 MS mit 200mM NaCl angezogen. Die AtbZIP53 Überexpressionslinien zeigte eine erhöhte Resistenz gegen Salzstress. B: Wildtyp, eine AtbZIP53 Überexpressionslinien und die atbzip53 Mutante wurden zwei Wochen auf Erde angezogen und von da an mit einer 500mM NaCl-Lösung gewässert. Oberes Bild 7 Tage und unteres Bild 14 Tage nach Beginn des Salzstresses. C: 6 Wochen alte Pflanzen wurden mit einer $500 \mathrm{mM} \mathrm{NaCl} \mathrm{Lösung}$ gewässert. Nach drei Tage waren die Infloreszenzen der Wildtyp-Pflanzen umgefallen, während die der AtbZIP53-Überexpressionspflanzen noch aufrecht standen 
einzuknicken, während die der AtbZIP53-Überexpressionspflanzen noch aufrecht standen (Abbildung 5.36 C). Die Salzstressphänotypen wurden mehrfach reproduziert. AtbZIP1-Überexpressionslinien oder die atbzipl Mutanten sowie Pflanzen mit einer veränderten Expression von AtbZIP9 oder AtbZIP63 zeigten keine veränderte Resistenz gegen Salzstress.

\subsubsection{AtbZIP-Transkriptionsfaktoren der Gruppen C und S1 werden durch abiotischen Stress reguliert}

Änderungen des Transkriptoms unter abiotischem Stress wurden bereits mehrfach untersucht (Chen et al., 2002; Liu et al., 2005). Einer der interessantesten der hierzu verfügbaren Datensätze stammt aus dem AtGenExpress Projekt (http://web.unifrankfurt.de/fb15/botanik/mcb/AFGN/atgenex.htm). Hier wurden Expressionsprofile zu verschiedenen Zeitpunkten nach Kältestress, Salzstress, osmotischem Stress und verschiedenen weiteren Stressen erstellt, wobei das Transkriptom der Wurzeln und der grünen Pflanzenteile jeweils getrennt analysiert wurde. Auf den verwendeten Mikroarrays der Firma Affymetrix sind sämtliche AtbZIP-Transkriptionsfaktoren der Gruppen C und S1 vorhanden, sodass sich aus diesen Daten Diagramme der Änderung der Transkriptmengen dieser Faktoren unter den verschiedenen Stressen erstellen lassen (Abbildung 5.37).

In der Tat zeigen mehrere AtbZIP-Transkriptionsfaktoren der Gruppen C und S1 deutliche Veränderungen in der Transkription unter den getesteten Bedingungen. Desweiteren fällt auf, dass die Regulation in Blättern und Wurzeln oft deutlich unterschiedlich ist. So wird z.B. AtbZIP1 in den Blättern durch Kälte deutlich reprimiert, während in den Wurzeln eine ebenso deutliche Induktion zu sehen ist. Für die Gruppe S1 AtbZIP-Transkriptionsfaktoren BZI-3/tbzf (Strathmann et al., 2001; Yang et al., 2001), mlip (Kusano et al., 1995) und lip19 (Aguan et al., 1993) wurde eine Induktion durch Kälte in Blättern beschrieben. Sie werden ihrer Sequenz nach zur Untergruppe der tbzf-ähnlichen bZIP-Transkriptionsfaktoren gezählt, zu der in Arabidopsis nur AtbZIP1 und AtbZIP53 gehören, die jedoch beide in Blättern nicht durch Kälte induziert werden. 


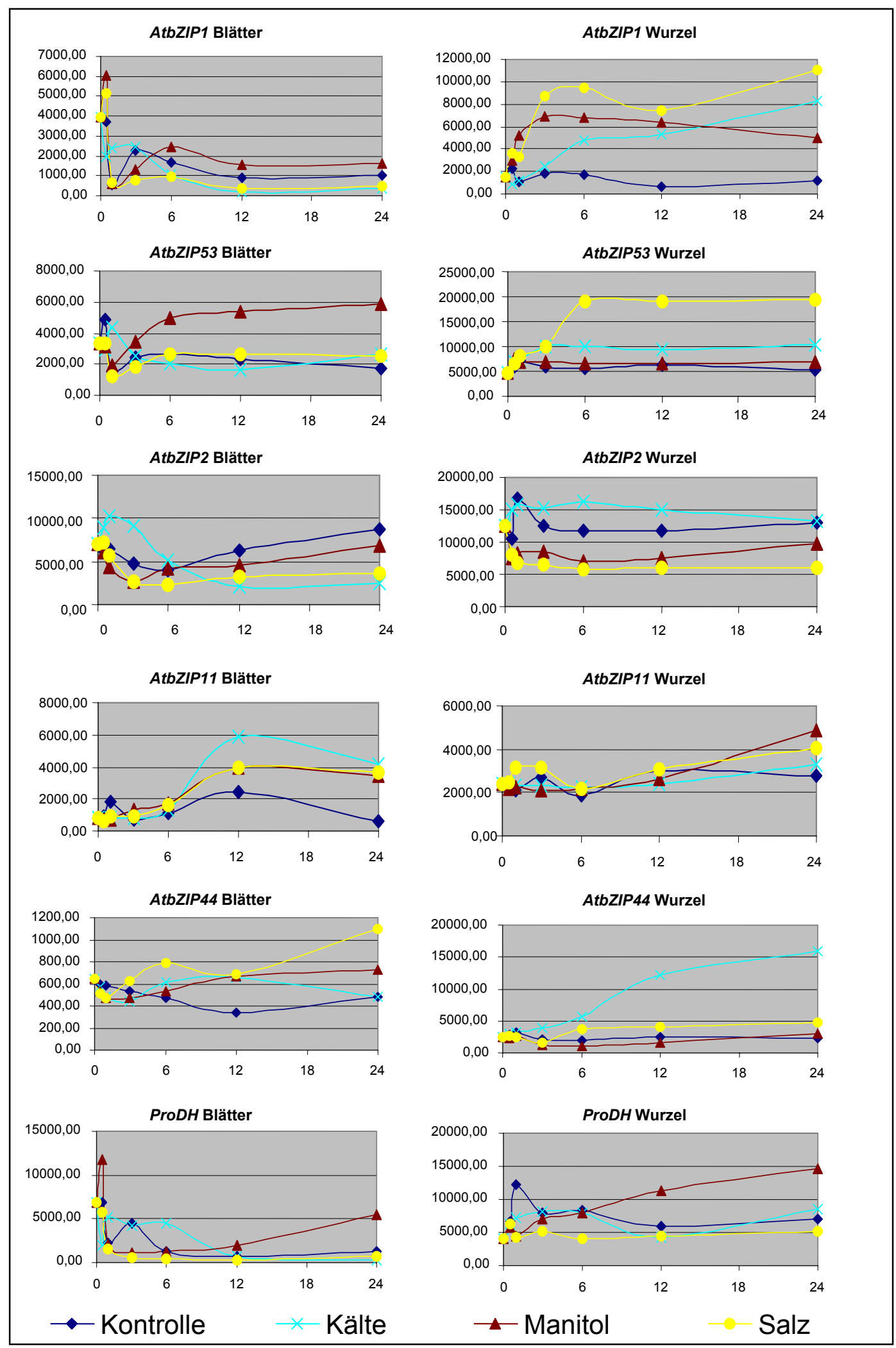

Abbildung 5.37a: Kinetik der Expression von Gruppe S1 AtbZIP-Transkriptionsfaktoren sowie von der ProDH nach Kälte- Salz- oder osmotischem Stress. Transkriptionsanalysen der Gruppe C AtbZIP-Transkriptionsfaktoren sowie nähere Erläuterungen auf der folgenden Seite. 


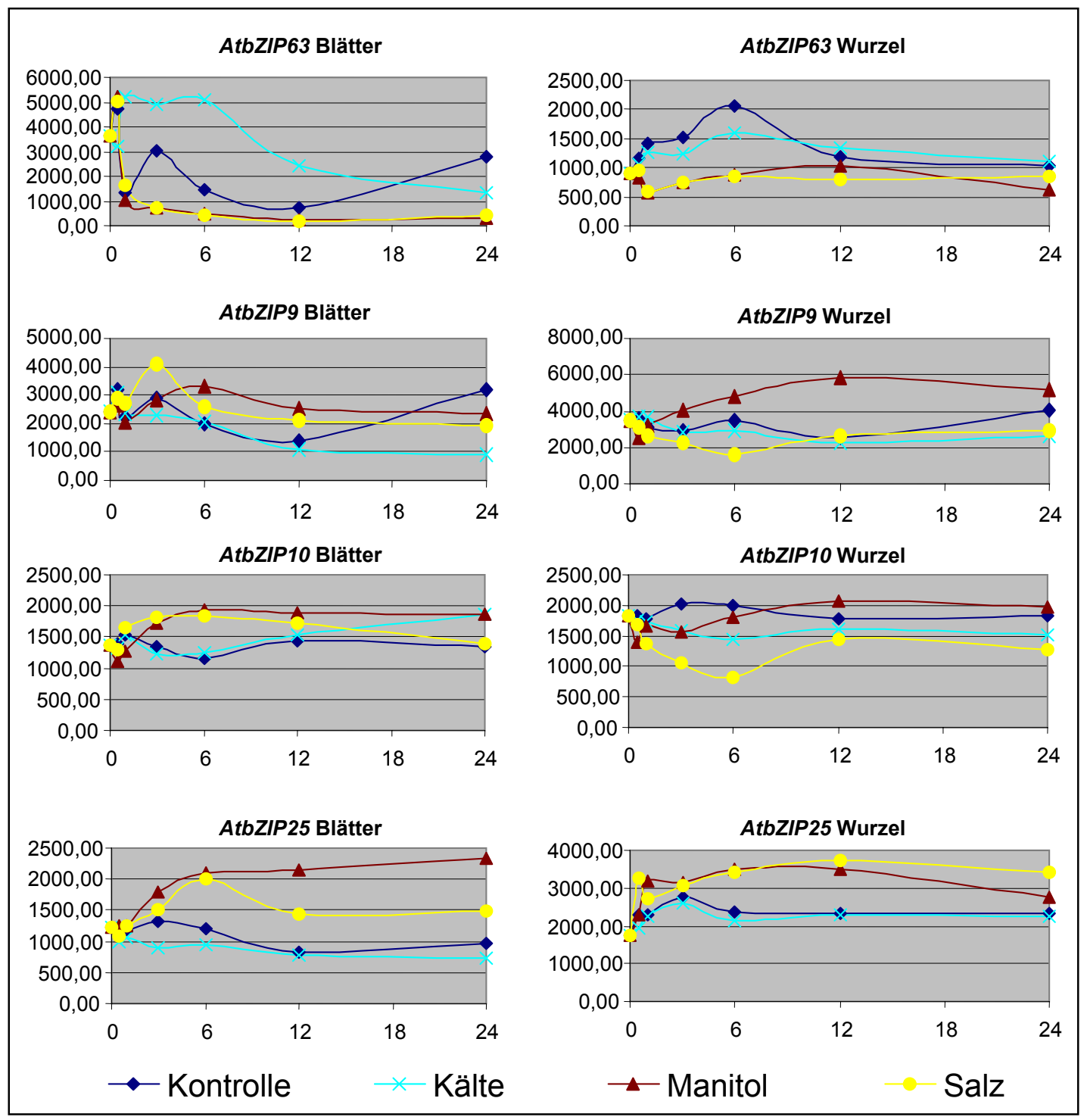

Abbildung 5.37b: Kinetik der Expression von Gruppe S1 AtbZIP-Transkriptionsfaktoren sowie von der ProDH nach Kälte- Salz- oder osmotischem Stress. Die Diagramme basieren auf Daten aus dem AtGenExpress Projekt. Die Experimente wurden mit 16 Tage alten Pflanzen in hydroponischer Kultur durchgeführt. Der Kältestress erfolgte bei $4{ }^{\circ} \mathrm{C}$, der osmotische Stress durch Zugabe von 300mM Mannitol zum Hydroponikmedium, der Salzstress durch Zugabe von 150mM NaCl. Die Pflanzen wurden unter Langtagsbedingungen (16h L / 8h D) angezogen. Die Stress-Behandlungen starteten drei Stunden nach Beginn der Lichtphase. Die Kontrollpflanzen wurden parallel zu den gestressten Pflanzen behandelt, d.h. auch sie wurden parallel aus den Klimakammern und dem Hydroponikgefäß genommen und anschließend zurückgestellt.

Für den S1 bZIP-Transkriptionsfaktor Rdlip (Ito et al., 1999) wurde unter Kältestress ebenfalls eine wurzelspezifische, kontinuierliche Induktion über 24 Stunden beschrieben, wie sie auch bei AtbZIPl zu sehen ist. Es scheint also als hätte sich die Kälteinduzierbarkeit von $t b z f$-ähnlichen AtbZIP-Transkriptionsfaktoren im Laufe der Evolution unterschiedlich entwickelt. 
Die Regulation durch Kälte wurde mit auf Erde angezogenen Pflanzen reproduziert (Abbildung 5.38). Dabei zeigte AtbZIP1, wie in den AtGenExpress Daten, eine leicht Abnahme der Transkriptmenge unter Kältestress. AtbZIP9 und AtbZIP53 verhielten sich anders als in den AtGenExpress Daten, AtbZIP9 zeigte eine transiente Repression, während AtbZIP53 leicht induziert wurde. Interessanterweise wird vor allem ein kürzeres Transkript induziert. Da dieses Transkript in der atbzip53 Mutante ebenso wie das längere nicht detektierbar ist, ist unwahrscheinlich, das es sich um eine Kreuzhybridisierung handelt. Dagegen spricht auch, dass AtbZIP1, das Gen mit der größten Sequenzhomologie zu AtbZIP53, definitiv nicht von der AtbZIP53-Sonde erkannt wird (Siehe Abbildung 5.38). Es wäre als denkbar, dass es ein zweites, kürzeres, durch Kälte induzierbares Transkript von AtbZIP53 gibt. Ein solches kürzeres, durch Kälte induzierbares Transkript wird auch mit der AtbZIP9 Sonde detektiert.

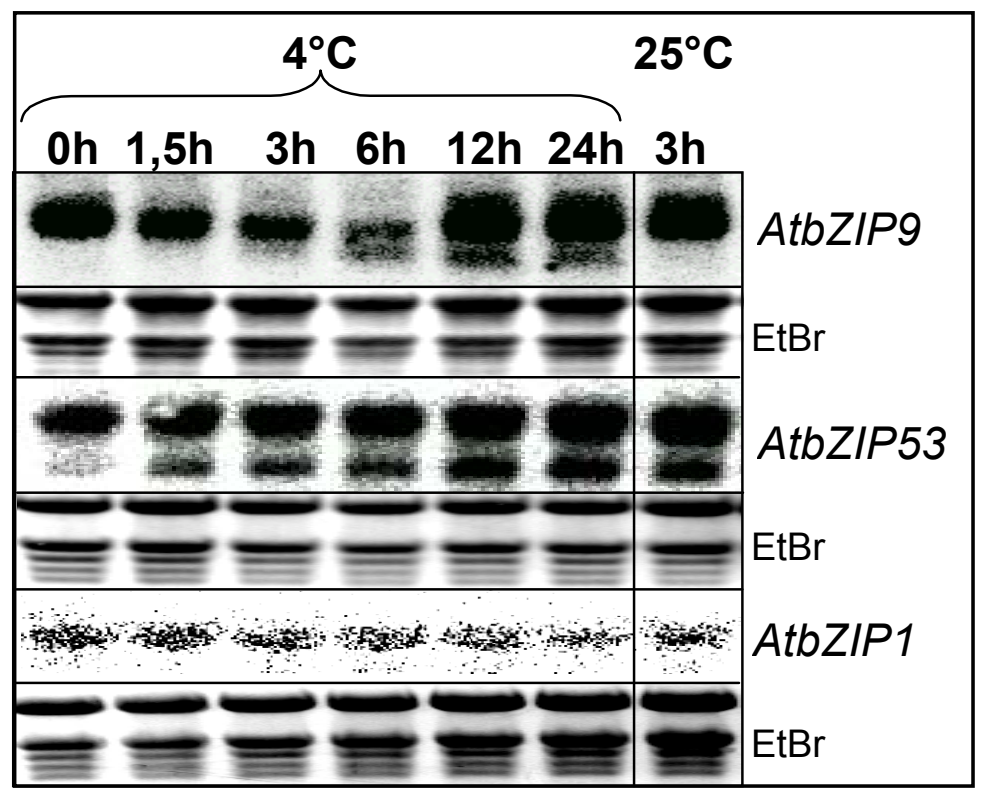

Abbildung 5.38: Northern Analyse der Expression von AtbZIP1, AtbZIP53 und AtbZIP9 nach Kältestress. Es wurden auf Erde angezogene, 20 Tage alte Pflanzen verwendet. Zwei Stunden nach Beginn der Lichtphase wurde der Klimaschrank auf $4^{\circ} \mathrm{C}$ heruntergekühlt. Zu den angegebenen Zeitpunkten wurden jeweils mehrere Pflanzen durch Abschneiden am Hypokotyl geerntet. Nach 24 Stunden wurde der Klimaschrank wieder auf $25^{\circ} \mathrm{C}$ gestellt, und 3 Stunden später eine weitere Probe geerntet. EtBr: Etidiumbromid-Färbung der verwendeten RNAGele zum Nachweis gleichmäßiger Beladung. 


\subsubsection{Die wurzelspezifische Induktion eines Trehalosephosphat-} Phosphatase-Gens nach Salzstress wird durch AtbZIP1 und/oder AtbZIP53 vermittelt

Unter den im Mikroarray-Experiment durch AtbZIP53 aktivierten Genen befinden sich mehrere, die ebenfalls durch Salzstress aktiviert werden. Der Vergleich der Kinetik der Aktivierung durch Salzstress von AtbZIP1 bzw. AtbZIP53 mit diesen Genen zeigte vor allem Parallelen zu dem LEA-Gen AIL1 und einer Trehalose-6-phosphat Phosphatase. Beide werden wie AtbZIP1 und AtbZIP53 durch Salzstress nur in den Wurzeln induziert und erreichen nach etwa 6 Stunden ein Maximum (Abbildung 5.39).

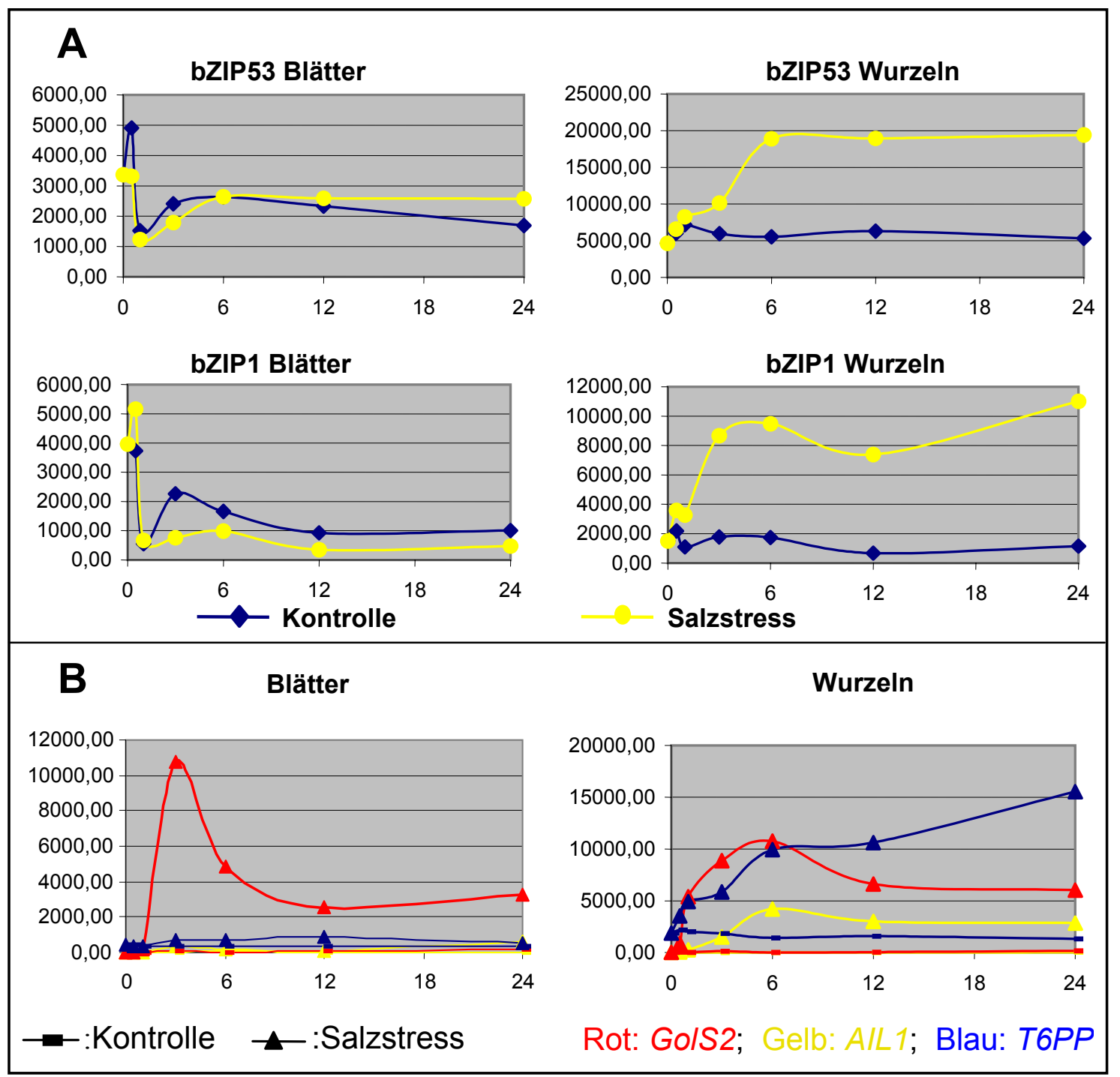

Abbildung 5.39: Kinetik der Salzstress-Induktion von AtbZIP1, AtbZIP53, sowie von putativen Zielgenen von AtbZIP53, einer Galactinol-Synthase (GolS2; At1g56600), eines LEA-Gens (AIL1; At3g15670) sowie einer Trehalose-6-phosphat Phosphatase (T6PP; At4g22590). Die Diagramme basieren auf Daten aus dem AtGenExpress Projekt (siehe oben). 
Andere Salzstress-assoziierte Gene, wie z.B. das einer Galactinol-Synthase, zeigen eine andere Kinetik, und keine wurzelspezifische Induktion. Im folgenden wurde untersucht, ob die Induktion dieser Gene in der atbzip1/atbzip53 Doppelmutante reduziert ist. Die hierzu notwendigen Northern Analysen wurden von Katrin Dietrich im Rahmen ihrer Diplomarbeit durchgeführt. Dabei konnte die wurzelspezifische, starke Induktion von AtbZIP1, AtbZIP53 sowie des Trehalose-6-phosphat Phosphatase- (T6PP)-Gens reproduziert werden (Abbildung 5.40). Die Induktion der T6PP ist in der atbzip1/atbzip53 Doppelmutante deutlich reduziert, was belegt, dass AtbZIP1 und /oder AtbZIP53 entscheidend an ihrer Induktion durch Salzstress beteiligt sind. Die Expression des LEA-Gens AIL1 sollte ebenfalls untersucht werden, jedoch lieferten zwei unterschiedliche getestete Northern Sonden keine Signal.

\begin{tabular}{|c|c|c|c|c|c|c|c|c|}
\hline \multicolumn{4}{|c|}{ Kontrolle } & \multicolumn{4}{|c|}{$150 \mathrm{mM} \mathrm{NaCl}$} & \\
\hline \multicolumn{2}{|c|}{ Blatt } & \multicolumn{2}{|c|}{ Wurzel } & \multicolumn{2}{|c|}{ Blatt } & \multicolumn{2}{|c|}{ Wurzel } & \multirow{6}{*}{$\begin{array}{l}\text { AtbZIP53 } \\
\text { AtbZIP1 } \\
\text { T6PP }\end{array}$} \\
\hline WT & 1/53KO & WT & 1/53KO & WT & $1 / 53 \mathrm{KO}$ & WT & $1 / 53 \mathrm{Kd}$ & \\
\hline \multirow[t]{4}{*}{ Oh 4h 8h } & Oh $4 \mathrm{~h} 8 \mathrm{~h}$ & Oh $4 \mathrm{~h} 8 \mathrm{~h}$ & Oh $4 \mathrm{~h} 8 \mathrm{~h}$ & $4 \mathrm{~h} 8 \mathrm{~h}$ & $4 \mathrm{~h} 8 \mathrm{~h}$ & $4 \mathrm{~h} 8 \mathrm{~h}$ & $4 \mathrm{~h} 8 \mathrm{~h}$ & \\
\hline & & - m ans & & & & & & \\
\hline & & & & & & & & \\
\hline & . & test & $y^{2}=$ & & & & $-2=$ & \\
\hline & & 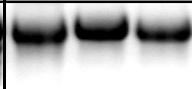 & & & & $-2=$ & $-\infty$ & \\
\hline
\end{tabular}

Abbildung 5.40: AtbZIP1 und AtbZIP53 werden nur in der Wurzel durch Salzstress induziert und sind essentiell für die Wurzel-spezifische Induktion einer T6PP. Wildtyp (WT) und atbzip1/atbzip53 Doppelmutanten $(1 / 53 \mathrm{KO})$ wurden in einer Hydroponik unter Kurztagsbedingungen angezogen. Die Salzstress-Behandlung erfolgte durch Zugabe von $\mathrm{NaCl}$ (Endkonzentration $150 \mathrm{mM}$ ) kurz nach Beginn der Lichtphase. Wurzeln und grüne Pflanzenteile wurden getrennt geerntet. T6PP: Trehalose-6-phosphat Phosphatase (At4g22590). Wt: Wildtyp; 1/53KO: atbzip1/atbzip53 Doppelmutante. Die verwendeten Sonden sind links neben den Northern angegeben. EtBr: Etidiumbromid-Färbung der verwendeten RNAGele zum Nachweis gleichmäßiger Beladung. 


\subsection{AtbZIP-Transkriptionsfaktoren der Gruppen C und S1 sind an der Samenentwicklung beteiligt}

In dem Transkriptomanalyse Experiment mit 35S:AtbZIP53 Pflanzen wurde gezeigt, dass die Überexpression von AtbZIP53 zur Aktivierung von $12 S$ und $2 S$ Samenspeicherprotein-Genen führte. (Lara et al., 2003) konnten nachweisen, dass AtbZIP10 und AtbZIP25 an ein ACGT-Element im Promotor eines dieser Gene, 2S1, binden und dessen Transkription aktivieren können. Eine Beteiligung von AtbZIP10 und AtbZIP25 an der Regulation der anderen Samenspeicherprotein-Gene ist wahrscheinlich, da diese eine ähnliche Promotorstruktur aufweisen. Da in dieser Arbeit für AtbZIP10 und AtbZIP25 eine bevorzugte Bildung von Heterodimeren mit AtbZIP53 gezeigt wurde, ist anzunehmen, dass AtbZIP10/53 bzw. AtbZIP25/53 Heterodimere an der Regulation von Samenspeicherprotein-Genen beteiligt sind.

\subsubsection{AtbZIP-Transkriptionsfaktoren der Gruppe $\mathrm{S} 1$ zeigen eine gegenläufige Expressionskinetik während der Samenentwicklung}

Die Samenentwicklung lässt sich in zwei Phasen unterteilen. In der ersten Phase, in der Zellteilungen vorherrschen, entwickelt sich die Zygote und das Endosperm wird angelegt. Während der zweiten Phase findet kaum noch Zellteilung statt, der Samen lagert Nährstoffe ein und wird Austrocknungs-resistent. Sie endet mit Wasserentzug und der Samenruhe (Borisjuk et al., 2004).

Expressionsdaten $\mathrm{zu}$ verschiedenen Stadien der Samenentwicklung stehen aus Mikroarrayexperimenten zur Verfügung (Schmid et al., 2005). Anhand dieser Daten wurde die Expression von AtbZIP-Transkriptionsfaktoren der Gruppen C und S1 sowie von in Samen exprimierten putativen Zielgenen von AtbZIP53 verglichen (Abbildung 5.41). Für die Entwicklung vom späten globulären Stadium (Stadium 3) bis zum späten Herzstadium (Stadium 5) wurden ganze Schoten für die Transkriptomanalysen verwendet, für die weiteren Entwicklungsstadien nur Samen.

Das Transkript von AtbZIP53 ist bereits in Stadium 3 nachzuweisen, und die Transkriptmenge steigt während der Samenentwicklung kontinuierlich an. Die von AtbZIP53 in reifen Samen gemessene Transkription gehört zu den stärksten, die für 
dieses Gen in Mikroarray-Datenbanken zu finden sind. Die Kinetik der Expression von AtbZIP53 entspricht der von Samenspeicherprotein-Genen, von denen hier $2 S 3$ als Beispiel gezeigt wird. AtbZIP1 hingegen ist im Stadium 6 kaum exprimiert, die Expression steigt dann aber während der Samenreifung stark an, und entspricht mehr dem Expressionsmuster von LEA (late embryogenesis abundant) Genen, von denen hier AIL1 als Beispiel gezeigt wird. Die Transkriptmenge der ProDH nimmt vergleichbar zu der von AtbZIP53 während der Samenentwicklung zu, und im reifen Samen wird die ProDH stark exprimiert.

Interessanterweise sind die zur Gruppe S1 gehörenden Faktoren AtbZIP11 und $44 \mathrm{zu}$ Beginn der Samenentwicklung deutlich exprimiert, und die Expression nimmt während der Samenreifung ab. Sie sind also gegenläufig zu AtbZIP1 und 53 reguliert. AtbZIP10 und AtbZIP25, für die eine Beteiligung an der Samenentwicklung gezeigt wurde, zeigen nur eine sehr leichte Zunahme der Transkription, während sich die Transkriptmengen von AtbZIP2, 9 und 63 (nicht gezeigt) während der Samenentwicklung praktisch nicht ändern.

Für AtbZIP10 und AtbZIP25 wird vermutet, dass sie ABI3, ein ebenfalls an der Regulation von Samenspeicherprotein-Genen beteiligter Transkriptionsfaktor, als Koaktivator binden. Eine direkte Interaktion von AtbZIP10 und AtbZIP25 mit ABI3 konnte in "Yeast Two-Hybrid" Tests gezeigt werden (Lara et al., 2003). Daher wurde getestet, ob AtbZIP53 ebenfalls mit ABI3 interagiert. In "Yeast Two-Hybrid" Tests konnte zunächst keine Interaktion nachgewiesen werden (nicht gezeigt). Jedoch konnte von der Arbeitsgruppe unseres Kollaborationspartners Dr. Jesus Vicente-Carbajosa in "Yeast Three-Hybrid" Tests gezeigt werden, dass AtbZIP53 in Gegenwart von AtbZIP10 mit ABI3 interagiert.

Ein an der Regulation von LEA-Genen beteiligter AtbZIP-Transkriptionsfaktor ist ABI5 (Lopez-Molina et al., 2002). Daher wurde In "Yeast Two-Hybrid" Tests untersucht, ob AtbZIP-Transkriptionsfaktoren der Gruppe C und S1 mit ABI5 interagieren. Jedoch konnte auch hier keine Interaktion nachgewiesen werden (nicht gezeigt). 


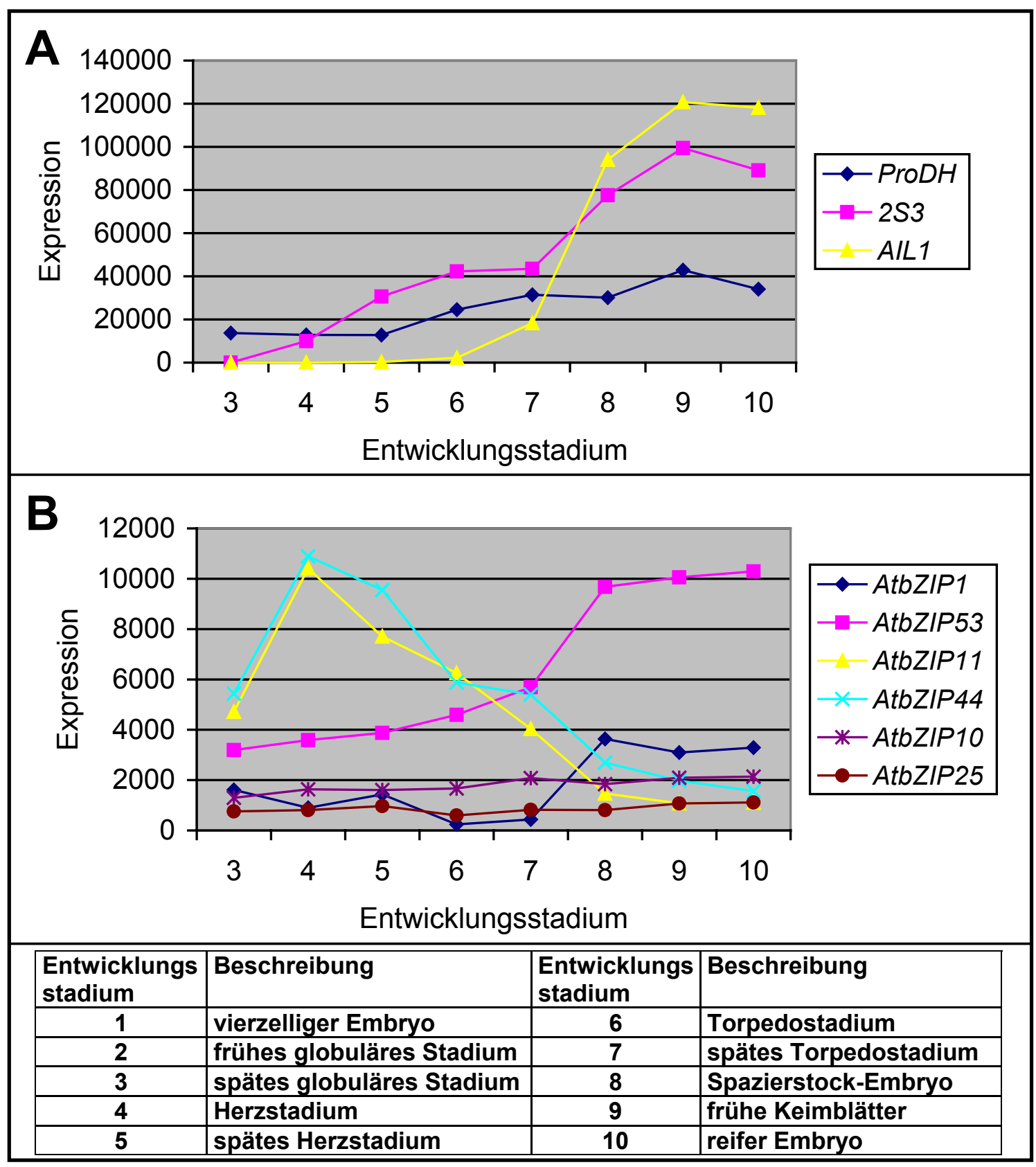

Abbildung 5.41: Kinetik der Transkription von den AtbZIP-Transkriptionsfaktoren der Gruppen C und S1 sowie von Samen-assoziierten putativen Zielgenen. A: Kinetik der Transkription von den Genen 2S3, AIL1 und ProDH während der Samenentwicklung. B: Kinetik der Transkription von verschiedenen AtbZIP-Transkriptionsfaktoren der Gruppen C und S1 während der Samenentwicklung. AtbZIP2, 9 und 63 werden in Samen nur sehr schwach exprimiert Die Tabelle unter den Diagrammen listet die den in den Diagrammen angegebenen Zahlen entsprechenden Entwicklungsstadien auf. Die Diagramme basieren auf Daten aus Mikroarrayexperimenten von Schmid et al (2005), jeder Datenpunkt entspricht dem Mittelwert aus 3 biologischen Replikaten. 


\subsubsection{AtbZIP53 wird während der Samenreifung im Embryo und in der Aleuronschicht exprimiert}

Die Expression von AtbZIP53 während der Samenentwicklung wurde auch histologisch untersucht. Dazu wurden von dem Labor von Dr. Jesus Vicente-Carbajosa Schnitte von Samen verschiedener Entwicklungsstadien erstellt, und in diesen Schnitten über in situ Hybridisierungen das Transkript von AtbZIP53 nachgewiesen (Abbildung 5.42 a-f). Während des Herz- und Torpedostadiums ist im Embryo noch kein Transkript nachzuweisen, dagegen zeigt sich im Torpedostadium schon eine Expression in der Aleuronschicht. Die Aleuronschicht zeichnet sich durch Protein- und Lipid-speichernde Organellen (Proteinbodies und Oleosomen) aus und dient dem Samen neben den Keimblättern als zusätzlicher Nährstoffspeicher. Im reifen Embryo ist das Transkript von AtbZIP53 deutlich nachzuweisen. Die Transkripte von AtbZIP10 und AtbZIP25, den Heterodimerisierungspartnern von AtbZIP53, konnten ebenfalls im Embryo und in der Aleuronschicht nachgewiesen werden (Lara et al., 2003), die Faktoren sind in Samen also kolokalisiert.

Die Expression von AtbZIP53 wurde darüber hinaus auch in histochemisch gefärbten

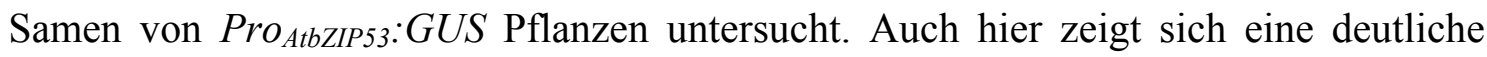
Expression im reifen Embryo (Abbildung $5.42 \mathrm{~g}$ ).

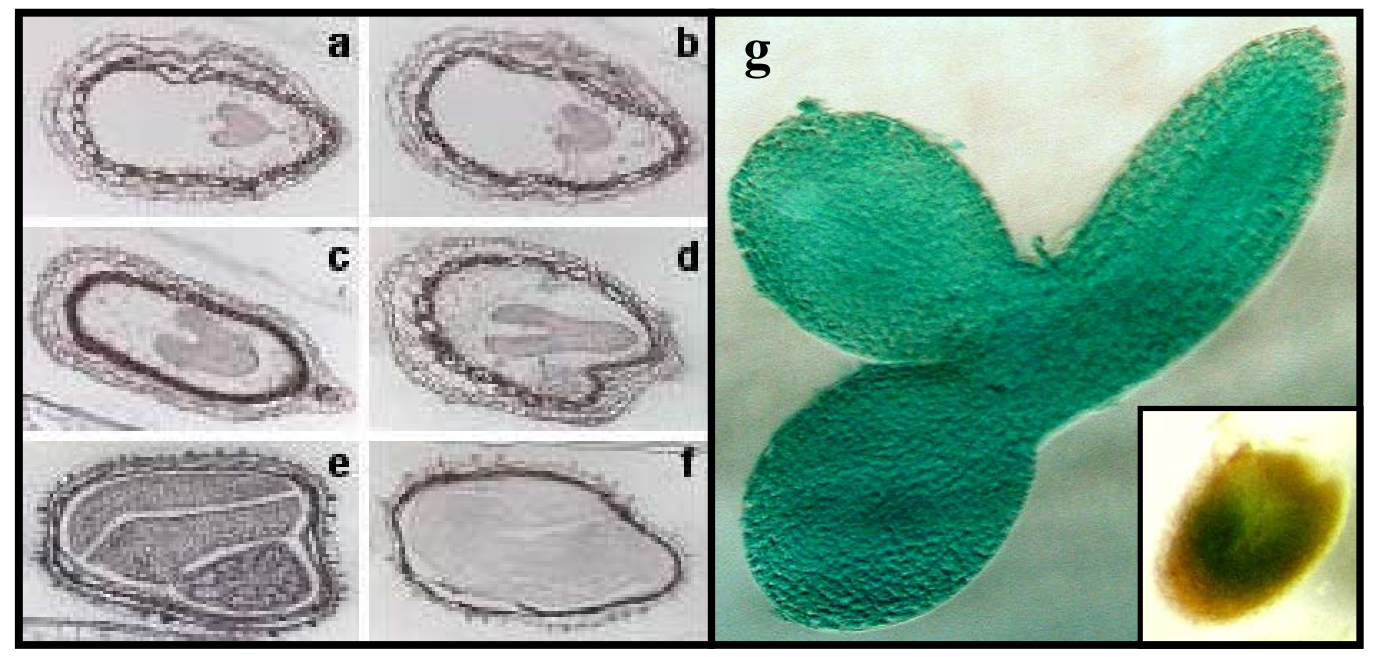

Abbildung 5.42: Histologischer Nachweis der Expression von AtbZIP53 in der Samenentwicklung. Linke Seite, a-f: in situ Hybridisierungen von Samen in verschiedenen Entwicklungsstadien. a,b: Herzstadium; b,c: Torpedostadium; e,f: reifer Embryo. a,c,e: AtbZIP53 antisense Sonde und b,d,f: AtbZIP53 sense Sonde. Die Bilder der in situ Hybridisierungen wurden von Dr. Jesus Vicente-Carbajosa zur Verfügung gestellt. g: Histochemische Färbung eines reifen Embryos aus Samen einer Pro $_{A t b Z I P 53}$ : GUS Linie. Unten rechts ist ein gefärbter Embryo innerhalb der Samenschale gezeigt. 


\subsection{AtbZIP-Transkriptionsfaktoren der Gruppen C und S1 sind Regulatoren natürlicher und induzierter Seneszenz}

Bei der Untersuchung zur Regulation von Gruppe C/S1 AtbZIP-Transkriptionsfaktoren durch Zucker oder Osmolarität in Kapitel 5.4 zeigte sich, dass AtbZIP1, 53, 9 und 63 deutlich durch Dunkelheit induziert werden. Dunkel-induzierte Gene sind häufig auch während der Seneszenz induziert (Fujiki et al., 2001). Lin und Wu (2004) konnten in Mikroarray-Experimenten zu Dunkel-induzierter Seneszenz zeigen, dass 40\% der 65 auf den verwendeten "Affymetrix whole genome arrays" vertretenen AtbZIPTranskriptionsfaktoren während der Seneszenz induziert werden, während nur 3\% reprimiert werden. Möglicherweise hat also die Klasse der bZIP-Transkriptionsfaktoren eine besondere Bedeutung in der Dunkel-induzierten Seneszenz. Für den Gruppe S1 bZIP-Transkriptionsfaktoren $t b z f$ aus Tabak konnte ebenfalls eine Induktion während der Seneszenz gezeigt werden (Yang et al., 2001). Daher wurde im folgenden die Funktion von AtbZIP-Transkriptionsfaktoren der Gruppen C und S1 als Regulatoren natürlicher und induzierter Seneszenz untersucht.

\subsubsection{AtbZIP1, AtbZIP53, AtbZIP9, AtbZIP25 und AtbZIP63 werden durch Seneszenz induziert}

Um zu untersuchen, wie sich die Expression der AtbZIP-Transkriptionsfaktoren im Laufe der Dunkel-induzierten Seneszenz verändert, wurden 25 Tage alte, unter Langtagsbedingungen angezogene, Arabidopsis Col-O Wildtyp Pflanzen in einem Klimaschrank unter kontrollierter Temperatur und Luftfeuchtigkeit dunkelgestellt. Ausgelegt waren 7 Pflanzen pro Topf, wobei auf eine gleichmäßige Verteilung der Pflanzen geachtet wurde, um gegenseitige Beschattung zu vermeiden. Zu Beginn der Dunkel-Induktion (11 Stunden nach Beginn der Lichtphase) wurden alle Pflanzen eines Topfes geerntet, indem sie am Hypokotyl abgeschnitten wurden. Von nun an wurde alle 24 Stunden eine weitere Probe geerntet, bis die Pflanzen nach 9 Tagen anfingen abzusterben. Anschließend wurde die Expression von AtbZIP-Transkriptionsfaktoren der Gruppen C und S1 in diesen Proben in Northern Analysen untersucht (Abbildung 5.43). 
Alle fünf untersuchten Faktoren zeigen eine Induktion nach einem Tag Dunkelheit. $\mathrm{Zu}$ einem zusätzlichen Anstieg der Transkriptmengen kommt es im Verlauf der Dunkelinduzierten Seneszenz in den folgenden Tagen. Hier zeigen die verschiedenen AtbZIPTranskriptionsfaktoren interessanterweise eine unterschiedliche Kinetik. Die Transkriptmenge von AtbZIP9 steigt bis zum fünften Tag, an dem die Pflanzen beginnen eine Gelbfärbung zu zeigen, und sinkt danach wieder. AtbZIP25 und AtbZIP53 erreichen am siebten Tag ein Maximum, jedoch steigt die Transkriptmenge von AtbZIP25 bis hierhin kontinuierlich an, während AtbZIP53 bereits nach einem Tag deutlich induziert ist, und der weitere Anstieg vergleichsweise gering ist. AtbZIP63 wird zwar nach einem Tag Dunkelheit induziert, danach sinkt die Transkriptmenge jedoch wieder bis zum vierten Tag, um in der Endphase der Seneszenz wieder zu steigen.

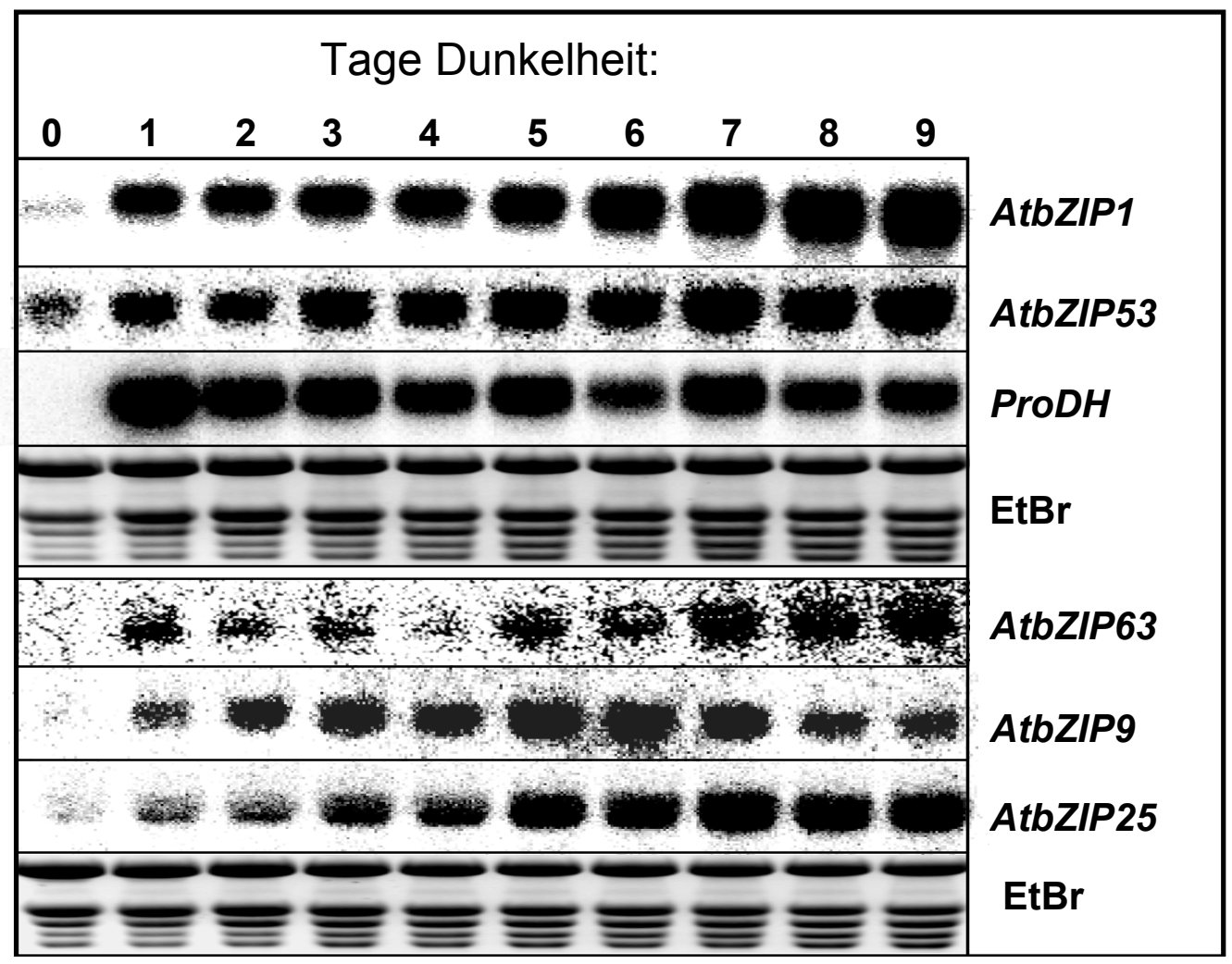

Abbildung 5.43: Northern Analysen der Kinetik der Transkription von AtbZIPTranskriptionsfaktoren der Gruppen C und S1 während der Dunkel-induzierten Seneszenz. 25 Tage alte, unter Langtagsbedingungen angezogene Arabidopsis Pflanzen wurden in einem Klimaschrank unter kontrollierter Temperatur und Luftfeuchtigkeit dunkelgestellt. Der NullZeitpunkt (Beginn der Dunkel-Induktion) wurde 11 Stunden nach Beginn der Lichtphase geerntet. Die Pflanzen wurden im Dunkeln geerntet, indem sie am Hypokotyl abgeschnitten wurden. Alle 24 Stunden wurde eine weitere Probe geerntet, bis die Pflanzen nach 9 Tagen anfingen abzusterben. Aus dem geernteten Material wurde RNA extrahiert und in Northern Analysen auf die Transkripte der verschiedenen AtbZIP-Transkriptionsfaktoren sowie der ProDH untersucht. Ein Transkript von AtbZIP10 konnte nicht detektiert werden. EtBr: Etidiumbromid-Färbung der verwendeten RNAGele zum Nachweis gleichmäßiger Beladung. 
Die Expression von AtbZIP1 steigt bis zum letzten Tag kontinuierlich an. Im Vergleich zu den AtbZIP-Transkriptionsfaktoren wurde auch die Transkription der ProDH analysiert. Hier ist zwar eine deutliche Dunkel-Induktion zusehen, aber keine weitere Induktion durch Dunkel-induzierte Seneszenz.

Um zu überprüfen, in welchen Geweben die Dunkel-Induktion von AtbZIP1 und AtbZIP53 stattfindet, wurden Pro $_{A t b Z I P I}: G U S$ und Pro $_{A t b Z I P 53}: G U S$ Linien dunkelgestellt und $\mathrm{zu}$ verschiedenen Zeitpunkten geerntet und gefärbt. Die Pflanzen wurden unter Langtagsbedingungen angezogen. Damit alle Proben parallel gefärbt werden konnten, und die Pflanzen in vergleichbaren Entwicklungsstadien waren, wurden die Pflanzen zeitlich versetzt ausgelegt, so dass alle Pflanzen, unabhängig von der Dauer der DunkelInduktion, gleich viele Tage im Licht gewachsen waren. Nach 20 Tagen im Licht wurden die Pflanzen für bis zu 5 Tage in Dunkelheit gestellt, und anschließend histochemisch gefärbt. Sowohl $\operatorname{Pro}_{A t b Z I P I}: G U S$ als auch $\operatorname{Pro}_{A t b Z I P 53}: G U S$ Linien zeigen im Laufe der Dunkel-Induktion, entsprechend zu den Northern-Daten, einen deutlichen Anstieg der GUS-Aktivität (Abbildung 5.44). Dabei steigt die auch bei Licht vorhandene GUS-Aktivität in den jüngsten Blättern, und es kommt zu einer steigenden GUS-Aktivität in den älteren, größten Blättern. In noch älteren, aber kleineren Blättern, z.B. den Keimblättern, ist kein Anstieg der GUS-Aktivität zu sehen.

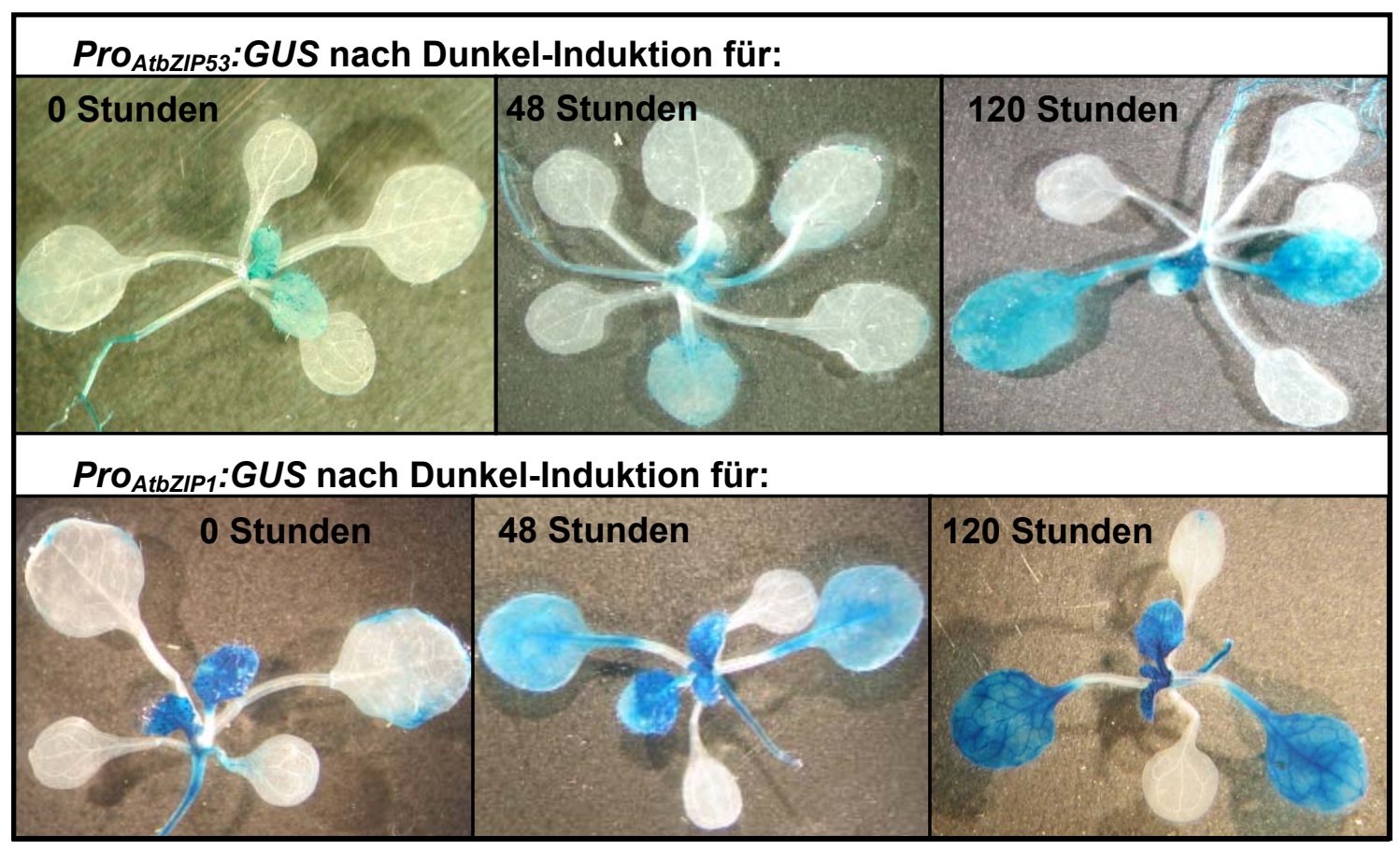

Abbildung 5.44: Histochemische Färbung von Pro $_{A t b Z I P 53}: G U S$ und Pro $_{A t b Z I P I}: G U S$ Pflanzen während Dunkel-induzierter Seneszenz. Die Kontrolle (0 Stunden) wurde 9 Stunden nach Beginn der Lichtphase gleichzeitig mit Pflanzen, die für 48 oder 120 Stunden dunkelgestellt waren, geerntet und 20

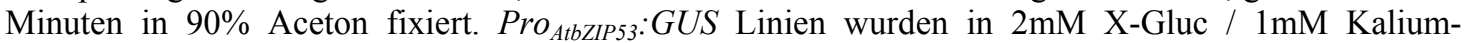
Hexacyanoferrat gefärbt, Pro AtbZIPI $_{\text {: }}$ GUS Linien in $1 \mathrm{mM}$ X-Gluc / $1 \mathrm{mM}$ Kalium-Hexacyanoferrat. 
Das Transkriptom Dunkel-induzierter Seneszenz hat viele Gemeinsamkeiten mit dem von natürlicher Seneszenz, es existieren aber auch klare Unterschiede. Um zu untersuchen, ob die bZIP-Transkriptionsfaktoren an einem allgemeinen oder einem für die Dunkel-Induktion spezifischen Signalweg beteiligt sind, wurde ihre Expression während der natürlichen Seneszenz in Northern-Analysen untersucht. Dazu wurden von etwa 7 Wochen alten, blühenden Pflanzen grüne, zu etwa 50\% gelbe und vollständig gelbe Blätter geerntet und RNA extrahiert. Für die vollständig gelben Blätter war die RNA-Ausbeute sehr niedrig, sodass von diesen Proben entsprechend weniger RNA für die Northern Analysen verwendet wurde. AtbZIP1, AtbZIP53, AtbZIP25 und AtbZIP63 werden, ebenso wie ihr Zielgen ProDH, im Verlauf der natürlichen Seneszenz induziert (Abbildung 5.45). Während die Expression von AtbZIP1, 53, 25 und der ProDH auch noch in der letzten Phase der Seneszenz, in der die Zellen beginnen abzusterben, deutlich nachweisbar ist, ist AtbZIP9 in den vollständig gelben Blättern nicht mehr zu detektieren.

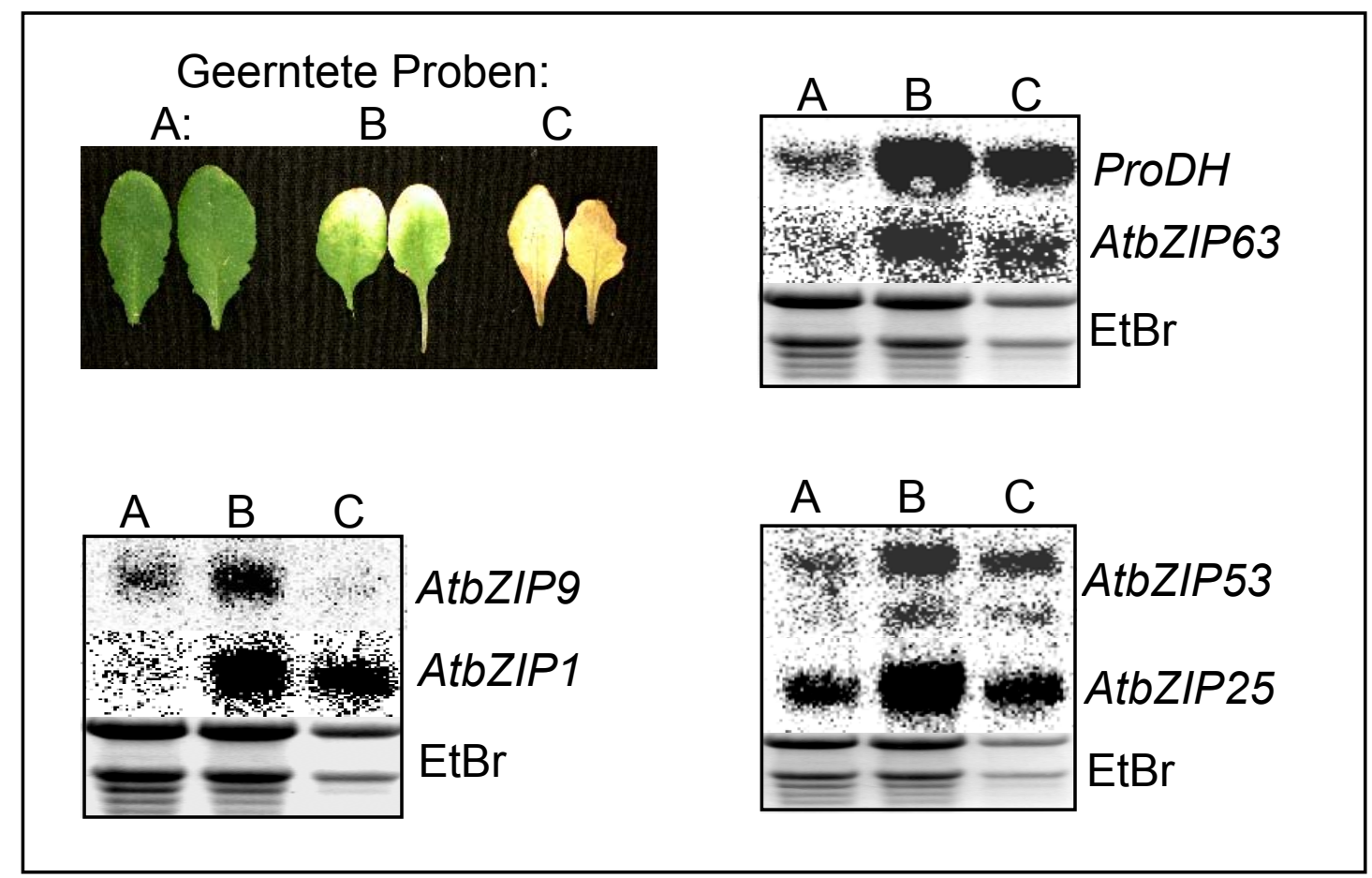

Abbildung 5.45: Northern Analyse zeigen, dass AtbZIP1, AtbZIP53, AtbZIP9, AtbZIP25 und AtbZIP63, ebenso wie ihr Zielgen ProDH, im Verlauf der natürlichen Seneszenz induziert werden. Geerntet wurden (A) grüne, (B) zu etwa 50\% gelbe und (C) vollständig gelbe Blätter. Die RNA-Ausbeute aus gelben Blättern war sehr niedrig, so dass hier nur $2 \mu \mathrm{g}$ statt der sonst üblichen $10 \mu \mathrm{g}$ RNA aufgetragen wurden. EtBr: Etidiumbromid-Färbung der verwendeten RNA-Gele zum Nachweis gleichmäßiger Beladung. 


\subsubsection{S:AtbZIP1 Linien zeigen ein rascheres Eintreten in die Dunkel- induzierter Seneszenz}

Die natürliche Seneszenz ist ein Prozess, der sich über einen langen Zeitraum erstreckt, und der nicht bei allen Blättern gleichzeitig eintritt. Dunkel-Induktion wird häufig als Methode genutzt, um eine Synchronisierung des Seneszenz-Prozesses zu erreichen (Lin und $\mathrm{Wu}, 2004)$. Daher wurden verschiedene transgene Linien mit einer veränderten Expression von AtbZIP1, 53, 9 oder 63 dunkelgestellt, um sie auf unterschiedliche Seneszenzphänotypen hin zu untersuchen. Für den Versuch wurden mehrere Samen pro Topf ausgelegt, und nach einer Woche wurden, bis auf vier gleichmäßig verteilte, gleich weit entwickelte Keimlinge, alle übrigen Keimlinge entfernt. So sollten möglichst vergleichbare Bedingungen erreicht werden. Nach weiteren zwei Wochen wurden die Pflanzen dunkelgestellt.

Bereits nach 3 Tagen Dunkelheit zeigten die Pflanzen der 35S:AtbZIP1 Linie eine deutliche Gelbfärbung, während die anderen Pflanzen alle noch grün waren. Nach 5 Tagen waren die Blätter der AtbZIP1-Überexpressionspflanzen fast vollständig gelb, während sich bei Wildtyp Pflanzen erst eine beginnende Gelbfärbung zeigte (Abbildung 5.46). Die atbzip1 und atbzipl/atbzip53 Mutanten hingegen zeigten eine leicht verzögerte Seneszenz, wobei der Unterschied am sechsten Tag Dunkelheit noch deutlicher wurde. In der Doppelmutante war dabei die Seneszenz noch etwas stärker verzögert als in atbzipl.

Diese Phänotypen wurden mit verschiedenen AtbZIP1-Überexpressionslinien, sowohl mit als auch ohne HA-tag, sowie mit beiden zur Verfügung stehenden atbzip1 Mutanten mehrfach reproduziert. Dabei wurden Pflanzen verschiedener Altersstufen verwendet, wobei sich zeigte, das die beobachteten Phänotypen nicht altersabhängig sind. Die AtbZIP9 oder AtbZIP63 Überexpressionslinien bzw. Mutanten zeigten hingegen keinen Seneszenzphänotyp. 


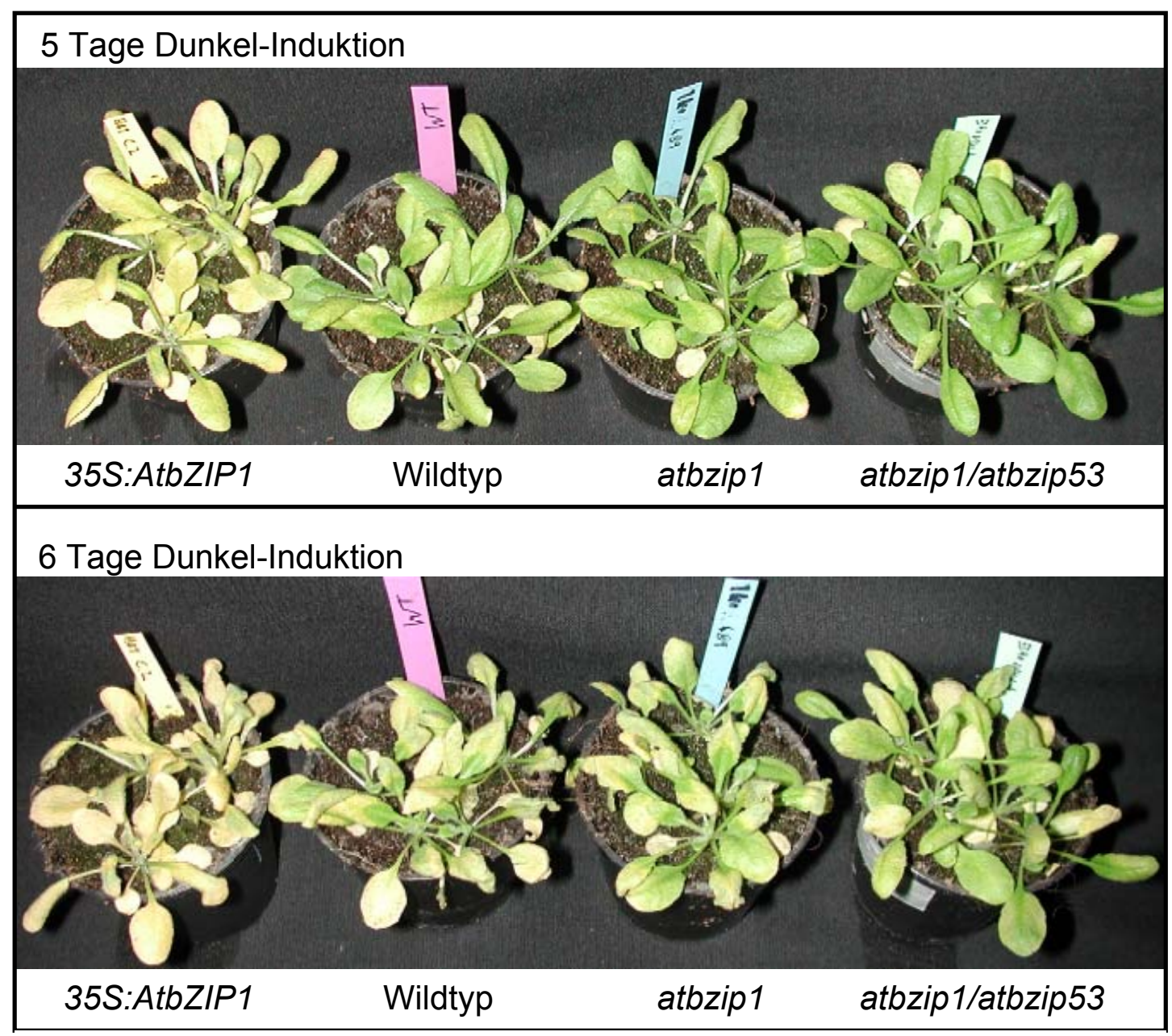

Abbildung 5.46: Überexpression von AtbZIP1 führt zu einem früheren Einsetzen Dunkelinduzierter Seneszenz. Je sechs Töpfe mit Wildtyp Pflanzen, einer AtbZIPl Überexpressionslinie sowie den Mutanten atbzip1 und atbzip1/atbzip53 wurden 3 Wochen auf Erde angezogen und dann dunkelgestellt. Die Bilder zeigen je einen repräsentativen Topf mit Pflanzen der verschiedenen Linien nach fünf bzw. sechs Tagen Dunkel-Induktion.

\subsubsection{Transkriptionelle Regulation von AtbZIP-Transkriptionsfaktoren der Gruppen C und S1 in Mikroarray-Experimenten zur Seneszenz}

Um zusätzliche Daten zur Regulation durch Seneszenz, insbesondere zur Regulation der noch nicht untersuchten Gruppe S1 Mitglieder AtbZIP1, 11 und 44 zu erhalten, wurde die Expression der AtbZIP-Transkriptionsfaktoren der Gruppen $\mathrm{C}$ und $\mathrm{S} 1$ in publizierten Mikroarray-Experimenten zur Seneszenz untersucht. Solche Daten stehen zu Dunkel-induzierter Seneszenz (Lin und $\mathrm{Wu}, 2004$ ), natürlicher Seneszenz (Buchanan-Wollaston et al., 2005), und einer durch Zuckerverarmung in die Seneszenz übergegangenen Zellkultur (Swidzinski et al., 2002) zur Verfügung. 
Die Daten zur Dunkel-induzierten Seneszenz wurden unter anderen Bedingungen als die in dieser Arbeit gezeigten gewonnen. Es wurden zwar etwa gleich alte Pflanzen verwendet, jedoch wurden diese unter Kurztagsbedingungen angezogen, und zu Beginn der Lichtphase geerntet. Durch ihre diurnale Regulation sind zu diesem Zeitpunkt AtbZIP1 und AtbZIP63 wesentlich stärker exprimiert als in den für die NorthernAnalysen geernteten Proben, durch die Anzucht unter Kurztag und die damit verbundene geringere Zucker-Synthese in den Pflanzen wird dieser Effekt möglicherweise nochmals verstärkt. Auch wenn die Induktionen durch die Probennahme des Nullzeitpunktes am Ende einer 16 Stunden langen Dunkelphase kleiner ausfallen, findet sich auch hier eine Induktion von AtbZIP9, AtbZIP25 und AtbZIP1 (Abbildung 5.47). AtbZIP11, dass im Gegensatz zu den anderen AtbZIP-Genen durch Licht und Zucker induziert wird, wird im Lauf der Dunkel-induzierten Seneszenz reprimiert.

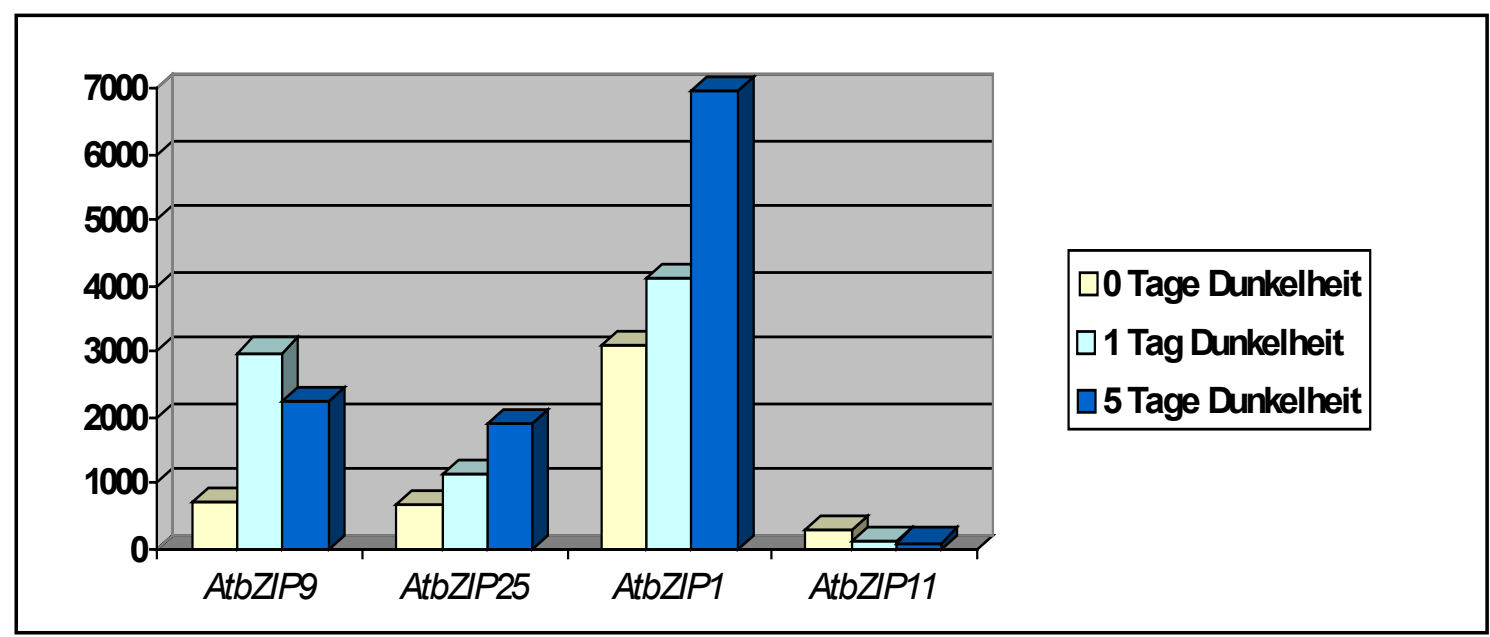

Abbildung 5.47: Induktion von AtbZIP9, AtbZIP25 und AtbZIP1 sowie Repression von AtbZIP11 durch Dunkel-induzierte Seneszenz. Die Daten stammen aus Transkriptomanalysen von (Lin und $\mathrm{Wu}$, 2004) und wurden mit 22 Tage alten, unter Kurztag-Bedingungen angezogenen Arabidopsis Pflanzen gewonnen. Der Nullzeitpunkt wurde eine Stunde nach Beginn der Lichtphase geerntet.

In einem andern Ansatz wurde in einer Zellkultur Seneszenz induziert, d.h. die Zellen wurden über 14 Tage nicht in neues Zellkulturmedium umgesetzt, sodass ein Verhungern der Zellen zu einem Eintreten in die Seneszenz führt (Swidzinski et al., 2002). Diese Form der Seneszenz ist der Dunkel-induzierten Seneszenz ähnlich, da beide letztlich auf Zuckerverarmung zurückzuführen sind, während es sich bei der natürlichen Seneszenz um ein entwicklungsbiologisches Programm handelt. Dementsprechend findet sich hier auch eine zur Dunkel-induzierten Seneszenz vergleichbare Regulation der AtbZIP-Transkriptionsfaktoren, d.h., AtbZIP1, 53, 63 und 
25 sind induziert, während AtbZIP11 reprimiert wird. Die hier zu sehende Repression von AtbZIP9 wird darauf zurückzuführen sein, dass der untersuchte Zeitpunkt in der Endphase der Seneszenz liegt, in der die Zellen bereits Symptome von programmiertem Zelltod (Zusammenbruch der Vakuolen, DNA-Degradation) zeigen. In den Northern Analysen wurde gezeigt, dass die Transkriptmenge von AtbZIP9 in der zweiten Hälfte der Dunkel-induzierten Seneszenz sinkt.

Besonders stark ist in diesem Experiment die Aktivierung von AtbZIP1. Während die Expression dieses Gens in der normalen Zellkultur kaum $\mathrm{zu}$ messen ist, ist die Expression in der seneszenten Zellkultur die stärkste, die in den über 1500 in der Genevestigator-Datenbank verfügbaren Mikroarray-Experimenten je für AtbZIP1 gemessen wurde.

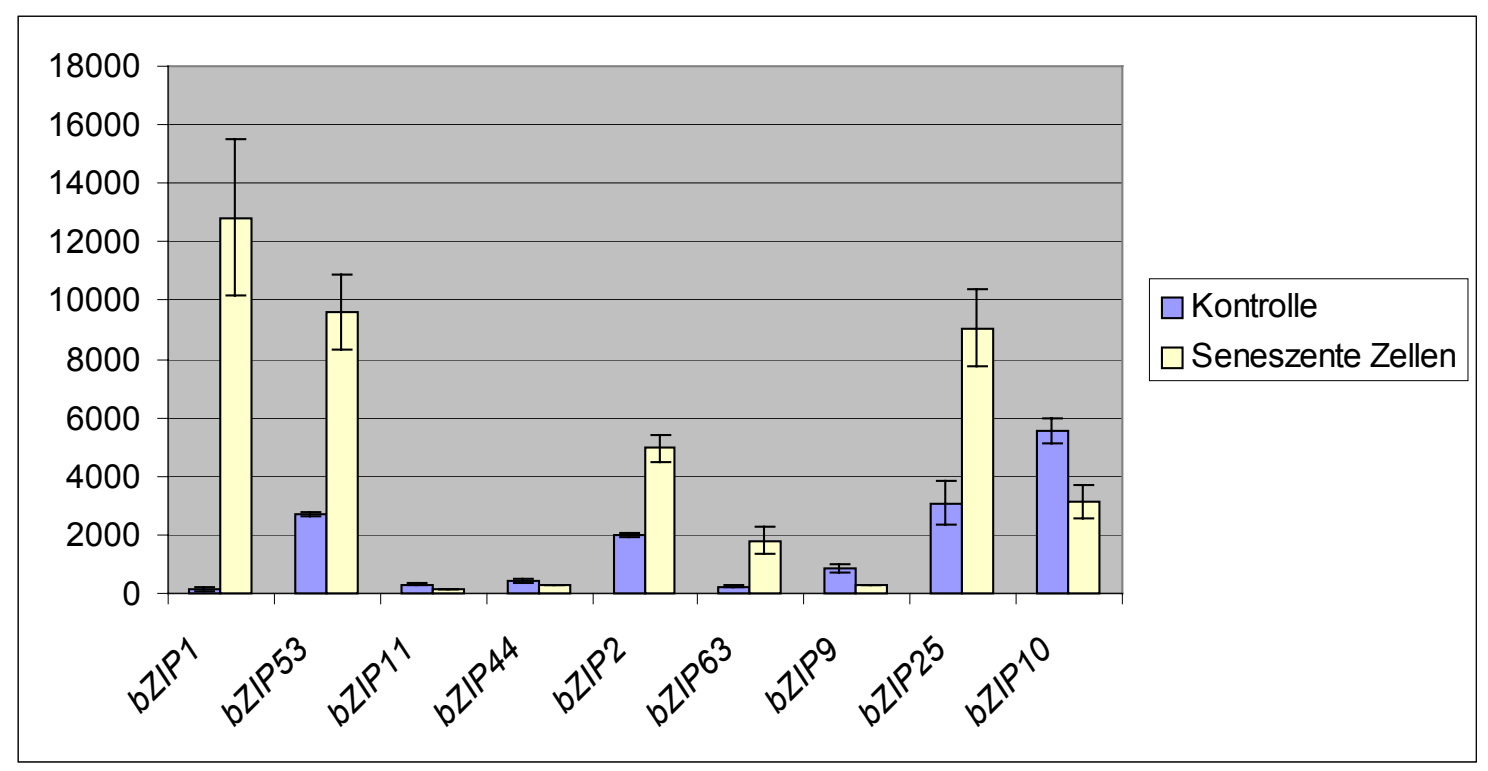

Abbildung 5.48: Unterschiede der Expression von C/S1 AtbZIP-Transkriptionsfaktoren zwischen einer gesunden und einer seneszenten Zellkultur. Arabidopsis Zellkulturen wurden nicht weiter mit Saccharose versorgt, so dass es zu einem Eintritt in die Seneszenz kam. Als Kontrolle diente eine gesunde Zellkultur (Swidzinski et al., 2002). Der Versuch umfasst zwei biologische Replikate, in dem Diagram sind Mittelwerte mit Standardabweichung dargestellt. Auf der X-Achse sind die gemessenen absoluten Signalstärken wiedergegeben. Ratios Kontrolle / Seneszenzte Zellen: AtbZIP1: 84,9; AtbZIP53: 3,5; AtbZIP11: 0,4; AtbZIP 2: 2,5; AtbZIP63: 7,6; AtbZIP 9: 0,3; AtbZIP25: 2,9.

Die natürliche Seneszenz zeigt neben vielen gemeinsamen Eigenschaften auch deutliche Unterschiede zur durch Verhungern induzierten Seneszenz (Buchanan-Wollaston et al., 2005). Diese werden auch in der Regulation der C/S1 AtbZIP-Transkriptionsfaktoren deutlich. Wird AtbZIP10 in den durch Zuckermangel verursachten Formen der Seneszenz nicht reguliert, findet sich in der natürlichen Seneszenz eine deutliche 
Induktion. Das gleiche gilt für AtbZIP44. Im Gegensatz dazu werden die stark durch Zuckermangel induzierten Faktoren AtbZIP1 und AtbZIP63 in der natürlichen Seneszenz nicht induziert, für AtbZIP63 findet sich sogar eine Repression. Allen Formen der Seneszenz gemeinsam ist hingegen die Induktion von AtbZIP25.

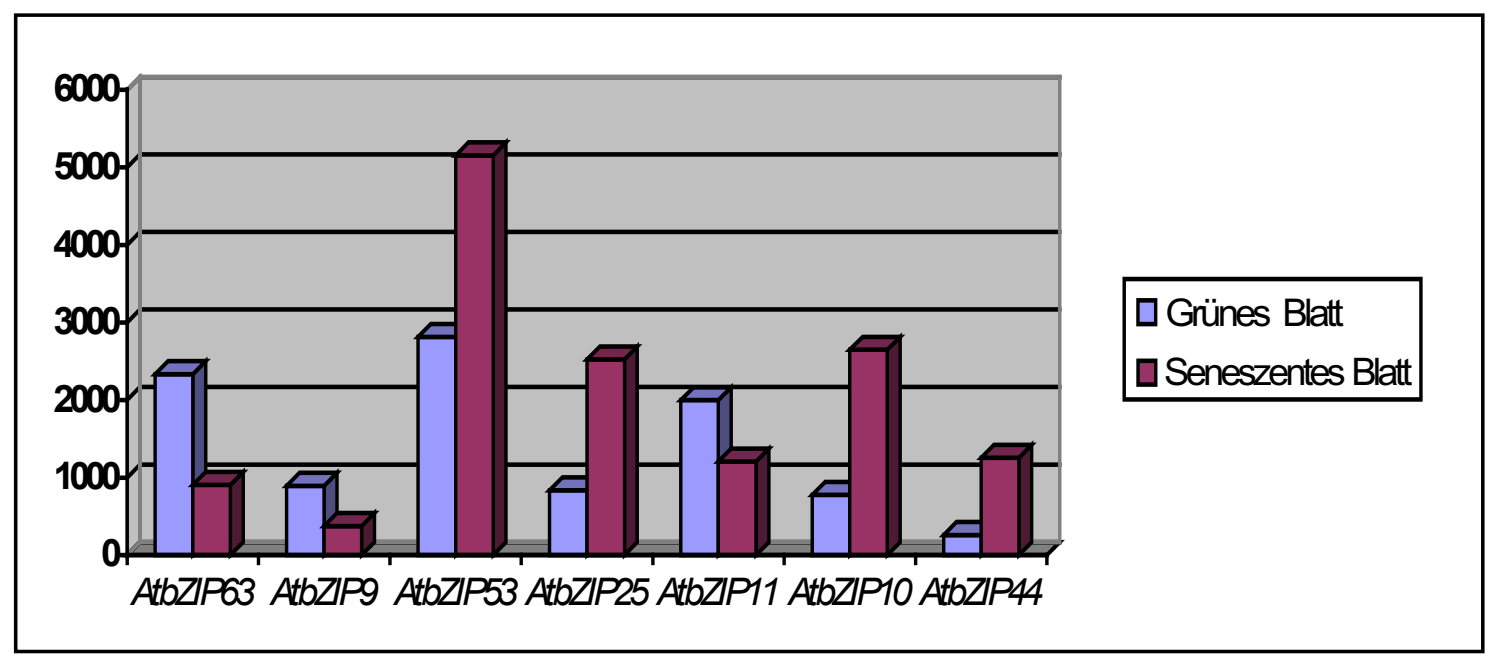

Abbildung 5.49: Unterschiede in der Expression von AtbZIP-Transkriptionsfaktoren der Gruppen C und S1 zwischen grünen und seneszenten Blättern (natürliche Seneszenz). Die verwendeten Daten stammen aus dem AtgenExpress Projekt (grüne Blätter: ATGE_10; seneszente Blätter: ATGE_25), gezeigt wird jeweils der Mittelwert aus drei biologischen Replikaten. 


\subsection{Analyse der Transkriptome von 35S:AtbZIP1 und atbzip1/atbzip53 Pflanzen}

Da AtbZIP1 und AtbZIP53 Transkriptionsfaktoren sind, ist zu erwarten, dass die gezeigten Seneszenz-Phänotypen letztlich auf der veränderten Transkription ihrer Zielgene beruhen. Um differentiell regulierte Gene zu identifizieren, wurde das Transkriptom von AtbZIP1 überexprimierenden Pflanzen mit dem des Wildtyps nach jeweils zwei Tagen Dunkelinduktion verglichen. Dieser frühe Zeitpunkt wurde gewählt, um die Detektion von Genen zu minimieren, die indirekt durch das schnellere Voranschreiten der Seneszenz in AtbZIP1 überexprimierenden Pflanzen reguliert werden.

Parallel wurde auch das Transkriptom der atbzip1/atbzip53 Doppelmutante unter den selben Bedingungen mit dem des Wildtyps verglichen. Die bisherige Erfahrung im Rahmen dieser Arbeit war, dass atbzip-Mutanten geringere Unterschiede zum Wildtyp zeigten als die entsprechenden Überexpressionslinien, was möglicherweise auf eine Redundanz zwischen den AtbZIP-Transkriptionsfaktoren zurückzuführen ist. Daher wurde die atbzipl/atbzip53 Doppelmutante, und nicht eine entsprechende Einzelmutante gewählt. Auf diese Weise wird Redundanz unwahrscheinlicher, und für die identifizierten Gene mit differentieller Expression lässt sich in folgenden Northern Analysen, die zur Reproduktion ohnehin notwendig sind, untersuchen, ob diese Unterschiede durch atbzipl oder atbzip53 verursacht werden, und ob die atbzip1/atbzip53 Doppelmutante einen verstärkten Effekt auf die Expression hat, was eine Redundanz belegen würde. Die in diesem Kapitel gezeigten Mikroarray Experimente wurden im Gegensatz zu dem aus Kapitel 5.6 nicht in Madrid, sondern im Transkriptomanalyse-Labor in Göttingen durchgeführt.

Für die Transkriptomanalysen wurden Wildtyp-Samen, Samen der 35S:HA-AtbZIP1 Linie C.2 und Samen der atbzipl/atbzip53 Doppelmutante ausgelegt, und nach einer Woche wurden, bis auf sechs gleichmäßig verteilte, gleich weit entwickelte Keimling, alle übrigen Keimlinge entfernt, um möglichst vergleichbare Bedingungen zu erhalten. Nach 20 Tagen wurden die Pflanzen dunkelgestellt, und nach 48 Stunden Dunkelheit geerntet. Dabei wurden für jede Linie vier biologische Replikate geerntet, die jeweils 18 Pflanzen umfassten. Aus den Proben wurde nach dem Trizol-Protokoll RNA extrahiert und diese mit dem RNeasy-Kit von Qiagen aufgereinigt. Die Qualität der RNA wurde 
im Bioanalyzer überprüft (nicht gezeigt), und im Anschluss wurde die RNA zu Aminoallyl-aRNA amplifiziert. Auf dringendes Anraten des Göttinger Transkriptomanalyse-Labors hin wurden nicht verschiedene biologische Replikate auf verschiedene Arrays hybridisiert, sondern die biologischen Replikate wurden vereinigt, und anschließend wieder in vier identische Proben aufgeteilt, sodass die Analysen letztlich nur mit vier technischen Replikaten durchgeführt wurden. Die anschließende Kopplung der Fluoreszenzfarbstoffe Cy3 bzw. Cy5 an die aRNA fand so statt, dass je zwei Proben mit Cy3 und zwei Proben mit Cy5 gekoppelt wurden, um mögliche Effekte durch die Kopplung mit den unterschiedlichen Farbstoffen auszugleichen (dye swap). Für die Hybridisierung wurden 1,5 $\mu \mathrm{g}$ Cy-aRNA je Probe verwendet, was einer Inkorporation von 100-300 pmol/ $\mu \mathrm{g}$ Farbstoff entspricht.

Die Hybridisierung fand nach einem Dreiecksschema statt, so dass jede mögliche Kombination von Proben mit dye swap auf zwei Arrays hybridisiert wurde. Rechnerisch lassen sich dann Daten für zwei weitere Replikate für jede Kombination von Proben gewinnen, in dem die Daten aus den beiden anderen Kombinationen integriert werden (Siehe Abbildung 5.50, der rote Pfeil zeigt beispielhaft den rechnerischen Vergleich einer Wildtyp-Probe mit einer atbzip1/atbzip53 Probe).

In Abbildung 5.51 ist für jede Kombination der verglichenen Proben der Grad der differentiellen Expression (der Logarithmus des Verhältnisses der für das jeweilige Gen gemessenen Signalstärke zwischen zwei verglichenen Proben, kurz logRatio) gegen die statistische Signifikanz dieses logRatios (p-Wert) aufgetragen. Die statistische

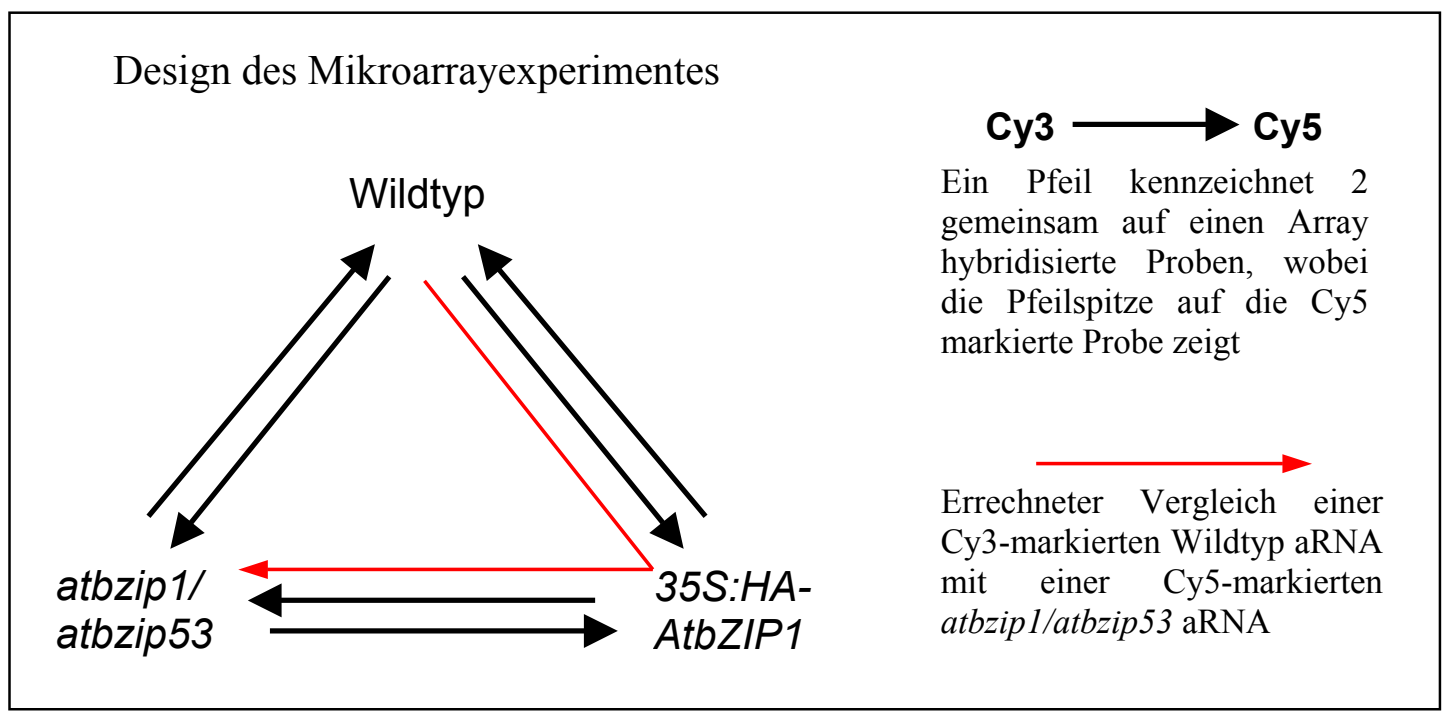

Abbildung 5.50: Schema des Mikroarrayexperiment Designs. Vier Wildtyp aRNAs, vier aRNAs der Doppelmutante atbzipl/atbzip53 und vier 35S:HA-AtbZIP1 aRNAs wurden entsprechend dem Schema auf sechs Arizona whole genome Arrays hybridisiert. 
Signifikanz errechnet sich aus den Schwankungen zwischen den technischen Replikaten. Für den Vergleich der Wildtyp aRNA-Proben mit aRNA-Proben aus ektopischen AtbZIP1 Überexprimierern sieht man, dass unter den statistisch signifikant differentiell exprimierten Genen $(p-W e r t<0,05)$, die in der Überexpressionslinie aktivierten Gene überwiegen (positives logRatio). Dies entspricht den Beobachtungen bei der Transkriptomanalyse von 35:AtbZIP53 Pflanzen, und ist ein Hinweis auf die Fähigkeit von AtbZIP1 die Transkription zu aktivieren.

Entsprechend sieht man bei dem Vergleich von aRNA-Proben der atbzip1/atbzip53 Doppelmutante mit Wildtyp aRNA-Proben, dass reprimierte Gene überwiegen. Die pWerte fallen hier insgesamt schlechter aus, was auf ein deutlich geringeres Maß an differentiell regulierten Genen schließen lässt, eventuell aber auch Folge eines technischen Fehlers ist. Bei dem direkten Vergleich von der Überexpressionslinie mit der Doppelmutante finden sich die meisten signifikant regulierten Gene.

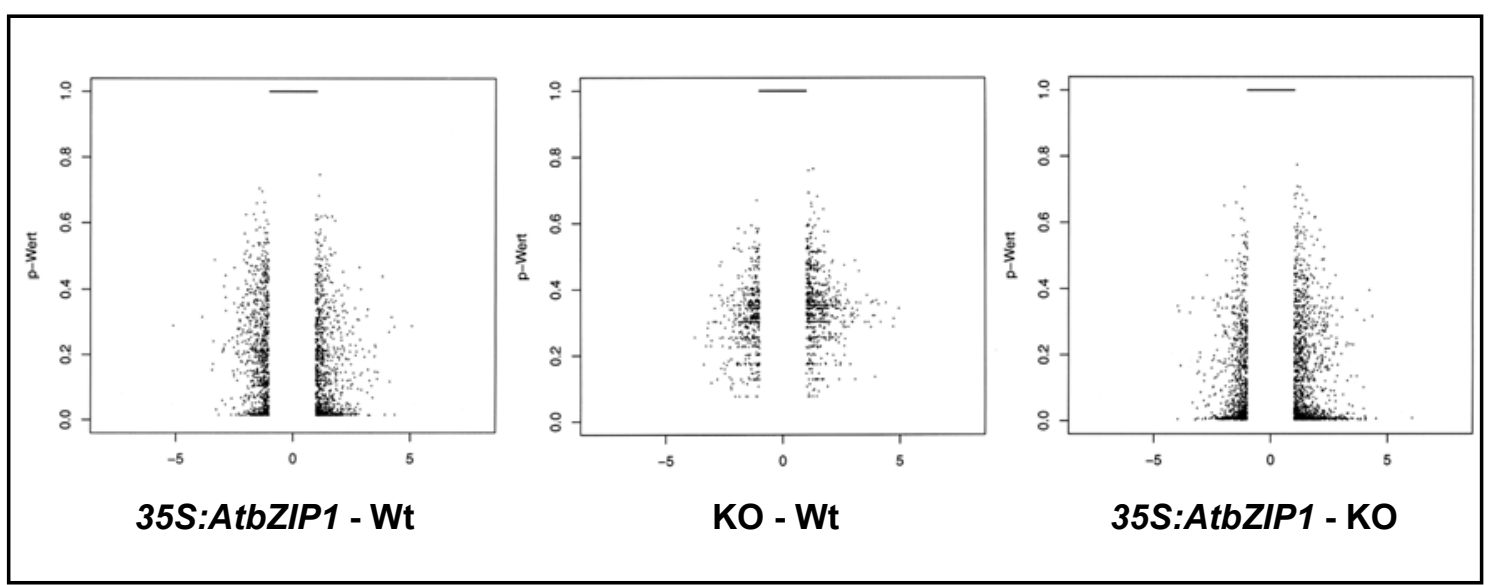

Abbildung 5.51: Auftragung des Logarithmus des Verhältnisses der Signalstärke zwischen zwei verglichenen Proben (logRatio; X-Achse) gegen die statistische Signifikanz diese Wertes (p-Wert; Y-Achse). LogRatios mit einem Betrag kleiner 1 wurden auf den p-Wert 1 (nicht signifikant) gesetzt. Wt35S:AtbZIP1: Auftragung der Werte aus dem Vergleich von Wildtyp aRNA-Proben mit aRNA-Proben aus ektopischen AtbZIP1 Überexprimierern. Wt-KO: Auftragung der Werte aus dem Vergleich von aRNA-Proben der atbzip1/atbzip53 Doppelmutante mit Wildtyp aRNA-Proben. 35S:AtbZIP1-Wt: Auftragung der Werte aus dem Vergleich von aRNA-Proben des ektopischen AtbZIP1 Überexprimierers mit aRNA-Proben der atbzip1/atbzip53 Doppelmutante.

\subsubsection{Viele der Gene mit einer erhöhten Expression in der 35S:AtbZIP1 Linie werden durch Seneszenz induziert}

Für die Identifizierung von in der 35S:AtbZIP1 Linie im Vergleich zum Wildtyp signifikant stärker exprimierten Genen wurden als Schwellenwerte ein p-Wert von 
höchstens 0,05 und ein Unterschied in der Signalstärke (logRatio) von mindestens 2 festgesetzt, was einem vierfach stärkeren Signal entspricht. Um herauszufinden, ob die in der 35S:HA-AtbZIP1 Linie stärker exprimierten Gene möglicherweise eine Funktion in der Seneszenz erfüllen, wurde überprüft, für welche dieser Gene bereits ein Induktion durch verschiedene Formen von Seneszenz gezeigt wurde. Dazu wurde die Gruppe der stärker exprimierten Gene mit veröffentlichten Expressionsprofilen zu natürlicher Seneszenz (Buchanan-Wollaston et al., 2005), Dunkel-induzierter Seneszenz (Lin und $\mathrm{Wu}, 2004$ ) und einer durch Zuckerverarmung seneszenten Zellkultur (Swidzinski et al., 2002) verglichen. Tatsächlich wurde die Mehrheit der im 35S:HA-AtbZIP1 Hintergrund stärker exprimierten Gene auch während verschiedener Formen von Seneszenz induziert. Von den 50 untersuchten Genen werden 22 durch Dunkel-induzierte Seneszenz induziert, 23 in seneszenten Zellkulturen und 19 während der natürlichen Seneszenz. Dabei werden 12 Gene durch alle drei Formen der Seneszenz induziert (vier der in Tabelle 5.4 aufgeführten 54 Gene sind nicht auf den Affymetrix-Arrays vorhanden, mit denen die Seneszenz-Expressionsprofile erstellt wurden. Daher lässt sich über diese Gene keine Aussage treffen.).

Tabelle 5.4: In 35S:AtbZIP1 Pflanzen stärker als im Wildtyp exprimierte Gene. Die Spalte 35S/Wt gibt den Logarithmus des Quotienten der für 35S:AtbZIP53 und Wildtyp Pflanzen erhaltenen Signale (logRatio) wieder, die Spalte p-Wert die statistische Signifikanz dieser Werte (je niedriger der p-Wert, desto zuverlässiger die Daten). In der Spalte KO/Wt wird zusätzlich das logRatio der Expression zwischen der atbzip1/atbzip53 Doppelmutante und dem Wildtyp wiedergegeben. Für jedes Gen wurde anhand von veröffentlichten Expressionsprofilen (Buchanan-Wollaston et al., 2005; Lin und Wu, 2004; Swidzinski et al., 2002) untersucht, durch welche Formen der Seneszenz es induziert wird. Anhand dieser Daten wurden die Gene dem unter der Tabelle wiedergegebenen Farbkode zugeordnet: Gene, welche eine ACGTTAC Konsensussequenz enthalten (siehe Tabelle 5.6), wurden mit einem \# gekennzeichnet.

\begin{tabular}{|l|l|r|r|r|}
\hline AGI & Beschreibung & $\begin{array}{l}\text { 35S/ } \\
\text { Wt }\end{array}$ & $\begin{array}{l}\mathrm{P}- \\
\text { Wert }\end{array}$ & $\begin{array}{l}\text { KOI } \\
\text { Wt }\end{array}$ \\
\hline At4g15210 & beta-amylase (BMY1) / 1,4-D-glucan maltohydrolase (EC 3.2.1.2) & 4,4 & 0,013 & 2,5 \\
\hline At3g04320 & trypsin and protease inhibitor family / Kunitz family protein & 3,9 & 0,013 & $-0,6$ \\
\hline At1g55020 & lipoxygenase (LOX1) & 3,3 & 0,012 & $-0,7$ \\
\hline At4g22470 & protease inhibitor/seed storage/lipid transfer protein (LTP) family & 3,2 & 0,012 & $-0,6$ \\
\hline At4g38050\# & xanthine/uracil permease family protein & 2,9 & 0,03 & 1,8 \\
\hline At5g43580\# & $\begin{array}{l}\text { protease inhibitor, putative similar to SP|P19873 Inhibitor of trypsin } \\
\text { and hageman factor (CMTI-V) \{Cucurbita maxima\}; }\end{array}$ & 2,8 & 0,016 & $-0,6$ \\
\hline At2g02990\# & ribonuclease 1 (RNS1) (EC 3.1.27.1) & 2,8 & 0,047 & $-0,8$ \\
\hline At2g43510\# & trypsin inhibitor, putative similar to SP|P26780 & 2,7 & 0,037 & $-0,5$ \\
\hline At1g70670\# & caleosin-related family protein & 2,7 & 0,017 & $-0,5$ \\
\hline At3g16150\# & L-asparagine amidohydrolase, similar to L-asparaginase (EC 3.5.1.1) & 2,7 & 0,025 & $-0,8$ \\
\hline At4g22590\# & trehalose-6-phosphate phosphatase, putative & 2,7 & 0,015 & -1 \\
\hline At3g04720\# & Hevein-like protein precursor; PR4 & 2,7 & 0,015 & -1 \\
\hline At4g08300\# & nodulin MtN21 family protein similar to MtN21 Gl:2598575 & 2,6 & 0,012 & $-0,4$ \\
\hline At4g16260\# & glycosyl hydrolase family 17 protein similar to glucan endo-1,3-beta- \\
& glucosidase, SP:P52407 from [Hevea brasiliensis] & 2,6 & 0,019 & $-1,2$ \\
\hline At2g29350\# & sag13; short chain alcohol dehydrogenase; tropinone reductase & 2,6 & 0,017 & $-1,4$ \\
\hline
\end{tabular}




\begin{tabular}{|c|c|c|c|c|}
\hline At4g07450 & hypothetical protein & 2,5 & 0,03 & 2 \\
\hline At4g30420\# & nodulin MtN21 family protein similar to MtN21 GI:2598575; & 2,5 & 0,033 & 1,7 \\
\hline At1g26380 & $\begin{array}{l}\text { FAD-binding domain-containing protein similar to SP|P30986 } \\
\text { reticuline oxidase precursor (Berberine-bridge-forming enzyme) }\end{array}$ & 2,5 & 0,044 & $-0,5$ \\
\hline At1g32450 & proton-dependent oligopeptide transport (POT) family protein & 2,5 & 0,032 & $-0,5$ \\
\hline At1g30700 & $\begin{array}{l}\text { FAD-binding domain-containing protein similar to SP|P30986 } \\
\text { reticuline oxidase precursor (Berberine-bridge-forming enzyme) }\end{array}$ & 2,5 & 0,012 & $-1,3$ \\
\hline At1g32350\# & $\begin{array}{l}\text { Alternative oxidase 1a, mitochondrial precursor from Arabidopsis } \\
\text { thaliana [SP|Q39219], alternative oxidase 2, }\end{array}$ & 2,5 & 0,015 & $-1,3$ \\
\hline At5g09790 & PHD finger family protein / SET domain-containing protein & 2,4 & 0,031 & 1,2 \\
\hline At5g49380\# & hypothetical protein contains Pfam domain, PF04802 & 2,4 & 0,032 & \\
\hline At3g07600\# & $\begin{array}{l}\text { heavy-metal-associated domain-containing protein identical to } \\
\text { residues } 23 \text { to } 179 \text { of farnesylated protein ATFP4 GB:AAD09508 }\end{array}$ & 2,4 & 0,025 & $-0,3$ \\
\hline At1g61820 & $\begin{array}{l}\text { glycosyl hydrolase family } 1 \text { protein; 6-phospho-ß-galactosidase; } \\
\text { similar to beta-mannosidase enzyme (GI:17226270) }\end{array}$ & 2,4 & 0,047 & $-0,3$ \\
\hline At4g34950\# & similar to nodulin-like protein [Arabidopsis thaliana] GI:3329368 & 2,4 & 0,014 & $-0,4$ \\
\hline At5g40690 & expressed protein & 2,3 & 0,015 & $-0,1$ \\
\hline At5g24770 & vegetative storage protein 2 (VSP2) & 2,3 & 0,049 & $-0,6$ \\
\hline At3g25950 & hypothetical protein & 2,3 & 0,042 & $-0,8$ \\
\hline At1g74010\# & strictosidine synthase family protein similar to [SP|P15324]; & 2,3 & 0,017 & $-0,9$ \\
\hline At3g63470 & $\begin{array}{l}\text { serine carboxypeptidase, putative similar to SP|P52711 Serine } \\
\text { carboxypeptidase II-3 precursor (EC 3.4.16.6) Hordeum vulgare; }\end{array}$ & 2,3 & 0,012 & -1 \\
\hline At1g73610 & similar to family II lipase EXL6, EXL4 [Arabidopsis thaliana] & 2,2 & 0,03 & $-0,1$ \\
\hline At5g10625 & expressed protein & 2,2 & 0,017 & $-0,1$ \\
\hline At5g45630 & expressed protein & 2,2 & 0,014 & $-0,6$ \\
\hline At2g29470\# & glutathione S-transferase, putative & 2,2 & 0,028 & $-0,6$ \\
\hline At2g39030\# & GCN5-related N-acetyltransferase family protein (EC 2.3.1.110) & 2,2 & 0,013 & $-1,9$ \\
\hline At1g55390 & DC1 domain-containing protein & 2,1 & 0,021 & 1 \\
\hline At3g28210\# & zinc finger (AN1-like) family protein & 2,1 & 0,034 & 0,4 \\
\hline At3g05400 & similar to sugar-porter proteins 1 \& 2 GI:14585699, GI:14585701, & 2,1 & 0,032 & 0,1 \\
\hline At4g11320\# & cysteine proteinase, putative contains similarity to GI:435619, & 2,1 & 0,042 & $-0,3$ \\
\hline At1g66570 & similar to sucrose-proton symporter SUC1 [Arabidopsis thaliana] & 2,1 & 0,025 & $-0,3$ \\
\hline At2g22880\# & VQ motif-containing protein contains PF05678: VQ motif & 2,1 & 0,012 & $-0,3$ \\
\hline At1g73260 & trypsin and protease inhibitor family protein / Kunitz family protein & 2,1 & 0,032 & $-0,4$ \\
\hline At2g36310\# & inosine-uridine preferring nucleoside hydrolase family protein & 2,1 & 0,017 & $-0,4$ \\
\hline At3g49620 & 2-oxoacid-dependent oxidase, putative (DIN11) & 2,1 & 0,012 & $-0,6$ \\
\hline At2g16660 & nodulin family protein similar to nodulin-like protein GI:3329368, & 2,1 & 0,013 & $-0,7$ \\
\hline At3g26840 & esterase/lipase/thioesterase family protein & 2,1 & 0,012 & $-0,8$ \\
\hline At3g09440\# & heat shock cognate 70 kDa protein 3 (HSC70-3) (HSP70-3) & 2,1 & 0,013 & -1 \\
\hline At4g21990 & $\begin{array}{l}\text { 5'-adenylylsulfate reductase (APR1) / PAPS reductase homolog } \\
\text { (PRH19) identical to [Arabidopsis thaliana] GI:2738756 }\end{array}$ & 2,1 & 0,023 & $-1,1$ \\
\hline At3g46080\# & zinc finger ( $\mathrm{C} 2 \mathrm{H} 2$ type) family protein & 2,1 & 0,012 & $-1,1$ \\
\hline At5g49450\# & AtbZIP1 & 2,1 & 0,012 & $-3,9$ \\
\hline At2g32200\# & hypothetical protein & 2 & 0,016 & $-0,3$ \\
\hline At4g37150 & similar to ethylene-induced esterase GI:14279437 & 2 & 0,018 & $-0,3$ \\
\hline At1g13520 & expressed protein & 2 & 0,048 & $-0,7$ \\
\hline
\end{tabular}

\begin{tabular}{|l|l|}
\hline Durch alle Formen der Seneszenz induziert & 12 Gene \\
\hline In seneszenter Zellkultur und durch dunkelinduzierter Seneszenz induziert & 9 Gene \\
\hline Durch natürliche und dunkelinduzierte Seneszenz induziert & 2 Gene \\
\hline Durch natürliche Seneszenz induziert & 5 Gene \\
\hline Durch dunkelinduzierte Seneszenz induziert & 2 Gene \\
\hline In seneszenter Zellkultur induziert & 5 Gene \\
\hline In seneszenter Zellkultur und durch natürliche Seneszenz induziert & 1 Gene \\
\hline
\end{tabular}


Viele der bekannten Seneszenz-assoziierten Gene sind am Katabolismus beteiligt, unter ihnen finden sich Proteasen, RNasen, oder Lipasen (Buchanan-Wollaston und Ainsworth, 1997; Weaver et al., 1998). Solche Gene finden sich auch in der Liste der im 35S:AtbZIP1 Hintergrund stärker exprimierten Gene. Interessanterweise findet sich auch eine Gruppe von fünf Seneszenz-induzierten Protease-Inhibitor Genen in der Liste. Die Funktion von Protease-Inhibitoren im Zusammenhang mit der Seneszenz ist noch nicht untersucht wurde, für sie wurde in Pflanzen bisher vor allem eine Funktion in der Pathogenabwehr gezeigt (Garcia et al., 2004; Ingvarsson, 2005; Kim et al., 2005). Jedoch werden diese Protease-Inhbitoren sehr deutlich durch verschiedene Formen der Seneszenz induziert, was ein deutlicher Hinweis auf ihre Bedeutung in der Seneszenz ist.

Tabelle 5.5: In 35S:AtbZIP1 Pflanzen stärker exprimierte Proteasen werden in hohem Maße durch verschiedenen Formen der Seneszenz induziert. Dis1d: Ein Tag Dunkelinduzierte Seneszenz, Dis5d: Fünf Tage Dunkel-induzierte Seneszenz (Lin und Wu, 2004); Zellkultur: Durch Zuckerverarmung seneszente Zellkultur (Swidzinski et al., 2002); ATGE: Daten zur natürlichen Seneszenz aus dem AtGenExpress Projekt; OE-Wt: Aktivierung im 35S:AtbZIP1 Hintergrund, diese Arbeit; KO-Wt: Repression in der atbzip1/atbzip53 Doppelmutante, diese Arbeit.

\begin{tabular}{|l|l|r|r|r|r|r|r|}
\hline AGI & Beschreibung & DIS1d & DIS5d & $\begin{array}{l}\text { Zell- } \\
\text { Kultur }\end{array}$ & ATGE & $\begin{array}{c}\mathbf{3 5 S} / \\
\text { Wt }\end{array}$ & $\begin{array}{l}\text { KO/ } \\
\text { Wt }\end{array}$ \\
\hline At1g73260 & $\begin{array}{l}\text { trypsin and protease inhibitor family / Kunitz } \\
\text { family protein }\end{array}$ & 15,4 & 80,4 & 229,6 & 128,4 & 2,1 & $-0,4$ \\
\hline At2g43510 & trypsin inhibitor, putative similar to SP|P26780 & 1,8 & 13,9 & 8,9 & 14,2 & 2,7 & $-0,5$ \\
\hline At5g43580 & $\begin{array}{l}\text { protease inhibitor, putative similar to SP|P19873 } \\
\text { Inhibitor of trypsin and hageman factor (CMTI-V) } \\
\text { Cucurbita maxima\}; }\end{array}$ & 2,8 & 65,3 & 140,6 & 0,2 & 2,8 & $-0,6$ \\
\hline At3g04320 & $\begin{array}{l}\text { trypsin and protease inhibitor family / Kunitz } \\
\text { family protein }\end{array}$ & 1,8 & 1150,8 & 1,3 & 10,5 & 3,9 & $-0,6$ \\
\hline At4g22470 & $\begin{array}{l}\text { protease inhibitor/seed storage/lipid transfer } \\
\text { protein (LTP) family }\end{array}$ & 1,5 & 10,8 & 4,5 & 0,7 & 3,2 & $-0,6$ \\
\hline
\end{tabular}

Um zu überprüfen, ob die Gruppe der in 35S:AtbZIP1 Pflanzen aktivierten Gene eine ähnliche Gewebespezifität zeigt, wie sie bei den in 35S:AtbZIP53 Pflanzen aktivierten Genen beobachtet wurde, wurde ihre Expression mit dem Metaanalyzer Programm der Genevestigator Software (Zimmermann et al., 2004) analysiert (Abbildung 5.52). Dieses Programm fast Daten mehrerer Mikroarray-Experimente zusammen, und ermöglicht so die Expression einzelner Gene in verschiedenen Geweben miteinander zu vergleichen. Für jedes Gen werden die stärksten gemessenen Expressionen dunkelblau, die schwächsten weiß dargestellt. Insgesamt zeigt sich ein uneinheitliches Bild. 


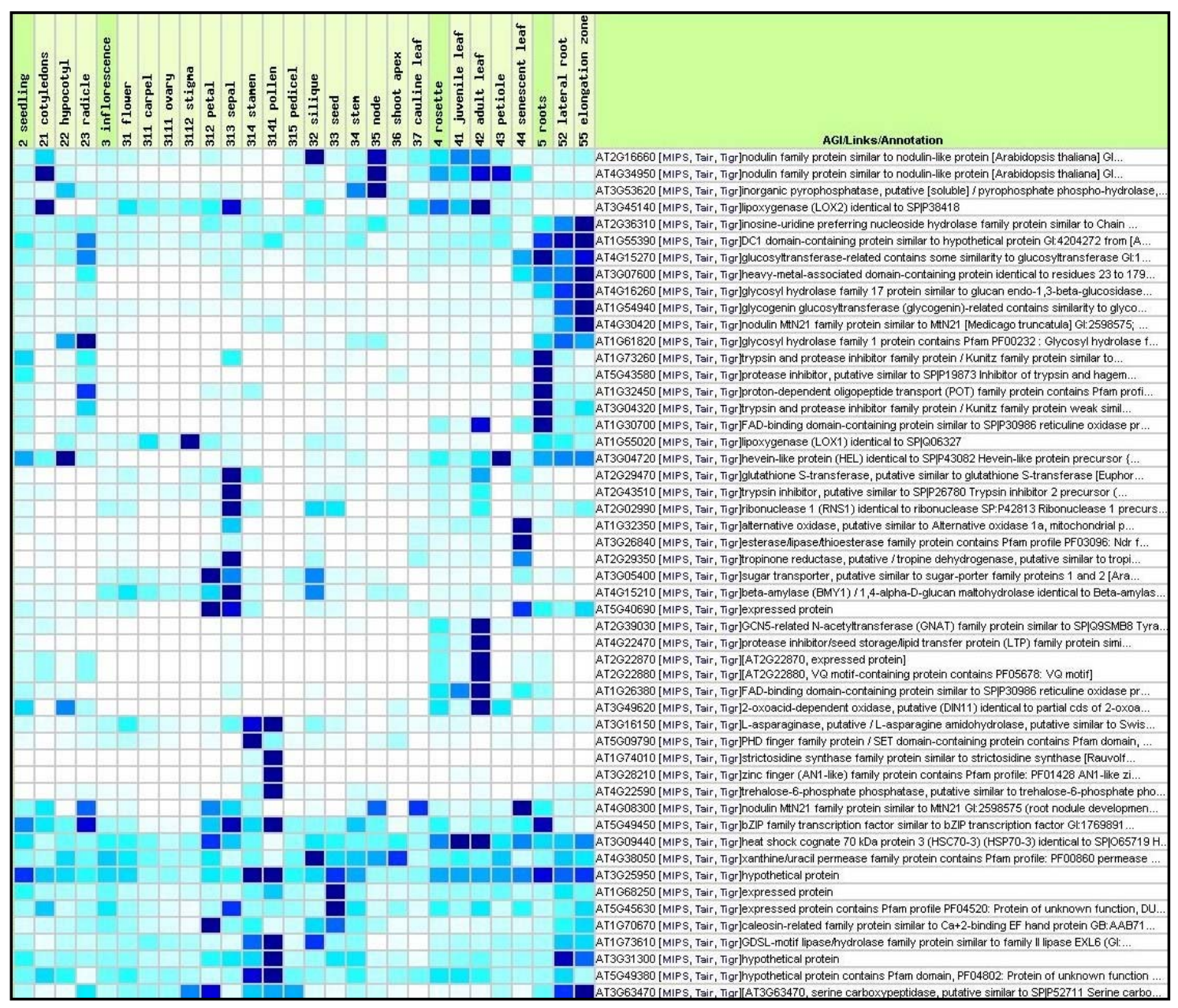

Abbildung 5.52: Genevestigator-Analyse der gewebespezifischen Expressionsmuster der in den 35S:AtbZIP1 Pflanzen im Vergleich zum Wildtyp am stärksten aktivierten Gene. Je dunkler das Blau, desto stärker ist die Expression in dem jeweiligen Gewebe. Für die Darstellung wurden Kallus und Zellkultur von der Liste der Gewebe ausgeschlossen, verwendete Einstellungen für die Berechnung der Cluster waren Euclidean und Average.

Während sich wie bei den für AtbZIP53 durchgeführten Analysen auch hier ein Gruppe von stark in Pollen exprimierten Genen findet, gibt es kaum stark in Samen exprimierte Gene. Dagegen fällt die Gruppe der stark in Wurzeln exprimierten Gene deutlich größer aus als bei AtbZIP53.

Ähnlich zu Analyse der gewebespezifischen Expression wurde mit Genevestigator auch eine Analyse der Stressregulation der in 35S:AtbZIP1 Pflanzen aktivierten Gene durchgeführt. Aus Gründen der Übersichtlichkeit sind hier nur Experimente gezeigt, in denen ein Großteil der Gene eine deutliche Regulation zeigt. Auffallend ist, dass etwa die Hälfte aller Gene durch verschiedene Arten von Pathogenen induziert werden, am deutlichsten durch Infektion mit Pseudomonas syringae. Unter "PCD: senescence" sind Mikroarray Daten von einer durch Zuckerverarmung in die Seneszenz übergegangenen 


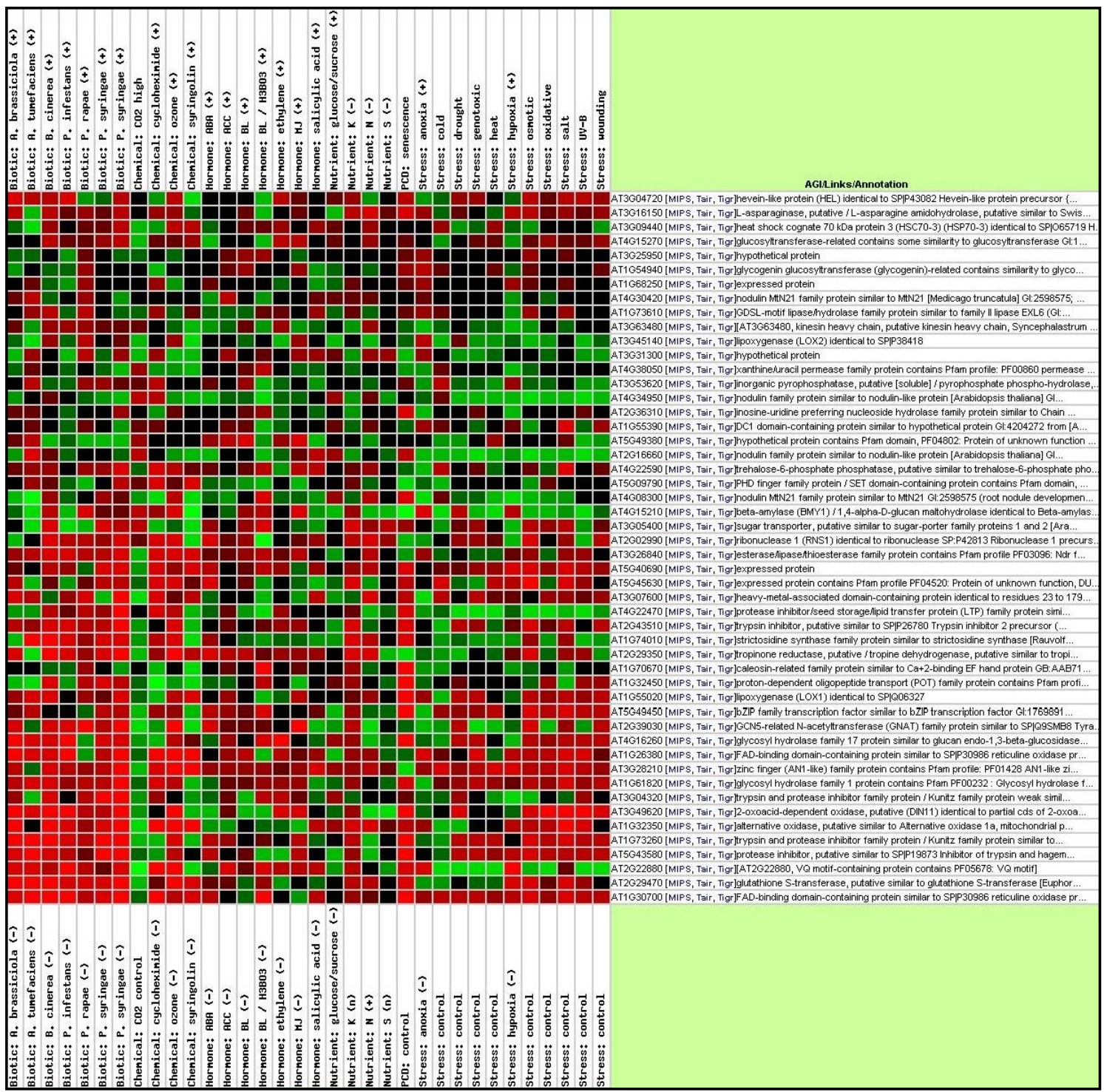

Abbildung 5.53: Übersicht über die Regulation der in 35S:AtbZIP1 Pflanzen aktivierten Gene unter verschiedenen Stressbedingungen. Die Beschriftungen oben bezeichnen das jeweilige Experiment, rechts sind die aktivierten Gene aufgeführt. Ist ein Feld rot, ist das Gen im Experiment stärker exprimiert, ist es grün, so ist das Gen im Experiment schwächer exprimiert. Je heller die Farben sind, desto stärker ist die Differenz zwischen Experiment und Kontrolle. Schwarze Felder bedeuten eine gleichstarke Expression in Experiment und Kontrolle.

Zellkultur zu finden (Swidzinski et al., 2002). Eine sehr starke Induktion von AtbZIP1 in diesem Experiment wurde bereits unter 5.9.3 und in Abbildung 5.48 gezeigt.Hier wird neben AtbZIP1 selbst auch etwa die Hälfte der in 35S:AtbZIP1 Pflanzen am stärksten aktivierten Gene deutlich induziert. Viele dieser Gene werden auch durch Salzstress und unter oxidativem Stress nach Ozon-Behandlung oder durch 10mM Methyl-Viologen (hier als "Stress: oxidative" beschriftet) induziert.

Durch hohe $\mathrm{CO}_{2}$-Konzentrationen und Behandlung mit Syringolin wird hingegen die Mehrheit der Gene reprimiert. Durch Behandlung mit Syringolin kann eine 
hypersensitive Antwort ausgelöst werden, die programmierten Zelltod zur Folge hat. Das hier die Mehrheit der Gene reprimiert ist, zeigt dass die unter "PCD: senescence" gezeigten Induktionen in der seneszenten Zellkultur eher auf die Seneszenz, nicht auf den programmierten Zelltod zurückzuführen sind. Eine überwiegende Repression findet sich auch bei Kälte-Behandlung.

\subsubsection{Die Promotoren von in der 35S:AtbZIP1 Linie stärker exprimierten zeigen ein gehäuftes Auftreten eines ACGTTAC-Motivs}

Da AtbZIP1 wahrscheinlich als Heterodimer seine Zielgene reguliert, und die von AtbZIP1 gebundenen cis-Elemente wahrscheinlich auch von dem Heterodimerisierungspartner abhängen, wird es schwierig sein ein konkretes Bindeelement $\mathrm{zu}$ identifizieren (Matsushima-Hibiya et al., 1998). Aussagen über mögliche cis-Elemente anhand der Arraydaten werden zusätzlich erschwert, da die Gruppe der dort aktivierten Gene wahrscheinlich nur zu einem Teil direkte Zielgene beinhaltet.

Zunächst wurden die -1 bis -1000 bp Promotorregionen der in 35S:HA-AtbZIP1 Pflanzen am stärksten aktivierten Gene mit dem Programm Bioprospector analysiert (Liu et al., 2001). Die Suche lieferte ein ACGTTAC Motiv, das die Kernbindesequenz von AtbZIP-Transkriptionsfaktoren, $A C G T$, beinhaltet (Tabelle 5.6). Es könnte sich also möglicherweise wirklich um ein Bindemotiv von AtbZIP1 handeln.

Tabelle 5.6: Mit Hilfe des Programms Bioprospector identifiziertes Motiv, das gehäuft in den Promotoren der im 35S:AtbZIP1 Hintergrund aktivierten Gene auftritt. In Zeile 1 ist die Konsensus-Sequenz wiedergegeben, in den folgenden Zeilen, mit welcher Häufigkeit die Basen an den entsprechenden Positionen auftreten. Gene, welche die ACGTTAC Konsensussequenz enthalten, wurden in der Liste der aktivierten Gene (Tabelle 5.4) mit einem \# gekennzeichnet. Der Promotor von AT3G04720 (Hevein-like protein precursor) enthält 2 ACGTTAC Motive.

\begin{tabular}{|c|c|c|c|c|c|c|c|}
\hline Konsensus: & A & $\mathbf{C}$ & $\mathbf{G}$ & $\mathbf{T}$ & $\mathbf{T}$ & $\mathbf{A}$ & $\mathbf{C}$ \\
\hline$\% \mathrm{~A}$ & 100 & 0 & 0 & 0 & 0 & 78 & 0 \\
\hline$\% \mathrm{C}$ & 0 & 78 & 0 & 9 & 0 & 0 & 100 \\
\hline$\% \mathrm{G}$ & 0 & 22 & 100 & 0 & 0 & 22 & 0 \\
\hline$\% \mathrm{~T}$ & 0 & 0 & 0 & 91 & 100 & 0 & 0 \\
\hline
\end{tabular}


Die relative Häufigkeit des ACGTTAC Motivs wurde im folgenden mit dem Programm POBO analysiert. Dazu wurden die -1 bis -1000 Basenpaare Promotorregionen der 38 in 35S:HA-AtbZIP1 Pflanzen am stärksten aktivierten Gene verwendet. Tatsächlich findet sich das Motiv deutlich häufiger als im Durchschnitt aller -1 bis -1000 Basenpaare Promotorregionen aus Arabidopsis (Abbildung 5.54). Entsprechend tritt auch das ACGT-Motiv gehäuft auf, während dies bei dem ACTCAT Motiv aus dem ProDH Promotor oder dem ABRE-Motiv, dass in den Transkriptomanalysen der 35S:AtbZIP53 Pflanzen identifiziert wurde, nicht der Fall ist. In der Literatur wurde ein ACGTTAC Motiv bisher nicht beschrieben.
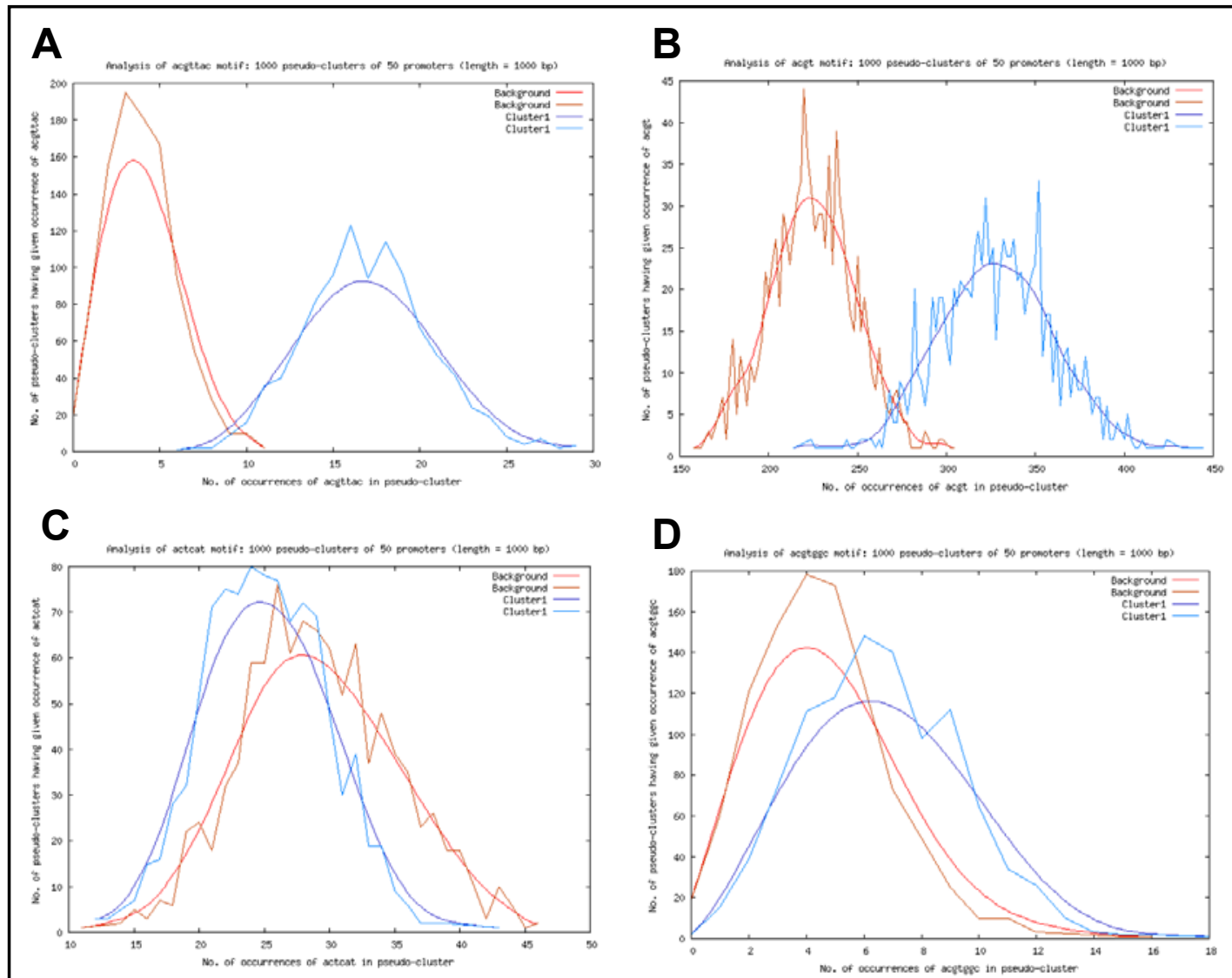

\begin{abstract}
Abbildung 5.54: Analyse der -1 bis $\mathbf{- 1 0 0 0}$ bp Promotorregionen der in 35S:HA-AtbZIP1 Pflanzen am stärksten aktivierten Gene mit dem Programm POBO. A: Häufigkeit des ACGTTAC-Motivs; B: Häufigkeit des ACGT-Motivs; C: Häufigkeit des ACTCAT-Motivs; D: Häufigkeit des ACGTGGCMotivs. Als Kontrolle diente Arabidopsis_thalian_full, ein Datensatz der die 1000bp Promotorregionen fast aller Gene aus Arabidopsis enthält. Die Bootstrapping-Analysen wurden mit jeweils 1000 Clustern aus je 50 Promotoren durchgeführt. Die roten Linien zeigen die Häufigkeit des untersuchten Motivs in der Kontrollgruppe, die blauen Linien die Häufigkeit des Motivs in den Promotoren der aktivierten Gene (X-Achse: Häufigkeit des Motivs im Pseudo-Kluster; Y-Achse: Zahl der Pseudokluster).
\end{abstract}




\subsubsection{Gene mit einer im Vergleich zum Wildtyp reduzierten Expression in der atbzip1/atbzip53 Doppelmutante}

Für die Identifizierung von in der atbzip1/atbzip53 Doppelmutante im Vergleich zum Wildtyp signifikant schwächer exprimierten Genen wurden als Schwellenwerte ein p-Wert von höchstens 0,1 und ein Unterschied in der Signalstärke (logRatio) von mindestens -1 festgesetzt, was einer halbierten Signalstärke entspricht (Tabelle 5.7). Wie zu erwarten, gehören einige der in der Doppelmutante am stärksten reprimierten Gene auch zu den in AtbZIPl Überexprimierern am stärksten aktivierten Gene. Bei anderen Genen, wie zum Beispiel dem deutlich reprimierten F-box Protein At1g58090, ist die Repression möglicherweise auf die Mutation von AtbZIP53 zurückzuführen. Hier bleiben die Ergebnisse der entsprechenden Northern-Analysen abzuwarten, die im Rahmen der Dissertation aus zeitlichen Gründen nicht mehr durchführbar waren. Auch unter den in der atbzip1/atbzip53 Doppelmutante reprimierten Genen finden sich viele während der Seneszenz induzierte Gene, die den bei dieser Mutante beobachteten Phänotyp eines verzögerten Eintretens in die Dunkel-induzierte Seneszenz erklären könnten.

Tabelle 5.7: In der atbzip1/atbzip53 Doppelmutante schwächer als im Wildtyp exprimierte Gene. Die Spalte KO/Wt gibt den Logarithmus des Quotienten der für 35S:AtbZIP53 und Wildtyp Pflanzen erhaltenen Signale (logRatio) wieder, die Spalte p-Wert die statistische Signifikanz dieser Werte (je niedriger der p-Wert, desto zuverlässiger die Daten). In der Spalte 35S/Wt wird zusätzlich das logRatio der Expression zwischen 35s:AtbZIP1 Pflanzen und dem Wildtyp wiedergegeben. Für jedes Gene wurde anhand von veröffentlichten Expressionsprofilen (Buchanan-Wollaston et al., 2005; Lin und Wu, 2004; Swidzinski et al., 2002) untersucht, durch welche Formen der Seneszenz sie induziert werden. Anhand dieser Daten wurden die Gene dem unter der Tabelle wiedergegebenen Farbkode zugeordnet:

\begin{tabular}{|l|l|r|r|r|}
\hline AGI & Beschreibung & $\begin{array}{l}\text { KOI } \\
\text { Wt }\end{array}$ & $\begin{array}{l}\text { p- } \\
\text { Wert }\end{array}$ & $\begin{array}{l}35 \mathrm{~S} / \\
\text { Wt }\end{array}$ \\
\hline At5g49450\# & AtbZIP1 & $-3,9$ & 0,135 & 2,1 \\
\hline At1g58090\# & F-box family protein & $-2,9$ & 0,173 & $-2,9$ \\
\hline At5g49590\# & hypothetical protein & $-2,5$ & 0,178 & 1,6 \\
\hline At3g62420\# & AtbZIP53 & $-2,4$ & 0,128 & $-0,4$ \\
\hline At5g52290 & hypothetical protein & $-2,1$ & 0,201 & $-3,3$ \\
\hline At2g39030\# & GCN5-related N-acetyltransferase (GNAT) family protein & $-1,9$ & 0,106 & 2,2 \\
\hline At5g38900\# & $\begin{array}{l}\text { DSBA oxidoreductase family protein contains Pfam profile: PF01323 } \\
\text { DSBA-like thioredoxin domain }\end{array}$ & $-1,7$ & 0,128 & 1,5 \\
\hline At2g31081 & Clavata3 / ESR-Related-4 (CLE4) & $-1,6$ & 0,227 & $-2,5$ \\
\hline At2g35980\# & $\begin{array}{l}\text { harpin-induced family protein (YLS9) / similar to harpin-induced } \\
\text { protein hin1 ( Gl:1619321) [Nicotiana tabacum]; }\end{array}$ & $-1,5$ & 0,092 & 1,8 \\
\hline At3g55970\# & $\begin{array}{l}\text { oxidoreductase, 2OG-Fe(II) similar to leucoanthocyanidin } \\
\text { dioxygenase, Malus domestica, SP|P51091; }\end{array}$ & $-1,5$ & 0,128 & 1,7 \\
\hline At4g26260\# & myo-inositol oxygenase & $-1,5$ & 0,128 & 1,2 \\
\hline At2g29350 & sag13; short chain alcohol dehydrogenase; tropinone reductase & $-1,4$ & 0,239 & 2,6 \\
\hline At3g05950\# & similar to germin-like protein GLP6 [SP|P92997] & $-1,4$ & 0,173 & 1,7 \\
\hline
\end{tabular}




\begin{tabular}{|c|c|c|c|c|}
\hline At1g02930 & glutathione S-transferase & $-1,4$ & 0,076 & 1,6 \\
\hline At1g15520\# & $\begin{array}{l}\text { ABC transporter family protein similar to } \mathrm{ABC} 1 \text { protein } \mathrm{Gl}: 14331118 \\
\text { from [Nicotiana plumbaginifolia] }\end{array}$ & $-1,4$ & 0,128 & 0,5 \\
\hline At1g30700 & FAD-binding domain-containing protein similar to SP|P30986 & $-1,3$ & 0,099 & 2,5 \\
\hline At1g32350\# & $\begin{array}{l}\text { similar to Alternative oxidase 1a, mitochondrial precursor from } \\
\text { Arabidopsis thaliana [SP|Q39219] }\end{array}$ & $-1,3$ & 0,173 & 2,5 \\
\hline At1g47510\# & endonuclease/exonuclease/phosphatase family protein & $-1,3$ & 0,173 & 1 \\
\hline At1g20850\# & cysteine endopeptidase, papain-type (XCP2) & $-1,3$ & 0,095 & 0,5 \\
\hline At3g15356 & legume lectin family protein & $-1,3$ & 0,076 & 0,3 \\
\hline At4g16260\# & $\begin{array}{l}\text { glycosyl hydrolase family } 17 \text { protein similar to glucan endo-1,3-beta- } \\
\text { glucosidase, }\end{array}$ & $-1,2$ & 0,201 & 2,6 \\
\hline At1g54890\# & $\begin{array}{l}\text { LEA protein-related similar to late embryogenesis abundant protein } \\
\text { (EMB7) GI:1350543 from [Picea glauca] }\end{array}$ & $-1,2$ & 0,261 & 1,8 \\
\hline At2g43570\# & chitinase, putative similar to chitinase class IV GI:722272 & $-1,2$ & 0,178 & 0,9 \\
\hline At5g46230\# & expressed protein & $-1,2$ & 0,185 & 0,6 \\
\hline At2g07751 & NADH-ubiquinone oxidoreductas & $-1,2$ & 0,227 & $-1,6$ \\
\hline At4g21990 & $\begin{array}{l}\text { 5'-adenylylsulfate reductase (APR1) / PAPS reductase homolog } \\
\text { (PRH19) }\end{array}$ & $-1,1$ & 0,128 & 2,1 \\
\hline At3g46080\# & zinc finger (C2H2 type) family protein & $-1,1$ & 0,159 & 2,1 \\
\hline At3g45140\# & lipox & $-1,1$ & 0,203 & \\
\hline At4g36820\# & hypothetical protein contains Pfam domain, PF04678: & $-1,1$ & 0,173 & 1,7 \\
\hline At1g02920\# & glutathione S-transferase, putative & $-1,1$ & 0,085 & 1,7 \\
\hline At2g18690\# & expressed protein & $-1,1$ & 0,076 & 1,6 \\
\hline At2g38860 & proteasel (pfpl)-like protein GI:13122288 & $-1,1$ & 0,076 & 1,1 \\
\hline At1g55265 & Kelch repeat containing F-box protein, iden & $-1,1$ & 0,113 & 0,9 \\
\hline At5g22300 & nitrilase 4 (NIT4) (EC 3.5.5.1) \{Arabidopsis thaliana\} & $-1,1$ & 0,076 & 0,8 \\
\hline At4g03070\# & $\begin{array}{l}\text { 2-oxoglutarate-dependent dioxygenase (AOP1.2) identical to } \\
\text { GI:16118887 }\end{array}$ & $-1,1$ & 0,252 & $-1,7$ \\
\hline At4g22590\# & trehalose-6-phosphate phosphatase & -1 & 0,223 & 2,7 \\
\hline At3g04720\# & $\begin{array}{l}\text { Hevein-like protein precursor; similar to SP|P09762 Wound-induced } \\
\text { protein WIN2 precursor }\end{array}$ & -1 & 0,173 & 2,7 \\
\hline At3g63470 & $\begin{array}{l}\text { similar to SP|P52711 Serine carboxypeptidase II-3 precursor (EC } \\
\text { 3.4.16.6) Hordeum vulgare; }\end{array}$ & -1 & 0,146 & 2,3 \\
\hline At1g17745 & $\begin{array}{l}\text { D-3-phosphoglycerate dehydrogenase / 3-PGDH identical to } \\
\text { SP|O04130 }\end{array}$ & -1 & 0,226 & 1,3 \\
\hline At2g44670\# & similar to senescence-associated protein SAG102 (Gl:22331931) & -1 & 0,106 & 1,1 \\
\hline At3g58070 & zinc finger (C2H2 type) family protein & -1 & 0,175 & $-2,4$ \\
\hline
\end{tabular}

\begin{tabular}{|l|l|}
\hline Durch alle Formen der Seneszenz induziert & 6 Gene \\
\hline In seneszenter Zellkultur und durch Dunkel-induzierte Seneszenz induziert & 2 Gene \\
\hline Durch natürliche und Dunkel-induzierte Seneszenz induziert & 5 Gene \\
\hline Durch natürliche Seneszenz induziert & 3 Gene \\
\hline Durch Dunkel-induzierte Seneszenz induziert & 1 Gen \\
\hline In seneszenter Zellkultur induziert & 3 Gene \\
\hline In seneszenter Zellkultur und durch natürliche Seneszenz induziert & 2 Gene \\
\hline
\end{tabular}

Eine Analyse der in der Doppelmutante reprimierten Gene mit der Genevestigator Software zeigte keine klare Anhäufung von bestimmten gewebespezifischen Expressionsmustern. Jedoch findet sich in dieser Gruppe, wie schon bei den in 35S:AtbZIP1 Pflanzen aktivierten Genen, eine deutliche Anhäufung von Genen, die durch biotischen Stress aktiviert werden (Abbildung 5.55). Ebenso finden sich auch viele durch Ozon oder Salzstress induzierte Gene, sowie viele in Gegenwart von hohen $\mathrm{CO}_{2}$-Konzentrationen reprimierte Gene. 


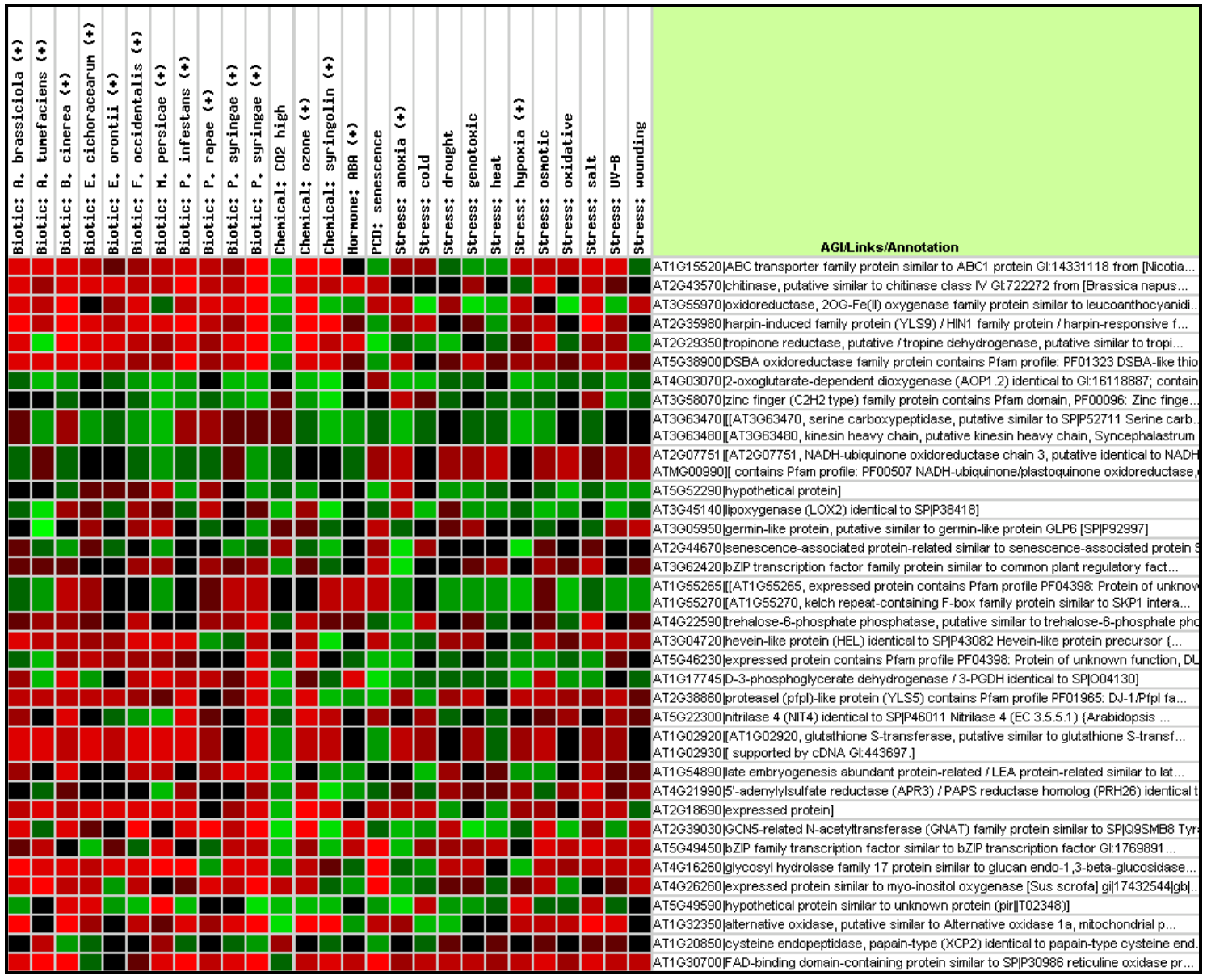

Abbildung 5.55: Übersicht über die Expression der in 35S:AtbZIP1 Pflanzen aktivierten Gene unter verschiedenen Stressbedingungen. Die Beschriftungen oben bezeichnen das jeweilige Experiment, rechts sind die verschiedenen Gene aufgeführt. Ist ein Feld rot, ist das Gen im Experiment stärker exprimiert, ist es grün, so ist das Gen im Experiment schwächer exprimiert. Je heller die Farben sind, desto stärker ist die Differenz zwischen Experiment und Kontrolle. Schwarze Felder bedeuten eine gleichstarke Expression in Experiment und Kontrolle.

\subsubsection{Analyse der Promotoren von Genen mit einer reduzierten Expression in der atbzip1/atbzip53 Doppelmutante}

Eine Analyse der -1 bis -1000 Basenpaare Promotorregionen der in der Doppelmutante reprimierten Gene mit dem Programm Bioprospector zeigte, wie schon bei der vorherigen Analyse, ein gehäuftes Auftreten eines ACGTTAC Motivs (Tabelle 5.8). Diese Anhäufung wurde durch eine Analyse mit dem Programm POBO bestätigt (Abbildung 5.56). Eine Häufung von $A C G T G G C$ Motiven wurde auch in dieser Gruppe nicht gefunden, ACTCAT Motive traten nur wenig häufiger auf. Um zu kontrollieren, ob dieses Motiv auch in den Promotorregionen der in Kapitel 5.6 durch AtbZIP53 
aktivierten Gene gehäuft auftritt, wurden diese ebenfalls mit POBO auf die Häufigkeit des ACGTTAC Motivs untersucht. Jedoch war hier keine Häufung zu finden.

Tabelle 5.8: Mit Hilfe des Programms Bioprospector wurde ein ACGTCAT-Motiv identifiziert, das gehäuft in den Promotoren der in der atbzip1/atbzip53 Doppelmutante reprimierten Gene auftritt. In Zeile 1 ist die Konsensus-Sequenz wiedergegeben, in den folgenden Zeilen, mit welcher Häufigkeit (in \%) die Basen an den entsprechenden Positionen auftreten. Gene, welche die ACGTTAC Konsensussequenz enthalten, wurden in der Liste der reprimierten Gene (Tabelle 5.7) mit einem \# gekennzeichnet.

\begin{tabular}{|c|c|c|c|c|c|c|c|}
\hline Konsensus: & A & C & G & T & T & A & C \\
\hline$\%$ A & 86 & 0 & 0 & 0 & 45 & 100 & 0 \\
\hline$\%$ C & 5 & 100 & 0 & 0 & 0 & 0 & 100 \\
\hline$\%$ G & 9 & 0 & 100 & 0 & 0 & 0 & 0 \\
\hline$\%$ T & 0 & 0 & 0 & 100 & 54 & 0 & 0 \\
\hline
\end{tabular}
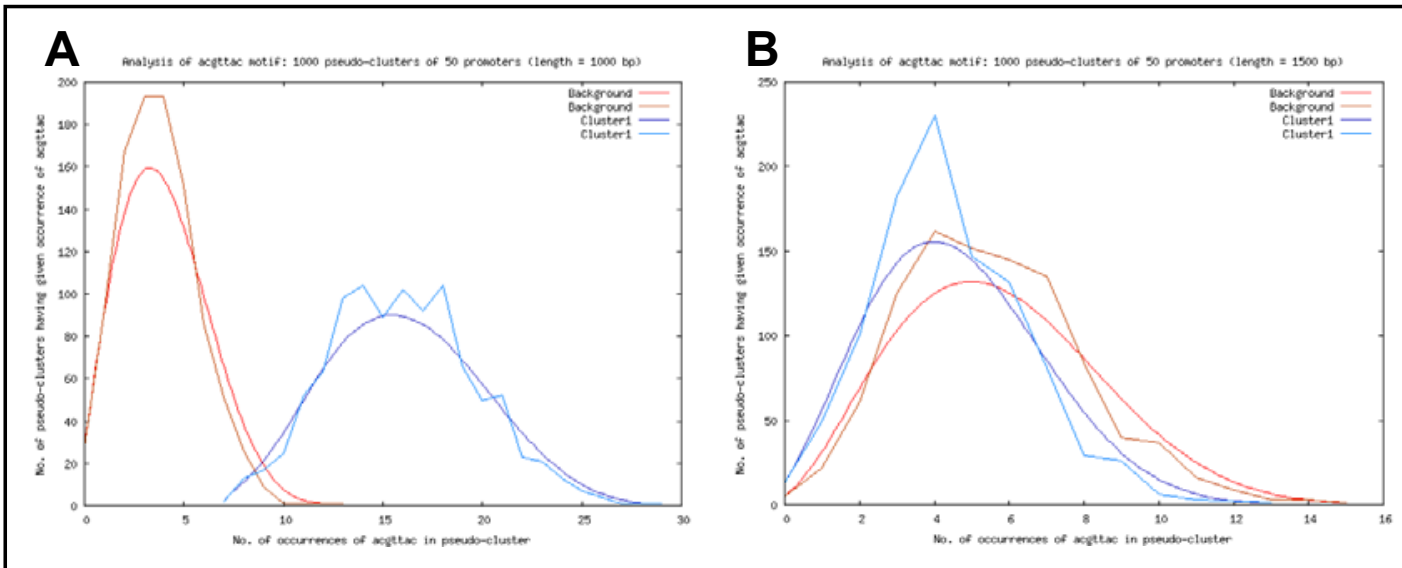

Abbildung 5.56: A: Häufigkeit des ACGTTAC-Motivs in den -1 bis -1000 bp Promotorregionen der in der atbzip1 atbzip53 Doppelmutante reprimierten Gene; B: Häufigkeit des ACGTTAC Motivs in den -1 bis -1000 bp Promotorregionen der in 35S:AtbZIP53 Pflanzen aktivierten Gene. Als Kontrolle diente Arabidopsis_thalian_full, ein Datensatz der die 1000bp Promotorregionen fast aller Gene aus Arabidopsis enthält. Die Bootstrap-Analysen wurden mit jeweils mit 1000 Klustern aus je 50 Promotoren durchgeführt. Die roten Linien zeigen die Häufigkeit des untersuchten Motivs in der Kontrollgruppe, die blau Linie die Häufigkeit des Motivs in den Promotoren der aktivierten Gene (XAchse: Häufigkeit des Motivs im Pseudo-Kluster; Y-Achse: Zahl der Pseudo-Kluster). 


\section{Diskussion:}

\subsection{AtbZIP-Transkriptionsfaktoren der Gruppen C und S1 bilden ein Heterodimerisierungsnetzwerk}

In dieser Arbeit konnten in Hefe für alle AtbZIP-Transkriptionsfaktoren der Gruppe S1 eine starke Protein-Protein Interaktion mit allen Faktoren der Gruppe C gezeigt werden. Interaktionen fanden sich auch zwischen den Gruppe S1 Mitgliedern AtbZIP1 und AtbZIP11 bzw. 44, jedoch waren diese Interaktionen deutlich schwächer als die mit Faktoren der Gruppe C. "Yeast Two-Hybrid" (Y2H) Untersuchungen konnten am Beispiel von AtbZIP53 zeigen, dass Mutationen, welche die $\alpha$-helikale Struktur der bei bZIP-Proteinen für die Heterodimerisierung verantwortlichen Zipper-Domäne brechen, zu einem Ausbleiben der Interaktion führen. Es kann also angenommen werden, dass es sich bei den gezeigten Interaktionen um Zipper-vermittelte Heterodimerisierungen handelt.

Aufgrund ihrer starken Aktivierungseigenschaften konnten AtbZIP9 und AtbZIP10 im Y2H System nicht als Bindedomäne verwendet werden. Daher fehlen hier Daten zur Interaktion zwischen diesen beiden Proteinen sowie $\mathrm{zu}$ ihrer Fähigkeit zur Homodimerisierung. Um diese Daten $\mathrm{zu}$ erhalten, und um die gezeigten Dimerisierungen zu verifizieren, wurde versucht, Interaktionen mit dem RTA (repressed transactivator) System zu quantifizieren (Hirst et al., 2001). Das RTA System ist eine Y2H-Variante, die speziell für Proteine mit starken Aktivierungseigenschaften gedacht ist. Es verwendet statt der GAL4-AD eine Repressordomäne. Ein über die GAL4-BD an den Promotor eines Reportergens gebrachten Proteins mit Aktivierungseigenschaften aktiviert zunächst das Reportergen. Kommt es zu einer Interaktion mit einem an die Repressordomäne fusionierten Protein, so wird diese Aktivierung des Reportergens messbar reprimiert. Leider ließen sich mit diesem System bekannte Interaktionen nicht reproduzieren. Da diese Methode seit ihrer Publikation vor über vier Jahren nur einmal zitiert wurde, ist anzunehmen, dass das RTA System nur begrenzt funktioniert.

Dafür konnten exemplarisch Interaktionen zwischen AtbZIP53 und AtbZIP10 von Caroline Mayer durch ein System zum Nachweis von Protein-Protein Interaktionen in 
planta, der bimolekularen Fluoreszenz-Komplementation, bestätigt werden (persönliche Mitteilung).

Während anhand der "Yeast Two-Hybrid" Daten zunächst keine Bildung von Homodimeren zu erkennen war, wird für den Gruppe C Faktor AtbZIP63 in der Literatur die Fähigkeit zur Homodimerisierung beschrieben (Walter et al., 2004). Die in dieser Publikation im Hefe-System gezeigte Interaktion ist jedoch sehr schwach. Bei genauerer Betrachtung zeigte sich, dass sie in den eigenen Daten ebenfalls zu erkennen war, jedoch angesichts der etwa 20-fach stärkeren Interaktion mit Gruppe S1 Faktoren zunächst als Hintergrund eingestuft wurde. Da die Homodimerisierung von AtbZIP63 jedoch auch durch bimolekulare Fluoreszenz-Komplementation bestätigt werden konnte, ist eine biologische Relevanz nicht auszuschließen (Walter et al., 2004).

Bimolekulare Fluoreszenz-Komplementation sowie Ko-Immunopräzipitation sind beides Methoden, welche die Untersuchung von Protein-Protein-Interaktionen in planta erlauben. Ein Nachteil dieser beiden Methoden ist, dass sie nicht dazu geeignet sind, Interaktionsstärken zu quantifizieren. Dass dies von Nachteil ist zeigt das oben zitierte Beispiel von AtbZIP63.

Um quantitative Daten über die Heterodimerisierungen in planta zu erhalten, wurde das Y2H-System von Andrea Ehlert in Mesophyll-Protoplasten übertragen. Dabei wird ein Reporterplasmid, das ein unter Kontrolle der Gal4-UAS stehendes GUS-Reportergen enthält, gemeinsam mit Effektorplasmiden für die Expression von an die GAL4-AD bzw. GAL4-BD fusionierten AtbZIP Proteinen transient in die Mesophyll-Protoplasten transformiert, und nach einer Inkubation wird die Expression des Reportergens enzymatisch gemessen (Ehlert et al., zur Veröffentlichung eingereicht).

Bei einer Reproduktion der Interaktionsdaten aus Hefe in Protoplasten-Assays konnten die bereits in Hefe gezeigten spezifische Heterodimerisierungen zwischen AtbZIPTranskriptionsfaktoren der Gruppen C und S1 bestätigt werden.

Zusätzlich wurden auch weitere, allerdings deutlich schwächere Interaktionen innerhalb der einzelnen Gruppen gemessen. Innerhalb der Gruppe C zeigte AtbZIP10 eine Interaktion mit Atbzip63 und AtbZIP9, innerhalb der Gruppe S1 wurde eine Interaktion von AtbZIP53 mit AtbZIP2, 11 und 44 festgestellt. Diese schwächeren Interaktionen innerhalb der Gruppe S1 unterscheiden sich von den in Hefe gefundenen (diese Arbeit), wo AtbZIP1 mit AtbZIP11 oder AtbZIP44 interagierte. Ob diese Interaktionen von biologischer Relevanz sind bleibt somit abzuwarten. 
Aufgrund des sehr langen Leucin-Zippers mit acht heptameren Wiederholungen, der nur bei bZIP-Transkriptionsfaktoren der Gruppen $\mathrm{C}$ und $\mathrm{S}$ vorkommt, gilt eine Interaktion mit $\mathrm{zu}$ anderen Gruppen gehörenden bZIP-Transkriptionsfaktoren als wenig wahrscheinlich (Deppmann et al., 2004).

Interaktionen von AtbZIP-Transkriptionsfaktoren der Gruppen $\mathrm{C}$ oder S mit zu anderen Gruppen gehörenden Faktoren wurden bisher nur exemplarisch für verschiedene Gruppen getestet. Signifikante Interaktionen wurden dabei nicht gefunden, sodass die Interaktionen spezifisch für die Gruppen $\mathrm{C}$ und $\mathrm{S}$ zu sein scheinen. Jedoch wurde für Petersilie in Gel-Retardationsanalysen eine Heterodimerisierung des zur Gruppe C gehörenden bZIP-Proteins CPRF2 mit dem zur Gruppe $\mathrm{G}$ gehörenden bZIP-Protein CPRF3 gezeigt (Armstrong et al., 1992). Daher sollte, wenn über die Funktion der Gruppe C/S1 AtbZIP-Transkriptionsfaktoren spekuliert wird, die mögliche Existenz weiterer Heterodimerisierungspartner berücksichtigt werden. Die in GelRetardationsanalysen gezeigte Interaktion findet in Gegenwart von DNA statt, und unterscheidet sich dadurch von den im Y2H-System beobachteten Interaktionen. Vielleicht beeinflusst die Bindung an DNA die Dimerisierungseigenschaften von bZIPProteinen, sodass manche Homo- oder Heterodimere möglicherweise nur bei gleichzeitiger Bindung an DNA auftreten.

\subsection{Bisher unbekannte Strukturmerkmale der Zipper-Domäne sind für die Spezifität von C/S1 Heterodimerisierungen verantwortlich}

Viele Publikationen befassen sich damit, welche Strukturmerkmale für die Spezifität von bZIP-bZIP Heterodimerisierungen verantwortlich sind. Mehrfach wurde die Bedeutung von elektrostatische Wechselwirkungen zwischen positiv oder negativ geladenen Aminosäureresten, die sich am Rand der hydrophoben Interaktionsfläche befindenden, gezeigt (Alber, 1992; Cohen und Curran, 1990; Vinson et al., 2002; Vinson et al., 1993). Solche Aminosäure-Paare finden sich in den nach (McLachlan und Steward, 1975) e und g' bzw. g und e' genannten Positionen (zu den Positionsbezeichnungen siehe Abbildung 6.1). Zusätzlich sind die Aminosäuren in den Positionen a und d für die Spezifität der Heterodimerisierung verantwortlich. Für 
Zipper-Domänen mit Asparagin in der Position a wurde eine bevorzugte Dimerisierung mit anderen Zipper-Domänen, die in der selben heptameren Wiederholungen an Position a ebenfalls ein Asparagin enthalten, gezeigt (Acharya et al., 2002; Zeng et al., 1997).

Gruppe C und S1 bZIP Proteine enthalten Asparagine in Position a der heptameren Widerholungen 2 und 5 (Abbildung 6.2). Dieser Aspekt unterstützt die gefundenen CS1 Heterodimerisierungen, erklärt jedoch nicht, warum es kaum zu S1-S1 oder C-C Interaktionen oder Homodimerisierungen kommt. Der Versuch, dies durch elektrostatische Interaktionen zwischen Aminosäuren in den Positionen g und e zu erklären scheitert, da in $\mathrm{C} / \mathrm{S} 1$ Heterodimeren weniger anziehende g-e Paare vorhanden sind als in den entsprechenden Homodimeren. So könnten zum Beispiel Gruppe C Faktoren als Homodimere in den heptameren Wiederholungen 6 und 7 anziehende $\mathrm{D} \leftrightarrow \mathrm{R}$ und $\mathrm{K} \leftrightarrow \mathrm{E}$ Paare bilden, die sie mit S1 Faktoren nicht bilden können (in Abbildung 6.2 durch den roten Kasten hervorgehoben). Bei ihrem Versuch, eine Voraussage der Heterodimerisierungen zwischen Arabidopsis bZIPTranskriptionsfaktoren zu machen, kommen (Deppmann et al., 2004) daher zu dem Schluss, das C/S1 Heterodimere gegenüber den entsprechenden Homodimeren weniger favorisiert werden. Da die experimentellen Daten dem wiedersprechen, sind wohl andere, bisher unbekannte Faktoren für die Spezifität der $\mathrm{C} / \mathrm{S} 1$ Interaktion verantwortlich. Gerade diese beiden heptameren Wiederholungen 6 und 7, für die eine bevorzugte Homodimerisierung vorausgesagt wurde, könnten für die Spezifität der Heterodimerisierung verantwortlich sein, da sie innerhalb der Gruppe C bzw. S1 stark konserviert sind, sich aber untereinander und zu denen der Gruppen S2 und S3 unterscheiden (Abbildung 6.2; durch einen roten Kasten hervorgehoben). C/S1 Heterodimerisierung scheinen konserviert zu sein, da für BZI-1 aus Tabak (Gruppe C) auch eine Heterodimerisierung mit den S1 bZIP-Proteinen CPRF6 und CPRF7 aus Petersilie gezeigt werden konnte (Strathmann, 2003). Die heptameren Wiederholung 6 und 7 sind nicht nur innerhalb der Gruppen C und S1 konserviert, sondern auch zwischen verschiedenen Spezies, was ein weitere Hinweis auf ihre Bedeutung ist. Diese ließe sich experimentell überprüfen, in dem man testet, ob durch Austausch der heptameren Wiederholung 6 und 7 zwischen zwei Faktoren der beiden Gruppen die Heterodimerisierungsspezifität geändert wird.

Im Gegensatz zu den anderen AtbZIP-Transkriptionsfaktoren der Gruppen C und S1 ließe sich für AtbZIP1 durch die Abstoßung zwischen den g-e Paare $\mathrm{E} \leftrightarrow \mathrm{E}$ und $\mathrm{R} \leftrightarrow \mathrm{K}$ in 
den heptameren Wiederholungen 1 und 3 zumindest eine bevorzugte

Heterodimerisierung erklären. AtbZIP1 zeigt auch sonst Unterschiede in den für die

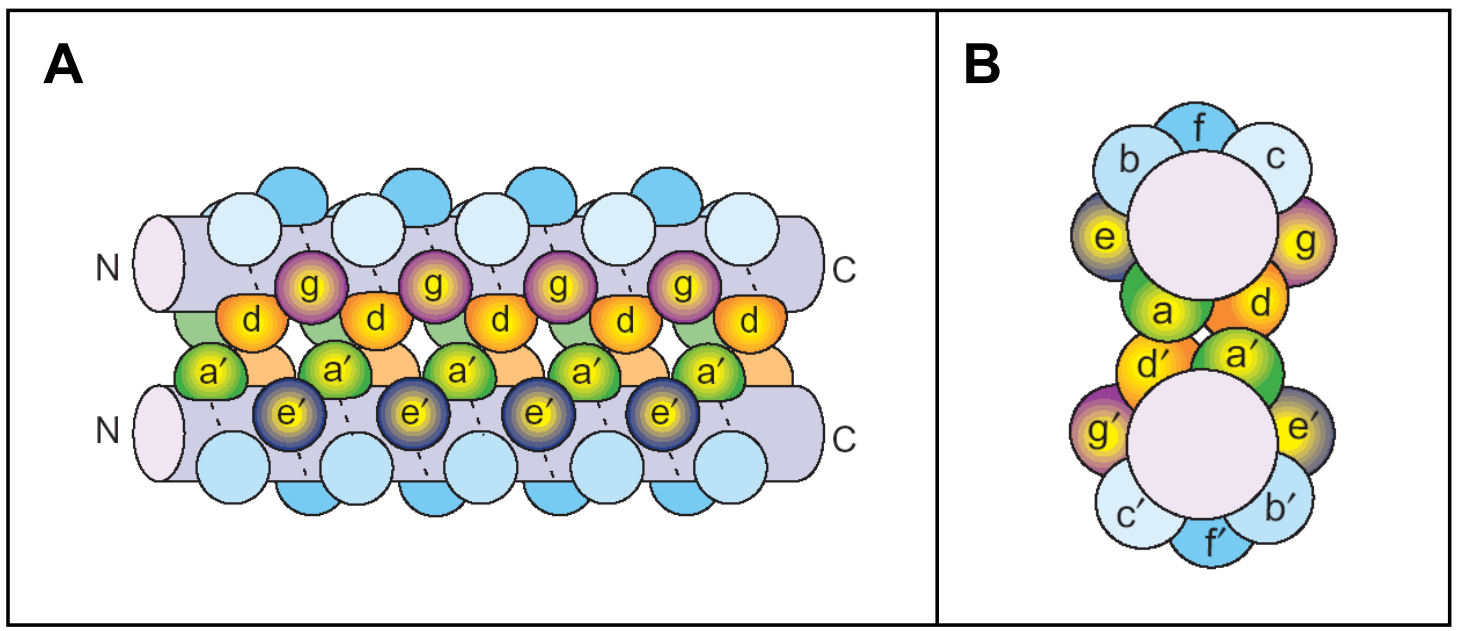

Abbildung 6.1: Skizze der Coiled Coil Struktur von bZIP-Proteinen, in der Ansicht von der Seite (A) und entlang der Achse (B). Die Berührungsfläche zwischen den beiden bZIP-Proteinen wird von den Aminosäuren in den Positionen a, d, e und f gebildet. Durch ein Apostroph wird angezeigt, zu welchem der beiden bZIP-Proteine die jeweilige Position gehört Die Aminosäuren an Position a und d (dem Leucin) bilden ein hydrophobes Zentrum, die Aminosäuren an Position e und g können über elektrostatische Wechselwirkungen die Spezifität der Heterodimerisierung beeinflussen. N: N-Terminus; C: C-Terminus (nach Fong et al., 2004).

\begin{tabular}{|c|c|c|c|c|c|c|c|c|c|c|}
\hline & & 0 & $1 \quad \mathrm{~L}$ & 2 & 3 & 4 & $5 \quad \mathrm{~L}$ & 6 & 7 & 8 \\
\hline Gruppe & C & gabcdef & gabcdef & gabcdef & gabcdef & gabcdef & gabcdef & gabcdef & & gabcdef \\
\hline bZIP9 & RIRRMNSNRESAKRSRRRKQE & YLVDLET & QVDSLKG & DNSTLYK & QLIDATQ & QFRSAGT & NNRVLKS & DVETLRV & KVKLAED & LVARGSL * \\
\hline bZIP10 & KSRRMLSNRESARRSRRRKQE & QTSDLET & QVNDLKG & EHSSLLK & QLSNMNH & KYDEAAV & GNRILKA & DIETLRA & KVKMAEE & TVKRVTG* \\
\hline bZIP25 & RARRMLSNRESARRSRRRKQE & QMNEFDT & QVGQLRA & EHSTLIN & RLSDMNH & KYDAAAV & DNRILRA & DIETLRT & KVKMAEE & TVKRVTG* \\
\hline bZIP63 & RVKRMLSNRESARRSRRRKQA & HLSELET & QVSQLRV & ENSKLMK & GLTDVTQ & TFNDASV & ENRVLKA & NIETLRA & KVKMAEE & TVKRLTG* \\
\hline & & 0 & $1 \mathrm{~L}$ & 2 & 3 & 4 & $5 \mathrm{~L}$ & 6 & 7 & 8 \\
\hline Gruppe & s1 & gabcdef & gabcdef & gabcdef & gabcdef & gabcdef & gabcdef & gabcdef & gabcdef & gabcdef \\
\hline bZIP1 & KRKRKLSNRESARRSRLKKQK & LMEDTIH & EISSLER & RIKENSE & RCRAVKQ & RLDSVET & ENAGLRS & EKIWLSS & YVSDLEN & MIATTSL* \\
\hline bZIP53 & KRKRMISNRESARRSRMRKQK & QLGDLIN & EVTLLKN & DNAKITE & QVDEASK & KYIEMES & KNNVLRA & QASELTD & RLRSLNS & VLEMVEE* \\
\hline bZIP2 & KRKRMLSNRESARRSRMRKQK & HVDDLTA & QINQLSN & DNRQILN & SLTVTSQ & LYMKIQA & ENSVLTA & QMEELST & RLQSLNE & IVDLVQS * \\
\hline bZIP11 & KRKRMLSNRESARRSRMKKQK & LLDDLTA & QVNHLKK & ENTEIVT & SVSITTQ & HYLTVEA & ENSVLRA & QLDELNH & RLQSLND & IIEFLDS* \\
\hline $\begin{array}{l}\text { bZIP44 } \\
\text { Gruppe }\end{array}$ & $\begin{array}{l}\text { KRKRKQSNRESARRSRMRKQK } \\
\text { S2 }\end{array}$ & HLDDLTA & QVTHLRK & ENAQIVA & GIAVTTQ & HYVTIEA & ENDILRA & QVLELNH & RLQSLNE & IVDFVES* \\
\hline bZIP3 & KQRRMVSNRESARRSRMRKQR & HLDELLS & QVAWLRS & ENHQLLD & KLNQVSD & NNDLVIQ & ENSSLKE & ENLELRQ & VITSMKK* & LGGGIHD \\
\hline bZIP42 & KQRRMISNRESARRSRMRKQR & HLDELWS & QVMWLRI & ENHQLLD & KLNNLSE & SHDKVLQ & ENAQLKE & ETFELKQ & VISD & QSPF \\
\hline bZIP43 & KQKRKISNRESARRSRMRKQR & QVDELWS & QVMWLRD & ENHQLLR & KLNCVLE & SQEKVIE & ENVQLKE & ETTELKQ & MISD & PFS \\
\hline bZIP48 & KQRRMLSNRES & HLDELWS & QVIRLRN & ENNCLID & KLNRVSE & TQNCVLK & ENSKLKE & EASDLRQ & LVCE & NKNNNNS \\
\hline bZIP58 & KQRRMISNRESARRSRMRKQR & HLDELWS & QVIRLRT & DNHCLMD & KLNRVSE & SHELALK & ENAKLKE & ETSDLRQ & LISEIKS * & HNEDDNS \\
\hline bZIP8 & KRRRKVSNRESARRSRMRKQR & HMEELWS & MLVQLIN & KNKSLVD & ELSQARE & CYEKVIE & ENMKLRE & ENSKSRK & ^MIGEIGL & NRFLSVE \\
\hline bZIP70 & RARRMVSNRESARRSRMRKKK & QIEELQQ & QVEQLMM & LNHHLSE & KVINLLE & SNHQILQ & ENSQLKE & KVSSFHL & LMADVLL* & PMRNAES \\
\hline bZIP75 & RLRRMASNRESARRTRMRERM & MKEGLQM & QVKQLMA & YNQFLYN & KYISLLE & YNHQILQ & ENSQLKE & TVSSFHD & QYTISYG & NHEGIIG \\
\hline ruppe & S3 & & & & & & & & & \\
\hline bZIP4 & KRRRTISNRESAKRSRMKKKK & RFEELTE & EVNRLNI & RNQELKN & RLANVVS & CGNFISR & ENNRLKT & ESVCLEI & RLLELYR & FLVAMQS* \\
\hline bZIP5 & KKKRKLSNRESAKRSREKKQK & HLEEMSI & QLNQLKI & QNQELKN & QLRYVLY & HCQRTKM & ENDRLLM & EHRILHD & KLLNIRQ & VLMFRQT* \\
\hline bZIP7 & KRKRMESNRESAKRSRMRKQS & HIDNLRE & QVNRLDL & ENRELGN & RLRLVLH & QLQRVNS & DNNRLVT & EQEILRL & RLSEMRR* & ILIIRQL \\
\hline bZIP6 & KRKRMESNRESAKRSRMRKQR & HIDNLKD & EANRLGL & ENRELAN & RLRIVLY & NIALMCT & DNNQLLS & EQEILRR & RFLEMRQ* & ILIFRQL \\
\hline
\end{tabular}

Abbildung 6.2: Aminosäuresequenzvergleich der bZIP-Domänen von den AtbZIP-Proteine der Gruppen C und S. Ein in der Gruppe S1, aber nicht in den Gruppen S2 und S3 konservierte Bereich, der möglicherweise für die Spezifität der C/S1 Heterodimerisierung verantwortlich ist, ist durch eine rote Umrandung gekennzeichnet. Die heptamere Wiederholung des Leucin-Zippers sind nach (McLachlan und Steward, 1975) mit den Buchstaben a-g gekennzeichnet und durchnummeriert. Das wahrscheinliche Ende der bZIP-Domäne ist durch einen roten Stern gekennzeichnet. Rot auf Grau: identische AS; Blau: konservierte AS; Schwarz auf Grau: ähnliche AS; Grün: schwache Ähnlichkeit. 
Heterodimerisierungsspezifität relevanten Position a, e und g, was das im Vergleich zu den anderen Gruppe S1 Faktoren leicht abweichende Heterodimerisierungsverhalten erklären könnte (Ehlert et al., zur Veröffentlichung eingereicht).

Ein anderer Ansatz, der Vorhersagen zur Heterodimerisierung über den Vergleich mit bekannten Interaktionen zwischen menschlichen bZIP-Proteinen versucht, ist ebenfalls nicht in der Lage, die C/S1 Heterodimerisierung vorherzusagen (Fong et al., 2004).

Ein mögliche Erklärung für das Scheitern ist, dass die für die Vorhersagen genutzten Daten aus tierischen Systemen stammen. bZIP-Transkriptionsfaktoren mit langen Leucin-Zippern, wie man sie in Pflanzen in den Gruppen $\mathrm{C}$ und $\mathrm{S}$ findet, existieren in tierischen Organismen nicht (Deppmann et al., 2004). Durch die langen Zipper-Domäne mit acht heptameren Wiederholungen existiert ein große Interaktionsfläche, die diverse Möglichkeiten zur Erzeugung von Spezifität lässt. Berechnet man die Wahrscheinlichkeit für die Ausbildung von coiled-coil-Strukturen im Bereich des Leucin-Zippers mit dem „Coils“-Programm (Lupas, 1996), sieht man bei AtbZIPProteinen der Gruppen C und S1 einen deutlichen Rückgang der Wahrscheinlichkeit zur Ausbildung einer coiled-coil Konformation im Bereich der 4. bis 5. Wiederholung. Bei den kurzen Zippern der zu den anderen Gruppen gehörenden AtbZIP-Proteinen ist die Proteinsequenz des Zippers generell weniger flexibel, wahrscheinlich da die Aminosäuren dieses kurzen Bereichs für die Dimerbildung optimiert sein muss (Vinson et al., 2002). Möglicherweise ist die Länge des Zippers und auch die Struktur demnach entscheidend für eine Interaktion und Dimerbildung.

\subsection{AtbZIP-Transkriptionsfaktoren der Gruppen C und S1 unterscheiden sich in ihren Aktivierungseigenschaften}

Die in Protoplasten erhaltene Daten zur Regulation des ProDH-Gens zeigten, dass alle AtbZIP-Transkriptionsfaktoren der Gruppen C und S1 die Expression dieses Gens regulieren können. Eine denkbare Erklärung für diese Vielfalt an Regulatoren wäre, dass sie unterschiedliche Signale in die Regulation dieser Gene integrieren, die zu einer unterschiedlich starken Aktivierung der jeweiligen Zielgene führen. So ist bei der Regulation der Transkription von Zielgenen nicht nur entscheidend, ob ein Gen exprimiert wird, sondern auch, wie stark diese Expression ist. In dieser Arbeit konnte 
gezeigt werden, dass die verschiedenen AtbZIP-Transkriptionsfaktoren der Gruppen C und S1 in Hefe deutlich unterschiedliche Aktivierungseigenschaften haben. Die Aktivierungseigenschaften der bZIP-Proteine unterscheiden sich auch zwischen den Pflanzenspezies. Während Arabidopsis AtbZIP63 und AtbZIP53 in Hefe nicht aktivieren, zeigen ihre Homologe aus Tabak, BZI-1 und BZI-3, in Hefe deutliche Aktivierungseigenschaften. Für BZI-3 konnten Yang et al., (2001) zeigen, dass der Carboxyterminus wichtig für die Genaktivierung ist. BZI-3 weist einen konservierten Carboxyterminus mit zahlreichen Prolinen auf, die aktivierend wirken können (Sprenger-Haussels und Weisshaar, 2000). Diese finden sich jedoch auch bei AtbZIP53, so dass sie alleine nicht für die Aktivierungseigenschaften verantwortlich sein können.

Die Aktivierungseigenschaften von Gruppe C/S1 AtbZIP-Transkriptionsfaktoren wurden von Andrea Ehlert im Rahmen ihrer Diplomarbeit auch in Protoplasten analysiert (Ehlert, 2004). Dabei fanden sich teils deutliche Unterschiede zu den in Hefe gemessenen Aktivierungseigenschaften. Während in Hefe die Gruppe C Faktoren AtbZIP9 und 10 starke Aktivierungseigenschaften zeigten, waren diese in Protoplasten nicht $\mathrm{zu}$ beobachten. Interessanterweise konnte dabei gezeigt werden, dass, obwohl weder AtbZIP10 noch AtbZIP53 alleine nennenswert aktivieren können, AtbZIP10/53 Heterodimere über ein starkes Aktivierungspotential verfügen. Dieser Effekt wurde sowohl unabhängig von der DNA-Bindung als auch bei Bindung an verschiedene cisElemente beobachtet, und wurde "heterodimer-induced transactivation" (HIT) genannt (Weltmeier et al., zur Veröffentlichung eingereicht). HIT findet sich auch bei anderen Heterodimeren, z.B AtbZIP25/53 (Ehlert et al., zur Veröffentlichung eingereicht).

Einen mögliche Erklärung scheint, dass beide bZIP-Proteine notwendig sind, um das Epitop einer Aktivierungsdomäne $\mathrm{zu}$ bilden, eine andere wäre, das durch die Heterodimerisierung eine Interaktionsfläche gebildet wird, welche die Rekrutierung eines Koaktivators ermöglicht. Für AtbZIP10 und AtbZIP25 wurde eine schwache Interaktion mit $\mathrm{ABI} 3$ gezeigt, wobei für $\mathrm{ABI} 3$ in diesem Kontext eine Rolle als Koaktivator vermutet wird (Lara et al., 2003). Inzwischen konnte in Hefe in einen "Yeast Three-Hybrid" System gezeigt werden, das ABI3 deutlich mit AtbZIP10/53 Heterodimeren interagiert (Jesus Vicente-Carbajosa, persönliche Mitteilung). Damit scheint eine Erklärung des HIT-Mechanismus durch die spezifische Interaktion von Heterodimeren mit Koaktivatoren wie ABI3 möglich. 


\subsection{AtbZIP-Transkriptionsfaktoren der Gruppen C und S1 sind Teil eines Zucker-abhängigen Signalweges}

Die Tatsache, dass die Translation aller AtbZIP-Transkriptionsfaktoren der Gruppe S1 spezifisch durch Saccharose reprimiert wird, legt eine Funktion des C/S1 Heterodimerisierungsnetzwerkes in den Transduktion von Zuckersignalen nahe (Wiese et al., 2005). Eine deutliche Regulation findet sich auch auf der Transkriptionsebene. In dieser Arbeit konnte für AtbZIP1, 9 und 63 eine deutliche Repression durch Saccharose und Glukose gezeigt werden, und die gezeigten Transkriptomdaten bestätigen die bereits veröffentlichte Induktion von AtbZIP11 durch Glukose und Saccharose (Rook et al., 1998a; Rook et al., 1998b).

Das Glukose-Analog 3-OMG wird von der Zelle aufgenommen wie Glukose, kann aber keine Hexokinase-abhängigen Signalwege aktivieren, und wird daher oft benutzt, um zwischen einer Regulation über Hexokinase-abhängige oder Hexokinase-unabhängige Signalwege zu unterscheiden (Xiao et al., 2000). In dieser Arbeit wurde gezeigt, dass die Behandlung mit 3-OMG im Gegensatz zu Glukose nicht zu einer veränderten Transkription der AtbZIP-Transkriptionsfaktoren führte. Somit erfolgt die Übertragung des Zuckersignals zur Regulation der AtbZIP-Transkriptionsfaktoren wahrscheinlich über einen Hexokinase-abhängigen Signalweg. Bei den gezeigten Transkriptomdaten zur Glukoseregulation findet die Repression durch Glukose auch nach Vorbehandlung mit Cycloheximid statt, die Regulation erfolgt als über einen Signalweg, der keine Neusynthese von Proteinen benötigt. Das zudem bereits nach einer Stunde eine Abnahme der Transkriptmenge der durch Zucker reprimierten AtbZIPTranskriptionsfaktoren $\mathrm{zu}$ sehen ist, spricht für einen kurzen Signalweg. Die transkriptionelle Aktivierung von AtbZIP11 durch Glukose hingegen scheint die Neusynthese von Proteinen des Signalübertragungsweges zu benötigen, da sie nach Vorbehandlung mit Cycloheximid nicht mehr erfolgt.

Für AtbZIP53 konnte in dieser Arbeit eine Regulation durch Veränderungen des osmotischen Wertes gezeigt werden. Jedoch führt Hypoosmolarität in Gegenwart einer externen Zuckerquelle zu einer schwächeren Induktion als Hypoosmolarität alleine. Dies weißt auf eine Induktion von AtbZIP53 sowohl durch Hypoosmolarität als auch durch Zuckermangel hin. Dass gleiche gilt auch für die ProDH, ein direktes Zielgen von AtbZIP53. 
Für AtbZIP1, 53, 9, 25 und 63 wurde in dieser Arbeit eine deutliche Induktion durch Dunkelheit gezeigt. Diese steht wahrscheinlich in engem Zusammenhang mit der Zuckerregulation. Für viele DIN (dark-induced) Gene wurde eine Repression durch Glukose gezeigt, die über einen Hexokinase-abhängigen Signalweg erfolgt (Fujiki et al., 2001b). Dunkelheit führt zu einer Abnahme der zellulären Zuckerkonzentration (Gibon et al., 2004). Eine Induktion während der Dunkelheit kann also über Licht-abhängige Signale oder über Zucker-abhängige Signale erfolgen. Für die Transkription von AtbZIP1, 53, 9 und 63 konnte gezeigt werde, dass sie nach Dunkelinduktion unabhängig von Licht durch Zucker reprimiert wird. Für die "branched chain aminoacid transaminase" (BCAT), ein mögliches Zielgen, das in Mikroarrayexperimenten durch AtbZIP1 und AtbZIP53 (diese Arbeit) sowie auch durch AtbZIP63 (Jesus VicenteCarbajosa, persönliche Mitteilung) aktiviert wurde und somit eine mögliches direktes Zielgen darstellt, wurde eine Induktion nach Gabe von Photosynthese-Inhibitoren beschrieben, was ebenfalls für eine lichtunabhängige Regulation spricht (Fujiki et al., 2002). Anderseits wird AtbZIP25 zwar durch Dunkelheit induziert, aber nicht durch Zucker reprimiert, was hier eher für eine lichtabhängige Regulation spricht.

AtbZIP11 wird bei Dunkelheit durch Glukose induziert, was eine lichtunabhängige Regulation durch Zucker belegt. Andererseits wird AtbZIP11 in Keimlingen, bei den die Bildung von Chloroplasten pharmakologisch verhindert wurde, weiter durch Licht induziert (Rook et al., 1998b). Es muss also auch eine lichtabhängige, von der Photosynthese und der damit verbundenen Akkumulation von Zuckern unabhängige Regulation geben, sodass zumindest AtbZIP11 sowohl durch Zucker als auch durch Licht reguliert wird. Ein Regulation durch Licht könnte auch posttranslational stattfinden, wie ist sehr detailliert für einen Gruppe C Faktor aus Petersilie, CPRF2, beschrieben worden ist. CPRF2 befindet sich bei Dunkelheit im Zytoplasma, und wird bei Licht in den Kern transportiert (Kircher et al., 1999). Das Lichtsignal wird dabei über die Photochrome phyA und pyhB wahrgenommen (Kircher et al., 1999), und führt $\mathrm{zu}$ einer Phosphorylierung von CPRF2, die wahrscheinlich für den folgenden Kerntransport verantwortlich ist. (Wellmer et al., 1999). Viele durch Licht induzierte Gene, wie „Chlorophyll a/b binding protein“ Gene, enthalten G-Box oder C-Box Motive in ihren Promotoren, deren Bedeutung für die Licht-Regulation gezeigt wurde (Terzaghi und Cashmore, 1995). Es wird interessant sein zu untersuchen, in wie weit dies auch für Arabidopsis Gruppe C Faktoren zutrifft. Möglicherweise ist das C/S1 Netzwerk neben der in dieser Arbeit gezeigten Aktivierung von bei Dunkelheit 
induzierten Genen auch an der Aktivierung von bei Licht induzierten Genen beteiligt. Dann ließe sich ein Model aufstellen, bei dem es im Zellkern, abhängig von den Lichtund Zuckerverhältnissen, zu einer Bildung von unterschiedlichen Heterodimeren käme, die eine gezielten Aktivierung oder Repression von für die Anpassung an diese Unterschiede wichtigen Zielgenen vermitteln würden. Dabei scheint vor allem die Regulation in Sink-Geweben von Bedeutung zu sein, da hier mit Hilfe der PromotorGUS Fusionen eine vorwiegende Expression gezeigt werden konnte.

Sowohl AtbZIP1 als auch AtbZIP53 führen bei Überexpression zur Aktivierung von putativen Trehalose-6-Phosphat Phosphatase- (TPP-) Genen. Auch wenn die TPP Aktivität der von diesen Genen kodierten Enzyme noch nicht biochemisch nachgewiesen wurde, so konnte doch gezeigt werden, das sie spezifisch durch Trehalose-6-Phosphat (T-6-P) induziert werden, was ein deutlicher Hinweis darauf ist, das es sich wirklich um TPP handelt (Schluepmann et al., 2004). T-6-P wurde in den letzten Jahren vermehrt als ein wichtiges Signalmolekül in der Kontrolle des Zuckermetabolismus in Arabidopsis thaliana diskutiert (Avonce et al., 2005; Eastmond und Graham, 2003; Eastmond et al., 2003). In Hefe wird angenommen, dass T-6-P als Inhibitor der Hexokinase fungiert und auf diese Weise den Fluss von Trehalose durch

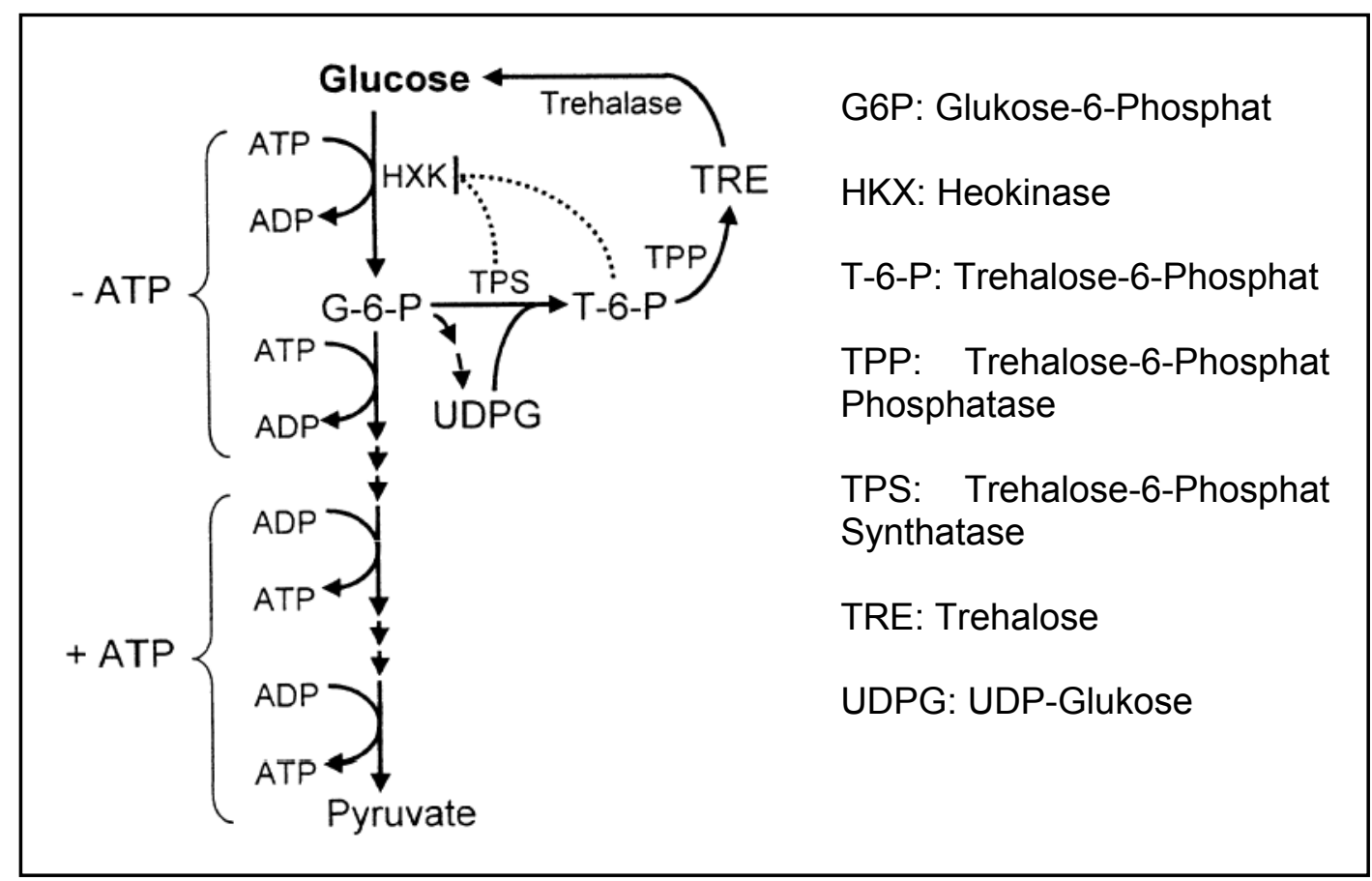

Abbildung 6.3: Modell des Trehalose-Metabolismus und seiner regulatorischen Wirkung in Hefe. Trehalose-6-Phosphat(T-6-P) führt zu einer Inhibierung der Hexokinase, und auf diese Weise zu einem Sinken der Glykolyse-Rate (Thevelein and Hohmann, 1995). Eine verstärkte Trehalose-6-Phosphat Synthatase Aktivität führt zur Akkumulation von T-6-P und senkt die Glykolyse-Rate, eine verstärkte Trehalose-6-Phosphat Phosphatase Aktivität führt zum Abbau von T-6-P und steigert die Glykolyse-Rate. 
die Glykolyse kontrollieren kann (Thevelein und Hohmann, 1995). Für Arabidopsis thaliana wird angenommen, dass T-6-P hier eine ähnliche Funktion hat (Schluepmann et al., 2003). Da AtbZIP1 und AtbZIP53 in Gegenwart niedriger Zuckerkonzentrationen induziert werden, scheint es sinnvoll, dass sie untere diesen Bedingungen über einen Abbau von T-6-P den Fluss von Glukose durch die Glykolyse fördern. Interessanterweise konnte in einem Mikroarrayexperiment mit Pflanzen, die eine TPS aus E.Coli überexprimierten und auf diese Weise ein 3-fach höheren T-6-P hatten, eine deutliche Induktion der ProDH gezeigt werden (Schluepmann et al., 2004). Möglicherweise existiert also eine Verbindung zwischen dem Trehalose- und dem Prolin-Metabolismus.

Die beiden durch AtbZIP53 aktivierten Trehalose-6-Phosphat Phosphatasen (TPP) At4g22590 und At4g12430 werden stark in Pollen und bei Salzstress spezifisch in den Wurzeln exprimiert. Für die Induktion nach Salzstress konnte in dieser Arbeit eine Beteiligung von AtbZIP53 und/oder AtbZIP1 gezeigt werden. Diese Expressionsmuster deuten eher auf eine Funktion unter Wasserstress hin, wie sie in einzelnen Pflanzenspezies für die TPP gezeigt werden konnte (Bianchi et al., 1993; Mueller et al., 1995). Dabei dient das von der TPP synthetisierte Produkt, Trehalose, als kompatibler Osmolyt. Jedoch wurden in Arabidopsis bisher nur Spuren von Trehalose nachgewiesen, so dass eine solche Funktion hier unwahrscheinlich erscheint (Leyman et al., 2001; Roessner et al., 2000; Vogel et al., 2001).

\subsection{C/S1 Heterodimere vermitteln eine durch Zucker, Prolin und osmotische Signale regulierte Expression der ProDH}

Als Reaktion auf Kälte, Salz oder Trocken-Stress akkumulieren viele Pflanzen Prolin (Delauney und Verma, 1993). Während der Erholung von abiotischem Stress kommt es zur Induktion einer Prolindehydrogenase, ein Enzym, welches den ersten Schritt der Degradation der Aminosäure Prolin katalysiert (Kiyosue et al., 1996; Peng et al., 1996; Verbruggen et al., 1996). Für AtbZIP53 wurde in dieser Arbeit die Bindung an den ProDH-Promotor durch ChIP nachgewiesen, und die Bindung von AtbZIP1 an den ProDH-Promotor konnte von Katrin Dietrich im Rahmen ihrer Diplomarbeit durch ChIP ebenfalls gezeigt werden. 
(Satoh et al., 2002) konnten ein cis-Element identifizieren, das für die Induktion der ProDH bei Erholung von osmotischem Stress oder bei hypoosmolarem Stress verantwortlich ist. In dieser Arbeit wurde gezeigt, dass die Expression der ProDH über dieses Element durch C/S1 Heterodimere erfolgt. Dabei scheint AtbZIP53 eine besonders wichtiger Regulator zu sein, da er wie die ProDH durch Hypoosmolarität und Prolin induziert wird. In Northern Analysen konnte gezeigt werden, das die Induktion der ProDH durch die verwendete Hypoosmolaritätsbehandlung in der atbzip53 Mutante reduziert ist. Das nur eine Reduktion zu sehen ist, ist dabei wahrscheinlich auf eine gewisse Redundanz zurückzuführen, da andere AtbZIP-Transkriptionsfaktoren der Gruppe S1 ebenfalls die ProDH aktivieren können.

Neben der Hypoosmolarität wird die ProDH auch durch Zucker reguliert. Nach Inkubation in einer Saccharose-Lösung wird die ProDH stärker reprimiert als nach Inkubation in einer PEG-Lösung gleicher Osmolarität, und dies obwohl die Differenz des osmotischen Potentials bei Inkubation in der Saccharose-Lösung kleiner sein sollte, da Saccharose von der Pflanze aufgenommen werden kann. Diese verstärkte Repression ist spezifisch für Saccharose, und sie findet sich nicht für AtbZIP53. Da die Translation von Gruppe S1 Faktoren spezifisch durch Saccharose inhibiert wird, ist anzunehmen, dass diese posttranskriptionale Regulation für die verstärke Repression der ProDH durch Saccharose verantwortlich ist. (Hellmann et al., 2000) konnten zeigen, dass die Repression der ProDH durch Saccharose in der Mutante rsrl reduziert ist. Es wird daher interessant sein zu untersuchen, ob rsr1 an Signalwegen beteiligt ist, die zu der transkriptionalen oder translationalen Regulation von AtbZIPTranskriptionsfaktoren der Gruppen C und S1 durch Zucker führen.

Von (Hare und Cress, 1997) wird ein möglicher Mechanismus für die Schutzfunktion von Prolin bei abiotischem Stress favorisiert, der über die Funktion als kompatibler Osmolyt hinausgeht. Prolin ist ein sehr guter Energieträger, die Prolin Biosynthese verbraucht viele Reduktionsäquivalente, und könnte unter Stress an der Wiederherstellung der terminalen Elektronenrezeptoren der Photosynthese beteilig sein. Nach Ende des Stresses stellt der Abbau von Prolin diese Energie wieder zur Verfügung, die dann für die Regeneration der Pflanze zur Verfügung steht. (Abraham et al., 2003) konnten zeigen, dass die Prolin Akkumulation nach Salzstress abhängig von Licht ist, was diese Modell unterstützt. Eine Funktion von Prolin als Energieträger könnte die Regulation durch Zucker erklären. Zu einer solchen Funktion von Prolin 
passt auch, dass die ProDH ebenso wie die in dieser Arbeit untersuchten AtbZIPTranskriptionsfaktoren durch Dunkelheit induziert werden.

Neben den bisher diskutierten Signalen muss es auch einen Prolin-abhängigen Signalweg geben. Eine Induktion durch Prolin war lange nur für die ProDH beschrieben, jedoch konnte in dieser Arbeit auch eine Induktion von AtbZIP53 durch Prolin gezeigt werden. Des weiteren wurden kürzlich einige Prolin-induzierte Gene mit Hilfe von zwei Subarrays, auf denen Gene für Membran- bzw. Chloroplasten-Proteine aufgetragen waren, identifiziert (Deuschle et al., 2004). Das dabei am stärksten induzierte Gen war $A S N 1$, dass in dieser Arbeit durch ChIP als direktes Zielgen von AtbZIP53 identifiziert wurde. Auch weitere, durch AtbZIP53 deutlich aktivierte Gene werden durch Prolin induziert (Tabelle 6.1). Somit ist anzunehmen, dass AtbZIP53 eine wichtige Rolle im Prolin-Signalweg spielt. Es wird spannend sein, zu sehen, welche Gene noch durch Prolin reguliert werden, wenn die ersten genomweiten Transkriptomanalysen hierzu veröffentlicht werden.

Tabelle 6.1: Durch AtbZIP53 und Prolin induzierte Gene. Die Daten zur Prolin-Induktion stammen von (Deuschle et al., 2004).

\begin{tabular}{|l|l|l|}
\hline Beschreibung & AGI-Code & Induktion durch Prolin (x-fach) \\
\hline ASN1 & At3g47340 & 21,35 \\
\hline ProDH & At3g30775 & 13,35 \\
\hline ankyrin repeat protein family & At1g10340 & 6,139 \\
\hline ankyrin repeat protein family & At5g54610 & 4,95 \\
\hline AtTIP3.1 & At1g73190 & 2,74 \\
\hline
\end{tabular}

\subsection{AtbZIP53 ist möglicherweise Teil eines ABA-Signalweges}

Promotor-Analysen der in dem Mikroarray-Experiment durch AtbZIP53 aktivierten Gene zeigte eine Anreicherung dieses $A C G T G G C$-Motivs. Ein Bindung an dieses Motiv konnte außerdem für mehrer Homologe von AtbZIP53 gezeigt werden, was dafür spricht, das auch AtbZIP53 an dieses Motiv bindet (siehe Tabelle 6.2). In der Literatur wurde dieses Motiv als ABRE (abscisic acid response element) beschrieben (Skriver et al., 1991). ABRE sind zwar nicht über eine exakt konservierte Sequenz, sondern eher über die Funktion definiert (Zur Übersicht siehe (Busk und Pages, 1998), aber Expressionsstudien zeigen, dass vor allem $A B R E$, die die Sequenz $A C G T G G C$ enthalten, eine starke ABA-Antwort vermitteln können (Shen und Ho, 1995; Vasil et al., 1995). 
Bindestudien der Tabak bZIP-Proteine BZI-1 (Gruppe C) und BZI-2, BZI-3 und BZI-4 (alle Gruppe S) zeigten, dass alle Faktoren in der Lage waren, alleine an dieses Element zu binden. Wurden jedoch Kotranslatate von BZI-1 und BZI-2, -3 oder -4 verwendet, zeigte sich eine bevorzugte Bindung des Heterodimers. Dies entspricht der in dieser Arbeit gezeigten bevorzugten Heterodimerisierung von bZIP-Proteinen der Gruppe C mit bZIP-Proteinen der Gruppe S1. Für AtbZIP10 und AtbZIP25 konnte in Gelretardationsanalysen die Bindung an ein $A B R E$-Element im Promotor des Speicherprotein-Gens Cruciferin gezeigt werden, der auch von AtbZIP53 aktiviert wird (Lara et al., 2003). Da für die BZI-Proteine eine bevorzugte Bindung der Heterodimere an dieses Element gezeigt wurde, wird es wahrscheinlich von AtbZIP10/AtbZIP53 oder AtbZIP25/AtbZIP53 Heterodimeren gebunden.

Tabelle 6.2: Durch Gelretardationsanalyse (GRA) identifiziert Bindeelemente von zu AtbZIP53 Homologen Proteinen. Anmerkungen: 1: Wird in GRA bevorzugt durch BZI1Heterodimere mit BZI-2, -3 und-4, aber auch durch die entsprechenden Homodimere gebunden. Bindung für BZI-1 durch ChIP bestätigt (Strathmann, 2003). 2: Wird in GRA durch BZI-4 Homodimere, aber nicht durch andere BZI-Homodimere oder Heterodimere gebunden. Bindung von BZI-4 durch ChIP bestätigt. 3: Das synthetische Bindeelement wurde durch Selex identifziert, und wurde als C/G-Hybrid auch von (Skimizu et al., 2005) verwendet. 4: Wird in GRA durch Homodimere gebunden, die Bindung wird durch das G-box Element (Kusano et al., 1998) kompetetiert. 5: Wird in GRA durch Homodimere gebunden, die Bindung wird durch das G-box Element kompetetiert. 6: Bindeelemente durch Selex identifiziert, die obere Zeile gibt variable Basen an. bZIP910 und bZIP911 binden nur Schlecht an die G-Box aus dem CHSPromotor. 7: Wird in GRA nur von dem OBF1/lip19 Heterodimer, nicht von den Homodimeren gebunden. 8: Bindung durch ChIP und in Protoplasten-Assays gezeigt. 9: Putative Bindestellen für AtbZIP53 in den Promotoren von in dieser Arbeit identifizierten möglichen Zielgenen, Bindung nicht gezeigt.

\begin{tabular}{|c|c|c|c|c|}
\hline Faktor & Bindeelement & Ursprung & $\begin{array}{l}\text { An- } \\
\text { merkung }\end{array}$ & Publikation \\
\hline BZI1,2,3,4 & tgtaGACGTGgcga & GH3-Promotor & 1 & Strathmann, 2003 \\
\hline BZI-4 & aaagCACGTGgcac & NIN88-Promotor & 2 & Strathmann, 2003 \\
\hline tbzf/tbz17 & tgggGACGTGgcag & Selex, C/G-hybrid & 3 & Yang et al., 2001 \\
\hline TBZ17 & $\begin{array}{l}\text { tggtGACGTGgCCg } \\
\text { cggCCACGTGgCCa }\end{array}$ & $\begin{array}{l}\text { Histon H3-Promotor } \\
\text { G-Box }\end{array}$ & & Kusano et al., 1998 \\
\hline mlip15 & tggtGACGTGgCCg & Histon H3-Promotor & 4 & Kusano et al., 1995 \\
\hline CPRF6,7 & attcCACGTGgCCa & CHS-Promotor & 5 & Rugner et al., 2001 \\
\hline bZIP910 & $\begin{array}{cc}\text { g } & \text { C } \\
\text { gatGACGTGgCa }\end{array}$ & Selex & 6 & $\begin{array}{l}\text { Martinez-Garcia et } \\
\text { al., } 1998\end{array}$ \\
\hline bZIP911 & $\stackrel{\text { g }}{\text { gat GACGTGgCC }}$ & Selex & 6 & $\begin{array}{l}\text { Martinez-Garcia et } \\
\text { al., } 1998\end{array}$ \\
\hline OsOBF1 & tggtGACGTGgCCg & Histon H3-Promotor & & Skimizu et al., 2005 \\
\hline OBF1/lip19 & tgggGACGTGgcag & C/G-Hybrid & 7 & Skimizu et al., 2005 \\
\hline AtbZIP53 & ggatGA GTGgatg & ProDH-Promotor & 8 & diese Arbeit \\
\hline AtbZIP53 & atccTACGTGgetc & CRU3 & 9 & \\
\hline AtbZIP53 & aagaCACGTGgcgt & atper1 & 9 & \\
\hline AtbZIP53 & ttgcTACGTGgcaa & AlL1 & 9 & \\
\hline
\end{tabular}


Ein $A C G T G G C$-Motiv wurde auch als durch Licht aktiviertes Element des Chalconsynthase (CHS) Gens beschrieben (Sprenger-Haussels und Weisshaar, 2000). Jedoch zeigen viele der ein $A C G T G G C$ Motiv enthaltenden, durch AtbZIP53 aktivierten Gene eine Induktion durch ABA, nicht jedoch durch Licht, und AtbZIP53 selbst wird durch Dunkelheit induziert. Eine Regulation von durch Licht aktivierten Elementen durch AtbZIP53 ist daher sehr unwahrscheinlich. Entsprechend wurde für den Gruppe C Faktor BZI-1 aus Tabak gezeigt, dass er zwar in vitro an dieses Element binden kann, jedoch nicht in vivo an der Regulation der CHS beteiligt ist (Heinekamp et al., 2002).

Neben der Bindung an das $A B R E$-Element gibt es weitere Hinweise auf eine Funktion von AtbZIP53 in einem ABA-Signalweg. So wird die Expression der Samenspezifischen Gene, an der AtbZIP53 beteiligt ist, über ABA gesteuert (Gubler et al., 2005). Zudem konnte für AtbZIP53 in dieser Arbeit eine spezifische Expression in Spaltöffnungen gezeigt werden, die durch ABA reguliert werden (Tallman, 2004). Außerdem ist ABA von zentraler Bedeutung in der Antwort auf Salzstress, und für AtbZIP53 konnte in dieser Arbeit ebenfalls eine Funktion bei Salzstress gezeigt werden. Interessanterweise sind ABA-Signalwege auch eng mit Zuckersignalwegen verknüpft (Rolland et al., 2002). So sind wichtige Mutanten des ABA- Signalweges, wie aba2, $a b a 3$ oder abi4, gleichzeitig auch Mutanten der Glukose Signalübertragung (gin1, gin5 und gin6; siehe Abbildung 6.4). Angesichts der Funktion der C/S1 AtbZIPTranskriptionsfaktoren in der Zucker-Signaltransduktion wäre es also nicht überraschend, wenn sie auch Funktionen in einem ABA-Signalweg hätten.

Andererseits aktiviert AtbZIP53 die ProDH, die durch ABA reprimiert wird. Zudem wird AtbZIP53 selbst nicht durch ABA induziert. Möglicherweise ist für die ABAabhängige Aktivierung der $A B R E$-Elemente ein Koaktivator wie $\mathrm{ABI} 3$ nötig, während dies bei dem ACTCAT-Motiv aus dem ProDH-Promotor nicht der Fall ist. Die Bedeutung von $\mathrm{ABI} 3$ für die Aktivierung des $A B R E$-Elementes wurde für Speicherprotein-Gene bereits gezeigt (Lara et al., 2003). Für ein weiteres von AtbZIP53 aktiviertes Gene, AtPer1, wurde gezeigt, dass ABI3 an der Aktivierung beteiligt ist, und dass diese über das in Tabelle 6.2 gezeigte $A B R E$-Element erfolgt (Haslekas et al., 2003). Da ABI3 nicht an $A C G T$-Motive bindet, fungiert es hier wahrscheinlich wie bei den Speicherprotein Genen als Koaktivator an C/S1 Heterodimeren. Dasselbe gilt möglicherweise auch für die Regulation des in dieser Arbeit als wahrscheinliches Zielgen von AtbZIP53 identifizierten LEA-Gens AIL1. Dieses Gen enthält zwei ABREMotive in seinem Promotor wird durch ABA induziert (Fujita et al., 2005). In dieser 


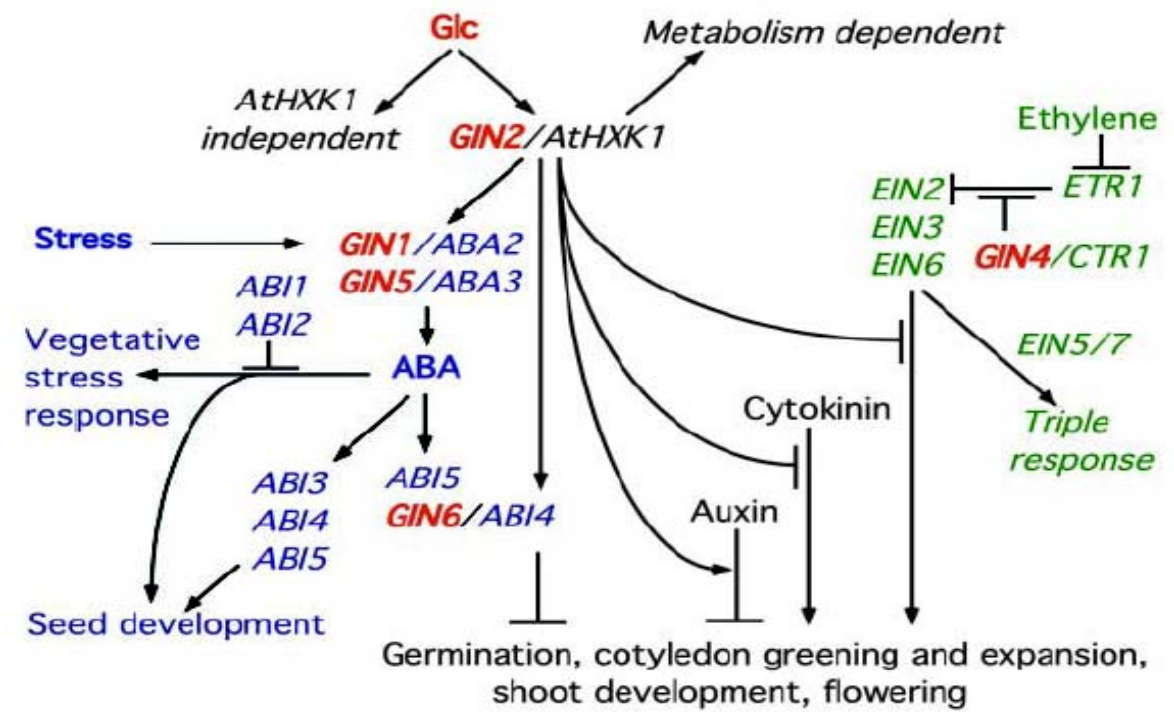

Abbildung 6.4: Übersicht über die Interaktionen zwischen Zucker- und Hormon-Signalwegen in Arabidopsis (nach Rolland et al., 2002). Die Mutanten ginl und aba2 sind allelisch und kodieren für eine Enzym der ABA-Biosynthese (Rook et al., 2001). Die Mutanten gin6, sun6, sis5, und isi3 sind allelisch zu abi4, einer ABA-insensitiven Mutante (Arenas-Huertero et al., 2000; Huijser et al., 2000; Rook et al., 2001). Glukose aktiviert Abi4, ein Gen dass einen AP2 Transkriptionsfaktor kodiert (Finkelstein et al., 1998). Die Aktivierung benötigt ABA, auch wenn Abi4 nicht direkt durch ABA induziert wird (Arenas-Huertero et al., 2000). Andere Mutanten, die kein ABA bilden können (abal-1, aba2-1, und aba3-2), sind ebenfalls Glukose-insensitiv (Arenas-Huertero et al., 2000; Huijser et al., 2000; Laby et al., 2000). Die abi5 Mutante ist ebenfalls Glukose-insensitiv. Andere ABA-insensitive Mutanten (abi1-1, abi2-1, und abi3-1) zeigen keinen Glukose-insensitiven Phänotyp (Arenas-Huertero et al., 2000; Huijser et al., 2000; Laby et al., 2000), sodass wahrscheinlich nur ein bestimmter ABASignalweg in die Zucker-Signaltransduktion involviert ist. (gin: Glukose-insensitv; abi: ABA-insensitv; aba: keine ABA-Synthese; sun, sis und isi: Saccharose-insensitiv)

Arbeit wurde gezeigt, dass AIL1 wie AtbZIP53 bei Salzstress spezifisch in der Wurzel induziert wird, und von unserem Kooperationspartner Jesus Vincente-Carbajosa konnte mittlerweile gezeigt werden, dass die Samen-spezifische Expression von AIL1 in der atbzip53 Mutante deutlich reduziert ist, was belegt, das es sich wirklich um ein Zielgen von AtbZIP53 handelt. In Arabidopsis wurde AIL1 bisher kaum untersucht, jedoch ist es ein Homolog zu HVA1 aus Gerste. Für HVA1 wurde eine ABA-vermittelte Aktivierung über das $A C G T G G C$ Motiv beschrieben, an der das ABI3-Homolg aus Gerste, VP1, beteiligt ist (Shen et al., 2001). Zudem wird HVA1, wie AtbZIP53 und AIL1, durch Salzstress induziert, und die Überexpression von HVAl führt $\mathrm{zu}$ einer erhöhten Salztoleranz (Xu et al., 1996). Sollte AIL1 ebenfalls eine erhöhte Salztoleranz bewirken, so könnte dies die erhöhte Salzresistenz von 35S:AtbZIP53 Pflanzen erklären. Durch Überexpression von AtbZIP53 in einer AIL1 Mutante und anschließender Analyse der Salzresistenz dieser Pflanzen ließe sich diese Hypothese experimentell überprüfen. 


\subsection{C/S1 Heterodimere regulieren die Expression von Samenspeicherprotein- und LEA-Genen.}

Die Samenentwicklung lässt sich in zwei Phasen unterteilen. In der ersten Phase, in der Zellteilungen vorherrschen, entwickelt sich die Zygote zum Embryo und das Endosperm wird angelegt. Während des zweiten Phase findet kaum noch Zellteilung statt, der Samen lagert Nährstoffe ein und wird Austrocknungsresistent (Zur Übersicht siehe (Fujiwaraa et al., 2002)). In dieser zweiten Phase findet die unter anderem auch durch das Phytohormon Abscisinsäure (ABA) regulierte Expression von Samnespeicherprotein-Genen und LEA-Genen statt (Bray, 1993; McCarty, 1995). In dieser Arbeit konnte gezeigt werden, dass AtbZIP53, vermutlich als Heterodimer mit AtbZIP10 oder AtbZIP25, an der Regulation der Speicherprotein-Gene beteiligt ist. Eine Aktivierung der Promotor der Speicherprotein-Gene 2S1 und Cruciferin durch AtbZIP53 konnte mittlerweile auch in Protoplasten-Assays gezeigt werden (Andrea Ehlert, persönliche Mitteilung).

Betrachtet man die Transkriptomdaten (Abbildung 5.41), wird AtbZIP53 wie die Speicherprotein-Gene bereits im Torpedo-Stadium exprimiert, und in den folgenden Entwicklungsstadien steigt die Expression weiter an. Für LEA Gene ist ein späterer Anstieg der Expression typisch, wie er sich auch für AtbZIP1 findet. AtbZIP1 und viele LEA-Gene werden im Torpedostadium nicht oder kaum exprimiert. Für AtbZIPI konnte in Protoplasten-Assays keine Aktivierung der Promotor der Speicherprotein-Gene 2S1 und Cruciferin gezeigt werden (Andrea Ehlert, persönliche Mitteilung). Somit ist AtbZIP1 wahrscheinlich eher an der Expression von LEA-Genen beteiligt, und entsprechend wurde in der Transkriptomanalyse von 35S:AtbZIP1 Pflanzen ein LEAGen (Atlg54890) als 3,24fach aktiviert gefunden.

Interessanterweise sind die S1 Faktoren AtbZIP11 und AtbZIP44 zu Beginn der Samenentwicklung deutlich exprimiert, und die Expression nimmt während der Samenreifung ab, sie sind also gegenläufig zu AtbZIP1 und AtbZIP53 reguliert. Dieses Muster lässt sich vielleicht mit Änderungen der Zuckerkonzentrationen in den Samen während der Entwicklung erklären. Am Beispiel von Gerste konnte gezeigt werden, dass Glukose nur in der ersten, meristematischen Phase der Entwicklung zur Ernährung des Embryos dient. Im Übergang zwischen der ersten und der zweiten findet eine Wechsel auf eine Ernährung durch Saccharose statt, und im Verlauf der zweiten Phase 
sinkt auch die Saccharose Konzentration (Abbildung 6.5; (Borisjuk et al., 2004). Die Zuckerkonzentrationen verlaufen dabei parallel zur Expression des Zuckerinduzierbaren Gens AtbZIP11, und reziprok zu der Expression der Zucker-reprimierten Gene AtbZIP1 und AtbZIP53.

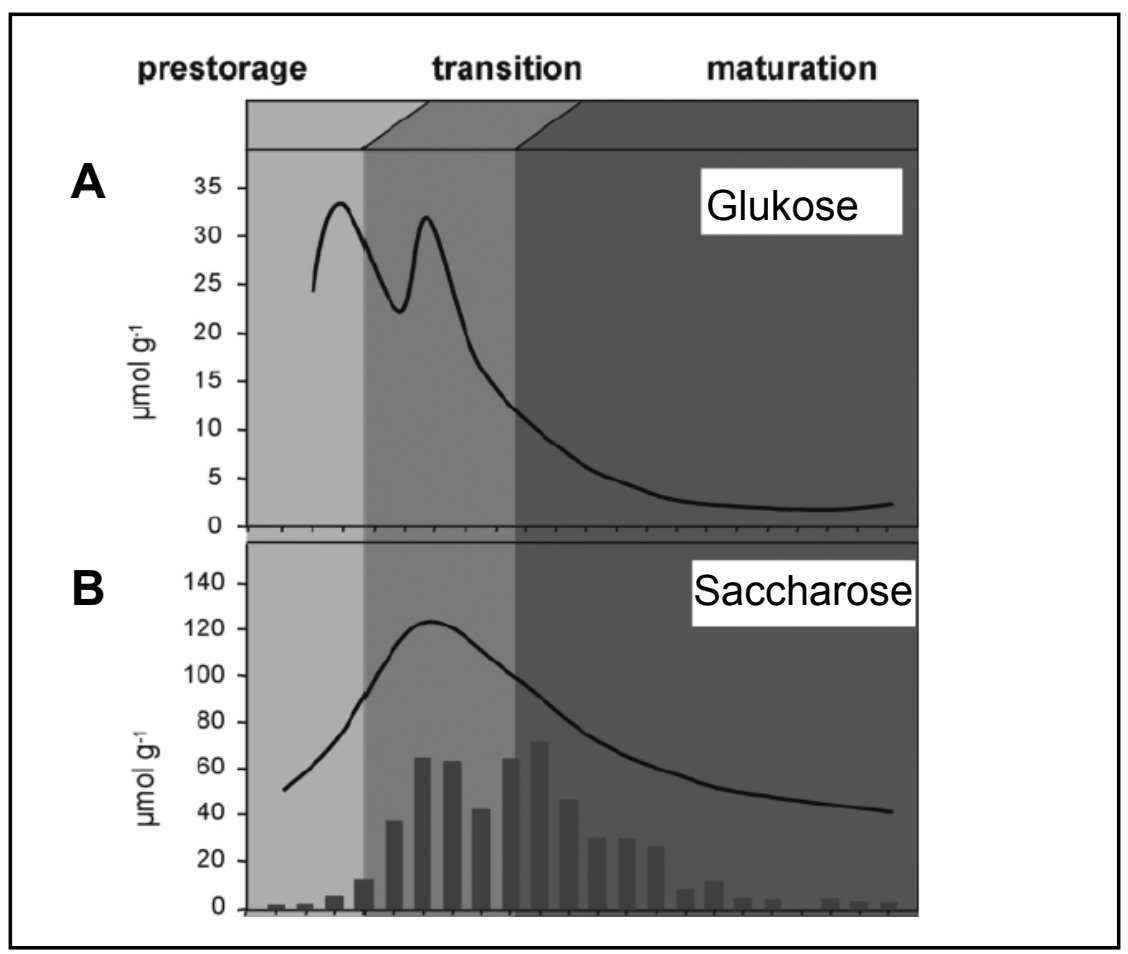

Abbildung 6.5: Zuckergehalt von Gerstenkörner während der Samenentwicklung. Die schwarze Linie gibt die Glukose- (A) bzw. Saccharose-Konzentration (B) wieder. Die Balken in B repräsentieren die Transkriptmenge des Saccharosetransporter-Gens HvSUT1. Prestorage: frühe Phase; Maturation: späte Phase der Samenentwicklung (aus Borisjuk et al., 2004)

\subsection{AtbZIP1 und AtbZIP53 regulieren die Umstellung des Metabolismus während Dunkel-induzierter Seneszenz}

In dieser Arbeit konnte eine Funktion von AtbZIP-Transkriptionsfaktoren der Gruppen $\mathrm{C}$ und S1 an der Seneszenz gezeigt werden. So wurde gezeigt, dass die Überexpression von AtbZIP1 oder AtbZIP53 zur Induktion von Seneszenz-assozierten Genen führt. Die Überexpression von AtbZIP63 führt ebenfalls zur Induktion von Seneszenz-assozierten Genen (Jesus Vicente-Carbajosa, persönliche Mitteilung). Zudem konnte in dieser Arbeit gezeigt werden, dass der Prozess der Dunkel-induzierten Seneszenz in 
35S:AtbZIP1 Linien deutlich schneller abläuft, während er in einer atbzip1 Mutante verlangsamt ist. In Northern-Analysen und durch Transkriptomdaten wurde gezeigt, dass alle AtbZIP-Transkriptionsfaktoren der Gruppen $\mathrm{C}$ und $\mathrm{S} 1$ auf der Transkriptionsebene durch Seneszenzprozesse reguliert werden. Dabei ist jedoch die Kinetik der Transkription der verschiedenen Faktoren unterschiedlich und von der Form der Seneszenz abhängig. Dies könnte dazu führen, das bestimmte Heterodimere in verschiedenen Phasen oder Formen der Seneszenz überwiegen, und so eine unterschiedliche, der jeweiligen Phase oder Form der Seneszenz entsprechende Regulation von Zielgenen erlauben.

Die Seneszenz von Blättern ist ein Abfolge von degradativen Prozessen, die neben dem Stop der Photosynthese den Abbau von Proteinen, Membranen, RNA und DNA, die Hydrolyse von Polysachariden und die Oxidation von Fettsäuren beinhaltet (Smart, 1994). Für Mais konnte gezeigt werden, dass die durch andauernde Dunkelheit induzierten degradativen Prozesse in Sink-Geweben früher beginnen als in ausgewachsenen Blättern (Brouquisse et al., 1998). Mit Hilfe von Promotor-GUS Fusionen konnte in dieser Arbeit gezeigt werden, dass die Expression von AtbZIP1 und AtbZIP53 bei andauernder Dunkelheit vorwiegend in diesen Geweben erfolgt. Zudem fanden sich unter den in den Transkritom-Analysen von 35S:AtbZIP1 und 35S:AtbZIP53 Pflanzen identifizierten putativen Zielgenen verschiedene Gene, die Enzyme des Katabolismus kodieren. Eines dieser Enzyme, die branched chain aminoacid transaminase (BCAT; At1g10070), katalysiert die Eintrittsreaktion des Abbauweges von den verzweigten Aminosäuren Valin, Leucin und Isoleucin (Diebold et al., 2002; Fujiki et al., 2001a; Schuster und Binder, 2005). Dieses Enzym stellt ein besonders interessanten Kandidaten für ein direktes Zielgen dar, da es in Transkriptomanalysen sowohl in AtbZIP1, AtbZIP53 als auch in AtbZIP63Überexpressionslinien aktiviert und in der atbzipl/atbzip53 Doppelmutante reprimiert wurde. Zudem wurde für die BCAT gezeigt, das sie, wie die AtbZIPTranskriptionsfaktoren, stark durch Zucker-Verarmung und Dunkelheit induziert wird (Fujiki et al., 2002).

Ein anderes Enzym des Aminosäure-Katabolismus, die ProDH (At3g30775), wurde bereits ausführlich als direktes Zielgen besprochen. Von der ProDH existiert zudem ein Isoenzym (At5g38710), das ebenfalls durch AtbZIP53 aktiviert wurde, und das laut Genevestigator deutlich durch Seneszenz induziert wird. Enzyme des ArgininKatabolismus (Arginase (At4g08870); 3,6x aktiviert in 35S:AtbZIP1; 0,6x reprimiert in 
atbzip1/atbzip53; Alanine-Glyoxylate Aminotransferase (At4g08870); 2,25x aktiviert in 35S:AtbZIP1; 0,6x reprimiert in atbzip1/atbzip53) wurden ebenfalls aktiviert.

Besonders interessant ist eine Gruppe von Genen, die Enzyme des Glutamin- und Asparagin-Metabolismus regulieren. Es konnte gezeigt werden, dass es während Dunkel-induzierter Seneszenz zu einer verstärkten Akkumulation von Asparagin in den Blättern kommt, während die Konzentration von Glutamin, das normalerweise der bevorzugte Metabolit für Speicherung und Transport von Stickstoff ist, sinkt (Lin und $\mathrm{Wu}, 2004)$. Dies wird auf das bessere $\mathrm{C} / \mathrm{N}$ Verhältnis von Asparagin zurückgeführt, das bei Zuckermangel bedeutend wird. Anhand von Transkriptomdaten wurde von (Lin und $\mathrm{Wu}, 2004)$ ein Stoffwechselweg für die Synthese von Asparagin während der Dunkelinduzierten Seneszenz vorgeschlagen (Abbildung 6.6). Eine Zentrale Funktion hat dabei die Aspargin-Synthase $A S N 1$, für die in dieser Arbeit gezeigt werden konnte, dass sie

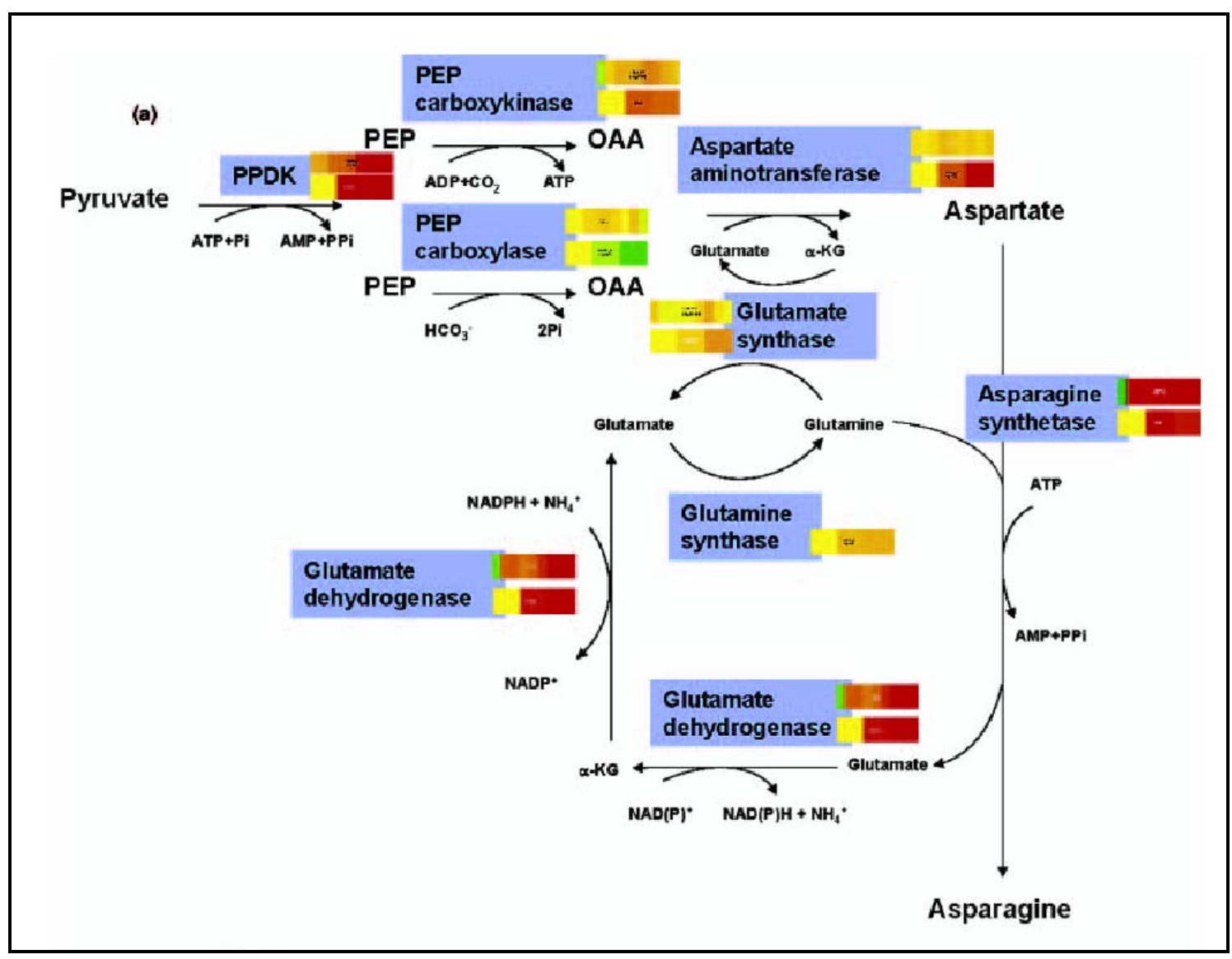

Abbildung 6.6: Modell eines Stoffwechselweges zur Mobilisierung von Stickstoff durch Synthese von Asparagin in Dunkelheit ausgesetzten Blättern (Lin und $\mathbf{W u}, 2004$ ). Die Balken neben den Enzymen geben die Expression der entsprechenden Gene im Laufe der Dunkel-induzierten Seneszenz wieder, die beiden Balken stehen dabei für mit zwei unterschiedlichen Mikroarray-Systemen gewonnene Daten. Dabei werden von links nach rechts die Expressionsunterschiede zu verschiedenen Zeitpunkten der Dunkel-Induktion wiedergegeben (0, 6, 12 Stunden und 1-6 Tage auf den oberen Balken, 0, 2 und 5 Tage auf den unteren Balken). PEP: Phosphoenol-Pyruvat; PPDK: Phosphoenol-Pyruvat Dikinase. 
ein direktes Zielgen von AtbZIP53 ist. Auch andere, an diesem Weg beteiligten Enzyme werden in den AtbZIP1 bzw. AtbZIP53 Überexpressionspflanzen verstärkt exprimiert. In Kapitel 5.6.4 wurde eine Induktion der ASN1 sowie der PEP-Carboxykinase in Transkritomanalysen von AtbZIP53 Überexpressionspflanzen gezeigt und in NorthernAnalysen reproduziert. Die Transkriptomanalysen einer 35S:AtbZIP1 Linie und der atbzip1/atbzip53 Doppelmutante zeigen auch eine Regulation anderer an dem Weg beteiligter Enzyme (glutamine synhtase (At5g37600); 2,25x aktiviert in 35S:AtbZIP1; 0,8x reprimiert in atbzip1/atbzip53; glutamate dehydrogenase 2 (At5g07440); 1,6x aktiviert in 35S:AtbZIP1; 0,36x reprimiert in atbzip1/atbzip53; aspartate aminotransferase (At5g11520); 2,25x aktiviert in 35S:AtbZIP1; 0,16x reprimiert in atbzip1/atbzip53).

Eine Funktion von $\mathrm{zu}$ den Gruppen $\mathrm{C}$ und $\mathrm{S} 1$ gehörenden AtbZIPTranskriptionsfaktoren in der Seneszenz würde zu ihrer vermuteten Rolle in ABASignalwegen ebenso wie zu ihrer Funktion bei Zuckermangel passen, da ABA ebenso wie Zuckermangel Seneszenz induzieren kann (Yang et al., 2003). Möglicherweise spielt auch $A B I 3$ hier ein Rolle, da für die abi3-Mutante ebenfalls eine verzögerte Seneszenz beschrieben wurde (Robinson und Hill, 1999). ASN1 und ABI3 könnten dabei auch Seneszenz-Prozesse und die Samenentwicklung verbinden, da für beide eine Funktion in der Umverteilung von Metaboliten in die Samen beschrieben wurde, wie sie möglicherweise während der Seneszenz stattfindet (Lam et al., 2003; Robinson und Hill, 1999).

Unter den durch Seneszenz bzw. Zuckermangel und durch Überexpression von AtbZIPI oder AtbZIP53 induzierten Genen finden sich auch solche, deren Funktion nicht gleich $\mathrm{zu}$ erkennen ist, darunter mehrere Protease-Inhibitoren, Lipoxygenasen oder PR-Gene. Diese Gene werden eher der Pathogenabwehr zugeordnet. In den in dieser Arbeit gezeigten Transkriptomanalysen führte die Überexpression von AtbZIP1 oder AtbZIP53 zur Expression von weiteren Pathogen-induzierbaren Genen. In der Literatur finden sich Hinweise auf eine mögliche Funktion von C/S1 bZIP-Transkriptionsfaktoren in der Pathogenabwehr. So wird die Transkription von BZI-1 durch virale und bakterielle Pathogene induziert (Kuhlmann et al., 2003), und in Capsicum chinense wurde für einen zur Gruppe S1 gehörenden bZIP-Transkriptionsfaktor, PPI1, ebenfalls eine Induktion durch Pathogene gezeigt (Lee et al., 2002). Für Arabidopsis thaliana zeigen Transkriptomdaten, dass aus den Gruppen C und S1 nur AtbZIP1 nach Pathogenbefall leicht induziert wird. Jedoch werden so posttranskriptionale Mechanismen nicht erfasst, 
die von entscheidender Bedeutung sein könnten. So wird z.B. der zur Gruppe C gehörende bZIP-Transkriptionsfaktor G/HBF-1 kurz nach Infektion mit dem Pathogen Pseudomonas phosphoryliert (Droge-Laser et al., 1997). AtbZIP1 bzw. AtbZIP53 Überexpressionslinien sowie die entsprechenden Mutanten wurden von Katrin Dietrich im Rahmen ihrer Diplomarbeit auf eine veränderte Resistenz gegen Pseudomonas syringae untersucht, jedoch konnten dabei keine Unterschiede zum Wildtyp festgestellt werden.

Viele Dunkel-induzierte oder Seneszenz-assoziierte Gene werden auch durch Pathogene induziert (Ho et al., 2001; Quirino et al., 2000). Die in der 35S:AtbZIP1Linie stärker exprimierten Lipoxygenasen sind Teil des Jasmonsäure-Syntheseweges und werden stark durch Pathogene oder Verwundung induziert, und viele Jasmonsäureinduzierbare Gene werden auch durch Zucker reguliert (Reinbothe et al., 1994; Sadka et al., 1994). Es scheint also eine enge Verbindung zwischen diesen Stressen und Zuckermangel $\mathrm{zu}$ geben. In Hefe und Mäusen wird die Existenz eines stark konservierten regulatorischen Systems postuliert, das Stress-Resistenz, Metabolismus und Alterungsprozesse reguliert (Kenyon, 2001). Die Existenz eines solchen Systems wäre auch in Pflanzen denkbar.

\subsection{Ausblick}

Die bisher verfügbaren Daten lassen vermuten, dass die AtbZIP-Transkriptionsfaktoren der Gruppen C und S1 ein komplexes regulatorisches Netzwerk darstellen, das vorwiegend Prozesse des Metabolismus in Abhängigkeit von verfügbaren Zuckern, verschiedenen Stressen und entwicklungsbiologischen Signalen kontrolliert.

Sollte diese Vermutung richtig sein, so sollten sich in Mutanten oder Überexpressionslinien Unterschiede im Zucker- oder Aminosäuregehalt finden. Erste Messungen des Zuckergehalts der in dieser Arbeit untersuchten transgenen Linien haben noch keine klaren Unterschiede gezeigt, vielleicht aufgrund der möglichen Redundanz zwischen den einzelnen AtbZIP-Transkriptionsfaktoren der Gruppen C und S1. Es wird daher, gerade für die Analyse der biologischen Funktion, notwendig sein, verschiedene Mehrfach-Mutanten zu erzeugen. Damit wurde in dieser Arbeit begonnen, jedoch stehen bisher nur Doppel-Mutanten zur Verfügung. Wichtig wird auch die 
Erzeugung von Linien sein, die beide Partner eines Heterodimers überexprimieren, idealerweise in einem Hintergrund, in dem die anderen Faktoren der Gruppen C und S1 nicht exprimiert werden, sodass gezielt die Funktion eines Heterodimers betrachtet werden kann.

Für die weitere Charakterisierung der AtbZIP-Transkriptionsfaktoren der Gruppen C und S1 wird es von entscheidender Bedeutung sein, weitere direkte Zielgene zu identifizieren. Dies bietet sich besonders an, da hierfür neue Methoden entwickelt wurden, die eine praktikable Möglichkeit bieten, genomweit nach Zielgenen zu suchen. Ein möglicher Ansatz sind Analysen des Transkriptoms kurz nach einer induzierten Expression der AtbZIP-Transkriptionsfaktoren, gefolgt von einer CycloheximidBehandlung (siehe z.B. Wang et al., 2005). Auf diese Weise werden überwiegend nur direkte Zielgene der AtbZIP-Transkriptionsfaktoren aktiviert. Wird das Transkriptom zu verschiedenen Zeitpunkten nach einer induzierten Expression der AtbZIPTranskriptionsfaktoren untersucht, lassen sich aufgrund der Kinetik direkt regulierte von indirekt regulierten Genen unterscheiden. Die Identifizierung von direkten Zielgenen wäre durch die Kombination von Chromatin-Immunopräziptation mit Promotor-Arrays möglich ("ChIP on chip“, siehe Blais und Dynlacht, 2005; Testa et al., 2005; Wang, 2005), jedoch ist dieser Ansatz wahrscheinlich aufwendiger.

Vieles spricht dafür, dass die spezifische Dimerisierung von bZIP Transkriptionsfaktoren eine Zielgen-Spezifität bewirken kann. So konnte in Tabak gezeigt werden, dass BZI-4 Homodimere an eine G-Box im NIN88 Promotor binden, BZI-1 / BZI-4 Heterodimere hingegen nicht (Strathmann, 2003). Diese binden dafür bevorzugt an eine G/C-Box im GH3 Promotor. Ähnliches konnte auch für Reis gezeigt werden, wo OBF1 Homodimere an die G/C Box aus dem Histon H3 Promotor binden, OBF1/LIP19 Heterodimere aber an ein fast identisches, "C/G hybrid" genanntes Element (siehe Tabelle 6.2; Shimizu et al., 2005). In Protoplasten-Assays konnte zwar gezeigt werden, dass alle AtbZIP-Transkriptionsfaktoren der Gruppen C und S1 die ProDH aktivieren können, jedoch scheint dies nicht auf alle Zielgen-Promotoren zuzutreffen. So konnte zum Beispiel für den Cruciferin-Promotor in ProtoplastenAssays gezeigt werden, dass er nicht durch AtbZIP1 aktiviert wird (Andrea Ehlert, persönliche Mitteilung). Das gleiche scheint auch für viele andere Zielgene zu gelten, da die Überexpression von AtbZIP1 und AtbZIP53 in den Transkriptomanalysen nur zu einem Teil zur Aktivierung von gemeinsamen Zielgenen führte. 
Um den Einfluss der Heterodimerisierung zwischen AtbZIP-Transkriptionsfaktoren der Gruppen $\mathrm{C}$ und S1 auf die Bindung an unterschiedliche cis-Elemente zu analysieren, sollten umfangreiche Bindestudien durchgeführt werden. Hierfür wäre eine Methode sinnvoll, die einen höheren Durchsatz als Gelretardationsanalysen erlaubt. Eine solche Methode wäre z.B. ein ELISA-basiertes System für DNA-Bindestudien (Benotmane et al., 1997; McKay et al., 1998; Mönke et al., 2004).

Die in dieser Arbeit durchgeführten Untersuchungen $\mathrm{zu}$ der Expression der verschiedenen AtbZIP-Transkriptionsfaktoren der Gruppen C und S1 auf Transkriptionsebene haben gezeigt, dass es neben klaren Übereinstimungen auch deutliche Unterschiede zwischen den Expressionsmustern der einzelnen Faktoren gibt. Dabei ist die posttranslationale Regulation der C/S1 AtbZIP-Transkriptionsfaktoren bisher wenig untersucht worden. Gerade bei den Gruppe C Faktoren finden sich viele putative Phosphroylierungsstellen, die an einer solche Regulation beteiligt sein könnten. Der Gruppe C Faktor AtbZIP10 zeigte in der Vielzahl von in Mikroarray Datenbanken verfügbaren Experimenten kaum eine Regulation auf Transkriptionsebene, jedoch gibt es deutliche Hinweise für eine Regulation durch gesteuerten Kernimport und Export (Klaus Harter, persönliche Mitteilung). Ein weiterer posttranslationaler Regulationsmechanismus könnte eine Heterodimer-spezifische Ubiquitinylierung und ein darauf folgender Abbau sein, wie sie in menschlichen Zellkulturen für ATF2 gezeigt wurde (Fuchs und Ronai, 1999).

Die räumliche und zeitliche Verteilung der AtbZIP-Proteine der Gruppen S1 und C ist eine wichtige Regulationsmöglichkeit für die Dimerbildung und damit letztlich für die Regulation der Zielgenexpression. Auch wenn sie in dieser Arbeit schon detailliert untersucht wurde, bietet die Fülle an verfügbaren Transkriptom-Daten die Möglichkeit für eine weit tiefer gehende Analyse. Da bereits jetzt die große Komplexität der Regulation der AtbZIP-Transkriptionsfaktoren des Heterodimerisierungsnetzwerkes abzusehen ist, wird hier möglicherweise eine Arbeit mit Computermodellen hilfreich sein. 


\section{Literatur}

Abraham, E., Rigo, G., Szekely, G., Nagy, R., Koncz, C. and Szabados, L. (2003): Light-dependent induction of proline biosynthesis by abscisic acid and salt stress is inhibited by brassinosteroid in Arabidopsis. Plant Mol Biol, 51, 363-72.

Acharya, A., Ruvinov, S.B., Gal, J., Moll, J.R. and Vinson, C. (2002): A heterodimerizing leucine zipper coiled coil system for examining the specificity of a position interactions: amino acids I, V, L, N, A, and K. Biochemistry, 41, 14122-31.

Aguan, K., Sugawara, K., Suzuki, N. and Kusano, T. (1993): Low-temperaturedependent expression of a rice gene encoding a protein with a leucine-zipper motif. Mol Gen Genet, 240, 1-8.

Alber, T. (1992): Structure of the leucine zipper. Curr Opin Genet Dev, 2, 205-10.

Alonso, J.M., Stepanova, A.N., Leisse, T.J., Kim, C.J., Chen, H., Shinn, P., Stevenson, D.K., Zimmerman, J., Barajas, P., Cheuk, R., Gadrinab, C., Heller, C., Jeske, A., Koesema, E., Meyers, C.C., Parker, H., Prednis, L., Ansari, Y., Choy, N., Deen, H., Geralt, M., Hazari, N., Hom, E., Karnes, M., Mulholland, C., Ndubaku, R., Schmidt, I., Guzman, P., Aguilar-Henonin, L., Schmid, M., Weigel, D., Carter, D.E., Marchand, T., Risseeuw, E., Brogden, D., Zeko, A., Crosby, W.L., Berry, C.C. and Ecker, J.R. (2003): Genome-wide insertional mutagenesis of Arabidopsis thaliana. Science, 301, 653-7.

Altschul, S.F., Madden, T.L., Schaffer, A.A., Zhang, J., Zhang, Z., Miller, W. and Lipman, D.J. (1997): Gapped BLAST and PSI-BLAST: a new generation of protein database search programs. Nucleic Acids Res, 25, 3389-402.

Arabidopsis_Genome_Initiative. (2000): Analysis of the genome sequence of the flowering plant Arabidopsis thaliana. Nature, 408, 796-815.

Arenas-Huertero, F., Arroyo, A., Zhou, L., Sheen, J. and Leon, P. (2000): Analysis of Arabidopsis glucose insensitive mutants, gin5 and gin6, reveals a central role of the plant hormone ABA in the regulation of plant vegetative development by sugar. Genes Dev, 14, 2085-2096.

Armstrong, G.A., Weisshaar, B. and Hahlbrock, K. (1992): Homodimeric and heterodimeric leucine zipper proteins and nuclear factors from parsley recognize diverse promoter elements with ACGT cores. Plant Cell, 4, 525-37.

Avonce, N., Leyman, B., Thevelein, J. and Iturriaga, G. (2005): Trehalose metabolism and glucose sensing in plants. Biochem Soc Trans, 33, 276-9.

Baxevanis, A.D. and Vinson, C.R. (1993): Interactions of coiled coils in transcription factors: where is the specificity? Curr Opin Genet Dev, 3, 278-85. 
Benotmane, A.M., Hoylaerts, M.F., Collen, D. and Belayew, A. (1997): Nonisotopic quantitative analysis of protein-DNA interactions at equilibrium. Anal Biochem, 250, 181-185.

Bent, A.F. (2000): Arabidopsis in planta transformation. Uses, mechanisms, and prospects for transformation of other species. Plant Physiol, 124, 1540-7.

Berberich, T., Sano, H. and Kusano, T. (1999): Involvement of a MAP kinase, ZmMPK5, in senescence and recovery from low-temperature-stress in maize. Mol Gen Genet, 262, 534-542.

Bernard, P., Kezdy, K.E., Van Melderen, L., Steyaert, J., Wyns, L., Pato, M.L., Higgins, P.N. and Couturier, M. (1993): The F plasmid CcdB protein induces efficient ATP-dependent DNA cleavage by gyrase. J Mol Biol, 234, 534-41.

Bianchi, G., Gamba, A., Limiroli, R., Pozzi, N., Elster, R., Salamini, F. and Bartels, D. (1993): Physiol. Plant., 87, 223-226.

Blais, A. and Dynlacht, B.D. (2005): Devising transcriptional regulatory networks operating during the cell cycle and differentiation using ChIP-on-chip. Chromosome Res, 13, 275-88.

Blum, A. and Ebercon, A. (1976): Genotypic responses in sorghum to drought stress. III. Free proline accumulation and drought resistance. Crop Sci, 16, 428-431.

Bolton, E.T. and McCarthy, B.J. (1962): A general method for isolation of RNA complementary to DNA. Proc Natl Acad Sci U S A, 48, 1390-1397.

Borisjuk, L., Rolletschek, H., Radchuk, R., Weschke, W., Wobus, U. and Weber, H. (2004): Seed development and differentiation: a role for metabolic regulation. Plant Biol (Stuttg), 6, 375-86.

Bray, E.A. (1993): Molecular responses to water deficit. Plant Physiol, 103, 1035-1040.

Brent, R. and Ptashne, M. (1985): A eukaryotic transcriptional activator bearing the DNA specificity of a prokaryotic repressor. Cell, 43, 729-36.

Brivanlou, A.H. and Darnell, J.E., Jr. (2002): Signal transduction and the control of gene expression. Science, 295, 813-8.

Brouquisse, R.M., Gaudillere, J.-P. and Raymond, P. (1998): Induction of carbonstarvation-related proteolysis in whole maize plants submitted to light dark cycles and to extended darkness. Plant Physiol, 117, 1281-1291.

Buchanan-Wollaston, V. and Ainsworth, C. (1997): Leaf senescence in Brassica napus: cloning of senescence related genes by subtractive hybridisation. Plant Mol Biol, 33, 821-34.

Buchanan-Wollaston, V., Page, T., Harrison, E., Breeze, E., Lim, P.O., Nam, H.G., Lin, J.F., Wu, S.H., Swidzinski, J., Ishizaki, K. and Leaver, C.J. (2005): Comparative transcriptome analysis reveals significant differences in gene expression and signalling pathways between developmental and dark/starvation-induced senescence in Arabidopsis. Plant J, 42, 567-85. 
Busk, P.K. and Pages, M. (1998): Regulation of abscisic acid-induced transcription. Plant Mol Biol, 37, 425-35.

Chen, W., Provart, N.J., Glazebrook, J., Katagiri, F., Chang, H.S., Eulgem, T., Mauch, F., Luan, S., Zou, G., Whitham, S.A., Budworth, P.R., Tao, Y., Xie, Z., Chen, X., Lam, S., Kreps, J.A., Harper, J.F., Si-Ammour, A., Mauch-Mani, B., Heinlein, M., Kobayashi, K., Hohn, T., Dangl, J.L., Wang, X. and Zhu, T. (2002): Expression profile matrix of Arabidopsis transcription factor genes suggests their putative functions in response to environmental stresses. Plant Cell, 14, 559-74.

Chiang, H.-H. and Dandekar, A.M. (1995): Regulation of proline accumulation in Arabidopsis thaliana (L.) Heynh during development and in response to desiccation. Plant Cell Environ, 18, 1280-1290.

Chiou, T.J. and Bush, D.R. (1998): Sucrose is a signal molecule in assimilate partitioning. Proc Natl Acad Sci U S A, 95, 4784-4788.

Choi, H., Hong, J., Ha, J., Kang, J. and Kim, S.Y. (2000): ABFs, a family of ABAresponsive element binding factors. $J$ Biol Chem, 275, 1723-30.

Chomczynski, P. (1993): A reagent for the single-step simultaneous isolation of RNA, DNA and proteins from cell and tissue samples. Biotechniques, 15, 532-4, 5367.

Chomczynski, P. and Sacchi, N. (1987): Single-step method of RNA isolation by acid guanidinium thiocyanate-phenol-chloroform extraction. Anal Biochem, 162, $156-9$.

Church, G.M. and Gilbert, W. (1984): Genomic sequencing. Proc Natl Acad Sci U S A, 81, 1991-5.

Clark, J.M. (1988): Novel non-templated nucleotide addition reactions catalyzed by procaryotic and eucaryotic DNA polymerases. Nucleic Acids Res, 16, 9677-86.

Clontech. (1996): Yeast Protocols Handbook.

Clough, S.J. and Bent, A.F. (1998): Floral dip: a simplified method for Agrobacteriummediated transformation of Arabidopsis thaliana. Plant J, 16, 735-43.

Cohen, D.R. and Curran, T. (1990): Analysis of dimerization and DNA binding functions in Fos and Jun by domain-swapping: involvement of residues outside the leucine zipper/basic region. Oncogene, 5, 929-39.

Cohen, S.N., Chang, A.C., Boyer, H.W. and Helling, R.B. (1973): Construction of biologically functional bacterial plasmids in vitro. Biotechnology, 24, 188-92.

Contento, A.L., Kim, S.-J. and Bassham, D.C. (2004): Transcriptome profiling of the response of Arabidopsis suspension culture cells to suc starvation. Plant Physiol, 135, $1-18$. 
Cortes, S., Gromova, M., Evrard, A., Roby, C., Heyraud, A., Rolin, D.B., Raymond, P. and Brouquisse, R.M. (2003): In plants, 3-o-methylglucose is phosphorylated by hexokinase but not perceived as a sugar. Plant Physiol, 131, 824-37.

Coruzzi, G. and Bush, D.R. (2001): Nitrogen and carbon nutrient and metabolite signaling in plants. Plant Physiol, 125, 61-64.

Craigon, D.J., James, N., Okyere, J., Higgins, J., Jotham, J. and May, S. (2004): NASCArrays: a repository for microarray data generated by NASC's transcriptomics service. Nucleic Acids Res, 32, D575-7.

Crowe, J.H., Hoekstra, F.A. and Crowe, L.M. (1992): Anhydrobiosis. Annu Rev Physiol, 54, 579-99.

de Pater, S., Katagiri, F., Kijne, J. and Chua, N.H. (1994): bZIP proteins bind to a palindromic sequence without an ACGT core located in a seed-specific element of the pea lectin promoter. Plant $J, 6,133-40$.

Delauney, A.J. and Verma, D.P. (1993): Proline biosynthesis and osmoregulation in plants. Plant $J, 4,215-223$.

Deppmann, C.D., Acharya, A., Rishi, V., Wobbes, B., Smeekens, S., Taparowsky, E.J. and Vinson, C. (2004): Dimerization specificity of all 67 B-ZIP motifs in Arabidopsis thaliana: a comparison to Homo sapiens B-ZIP motifs. Nucleic Acids Res, 32, 3435-45.

Deuschle, K., Funck, D., Forlani, G., Stransky, H., Biehl, A., Leister, D., Graaff, E.v.d., Kunze, R. and Frommer, W.B. (2004): The Role of D1-Pyrroline-5-Carboxylate Dehydrogenase in Proline Degradation. Plant Cell, 16, 3413-3425.

Deuschle, K., Funck, D., Hellmann, H., Daschner, K., Binder, S. and Frommer, W.B. (2001): A nuclear gene encoding mitochondrial Delta-pyrroline-5-carboxylate dehydrogenase and its potential role in protection from proline toxicity. Plant $J$, 27, 345-56.

Diebold, R., Schuster, J., Daschner, K. and Binder, S. (2002): The branched-chain amino acid transaminase gene family in Arabidopsis encodes plastid and mitochondrial proteins. Plant Physiol, 129, 540-50.

Ditzer, A. (2003): Untersuchungen zur Aktivität eines Trockenstress- und Abscisinsäure-induzierbaren Promotors aus der Wiederauferstehungspflanze Craterostigma plantagineum und Isolierung von DNA-Bindeproteinen. Dissertation.

Droge-Laser, W., Kaiser, A., Lindsay, W.P., Halkier, B.A., Loake, G.J., Doerner, P., Dixon, R.A. and Lamb, C. (1997): Rapid stimulation of a soybean protein-serine kinase that phosphorylates a novel bZIP DNA-binding protein, G/HBF-1, during the induction of early transcription-dependent defenses. Embo J, 16, 726-38.

Eastmond, P.J. and Graham, I.A. (2003): Trehalose metabolism: a regulatory role for trehalose-6-phosphate? Curr Opin Plant Biol, 6, 231-5. 
Eastmond, P.J., Li, Y. and Graham, I.A. (2003): Is trehalose-6-phosphate a regulator of sugar metabolism in plants? J Exp Bot, 54, 533-7.

Ehlert, A. (2004): Analyse der Dimerisierungs- und Aktivierungseigenschaften von Gruppe C und S bZIP- Transkriptionsfaktoren aus Arabidopsis thaliana. Diplomarbeit.

Ellenberger, T.E., Brandl, C.J., Struhl, K. and Harrison, S.C. (1992): The GCN4 basic region leucine zipper binds DNA as a dimer of uninterrupted alpha helices: crystal structure of the protein-DNA complex. Cell, 71, 1223-37.

Ellerstrom, M., Stalberg, K., Ezcurra, I. and Rask, L. (1996): Functional dissection of a napin gene promoter: identification of promoter elements required for embryo and endosperm-specific transcription. Plant Mol Biol, 32, 1019-27.

Ellis, C., Turner, J.G. and Devoto, A. (2002): Protein complexes mediate signalling in plant responses to hormones, light, sucrose and pathogens. Plant Mol Biol, 50, 971-980.

Ezcurra, I., Ellerstrom, M., Wycliffe, P., Stalberg, K. and Rask, L. (1999): Interaction between composite elements in the napA promoter: both the B-box ABAresponsive complex and the $\mathrm{RY} / \mathrm{G}$ complex are necessary for seed-specific expression. Plant Mol Biol, 40, 699-709.

Feinberg, A.P. and Vogelstein, B. (1983): A technique for radiolabeling DNA restriction endonuclease fragments to high specific activity. Anal Biochem, 132, 6-13.

Feinberg, A.P. and Vogelstein, B. (1984): "A technique for radiolabeling DNA restriction endonuclease fragments to high specific activity". Addendum. Anal Biochem, 137, 266-7.

Feldman, A.L., Costouros, N.G., Wang, E., Qian, M., Marincola, F.M., Alexander, H.R. and Libutti, S.K. (2002): Advantages of mRNA amplification for microarray analysis. Biotechniques, 33, 906-12, 914.

Fields, S. and Song, O. (1989): A novel genetic system to detect protein-protein interactions. Nature, 340, 245-6.

Finkelstein, R.R., Wang, M.L., Lynch, T.J., Rao, S. and Goodman, H.M. (1998): The Arabidopsis abscisic acid response locus ABI4 encodes an APETALA 2 domain protein. Plant Cell, 10, 1043-1054.

Fong, J.H., Keating, A.E. and Singh, M. (2004): Predicting specificity in bZIP coiledcoil protein interactions. Genome Biology, 5, R11.

Foster, R., Izawa, T. and Chua, N.H. (1994): Plant bZIP proteins gather at ACGT elements. Faseb J, 8, 192-200.

Fuchs, S.Y. and Ronai, Z. (1999): Ubiquitination and degradation of ATF2 are dimerization dependent. Mol Cell Biol, 19, 3289-98. 
Fujiki, Y., Ito, M., Itoh, T., Nishida, I. and Watanabe, A. (2002): Activation of the promoters of Arabidopsis genes for the branched-chain alpha-keto acid dehydrogenase complex in transgenic tobacco BY-2 cells under sugar starvation. Plant Cell Physiol, 43, 275-80.

Fujiki, Y., Ito, M., Nishida, I. and Watanabe, A. (2000): Multiple Signaling Pathways in Gene Expression during Sugar Starvation. Pharmacological Analysis of din Gene Expression in Suspension-Cultured Cells of Arabidopsis. Plant Physiol, 124, 1139-1147.

Fujiki, Y., Ito, M., Nishida, I. and Watanabe, A. (2001a): Leucine and its keto acid enhance the coordinated expression of genes for branched-chain amino acid catabolism in Arabidopsis under sugar starvation. FEBS Lett, 499, 161-5.

Fujiki, Y., Yoshikawa, Y., Sato, T., Inada, N., Ito, M., Nishida, I. and Watanabe, A. (2001b): Dark-inducible genes from Arabidopsis thaliana are associated with leaf senescence and repressed by sugars. Physiol Plant, 111, 345-352.

Fujita, Y., Fujita, M., Satoh, R., Maruyama, K., Parvez, M.M., Seki, M., Hiratsu, K., Ohme-Takagi, M., Shinozaki, K. and Yamaguchi-Shinozaki, K. (2005): AREB1 is a transcription activator of novel ABRE-dependent ABA signalling that enhances drought stress tolerance in Arabidopsis. Plant Cell, online publication.

Fujiwaraa, T., Nambarab, E., Yamagishib, K., Gotoc, D.B. and Naitoc, S. (2002): Storage Proteins. The Arabidopsis Book.

Fukazawa, J., Sakai, T., Ishida, S., Yamaguchi, I., Kamiya, Y. and Takahashi, Y. (2000): Repression of shoot growth, a bZIP transcriptional activator, regulates cell elongation by controlling the level of gibberellins. Plant Cell, 12, 901-15.

Fulton, T.M., Chunwongse, J. and Tanksley, S.D. (1995): Microprep protocol for Extraction of DNA from Tomato and other Herbaceous Plants. Plant Mol. Biol. Rep., 134, 207-209.

Geballe, A.P. and Morris, D.R. (1994): Initiation codons within 5'-leaders of mRNAs as regulators of translation. Trends Biochem Sci, 19, 159-64.

Gibon, Y., Blaesing, O.E., Hannemann, J., Carillo, P., Hoehne, M., Hendriks, J.H.M., Palacios, N., Cross, J., Selbig, J. and Stitt, M. (2004): A Robot-Based Platform to Measure Multiple Enzyme Activities in Arabidopsis Using a Set of Cycling Assays: Comparison of Changes of Enzyme Activities and Transcript Levels during Diurnal Cycles and in Prolonged Darkness. Plant Cell, 16, 3304-3325.

Giniger, E., Varnum, S.M. and Ptashne, M. (1985): Specific DNA binding of GAL4, a positive regulatory protein of yeast. Cell, 40, 767-74.

Goetz, M., Godt, D.E., Guivarc'h, A., Kahmann, U., Chriqui, D. and Roitsch, T. (2001): Induction of male sterility in plants by metabolic engineering of the carbohydrate supply. Proc Natl Acad Sci U S A, 98, 6522-7.

Goldberg, R.B., Beals, T.P. and Sanders, P.M. (1993): Anther development: basic principles and practical applications. Plant Cell, 5, 1217-29. 
Gubler, F., Millar, A.A. and Jacobsen, J.V. (2005): Dormancy release, ABA and preharvest sprouting. Curr Opin Plant Biol, 8, 183-7.

Guerche, P., Tire, C., De Sa, F.G., De Clercq, A., Van Montagu, M. and Krebbers, E. (1990): Differential Expression of the Arabidopsis 2S Albumin Genes and the Effect of Increasing Gene Family Size. Plant Cell, 2, 469-478.

Hanahan, D. (1983): Studies on transformation of Escherichia coli with plasmids. $J$ Mol Biol, 166, 557-80.

Handa, S., Handa, A.K., Hasegawa, P.M. and Bressan, R.A. (1986): Proline accumulation and the adaptation of cultured plant cells to salinity stress. Plant Physiol, 80, 938-945.

Hare, P.D. and Cress, W.A. (1997): Metabolic implications of stress-inducced proline accumulation in plants. Plant Growth Regulation, 21, 79-102.

Hare, P.D., Cress, W.A. and J., v.S. (1998): Dissecting the roles of osmolyte accumulation during stress. Plant, Cell and Environment, 21, 335-353.

Haslekas, C., Grini, P.E., Nordgard, S.H., Thorstensen, T., Viken, M.K., V., N. and Aalen, R.B. (2003): ABI3 mediates expression of the peroxiredoxin antioxidant AtPERl gene and induction by oxidative stress. Plant Mol Biol, 53, 313-326.

Hecht, A., Strahl-Bolsinger, S. and Grunstein, M. (1996): Spreading of transcriptional repressor SIR3 from telomeric heterochromatin. Nature, 383, 92-6.

Heinekamp, T., Kuhlmann, M., Lenk, A., Strathmann, A. and Droge-Laser, W. (2002): The tobacco bZIP transcription factor BZI-1 binds to G-box elements in the promoters of phenylpropanoid pathway genes in vitro, but it is not involved in their regulation in vivo. Mol Genet Genomics, 267, 16-26.

Hellmann, H., Funck, D., Rentsch, D. and Frommer, W.B. (2000): Hypersensitivity of an Arabidopsis sugar signaling mutant toward exogenous proline application. Plant Physiol, 123, 779-89.

Hempel, M. (1993): From Micropropagation to "Microponics". Practical Hydroponics International, 21-23.

Herrera-Estrella, L., Depicker, A., Van Montagu, M. and Schell, J. (1992): Expression of chimaeric genes transferred into plant cells using a Ti-plasmid-derived vector. 1983. Biotechnology, 24, 377-81.

Heslop-Harrison, J. (1978): Recognition and response in the pollen-stigma interaction. Symp Soc Exp Biol, 32, 121-38.

Hill, J., Donald, K.A. and Griffiths, D.E. (1991): DMSO-enhanced whole cell yeast transformation. Nucleic Acids Res, 19, 5791.

Hirst, M., Ho, C., Sabourin, L., Rudnicki, M., Penn, L. and Sadowski, I. (2001): A twohybrid system for transactivator bait proteins. Proc Natl Acad Sci US A, 98, 8726-8731. 
Ho, S.-L., Chao, Y.-C., Tong, W.-F. and Yu, S.-M. (2001): Sugar coordinately and differentially regulates growth- and stressrelated gene expression via a complex signal transduction network and multiple control mechanisms. Plant Physiol, 125, 877-890.

Huijser, C., Kortstee, A., Pego, J., Weisbeek, P., Wisman, E. and Smeekens, S. (2000): The Arabidopsis SUCROSE UNCOUPLED-6 gene is identical to ABSCISIC ACID INSENSITIVE-4: Involvement of abscisic acid in sugar responses. Plant $J$, 23, 577-585.

Hurst, H.C. (1995): Transcription factors 1: bZIP proteins. Protein Profile, 2, 101-168.

Imlau, A., Truernit, E. and Sauer, N. (1999): Cell-to-cell and long-distance trafficking of the green fluorescent protein in the phloem and symplastic unloading of the protein into sink tissues. Plant Cell, 11, 309-22.

Inoue, H., Nojima, H. and Okayama, H. (1990): High efficiency transformation of Escherichia coli with plasmids. Gene, 96, 23-28.

INVITROGEN. (2001): Proquest Two-Hybrid System. Instruction Manual.

Ito, H., Fukuda, Y., Murata, K. and Kimura, A. (1983): Transformation of intact yeast cells treated with alkali cations. J Bacteriol, 153, 163-8.

Ito, K., Kusano, T. and Tsutsumi, K.-i. (1999): A cold-inducible bZIP protein gene in radish root regulated by calcium- and cycloheximide-mediated signals. Plant Science, 142, 57-65.

Izawa, T., Foster, R. and Chua, N.H. (1993): Plant bZIP protein DNA binding specificity. J Mol Biol, 230, 1131-44.

Jakoby, M., Weisshaar, B., Droge-Laser, W., Vicente-Carbajosa, J., Tiedemann, J., Kroj, T. and Parcy, F. (2002): bZIP transcription factors in Arabidopsis. Trends Plant Sci, 7, 106-11.

Jefferson, R.A., Kavanagh, T.A. and Bevan, M.W. (1987): GUS fusions: betaglucuronidase as a sensitive and versatile gene fusion marker in higher plants. Embo J, 6, 3901-7.

Johnson, C., Boden, E., Desai, M., Pascuzzi, P. and Arias, J. (2001): In vivo target promoter-binding activities of a xenobiotic stress-activated TGA factor. Plant $J$, 28, 237-43.

Kankainen, M. and Holm, L. (2004): POBO, transcription factor binding site verification with bootstrapping. Nucleic Acids Res, 32, W222-9.

Kavi Kishor, P.B.K., Hong, Z., Miao, G.-H., Hu, C.-A. and Verma, D.P. (1995): Overexpression of delta1-pyrroline-5-carboxylat synthetase increases proline production and confers osmotolerance in transgenic plants. Plant Physiol, 108, 1387-1394.

Kenyon, C. (2001): A conserved regulatory system for aging. Cell, 105, 165-168. 
Kircher, S., Wellmer, F., Nick, P., Rugner, A., Schafer, E. and Harter, K. (1999): Nuclear import of the parsley bZIP transcription factor CPRF2 is regulated by phytochrome photoreceptors. J Cell Biol, 144, 201-11.

Kiyosue, T., Yoshiba, Y., Yamaguchi-Shinozaki, K. and Shinozaki, K. (1996): A nuclear gene encoding mitochondrial proline dehydrogenase, an enzyme involved in proline metabolism, is upregulated by proline but downregulated by dehydration in Arabidopsis. Plant Cell, 8, 1323-35.

Koncz, C. and Schell, J. (1986): The promoter of TL-DNA gene 5 controls the tissue specific expression chimeric genes carried by a novel type of Agrobacterium binary vector. Mol Gen Genet, 204, 383-396.

Kroj, T., Savino, G., Valon, C., Giraudat, J. and Parcy, F. (2003): Regulation of storage protein gene expression in Arabidopsis. Development, 130, 6065-73.

Kuhlmann, M., Horvay, K., Strathmann, A., Heinekamp, T., Fischer, U., Bottner, S. and Droge-Laser, W. (2003): The alpha-helical D1 domain of the tobacco bZIP transcription factor BZI-1 interacts with the ankyrin-repeat protein ANK1 and is important for BZI-1 function, both in auxin signaling and pathogen response. $J$ Biol Chem, 278, 8786-94.

Kusano, T., Berberich, T., Harada, M., Suzuki, N. and Sugawara, K. (1995): A maize DNA-binding factor with a bZIP motif is induced by low temperature. Mol Gen Genet, 248, 507-17.

Kusano, T., Sugawara, K., Harada, M. and Berberich, T. (1998): Molecular cloning and partial characterization of a tobacco cDNA encoding a small bZIP protein. Biochim Biophys Acta, 1395, 171-5.

Kyhse-Anderson, J. (1984): Electroblotting of multiple gels: a simple apparatus without buffer tank for rapid transfer of proteins from polyacrylamide to nitrocellulose. J. Biochem. Biophys. Meth., 10.

Laby, R.J., Kincaid, M.S., Kim, D. and Gibson, S.I. (2000): The Arabidopsis sugarinsensitive mutants sis4 and sis5 are defective in abscisic acid synthesis and response. Plant $J, 23,587-596$.

Laemmli, U.K. (1970): Cleavage of structural proteins during the assembly of the head of bacteriophage T4. Nature, 227, 680-5.

Lam, H.M., Wong, P., Chan, H.K., Yam, K.M., Chen, L., Chow, C.M. and Coruzzi, G.M. (2003): Overexpression of the ASN1 gene enhances nitrogen status in seeds of Arabidopsis. Plant Physiol, 132, 926-35.

Lamb, P. and McKnight, S.L. (1991): Diversity and specificity in transcriptional regulation: the benefits of heterotypic dimerization. Trends Biochem Sci, 16, 417-22.

Landschulz, W.H., Johnson, P.F. and McKnight, S.L. (1988): The leucine zipper: a hypothetical structure common to a new class of DNA binding proteins. Science, 240, 1759-64. 
Lara, P., Onate-Sanchez, L., Abraham, Z., Ferrandiz, C., Diaz, I., Carbonero, P. and Vicente-Carbajosa, J. (2003): Synergistic activation of seed storage protein gene expression in Arabidopsis by ABI3 and two bZIPs related to OPAQUE2. $J$ Biol Chem, 278, 21003-11.

Le_Gouill, C., Parent, J.-L., Rola-Pleszczynski, M. and Stankova, J. (1994): Analysis of recombinant plasmids by a modified alkaline lysis method. Anal biochem, 219, 164.

Lee, S.J., Lee, M.Y., Yi, S.Y., Oh, S.K., Choi, S.H., Her, N.H., Choi, D., Min, B.W., Yang, S.G. and Harn, C.H. (2002): PPI1: a novel pathogen-induced basic regionleucine zipper (bZIP): transcription factor from pepper. Mol Plant Microbe Interact, 15, 540-8.

Leon, P. and Sheen, J. (2003): Sugar and hormone connections. Trends Plant Sci, 8.

Leyman, B., Van Dijck, P. and Thevelein, J.M. (2001): An unexpected plethora of trehalose biosynthesis genes in Arabidopsis thaliana. Trends Plant Sci, 6, 510-3.

Lin, J.F. and Wu, S.H. (2004): Molecular events in senescing Arabidopsis leaves. Plant $J, 39,612-28$.

Liu, F., Vantoai, T., Moy, L.P., Bock, G., Linford, L.D. and Quackenbush, J. (2005): Global transcription profiling reveals comprehensive insights into hypoxic response in Arabidopsis. Plant Physiol, 137, 1115-29.

Liu, X., Brutlag, D.L. and Liu, J.S. (2001): BioProspector: discovering conserved DNA motifs in upstream regulatory regions of co-expressed genes. Pac Symp Biocomput., 127-138.

Lopez-Molina, L., Mongrand, S., McLachlin, D.T., Chait, B.T. and Chua, N.H. (2002): $\mathrm{ABI} 5$ acts downstream of $\mathrm{ABI} 3$ to execute an $\mathrm{ABA}-$ dependent growth arrest during germination. Plant $J, 32,317-28$.

Lupas, A. (1996): Coiled coils: new structures and new functions. Trends Biochem Sci, 21, 375-82.

Luscombe, N.M., Austin, S.E., Berman, H.M. and Thornton, J.M. (2000): An overview of the structures of protein-DNA complexes. Genome Biol, 1, 1-37.

Ma, J. and Ptashne, M. (1987): Deletion analysis of GAL4 defines two transcriptional activating segments. Cell, 48, 847-53.

Madden, T.L., Tatusov, R.L. and Zhang, J. (1996): Applications of network BLAST server. Methods Enzymol, 266, 131-41.

Mansfield, S.G. and Briarty, L.G. (1992): Cotyledon cell development in Arabidopsis thaliana during reserve deposition. Can. J. Bot., 70, 151-164.

Martin, T., Hellmann, H., Schmidt, R., Willmitzer, L. and Frommer, W.B. (1997): Identification of mutants in metabolically regulated gene expression. Plant J, 11, 53-62. 
Martinez-Garcia, J.F., Moyano, E., Alcocer, M.J. and Martin, C. (1998): Two bZIP proteins from Antirrhinum flowers preferentially bind a hybrid C-box/G-box motif and help to define a new sub-family of bZIP transcription factors. Plant $J$, 13, 489-505.

Matsushima-Hibiya, Y., Nishi, S. and Sakai, M. (1998): Rat maf-related factors: the specificities of DNA binding and heterodimer formation. Biochem Biophys Res Commun, 245, 412-8.

McCarty, D.R. (1995): Genetic control and integration of maturation and germination pathways in seed developement. Annu Rev Plant Physiol Plant Mol Biol, 46, 7193.

McDonell, M.W., Simon, M.N. and Studier, F.W. (1977): Analysis of restriction fragments of T7 DNA and determination of molecular weights by electrophoresis in neutral and alkaline gels. J Mol Biol, 110, 119-46.

McKay, I.A., Kirby, L., Volyanik, E.V., Kumar, V., Wong, P.W. and Bustin, S.A. (1998): An enzyme-linked immunosorbant assay for the detection of agents which interfere with the DNA binding activities of transcription factors exemplified by NF-IL6. Anal Biochem, 265, 28-34.

McLachlan, A. and Steward, M. (1975): Tropomyosin coiled-coil interactions: evidence for an unstaggered structure. J. Mol. Biol., 98, 293-304.

Menkens, A.E., Schindler, U. and Cashmore, A.R. (1995): The G-box: a ubiquitous regulatory DNA element in plants bound by the GBF family of bZIP proteins. Trends Biochem Sci, 20, 506-10.

Metallo, S.J. and Schepartz, A. (1997): Certain bZIP peptides bind DNA sequentially as monomers and dimerize on the DNA. Nat Struct Biol, 4, 115-7.

Miller, J.D., Arteca, R.N. and Pell, E.J. (1999): Senescence-associated gene expression during ozone-induced leaf senescence in Arabidopsis. Plant Physiol, 120, 101524.

Mönke, G., Altschmied, L., Tewes, A., Reidt, W., Mock, H.-P., Baeumlein, H. and Conrad, U. (2004): Seed-specific transcription factors ABI3 and FUS3: molecular interaction with DNA. Planta, 219, 158-166.

Moore, B., Zhou, L., Rolland, F., Hall, Q., Cheng, W.H., Liu, Y.X., Hwang, I., Jones, T. and Sheen, J. (2003): Role of the Arabidopsis glucose sensor HXK1 in nutrient, light, and hormonal signaling. Science, 300, 332-6.

Mueller, J., Boller, T. and Wiemken, A. (1995): Trehalose and trehalase in plants: recent developments. Plant Science, 112, 1-9.

Mullis, K.B. and Faloona, F.A. (1987): Specific synthesis of DNA in vitro via a polymerase-catalyzed chain reaction. Methods Enzymol, 155, 335-50.

Murashige, T. and Skoog, F. (1962): A revised medium for rapid growth and bioassays with tobacco tissue cultures. Physiol. Plant., 15, 473-497. 
Nakashima, K., Satoh, R., Kiyosue, T., Yamaguchi-Shinozaki, K. and Shinozaki, K. (1998): A gene encoding proline dehydrogenase is not only induced by proline and hypoosmolarity, but is also developmentally regulated in the reproductive organs of Arabidopsis. Plant Physiol, 118, 1233-41.

Nanjo, T., Kobayashi, M., Yoshiba, Y., Kakubari, Y., Yamaguchi-Shinozaki, K. and Shinozaki, K. (1999): Antisense suppression of proline degradation improves tolerance to freezing and salinity in Arabidopsis thaliana. FEBS Lett, 461, 20510.

Niu, X. and Guiltinan, M.J. (1994): DNA binding specificity of the wheat bZIP protein EmBP-1. Nucleic Acids Res, 22, 4969-78.

O'Shea, E.K., Rutkowski, R. and Kim, P.S. (1989): Evidence that the leucine zipper is a coiled coil. Science, 243, 538-42.

Oyama, T., Shimura, Y. and Okada, K. (1997): The Arabidopsis HY5 gene encodes a bZIP protein that regulates stimulus-induced development of root and hypocotyl. Genes Dev, 11, 2983-95.

Pang, P.P., Pruitt, R.E. and Meyerowitz, E.M. (1988): Molecular cloning, genomic organization, expression and evolution of $12 \mathrm{~S}$ seed storage protein genes of Arabidopsis thaliana. Plant Mol. Biol., 11, 805-820.

Pardha Saradhi P, Alia, Arora, S. and Prasad, K.V.S.K. (1995): Proline accumulates in plants exposed to UV radiation and protects them against UV induced peroxidation. Biochem Biophys Res Commun, 209, 1-5.

Paul, M.J. and Pellny, T.K. (2003): Carbon metabolite feedback regulation of leaf photosynthesis and development. J Exp Bot, 54, 539-547.

Peng, Z., Lu, Q. and Verma, D.P. (1996): Reciprocal regulation of delta 1-pyrroline-5carboxylate synthetase and proline dehydrogenase genes controls proline levels during and after osmotic stress in plants. Mol Gen Genet, 253, 334-41.

Polacek, D.C., Passerini, A.G., Shi, C., Francesco, N.M., Manduchi, E., Grant, G.R., Powell, S., Bischof, H., Winkler, H., Stoeckert, C.J., Jr. and Davies, P.F. (2003): Fidelity and enhanced sensitivity of differential transcription profiles following linear amplification of nanogram amounts of endothelial mRNA. Physiol Genomics, 13, 147-56.

Pourtau, N., Mares, M., Purdy, S., Quentin, N., Ruel, A. and Wingler, A. (2004): Interactions of abscisic acid and sugar signalling in the regulation of leaf senescence. Planta, 219, 765-72.

Price, J., Laxmi, A., St Martin, S.K. and Jang, J.C. (2004): Global transcription profiling reveals multiple sugar signal transduction mechanisms in Arabidopsis. Plant Cell, 16, 2128-50.

Ptashne, M. and Gann, A. (1997): Transcriptional activation by recruitment. Nature, 386, 569-77. 
Pysh, L.D., Aukerman, M.J. and Schmidt, R.J. (1993): OHP1: a maize basic domain/leucine zipper protein that interacts with opaque2. Plant Cell, 5, 227-36.

Quirino, B.F., Noh, Y.S., Himelblau, E. and Amasino, R.M. (2000): Molecular aspects of leaf senescence. Trends Plant Sci, 5, 278-282.

Reinbothe, S., Mollenhauer, B. and Reinbothe, C. (1994): JIPs and RIPs: The regulation of plant gene expression by jasmonates in response to environmental cues and pathogens. Plant Cell, 6, 1197-1209.

Riechmann, J.L., Heard, J., Martin, G., Reuber, L., Jiang, C., Keddie, J., Adam, L., Pineda, O., Ratcliffe, O.J., Samaha, R.R., Creelman, R., Pilgrim, M., Broun, P., Zhang, J.Z., Ghandehari, D., Sherman, B.K. and Yu, G. (2000): Arabidopsis transcription factors: genome-wide comparative analysis among eukaryotes. Science, 290, 2105-10.

Roberts, R.J. (1985): Restriction and modification enzymes and their recognition sequences. Nucleic Acids Res, 13 Suppl, r165-200.

Robinson, C.K. and Hill, S.A. (1999): Altered resource allocation during seed development in Arabidopsis caused by the abi3 mutation. Plant Cell Environ, 22, 117-123.

Roessner, U., Wagner, C., Kopka, J., Trethewey, R.N. and Willmitzer, L. (2000): Technical advance: simultaneous analysis of metabolites in potato tuber by gas chromatography-mass spectrometry. Plant $J, 23,131-142$.

Rolland, F., Moore, B. and Sheen, J. (2002): Sugar sensing and signaling in plants. Plant Cell, 14 Suppl, 185-205.

Rook, F., Corke, F., Card, R., Munz, G., Smith, C. and Bevan, M.W. (2001): Impaired sucrose-induction mutants reveal the modulation of sugar-induced starch biosynthetic gene expression by abscisic acid signalling. Plant J, 26, 421-433.

Rook, F., Gerrits, N., Kortstee, A., van Kampen, M., Borrias, M., Weisbeek, P. and Smeekens, S. (1998a): Sucrose-specific signalling represses translation of the Arabidopsis ATB2 bZIP transcription factor gene. Plant J, 15, 253-63.

Rook, F., Weisbeek, P. and Smeekens, S. (1998b): The light-regulated Arabidopsis bZIP transcription factor gene $A T B 2$ encodes a protein with an unusually long leucine zipper domain. Plant Mol Biol, 37, 171-8.

Rugner, A., Frohnmeyer, H., Nake, C., Wellmer, F., Kircher, S., Schafer, E. and Harter, K. (2001): Isolation and characterization of four novel parsley proteins that interact with the transcriptional regulators CPRF1 and CPRF2. Mol Genet Genomics, 265, 964-76.

Sadka, A., DeWald, D.B., May, G.D., Park, W.D. and Mullet, J.E. (1994): Phosphate modulates transcription of soybean VspB andother sugar-inducible genes. Plant Cell, 6, 737-749.

Sambrook, Fritsch and Maniatis. (1989): Molecular cloning: A Laboratory Manual. Cold Spring Habor LaboratoryPress. 
Sanger, F., Nicklen, S. and Coulson, A.R. (1977): DNA sequencing with chainterminating inhibitors. Proc Natl Acad Sci U S A, 74, 5463-7.

Satoh, R., Fujita, Y., Nakashima, K., Shinozaki, K. and Yamaguchi-Shinozaki, K. (2004): A novel subgroup of bZIP proteins functions as transcriptional activators in hypoosmolarity-responsive expression of the ProDH gene in Arabidopsis. Plant Cell Physiol, 45, 309-17.

Satoh, R., Nakashima, K., Seki, M., Shinozaki, K. and Yamaguchi-Shinozaki, K. (2002): ACTCAT, a novel cis-acting element for proline- and hypoosmolarityresponsive expression of the $\mathrm{ProDH}$ gene encoding proline dehydrogenase in Arabidopsis. Plant Physiol, 130, 709-19.

Schindler, U., Terzaghi, W., Beckmann, H., Kadesch, T. and Cashmore, A.R. (1992): DNA binding site preferences and transcriptional activation properties of the Arabidopsis transcription factor GBF1. Embo J, 11, 1275-89.

Schluepmann, H., Pellny, T., van Dijken, A., Smeekens, S. and Paul, M. (2003): Trehalose 6-phosphate is indispensable for carbohydrate utilization and growth in Arabidopsis thaliana. Proc Natl Acad Sci U S A, 100, 6849-54.

Schluepmann, H., van Dijken, A., Aghdasi, M., Wobbes, B., Paul, M. and Smeekens, S. (2004): Trehalose mediated growth inhibition of Arabidopsis seedlings is due to trehalose-6-phosphate accumulation. Plant Physiol, 135, 879-90.

Schmid, M., Davison, T.S., Henz, S.R., Pape, U.J., Demar, M., Vingron, M., Scholkopf, B., Weigel, D. and Lohmann, J.U. (2005): A gene expression map of Arabidopsis thaliana development. Nat Genet, 37, 501-6.

Schmidt, R.J., Ketudat, M., Aukerman, M.J. and Hoschek, G. (1992): Opaque-2 is a transcriptional activator that recognizes a specific target site in $22-\mathrm{kD}$ zein genes. Plant Cell, 4, 689-700.

Schobert, B. and Tschesche, H. (1978): Unusual solution properties of proline and its interaction with proteins. Biochim Biophys Acta, 541, 270-7.

Schuster, J. and Binder, S. (2005): The mitochondrial branched-chain aminotransferase (AtBCAT-1) is capable to initiate degradation of leucine, isoleucine and valine in almost all tissues in Arabidopsis thaliana. Plant Mol Biol, 57, 241-54.

Shen, Q., Gomez-Cadenas, A., Zhang, P., Walker-Simmons, M.K., Sheen, J. and Ho, T.H. (2001): Dissection of abscisic acid signal transduction pathways in barley aleurone layers. Plant Mol Biol, 47, 437-48.

Shen, Q. and Ho, T.-H.D. (1995): Functional dissection of an abscisic acid (ABAinducible gene reveals two independant ABA-responsive complexes each containing a G-box and a novel cis-acting element. Plant Cell, 7, 295-307.

Shen, Q.J., Casaretto, J.A., Zhang, P. and Ho, T.H. (2004): Functional definition of ABA-response complexes: the promoter units necessary and sufficient for ABA induction of gene expression in barley ( Hordeum vulgare L.). Plant Mol Biol, 54, 111-24. 
Shimizu, H., Sato, K., Berberich, T., Miyazaki, A., Ozaki, R., Imai, R. and Kusano, T. (2005): LIP19, a Basic Region Leucine Zipper Protein, is a Fos-like Molecular Switch in the Cold Signaling of Rice Plants. Plant Cell Physiol, 46, 1623-34.

Siberil, Y., Doireau, P. and Gantet, P. (2001): Plant bZIP G-box binding factors. Modular structure and activation mechanisms. Eur J Biochem, 268, 5655-66.

Skriver, K., Olsen, F.L., Rogers, J.C. and Mundy, J. (1991): cis-acting DNA elements responsive to gibberellin and its antagonist abscisic acid. Proc Natl Acad Sci U S $A, \mathbf{8 8}, 7266-70$.

Skubatz, H., Meeuse, B.J.D. and Bendich, A.J. (1989): Oxidation of proline and glutamate by mitochondria of the inflorescence of voodoo lily (Sauromatum guttatum). Plant Physiol, 91, 530-535.

Smart, C.M. (1994): Gene expression during leaf senescence. New Phytol, 126, 419448.

Smeekens, S. (2000): Sugar-induced Signal Transduction in plants. Annu. Rev. Plant Physiol. Plant Mol. Biol, 51, 49-81.

Smirnoff, N. and Cumbes, Q.J. (1989): Hydroxyl radical scavenging activity of compatible solutes. Phytochemistry, 28, 1057-1060.

Smith, H.O. and Wilcox, K.W. (1970): A restriction enzyme from Hemophilus influenzae. I. Purification and general properties. J Mol Biol, 51, 379-91.

Solomon, M.J., Larsen, P.L. and Varshavsky, A. (1988): Mapping protein-DNA interactions in vivo with formaldehyde: evidence that histone $\mathrm{H} 4$ is retained on a highly transcribed gene. Cell, 53, 937-47.

Solomon, M.J. and Varshavsky, A. (1985): Formaldehyde-mediated DNA-protein crosslinking: a probe for in vivo chromatin structures. Proc Natl Acad Sci U S A, 82, 6470-4.

Southern, E.M. (1979): Measurement of DNA length by gel electrophoresis. Anal Biochem, 100, 319-23.

Sprenger-Haussels, M. and Weisshaar, B. (2000): Transactivation properties of parsley proline-rich bZIP transcription factors. Plant J, 22, 1-8.

Strathmann, A. (2003): Charakterisierung der Nicotiana tabacum bZIPTranskriptionsfaktoren BZI-2, BZI-3 und BZI-4 als Heterodimerisierungspartner von BZI-1. Dissertation.

Strathmann, A., Kuhlmann, M., Heinekamp, T. and Droge-Laser, W. (2001): BZI-1 specifically heterodimerises with the tobacco bZIP transcription factors BZI-2, BZI-3/TBZF and BZI-4, and is functionally involved in flower development. Plant J, 28, 397-408.

Straub, P.F., Shen, Q. and Ho, T.D. (1994): Structure and promoter analysis of an ABAand stress-regulated barley gene, HVA1. Plant Mol Biol, 26, 617-30. 
Swidzinski, J.A., Sweetlove, L.J. and Leaver, C.J. (2002): A custom microarray analysis of gene expression during programmed cell death in Arabidopsis thaliana. Plant $J$, 30, 431-46.

Tallman, G. (2004): Are diurnal patterns of stomatal movement the result of alternating metabolism of endogenous guard cell ABA and accumulation of ABA delivered to the apoplast around guard cells by transpiration? J Exp Bot, 55, 1963-76.

Terzaghi, W.B. and Cashmore, A.R. (1995): Light-regulated transcription. Annu Rev Plant Physiol Plant Mol Biol, 46, 445-474.

Testa, A., Donati, G., Yan, P., Romani, F., Huang, T.H., Vigano, M.A. and Mantovani, R. (2005): Chromatin immunoprecipitation (ChIP) on chip experiments uncover a widespread distribution of NF-Y binding CCAAT sites outside of core promoters. J Biol Chem, 280, 13606-15.

Thevelein, J.M. and Hohmann, S. (1995): Trehalose synthase: guard to the gate of glycolysis in yeast? Trends in Biochemical Science, 20, 3-10.

Thum, K.E., Shasha, D.E., Lejay, L.V. and Coruzzi, G.M. (2003): Light- and carbonsignaling pathways. Modeling circuits of interactions. Plant Physiol, 132, 44052.

van der Krol, A.R. and Chua, N.H. (1991): The basic domain of plant B-ZIP proteins facilitates import of a reporter protein into plant nuclei. Plant Cell, 3, 667-75.

Varagona, M.J. and Raikhel, N.V. (1994): The basic domain in the bZIP regulatory protein Opaque2 serves two independent functions: DNA binding and nuclear localization. Plant J, 5, 207-14.

Vasil, V., Marcotte, W.R., Rosenkrans, L., Cocciolone, S.M., Vasil, I.K., Quatrano, R.S. and McCarty, R. (1995): Overlap of Viviparous1 (VP1) and abscisic acid response elements in the Em promoter: G-box elements are sufficient but not necesarry for VP1 transactivation. Plant Cell, 7, 1923-1932.

Vaucheret, H., Kronenberger, J., Lepingle, A., Vilaine, F., Boutin, J.-P. and Caboche, M. (1992): Inhibition of tobacco nitrite reductase activity by expression of antisense RNA. Plant J, 2, 559-569.

Verbruggen, N., Hua, X.J., May, M. and Van Montagu, M. (1996): Environmental and developmental signals modulate proline homeostasis: evidence for a negative transcriptional regulator. Proc Natl Acad Sci U S A, 93, 8787-91.

Vidal, M. (1997): The Reverse Two-Hybrid System in The Two-Hybrid System. Oxford University Press, New York, 109.

Vinson, C., Myakishev, M., Acharya, A., Mir, A.A., Moll, J.R. and Bonovich, M. (2002): Classification of human B-ZIP proteins based on dimerization properties. Mol Cell Biol, 22, 6321-35.

Vinson, C.R., Hai, T. and Boyd, S.M. (1993): Dimerization specificity of the leucine zipper-containing bZIP motif on DNA binding: prediction and rational design. Genes Dev, 7, 1047-58. 
Vinson, C.R., Sigler, P.B. and McKnight, S.L. (1989): Scissors-grip model for DNA recognition by a family of leucine zipper proteins. Science, 246, 911-6.

Vogel, G., Fiehn, O., Jean-Richard-dit-Bressel, L., Boller, T., Wiemken, A., Aeschbacher, R.A. and Wingler, A. (2001): Trehalose metabolism in Arabidopsis: occurrence of trehalose and molecular cloning and characterization of trehalose-6-phosphate synthase homologues. J Exp Bot, 52, 1817-26.

Walter, M., Chaban, C., Schutze, K., Batistic, O., Weckermann, K., Nake, C., Blazevic, D., Grefen, C., Schumacher, K., Oecking, C., Harter, K. and Kudla, J. (2004): Visualization of protein interactions in living plant cells using bimolecular fluorescence complementation. Plant $J, 40,428-38$.

Wang, D., Weaver, N.D., Kesarwani, M. and Dong, X. (2005): Induction of protein secretory pathway is required for systemic acquired resistance. Science, 308, 1036-40.

Wang, J.C. (2005): Finding primary targets of transcriptional regulators. Cell Cycle, 4, 356-8.

Weaver, L.M., Gan, S., Quirino, B. and Amasino, R.M. (1998): A comparison of the expression patterns of several senescence-associated genes in response to stress and hormone treatment. Plant Mol Biol, 37, 455-69.

Wellmer, F., Kircher, S., Rugner, A., Frohnmeyer, H., Schafer, E. and Harter, K. (1999): Phosphorylation of the parsley bZIP transcription factor CPRF2 is regulated by light. J Biol Chem, 274, 29476-82.

Weltmeier, F. (2002): Funktionelle Charakterisierung der Transkriptionsfaktoren AtbZIP1 und AtbZIP53 aus Arabidopsis thaliana.

White, J., Chang, S.Y. and Bibb, M.J. (1990): A cassette containing the bar gene of Streptomyces hygroscopicus: a selectable marker for plant transformation. Nucleic Acids Res, 18, 1062.

Wiese, A., Elzinga, N., Wobbes, B. and Smeekens, S. (2004): A conserved upstream open reading frame mediates sucrose-induced repression of translation. Plant Cell, 16, 1717-29.

Wiese, A., Elzinga, N., Wobbes, B. and Smeekens, S. (2005): Sucrose-induced translational repression of plant bZIP-type transcription factors. Biochem Soc Trans, 33, 272-5.

Wobbes, B. (2004): Control of plant carbohydrate partitioning by the Arabidopsis thaliana ATB2 bZIP transcription factor gene. Dissertation.

Xiao, W., Sheen, J. and Jang, J.C. (2000): The role of hexokinase in plant sugar signal transduction and growth and development. Plant Mol Biol, 44, 451-61.

Xu, D., Duan, X., Wang, B., Hong, B., Ho, T.-H.D. and Wu, R. (1996): Expression of a late Embryogenesis Abundant Protein Cene, HVA1, from Barley Confers Tolerance to Water Deficit and Salt Stress in Transgenic Rice. Plant Physiol, 110, 249-257. 
Yang, J.C., Zhang, J.H., Wang, Z.Q., Zhu, Q.S. and Liu, L.J. (2003): Involvement of abscisic acid and cytokinins in the senescence and remobilization of carbon reserves in wheat subjected to water stress during grain filling. Plant Cell Environ, 26, 1621-1631.

Yang, S.H., Berberich, T., Sano, H. and Kusano, T. (2001): Specific association of transcripts of $t b z F$ and $t b z 17$, tobacco genes encoding basic region leucine zipper-type transcriptional activators, with guard cells of senescing leaves and/or flowers. Plant Physiol, 127, 23-32.

Yang, S.H., Yamaguchi, Y., Koizumi, N., Kusano, T. and Sano, H. (2002): Promoter analysis of tbzF, a gene encoding a bZIP-type transcription factor, reveals distinct variation in cis-regions responsible for transcriptional activation between senescing leaves and flower buds in tobacco plants. Plant Science, 162, 973-980.

Zeng, X., Herndon, A.M. and Hu, J.C. (1997): Buried asparagines determine the dimerization specificities of leucine zipper mutants. Proc Natl Acad Sci US A, 94, 3673-8.

Zhang, H.Q. and Croes, A.F. (1983): Protection of pollen germination from adverse temperature: a possible role for proline. Plant Cell Environ, 6, 471-476.

Zhang, Y., Shewry, P.R., Jones, H., Barcelo, P., Lazzeri, P.A. and Halford, N.G. (2001): Expression of antisense SnRK1 protein kinase sequence causes abnormal pollen development and male sterility in transgenic barley. Plant $J, 28,431-441$.

Zhou, J.M., Trifa, Y., Silva, H., Pontier, D., Lam, E., Shah, J. and Klessig, D.F. (2000): NPR1 differentially interacts with members of the TGA/OBF family of transcription factors that bind an element of the $P R-1$ gene required for induction by salicylic acid. Mol Plant Microbe Interact, 13, 191-202.

Zimmermann, P., Hirsch-Hoffmann, M., Hennig, L. and Gruissem, W. (2004): GENEVESTIGATOR. Arabidopsis microarray database and analysis toolbox. Plant Physiol, 136, 2621-32. 


\section{Anhang}

\subsection{Abkürzungen}

A

A. tumefaciens

A.

aa

$\mathrm{AD}$

Ade

Amp

AMP

ATP

BAC

BD

bidest.

bp

BPB

BSA

bZIP

bzw.

C

C

C

ca.

cDNA

cfu

CIAP

CSM

$\mathrm{cv}$.

ddNTPs

d.h.

DMSO

DNA

DNase

dNTPs

DTT

E. coli

EDTA

EMSA

et al.

etc.

$\mathrm{EtOH}$

G

G

$\mathrm{Gm}$

HEC

HEPES

His

HSP

IPTG

KAc

$\mathrm{kb}$

$\mathrm{kDa}$
Adenosin

Agrobacterium tumefaciens

Arabidopsis thaliana (Acker-Schmalwand)

Aminosäuren (amino acids)

Aktivierungsdomäne

Adenin

Ampicillin

Adenosinmonophosphat

Adenosintriphosphat

Bacterial artificial chromosome

Bindedomäne

bidestilliert

Basenpaar(e)

Bromphenolblau

Rinderserumalbumin

basischer Leucinzipper

Beziehungsweise

Formelzeichen für Kapazität

Kohlenstoff

Cytosin

circa

komplementäre DNA

colony forming units

Calf Intestine Alcaline Phosphatase

Complete Supplement Mixture

Kultivar

Didesoxyribonucleotide

dass heißt

Dimethylsulfoxid

Desoxyribonucleinsäure

Desoxyribonuclease

Desoxyribonucleotide

Dithiothreitol

Escherichia coli

Ethylendiamin-N,N,N',N'-tetraessigsäure

Electrophoretic Mobility Shift Assay

und andere (et alii)

und so weiter (et cetera)

Ethanol

Formelzeichen für Fallbeschleunigung

Guanosin

Gentamycin

Hydroxyethyl-Cellulose

2-[4-(2-Hydroxyethyl)-1-piperazino]-ethansulfonsäure

Histidin

Heringsperma-DNA

Isopropyl- $\beta$-D-thiogalactopyranosid

Kaliumacetat

Kilobasen

Kilodalton 


\begin{tabular}{|c|c|}
\hline $\mathrm{Km}$ & Kanamycin \\
\hline LB & Luria-Bertani Broth \\
\hline Leu & Leucin \\
\hline LiAc & Lithiumacetat \\
\hline MCS & Multiple Cloning Site \\
\hline MES & $\beta$-Morpholino-ethansulfonsäure Hydrat \\
\hline MOPS & Morpholinopropansulfonsäure \\
\hline N.t. & Nicotiana tabacum \\
\hline $\mathrm{NaAc}$ & Natriumacetat \\
\hline OD & optische Dichte \\
\hline oNPG & o-Nitrophenyl $\beta$-D-Galactopyranosid \\
\hline ORF & offener Leserahmen (Open Reading Frame) \\
\hline PAA & Polyacrylamid \\
\hline PCR & Polymerase-Kettenreaktion (polymerase chain reaction) \\
\hline PEG & Polyethylenglycol \\
\hline $\mathrm{pH}$ & negativ dekadischer Logarithmus der Protonenkonzentration \\
\hline PIPES & 1,4-Piperazin-bis-(ethansulfonsäure) \\
\hline PMSF & Phenyl-Methyl-Sulfonyl-Fluorid \\
\hline PVDF & Polyvinylidene Fluorid \\
\hline $\mathrm{R}$ & Formelzeichen für Widerstand \\
\hline RNA & Ribonucleinsäure \\
\hline RNase & Ribonuclease \\
\hline rpm & Umdrehungen pro Minute (rotations per minute) \\
\hline RT & Raumtemperatur \\
\hline SDS & Natriumdodecylsulfat (sodiumdodecylsulfate) \\
\hline ss & einzelsträngig (single stranded) \\
\hline SD & Synthetic dropout \\
\hline SSC & Natriumcitrat (sodium salt citrat) \\
\hline $\mathrm{t}$ & Reaktionszeit \\
\hline $\mathrm{T}$ & Thymin \\
\hline Taq DNA-Polymerase & Thermus aquaticus DNA-Polymerase \\
\hline T-DNA & Transfer-DNA \\
\hline TEMED & $\mathrm{N}, \mathrm{N}, \mathrm{N}$, , N'-Tetraethylethylendiamin \\
\hline $\mathrm{T}_{\mathrm{m}}$ & Schmelztemperatur \\
\hline Tris & Tris-(hydroxymethyl)-aminomethan \\
\hline $\operatorname{Trp}$ & Trytophan \\
\hline $\mathrm{u}$ & definierte Enzymeinheit (unit) \\
\hline $\mathrm{U}$ & Uracil \\
\hline u.a. & unter anderem \\
\hline ü.N. & über Nacht \\
\hline UAS & Upstream Activating Sequence \\
\hline UV & Ultraviolettes Licht \\
\hline $\mathrm{v} / \mathrm{v}$ & Volumenprozent (volume per volume) \\
\hline $\mathrm{w} / \mathrm{v}$ & Gewichtsprozent (weight per volume) \\
\hline $\mathrm{X}-\mathrm{Gal}$ & 5-Brom-4-chlor-3-indolyl- $\beta$-D-galactopyranosid \\
\hline $\mathrm{Y} 2 \mathrm{H}$ & Hefe „Two-Hybrid“-System (Yeast-Two-Hybrid-System) \\
\hline z. B. & zum Beispiel \\
\hline$\lambda$ & Bakteriophage Lambda \\
\hline
\end{tabular}

\subsection{Aminosäuren}
A Alanin
C Cystein
D Asparaginsäure
E Glutaminsäure
F Phenylalanin

G Glycin

M Methionin

S Serin

H Histidin

N Asparagin

T Threonin

I Isoleucin

P Prolin

K Lysin

Q Glutamin

V Valin

L Leucin

R Arginin

W Tryptophan

Y Tyrosin 


\subsection{Einheiten}

$\begin{array}{lll}{ }^{\circ} \mathrm{C} & \text { Grad Celsius } & \begin{array}{l}\text { (Temperatur) } \\ \text { (Stromstärke) }\end{array} \\ \mathrm{A} & \text { Ampère } & \text { (Molekulargewicht) } \\ \mathrm{D} & \text { Dalton } & \text { (Kapazität) } \\ \mathrm{F} & \text { Farad } & \text { (Masse) } \\ \mathrm{g} & \text { Gramm } & \text { (Zeit) } \\ \mathrm{h} & \text { Stunde } & \text { (Volumen) } \\ \mathrm{l} & \text { Liter } & \text { (Länge) } \\ \mathrm{m} & \text { Meter } & \text { (Molarität) } \\ \mathrm{M} & \text { mol / } & \text { (Zeit) } \\ \mathrm{min} & \text { Minute } & \text { (Stoffmenge) } \\ \mathrm{mol} & \text { mol } & \text { (Zeit) } \\ \mathrm{s} & \text { Sekunde } & \text { (Spannung) } \\ \mathrm{V} & \text { Volt } & \text { (Widerstand) } \\ \Omega & \text { Ohm } & \end{array}$

\subsection{Vorsätze zur Bezeichnung von dezimalen Vielfachen und} Teilen von Einheiten

$\begin{array}{lll}\text { K } & \text { kilo- } & \left(10^{3}\right) \\ \mathrm{C} & \text { centi- } & \left(10^{-2}\right) \\ \mathrm{M} & \text { milli- } & \left(10^{-3}\right) \\ \mu & \text { mikro } & \left(10^{-6}\right) \\ \mathrm{N} & \text { nano- } & \left(10^{-9}\right) \\ \mathrm{P} & \text { pico- } & \left(10^{-12}\right)\end{array}$




\section{Danksagung}

Mein besonderer Dank gilt PD Dr. Wolfgang Dröge-Laser und Prof. Dr. Christiane Gatz für die Möglichkeit, diese Arbeit in ihrer Abteilung anzufertigen, und für die Übernahme des Referats bzw. des Korreferats.

Dem Graduiertenkolleg "Molekulare Genetik der Entwicklung" danke ich für die Finanzierung meiner Promotion, und für die Möglichkeit über den 'Tellerrand' Pflanze hinauszublicken.

Danken möchte ich auch unseren Kollaborationspartnern Dr. Jesus Vicente-Carbajosa, Professor Dr. Sjef Smeekens und Professor Dr. Klaus Harter sowie meinen Diplomandinen Andrea Ehlert und Katrin Dietrich, ohne deren Unterstützung die Bearbeitung eines so komplexen Themas nicht möglich gewesen wäre. Ein besonderer Dank geht dabei an Dr. Jesus Vicente-Carbajosa für die Möglichkeit, in seinem Labor die Mikroarray Experimente durchzuführen, sowie für seine außerordentliche Gastfreundschaft während meines Aufenthaltes in Madrid.

PD Dr. Gertrud Lohaus danke ich besonders für die Durchführung der Zuckermessungen.

Mein Dank gilt auch meinen Laborkollegen, die mich bei dem Lernen neuer Methoden unterstützt haben, und die mir immer wenn es notwendig war tatkräftig geholfen haben.

Ein ganz besonderer großes Dankeschön geht an Tanja, und an meine und ihre Familie, ohne deren Unterstützung ich diese Arbeit nicht hätte anfertigen können. 


\section{Lebenslauf:}

\section{Persönliche Daten:}

Name: $\quad$ Fridtjof Walter Engelbert Weltmeier

Geburtsdatum: $\quad 05.12 .1972$

Geburtsort: Dortmund

Staatsangehörigkeit: deutsch

\section{Ausbildung:}

Seit 07/2002 Dissertation "Ein Netzwerk von heterodimerisierenden C/S1 AtbZIP-Transkriptionsfaktoren und seine Funktion in Seneszenz, Stressantwort und Samenentwicklung"

06/2001-06/2002: Diplomarbeit "Funktionelle Charakterisierung der Transkriptionsfaktoren AtbZIP1 und AtbZIP53 aus Arabidopsis thaliana"

7.2.2001: mündliche Diplomprüfung Biochemie: sehr gut; Botanik: sehr gut; Chemie: sehr gut

1997-1999: $\quad$ Im März 1997 Diagnose Leukämie, im März 1998 erfolgte eine Knochenmarktransplantation; das Studium ausgesetzt bis Ende 1999

10/1996: $\quad$ Vordiplom $\quad$ Botanik: sehr gut; Mikrobiologie: gut; Physikalische Chemie: sehr gut; Anorganische Chemie: sehr gut

10/1994: Beginn des Diplomstudiengangs Biologie an der Universität Göttingen

03-05/1994: $\quad$ Praktikum im Garten und Landschaftsbau

10/1992-01/1994: Zivildienst bei dem Arbeiter Samariter Bund

1983-1992: Gymnasium an der Schweizer Allee, Dortmund; Abitur in den Fächern Chemie, Biologie, Englisch und Philosophie Gesamtnote 2,4

1979-1983: $\quad$ Aplerbecker Mark Grundschule, Dortmund 
